DOE/EIA-0560(96)

Distribution Category UC-950

\title{
Natural Gas 1996
}

\section{Issues and Trends}

December 1996

\section{Energy Information Administration \\ Office of Oil and Gas}

U.S. Department of Energy

Washington, DC 20585

\section{DISTRIBUTION OF THIS DOCUMENT IS UNLIMITED

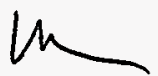

This report was prepared by the Energy Information Administration, the independent statistical and analytical agency within the Department of Energy. The information contained herein should not be construed as advocating or reflecting any policy position of the Department of Energy or any other organization. 


\section{DISCLAIMER}

This report was prepared as an account of work sponsored by an agency of the United States Government. Neither the United States Government nor any agency thereof, nor any of their employees, make any warranty, express or implied, or assumes any legal liability or responsibility for the accuracy, completeness, or usefulness of any information, apparatus, product, or process disclosed, or represents that its use would not iniringe privately owned rights. Reference herein to any specific commercial product, process, or service by trade name, trademark, manufacturer, or otherwise does not necessarily constitute or imply its endorsement, recommendation, or favoring by the United States Government or any agency thereof. The views and opinions of authors expressed herein do not necessarily state or reflect those of the United States Government or any agency thereof. 


\section{DISCLAIMER}

Portions of this document may be illegible in electronic image products. Images are produced from the best available original document. 


\section{Preface}

Natural Gas 1996: Issues and Trends provides a summary of the latest data and information relating to the U.S. natural gas industry, including prices, production, transmission, consumption, and financial aspects of the industry. The report consists of six chapters and seven appendices.

Chapter 1 presents a summary of various data trends and key issues in today's natural gas industry and examines some of the emerging trends. Chapters 2 through 6 focus on specific areas or segments of the industry, discussing in some detail the many choices and challenges of the current marketplace. Chapter 2 discusses the natural gas transportation market and pipeline capacity release and turnback issues. Chapter 3 examines the development of natural gas market centers during the past 5 years and how these entities have changed the way business is transacted in the natural gas marketplace. Chapter 4 looks at how natural gas producers have responded to the restructuring of the interstate pipeline industry and how they have improved operations to become more efficient in a more competitive market. Chapters 5 and 6 focus upon the distribution end of the natural gas industry, examining first how prices to final consumers have changed since restructuring, and second, how State regulatory agencies are dealing with competitive and operational changes in the intrastate and interstate markets.

Unless otherwise stated, historical data on natural gas production, consumption, and price through 1995 are from the Energy Information Administration (EIA) publication, Natural Gas Annual 1995, DOE/EIA-0131(95) (Washington, DC, November 1996). Similar annual data for 1996 and monthly data for 1995 and 1996 are from EIA, Natural Gas Monthly (NGM), DOE/EIA-0130 (96/11) (Washington, DC, November 1996).

Natural Gas 1996: Issues and Trends was prepared by the Energy Information Administration, Office of Oil and Gas, Kenneth A. Vagts, Director (202/586-6401). General information concerning this report may be obtained from Joan E. Heinkel, Director of the Reserves and Natural Gas Division (202/586-4680). Questions on specific sections of the report may be addressed to the following analysts:
- Chapter 1. "Overview," Mary E. Carlson (202/5864749).

- Chapter 2. "Changes in Firm Transportation Capacity Contracting," Barbara Mariner-Volpe (202/586-5878).

- Chapter 3. "The Emergence of Natural Gas Market Centers," John H. Herbert (202/586-4360) and James Tobin (202/586-4835).

- Chapter 4. "Producers in Today's Competitive Market," William A. Trapmann (202/586-6408).

- Chapter 5. "Consumer Prices Reflect Benefits of Restructuring," Margaret J. Jess (202/586-7499).

- Chapter 6. "State Regulators Promote Consumer Choice in Retail Gas Markets," Margaret J. Jess (202/586-7499).

The overall scope and content of the report was supervised by James Tobin. Overall coordination of the report was provided by James Thompson. Significant analytical contributions were made by the following individuals:

Christopher L. Ellsworth-Chapters 1 and 6

Jason Feld—Chapter 2

Kevin F. Forbes-Chapter 4

James P. O'Sullivan-Chapter 2

Philip Shambaugh-Chapters 1 and 2

Michael J. Tita-Chapters 1 and 2

James Thompson—Chapter 1

James Todaro-Chapter 1

Lillian (Willie) Young-Chapter 1.

Editorial support was provided by Ann C. Whitfield and Willie Young. Desktop publishing support was provided by Margareta Bennett. 
. 


\section{Contents}

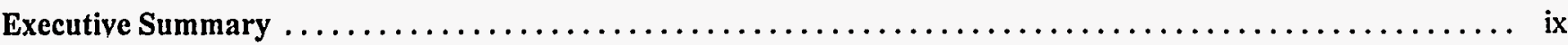

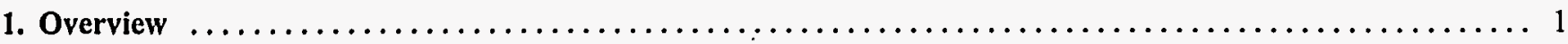





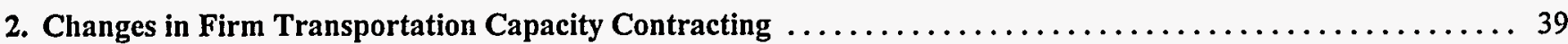

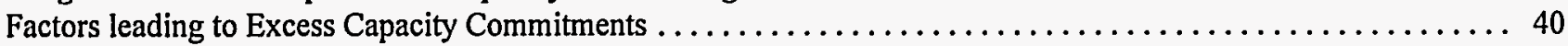

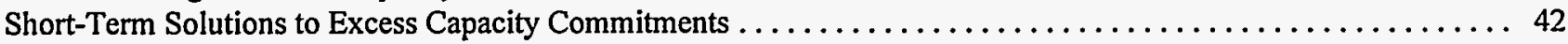

Capacity Turnback: Realigning Contracts with Requirements $\ldots \ldots \ldots \ldots \ldots \ldots \ldots \ldots \ldots \ldots \ldots \ldots \ldots \ldots$

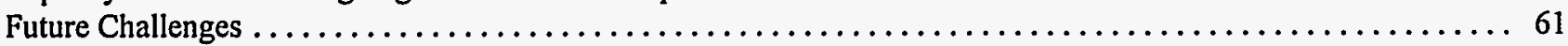

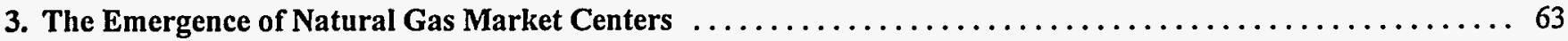

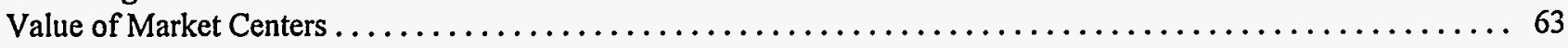

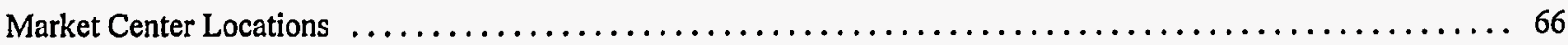

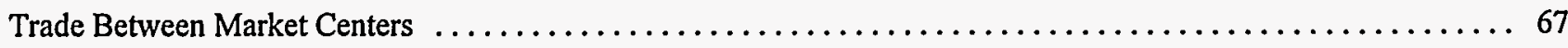

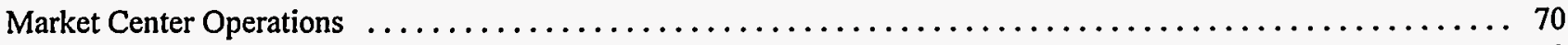

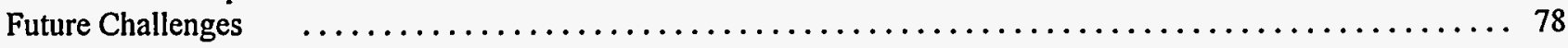



A More Competitive Supply Industry and Wellhead Market $\ldots \ldots \ldots \ldots \ldots \ldots \ldots \ldots \ldots \ldots \ldots \ldots \ldots . \ldots \ldots$

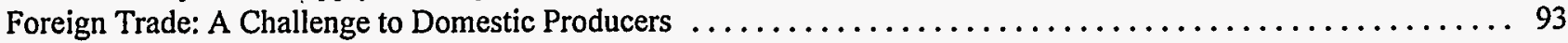



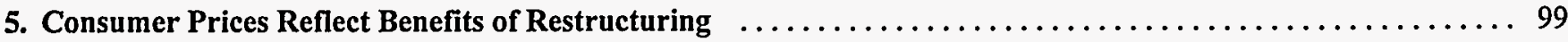

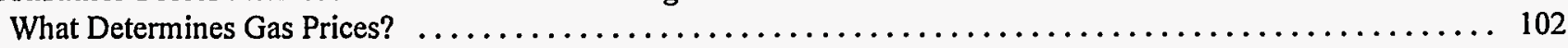

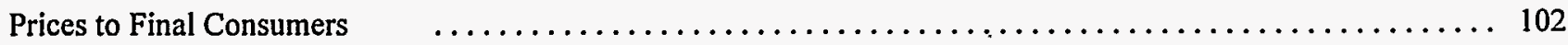

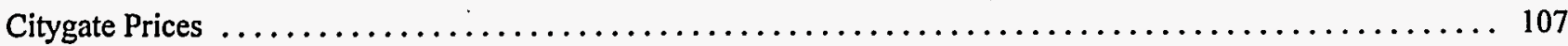

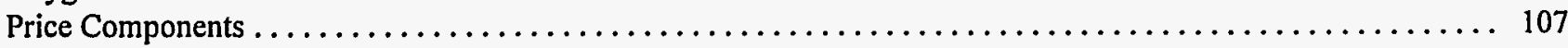

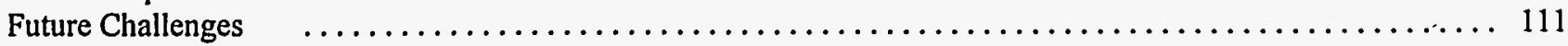

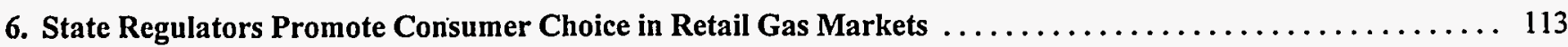

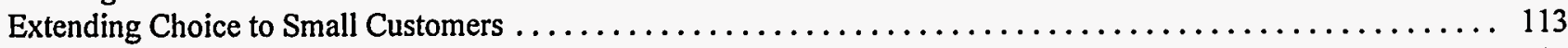



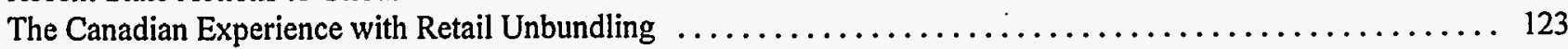



Appendix

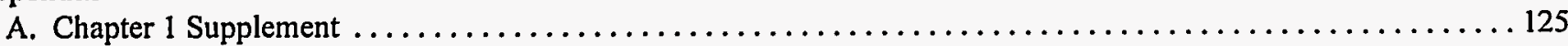

B. Analysis of Firm Transportation Contracts: Results and Methodology $\ldots \ldots \ldots \ldots \ldots \ldots \ldots \ldots \ldots \ldots \ldots . \ldots \ldots$

C. Summary of Industry Surveys on Future Capacity Commitments $\ldots \ldots \ldots \ldots \ldots \ldots \ldots \ldots \ldots \ldots \ldots \ldots \ldots$

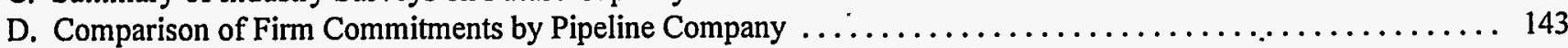

E. Analysis of Capacity Release Trading: Results and Methodology $\ldots \ldots \ldots \ldots \ldots \ldots \ldots \ldots \ldots \ldots \ldots \ldots 147$

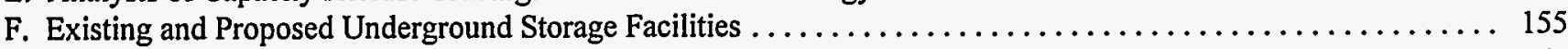

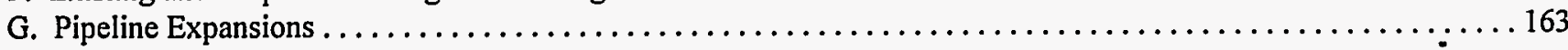




\section{Tables}

1. The Top Natural Gas Marketers Will Change After Mergers $\ldots \ldots \ldots \ldots \ldots \ldots \ldots \ldots \ldots \ldots \ldots \ldots \ldots, 22$

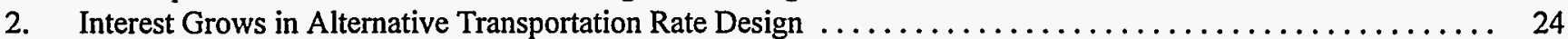

3. Regional Characteristics of Released Capacity, November 1993 - March 1996 . . . . . . . . . . . . . . . . . 49

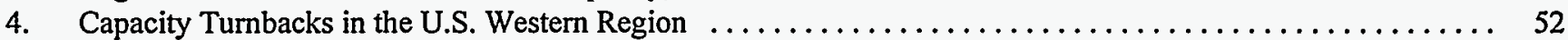

5. Current Capacity Commitments and Cumulative Expirations by Region and Period $\ldots \ldots \ldots \ldots \ldots \ldots \ldots$

6. Transportation Capacity Under Contract in 1990 and 1996 for a Sample of Interstate Pipeline Companies,

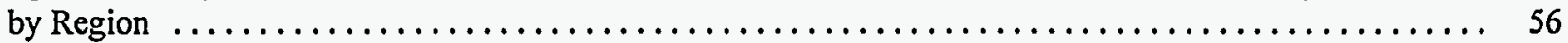

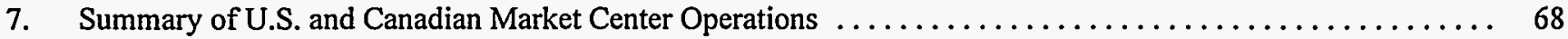

8. Operational Market Centers in the United States and Canada, September $1996 \ldots \ldots \ldots \ldots \ldots \ldots \ldots \ldots . \ldots 69$



10. Correlations Among Regional Spot Market Natural Gas Prices $\ldots \ldots \ldots \ldots \ldots \ldots \ldots \ldots \ldots \ldots \ldots \ldots . \quad 83$

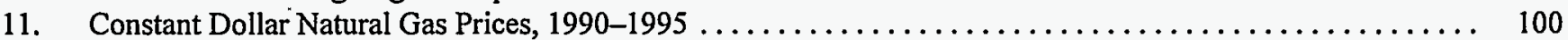

12. Natural Gas Consumption and LDC Sales by Region, $1995 \ldots \ldots \ldots \ldots \ldots \ldots \ldots \ldots \ldots \ldots \ldots \ldots \ldots \ldots \ldots \ldots$

13. Unbundling Actions by Selected Public Utility Commissions $\ldots \ldots \ldots \ldots \ldots \ldots \ldots \ldots \ldots \ldots \ldots \ldots$

\section{Figures}

Figures 1 through 13 (Chapter 1) are composed of multiple illustrations. Below the figure title for each there is a list of subtitles describing each illustration. The subtitles are listed in the order in which the illustrations appear in the figure, from left to right moving down the page. The remaining figures (14 through 42) are single illustrations with no subtitles.

1. . Increased Price Volatility Has Become Common in the Gas Industry $\ldots \ldots \ldots \ldots \ldots \ldots \ldots \ldots \ldots \ldots . \ldots 2$ - Monthly Natural Gas Wellhead Prices, 1991 - July 1996

- Daily Henry Hub Natural Gas Spot Prices, November 1995 - March 1996

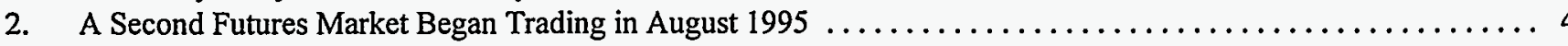

- Daily Settlement Price Levels for NYMEX and KCBOT Trading, August 1995 - July 1996

- NYMEX and KCBOT Monthly Futures Contracts Trading Levels, August 1995 - July 1996

- NYMEX and KCBOT Monthly Options Trading Levels, August 1995 - July 1996

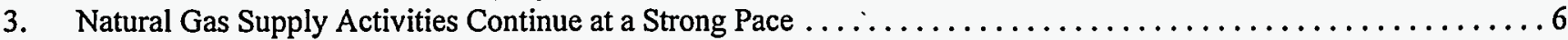

- Average Daily Domestic Natural Gas Production Levels by Month, 1994 - September 1996

- Indices of Domestic Natural Gas Well Completions and Average Wellhead Price, January 1994 - September 1996

- Shares of Rotary Rigs Directed Toward Natural Gas and Crude Oil, 1988-1996

4. Natural Gas Resources Are Heavily Centered Around the Gulf of Mexico $\ldots \ldots \ldots \ldots \ldots \ldots \ldots \ldots \ldots$

- Domestic Natural Gas Reserves, by State, 1995

- Costs Versus Estimated Economically Recoverable Nonassociated Conventional Gas Resources, 1995

- Percent of Remaining Undiscovered Natural Gas Fields, by Onshore Region and Size

5. Canadian Imports Dominate U.S. International Gas Trade $\ldots \ldots \ldots \ldots \ldots \ldots \ldots \ldots \ldots \ldots \ldots \ldots \ldots \ldots$

- U.S. Imports of Canadian Natural Gas, by Region, 1994 and 1995

- Indices of U.S. Average Wellhead Prices and Imported Canadian Gas Volumes and Prices, January 1994 - September 1996

- Cumulative Monthly LNG Import and Export Volumes, January 1994 - September 1996

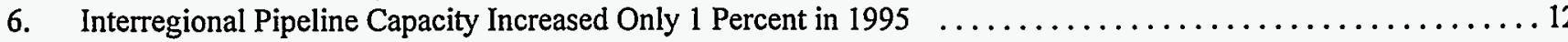

- Capacity Additions and Natural Gas Pipeline Projects Completions, 1995

- Summary of Interregional and Interstate Natural Gas Pipeline Capacity, 1995-1999

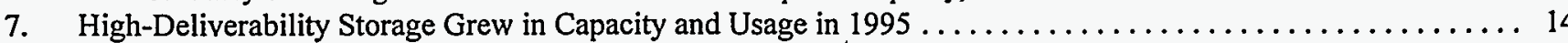

- Locations of Natural Gas Underground Storage Sites Completed in 1995 and Planned 1996-1999

- Inventory Turnover Rates for High Deliverability Storage, 1991-1996

8. Service Selection and Costs Have Changed in the Natural Gas Transmission Market ................

- - Natural Gas Pipeline Throughput by Type of Service, 1987-1995

- Interstate Pipeline Company Percent of Total Deliveries to Industrial Customers, 1989-1995

- Natural Gas Pipeline Throughput by Type of Service and Market Participant, 1995

- Annual Transmission and Distribution Cost by End-Use Sector, 1984-1995 
9. End-Use Consumption of Natural Gas Increases as Prices Fall $\ldots \ldots \ldots \ldots \ldots \ldots \ldots \ldots \ldots \ldots \ldots \ldots$

- Annual Percent Change in End-Use Consumption by Sector, 1992-1995

- End-Use Prices by Sector 1993-1995, Nominal and Real 1995 Dollars

- Fuel Prices to Electric Utility Plants, 1985

- Fuel Prices to Electric Utility Plants, 1995

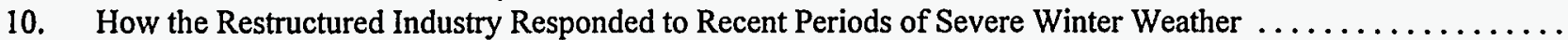

- Average of Actual and Normal Daily Temperatures for Four Cities (Chicago, Kansas City, New York, and Pittsburgh), Heating Seasons 1993-94 and 1995-96

- Working Gas in Underground Storage by Month, Heating Seasons 1993-94 and 1995-96

- Daily Henry Hub Natural Gas Spot Prices, Heating Seasons 1993-94 and 1995-96

- Daily Price Premium, January 12 - February 15, 1994 and 1996

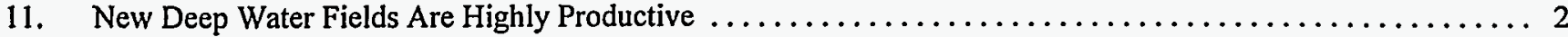

- Average Proved Reserves per Field for New Fields Discovered Between 1990 and 1994, by Region

- Shares of Proved Reserves of Associated-Dissolved Gas, by Region, 1990-1994

- Maximum Water Depth Levels Reached for Offshore Oil and Gas Projects, 1978-1997 (Planned)

Electronic Communication Services Have Increased

- Diagram of Electronic Access and Services Available to Natural Gas User Community

- Example of Natural Gas Market Center Electronic Gas Trading Transaction Screen

13.

Electric Restructuring Begins in Earnest

- Federal Energy Regulatory Commission Open Access Orders for Electric Transmission

- Residential Prices of Electricity and Natural Gas, 1990 and 1995

14.

15.

Seasonal Capacity Held by Replacement Shippers, November 1993 - March 1996 . . . . . . . . . . . . 44

Index of Capacity Held by Replacement Shippers During Heating Seasons, $1993-1996 \ldots \ldots \ldots \ldots \ldots \ldots \ldots 44$

Capacity Held by Replacement Shippers, November 1993 - March $1996 \ldots \ldots \ldots \ldots \ldots \ldots \ldots \ldots \ldots . \ldots 46$

Heating Season Capacity Release Revenues by Region, $1993-1996 \ldots \ldots \ldots \ldots \ldots \ldots \ldots \ldots \ldots \ldots \ldots$

Southern California Gas Company Activity on El Paso Natural Gas Company System $\ldots \ldots \ldots \ldots \ldots \ldots . \quad 50$

Capacity Associated with Expiring Firm Transportation Contracts on Transwestern System $\ldots \ldots \ldots \ldots \ldots .53$

Pipeline Capacity under Firm Contract in 1990 and 1996 for a Sample of Interstate Pipeline Companies ..... 55

Firm Transportation Capacity as of April 1, 1996, Grouped by Length of Contract $\ldots \ldots \ldots \ldots \ldots \ldots \ldots$. 55

Expiration of Firm Transportation Capacity Under Contract as of April 1, $1996 \ldots \ldots \ldots \ldots \ldots \ldots \ldots \ldots$. . . . . 57

Annual and Cumulative Expirations of Firm Transportation Capacity, $1996-2025 \ldots \ldots \ldots \ldots \ldots \ldots \ldots \ldots$. 57

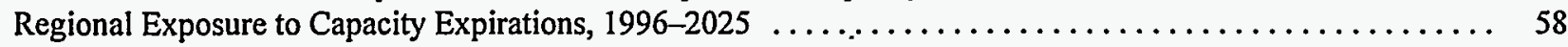

Expirations of Firm Transportation Capacity Under Contract as of April 1, 1996, by Region ............ 59

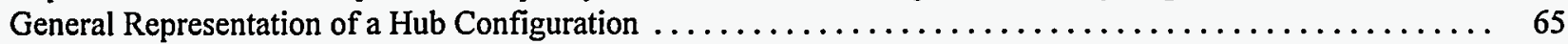

Locations of the Major Natural Gas Market Centers in the United States and Canada $\ldots \ldots \ldots \ldots \ldots \ldots .67$

West Texas Market Centers Interplay with North and East Texas and Louisiana Market Centers . . . . . . . 70

Premium Return for Quick and Flexible Delivery Capability, November 1995 - March 1996 .......... 76

30. Difference Between Futures Final Settlement Prices at the Henry Hub and Bid-Week Spot Prices at

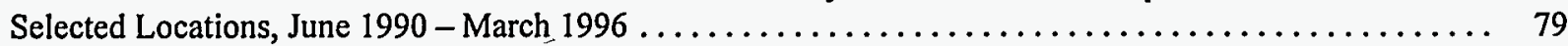

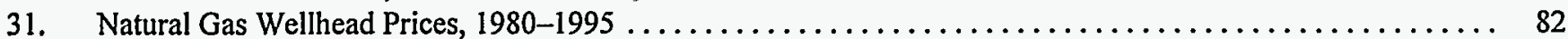

32. Lower 48 States Map Showing Reference Locations for Price Correlation Analysis $\ldots \ldots \ldots \ldots \ldots \ldots \ldots \ldots . \quad 83$



34. Growth in Ultimate Field Recovery: Recovery as Multiple of Initial Proved Reserves for a Stylized Field .... 88

35. Growth in Ultimate Recovery for the Top Five Gas Fields in the Lower 48 States, 1977-1992 . . . . . . . 88

36. U.S. Imports of Natural Gas: Total and from Canada, $1980-1995 \ldots \ldots \ldots \ldots \ldots \ldots \ldots \ldots \ldots \ldots \ldots . \ldots \ldots$

37. Reserves-to-Production Ratios, United States and Canada, $1980-1994 \ldots \ldots \ldots \ldots \ldots \ldots \ldots \ldots \ldots \ldots$

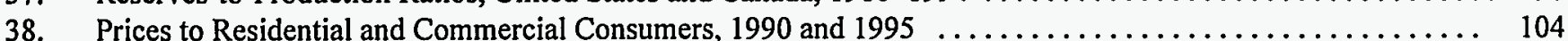

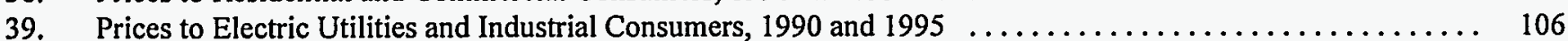

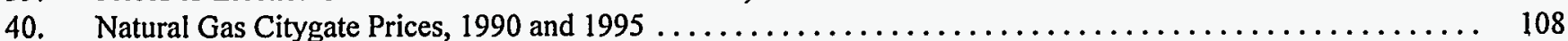

41. Distribution Margins for Residential and Commercial Customers, 1990 and $1995 \ldots \ldots \ldots \ldots \ldots \ldots . \ldots$

42. LDCs Sell a Smaller Share to Industrial and Commercial Customers, $1989-1995 \ldots \ldots \ldots \ldots \ldots \ldots \ldots . . .114$ 



\section{Executive Summary}

Natural Gas 1996: Issues and Trends focuses on the increasing choices available to participants in the natural gas industry, from suppliers to consumers, at a time when regulatory restraints increasingly are removed from the sale and transport of natural gas. The industry faces significant challenges, such as how to deal with price volatility. In addition, cost-conscious suppliers, marketers, distributors, and consumers now pay increased attention to inventory levels and reducing excess capacity and stocks. Highlights of recent trends and developments in the industry include the following:

- Wellhead prices in 1995 averaged $\$ 1.55$ per thousand cubic feet (Mcf), a steep decline of 16 percent from 1994 (Figure ES1). Monthly average prices rose sharply to $\$ 1.84$ per Mcf in December 1995 in response to cold weather and have continued higher than the December level throughout 1996 . The particularly high price for July 1996 of $\$ 2.35$ per Mcf was in part due to strong demand from storage customers who found their stocks at record lows after the cold winter of 1995-96.

- Residential and commercial gas consumption during the first 11 months of 1996 was 9 percent higher than during the same period of 1995 in response to cold weather that extended into the spring. Electric utility consumption was down 9 percent during this period, in part because the average price to this sector through July exceeded that of 1995 by 35 percent. Overall end-use consumption through November 1996 averaged 3 percent above the level for the same period in 1995, continuing the general upward trend since 1986. For the year 1995, overall enduse consumption of natural gas was 19.7 trillion cubic feet, an increase of 4 percent above the 1994 level.

- Natural gas production, which declined slightly in 1995 to 18.6 trillion cubic feet, is expected to reach the highest annual level since 1981 by the end of 1996 . Production for the year through November 1996 exceeds levels for the comparable period in both 1994 and 1995.

- Working gas storage levels at the end of March 1996 reached a record low of 755 billion cubic feet. As a consequence, storage refill activity from April through September 1996 was 20 percent higher than during the same period in 1995. Preliminary estimates indicate that working gas stocks at the start of the 1996-97 heating season (November 1) were about 2.8 trillion cubic feet, 7 percent lower than at the same time last year. Nevertheless, this level appears sufficient since net withdrawals during the past three heating seasons ranged from 1.8 to 2.3 trillion cubic feet.

- New and expanded storage facilities added 1,395 million cubic feet to daily deliverability in 1995, an increase of 2 percent over the 1994 level. High-deliverability salt cavern storage dominated the additional deliverability, accounting for 65 percent of the increase.

- Differences between the eastern and western supply markets are evident from the different price movements for two natural gas futures contracts: the New York Mercantile Exchange (NYMEX) contract at the Henry Hub in southern Louisiana; and the relatively new Kansas City Board of Trade (KCBOT) contract at the Waha Hub in West Texas. Prices for the nearby contract (for delivery the next month) on both futures markets rose from August through December 1995, but prices for the Henry Hub contract almost doubled while prices for Waha Hub contracts increased about 50 percent.

- Several recently completed and proposed pipeline expansions reflect the need to eliminate bottlenecks between western supply areas and eastern markets. During 1995, several intrastate pipeline companies in Texas increased capacity between the West Texas Waha area and market centers located in eastern Texas and Louisiana. This, and the planned expansion of 350 million cubic feet per day from the San Juan Basin (New Mexico) to the Waha area, should help to move production from western to eastern markets.

- The capacity release market has grown steadily since its inception in 1993 and has generated nearly $\$ 1.2$ billion in revenue to releasing shippers. But average rates for released capacity are still well below maximum tariff rates. In the 1995-96 heating season, rates were discounted an average of 65 percent from the maximum, while during the 1995 nonheating season, rates were discounted 83 percent.

\section{The Industry Continues to Adjust Inventory Practices and Test Adequate Storage Levels}

With significant price volatility in the spot and futures markets, the inherent risk in holding large storage inventories is great for distribution companies and other major users of conventional storage reservoirs, especially as energy markets have become increasingly competitive and cost conscious. In response, many companies have reduced the amount of gas 
Figure ES1. Wellhead Prices Are Very Volatile

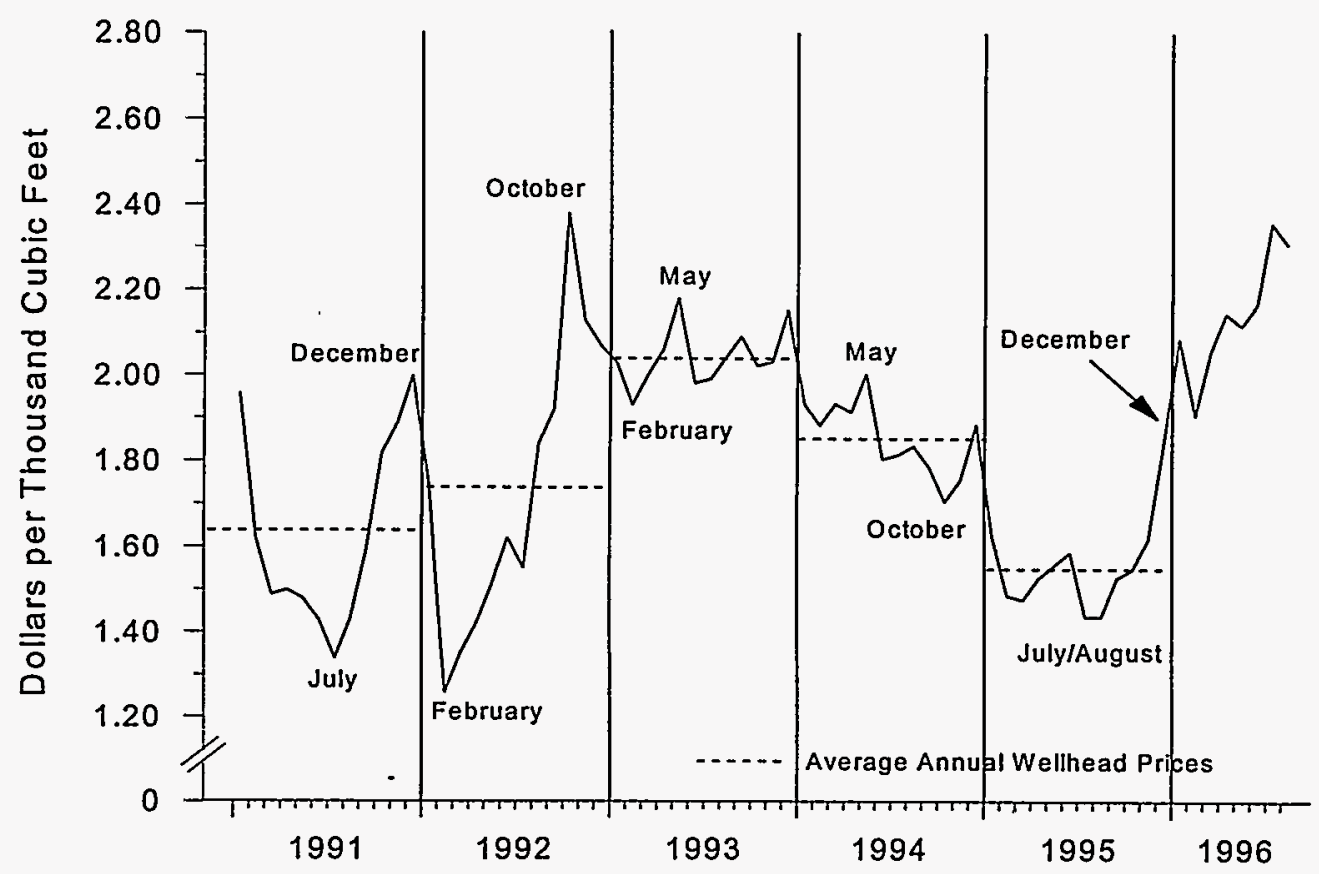

Notes: All prices are in nominal dollars. The labeled months are the month of the maximum and minimum prices in each year.

Sources: Energy Information Administration. 1991-1992-Historical Monthly Energy Review, 1973-1992. 1993-Natural Gas Monthly (March 1996). 1994-August 1996-Natural Gas Monthly (November 1996).

they hold in reserve at storage sites. This movement is illustrated by the use of underground storage during the past heating season. At the start of the 1995-96 heating season, the level of working gas in storage was below 3.0 trillion cubic feet (Tct) for only the second time in 15 years. By the end of December, working gas in storage was at a 20-year low of 2.2 Tcf for the month as record withdrawals of 1,002 billion cubic feet occurred during November and December. Preliminary monthly data indicate that $2.7 \mathrm{Tcf}$ of gas was withdrawn from storage during the 1995-96 heating season, the highest total ever recorded. By the end of March, storage levels were at record lows and were only 20 percent of total working gas capacity.

The industry, operating with lower storage levels, was able to provide reliable service during the past heating season. One reason is that new technologies, such as horizontal drilling in conventional oil/gas storage reservoirs, have enabled the industry to bring larger amounts of incremental supplies of gas to market more quickly than in the past. Another reason is the greater use of salt cavern or high-deliverability storage facilities, which can be cycled numerous times throughout the year. The industry is increasingly taking advantage of this type of storage facility. About two-thirds of the storage deliverability brought on line in 1995 was high-deliverability storage. In addition, storage operators cycled salt cavern storage about 1.14 times in the past heating season, up from 0.53 in 1991-92 (Figure ES2). At sites associated with market centers, cycling of storage was at a much higher average of 1.45 during the past heating season, reflecting the strategic value of storage sites, particularly salt cavern, associated with hubs and market centers. Before 1993, this type of storage was often marketed like conventional storage and used primarily as seasonal backup supply rather than as peaking or short-term swing supply.

\section{Hubs and Market Centers Are a Key Aspect of an Increasingly Integrated Delivery System}

The development of market centers and hubs is one of the most recent innovations in the natural gas marketplace. At least 39 centers are operating in the United States and Canada, providing numerous interconnections and routes to move gas from production areas to markets. Another 6 are expected to begin operations during the next several years. The market center segment of the industry is still in its formative years; 27 of the centers have been operating only since the beginning of 1994. Many of the recently opened market centers are gradually developing their business, concentrating their major marketing efforts on the services that are reflected 
Figure ES2. Salt Cavern Cycling Has Increased

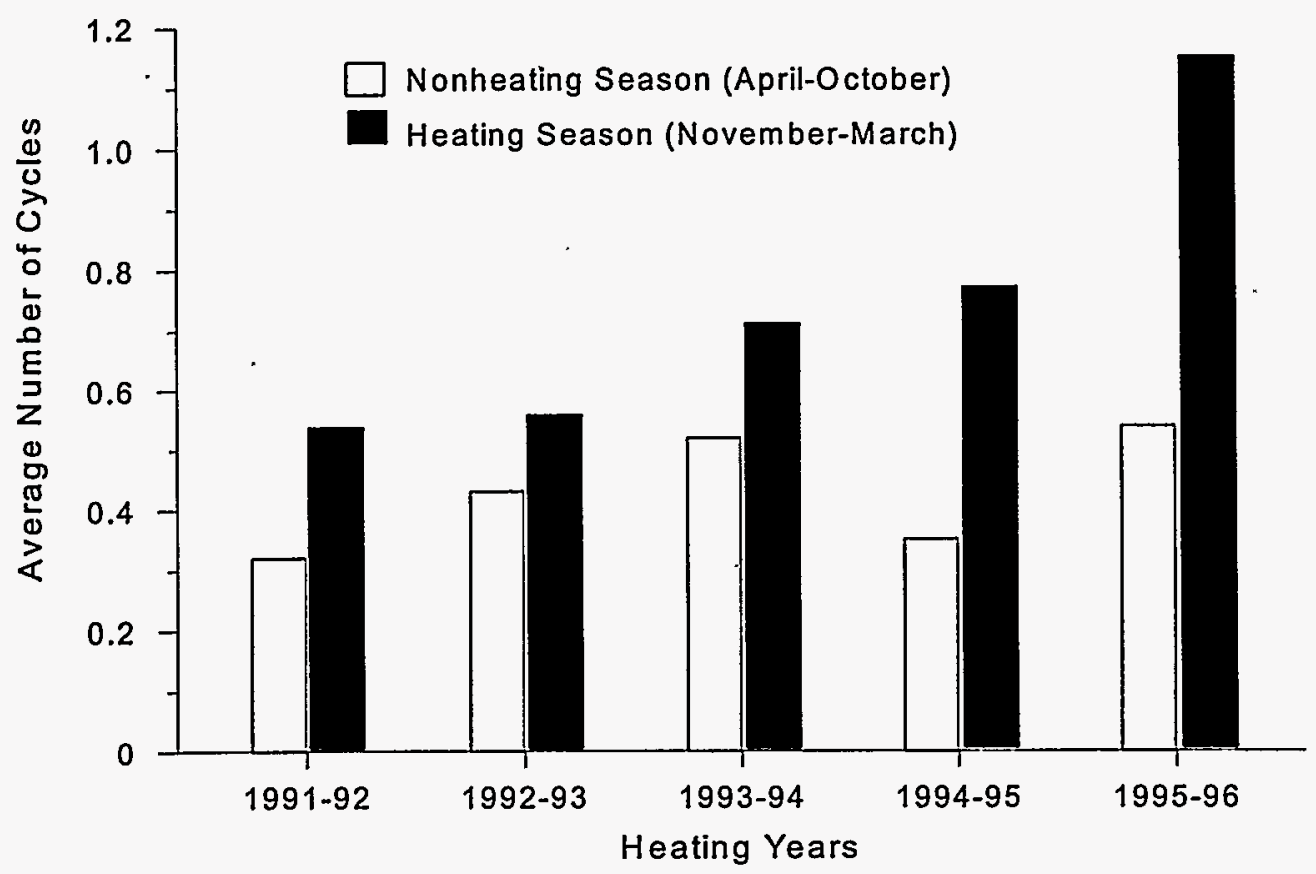

Notes: A heating year is from April of one year through March of the next year; for example, heating year 1991-92 is April 1991 through March 1992.

Source: Energy Information Administration (EIA), Form EIA-191, "Underground Gas Storage Report."

in the physical capabilities of their supporting systems. For instance, those with associated storage, in general, provide significant short-term parking, gas loans, and storage capacity brokering. In fact, storage is vital to the operations of most market centers; 47 percent of working gas storage capacity in North America is directly or indirectly accessible by market centers. Furthermore, market center operations are connected to practically all the high-deliverability storage facilities in North America.

Market centers, with their access to multiple pipeline interconnections and supplies, provide a natural platform for gas trading, risk management, and opportunities for arbitrage. More than 17 centers offer access to electronic trading while others provide a trading staff. Trading at market centers provides a means of reducing price risk exposure and gives traders access to lower cost supplies available at one site that can be transported and sold at another location offering higher prices. Very active trading at several centers has benefited from and/or has complemented the growth in the natural gas futures contract market, for instance, at the Henry Hub (NYMEX) and West Texas market center areas (NYMEX and $\mathrm{KCBOT}$ ). More than 25 pipeline systems have access to these market centers.

At this point, it would appear that most market centers are not operating near their full potential even though they have expanded the number of services they offer and are doing increasing business. For instance, salt cavern storage sites associated with market centers are frequently less than 40 percent full (Chapter 3), and the amount of withdrawals at these sites is rarely near upper limits from one week to the next. If these facilities were constantly being recycled (inventory turnover), they would be much closer to being filled and the percentage amount full would change from one week to the next. The recycling capability of these storage facilities could allow customers to take advantage of trading opportunities provided by the great daily volatility in gas prices and demand and by the daily and weekly imbalance situations experienced by many companies.

\section{Significant Price Divergence Continues Between Supply Regions}

The growth of market centers has created a more competitive environment for natural gas. In regional markets, gas prices are a signal of relative demand and supply conditions in those markets, and they also can indicate the degree of competition between markets. If gas markets are supported by an efficient infrastructure, such as the transmission network and institutional systems, regional demand and supply conditions will be interrelated, causing similar movements in prices, although price levels are not expected to be uniform. Analysis of spot market prices at selected locations across the United 
States for months between November 1993 and May 1996 indicates that the relatedness of markets varies widely. Markets within the western, central, and eastern regions seem well interconnected even for locations that are considerable distances apart, such as the Henry Hub location (south Louisiana) and Eastern Canada. Competition among the three broad regions is significantly weaker, especially between the western and eastern regions.

Market integration apparently improved in recent years, and regional clusters of markets across certain broad areas seem to be highly competitive, even between U.S. and Canadian markets. It is probably premature, however, to conclude that a true North American market for natural gas has emerged in light of the seeming separation in competition between the eastern, central, and western markets. Some of the market separation relates to capacity bottlenecks in parts of the country, and there is significant activity underway to address these capacity constraints. Several intrastate pipeline projects were completed in 1995 and more are proposed to expand capacity to move gas from the Permian and San Juan Basins to eastern and midwestern markets. Overall proposed capacity additions could increase interregional capacity as much as 7 percent by the end of 1999 .
Expiration of Contracts for the Reservation of Interstate Pipeline Capacity Concerns Many in the Industry

Some shippers are "turning back" all or part of their capacity commitments when transportation contracts come up for renewal. The extent and implications of a reduction in capacity reservations is an emerging concern for the transportation industry. In monetary terms, the potential impact of turnback is significant. By December 31, 2001, contracts covering half of current capacity reservations will expire. If 20 percent of this capacity would remain unsubscribed, it would represent a $\$ 686$ million reduction in annual pipeline company revenues. Cost recovery by pipeline companies is a major concern in this circumstance.

The amount of capacity under expiring contracts varies by region and by pipeline company, but the outlook for extensive capacity expirations ( 85 to 100 percent) by 2010 is the same for each of the regions (Figure ES3). Cumulative expirations in the United States will total 51 percent by 2001 and 89 percent by 2010 . The Southwest, Central, and Midwest regions have the greatest potential for significant turnback through the mid term (April 1996 through 2001), whereas the

Figure ES3. Extensive Expirations of Firm Capacity Contracts Will Occur in All Regions by 2010 (Trillion Btu)

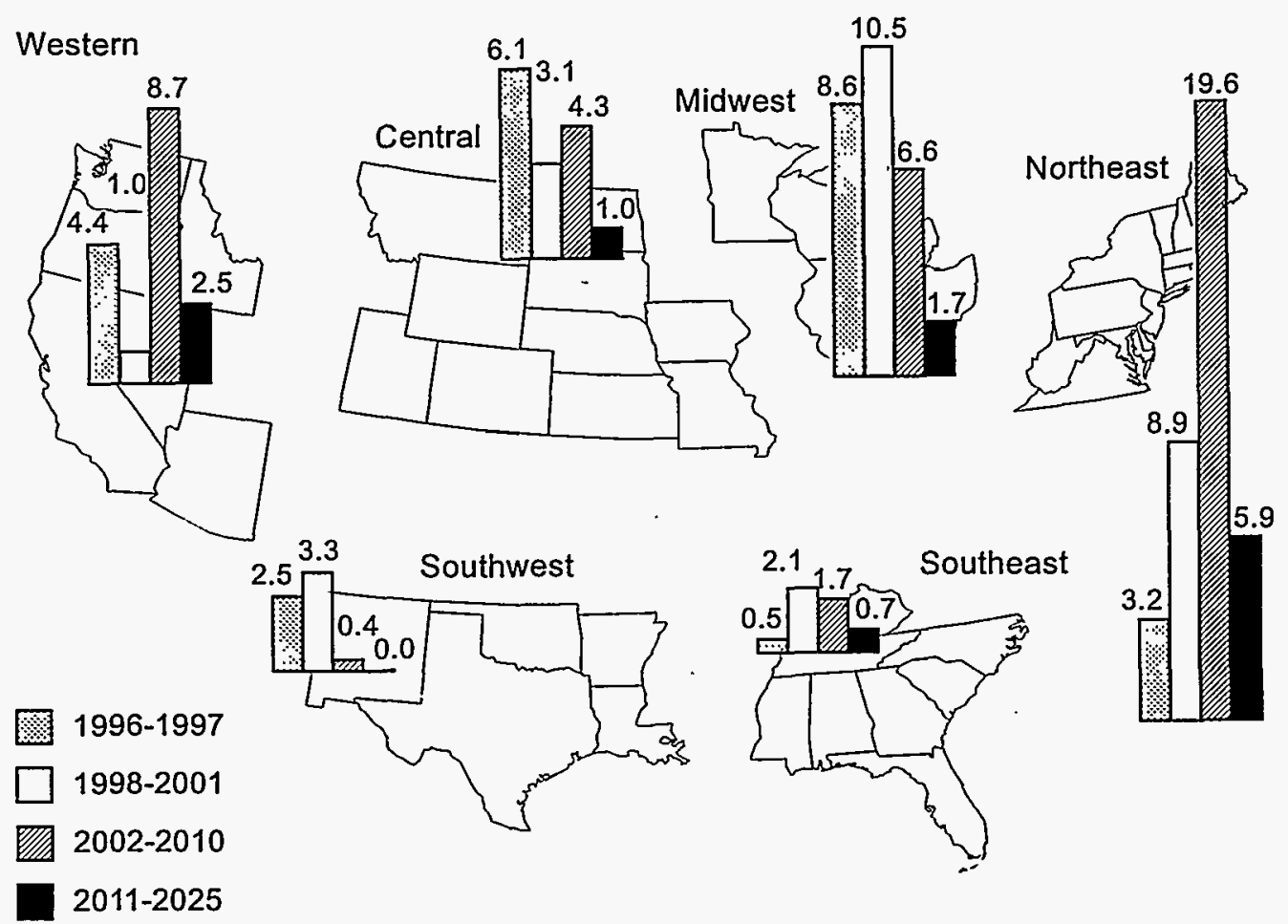

Source: Energy Information Administration, Office of Oil and Gas, derived from Federal Energy Regulatory Commission (FERC) Index of Customers data for April 1, 1996, FERC Bulletin Board (August 28, 1996). 
Northeast and West have the least because of the predominance of 20 to 30 year contracts. Between 2002 and 2010 , more than 50 percent of current reservations will expire in the Northeast and West, increasing cumulative expirations to 85 percent in both regions.

Today, in the market for pipeline capacity, long-term contracts may not be flexible enough to keep pace with changing market conditions. Capacity turnback may signify a period of adjustment for the transportation market similar to the transition from long-term to short-term and spot contracts that occurred in the wellhead gas market in the 1980's. Over the long term, the current changes may lead to the development of alternatives to current transportation services. Other possibilities include a spot market for transportation, increased commoditization of capacity, and the development of financial instruments for the transportation segment of the gas industry.

\section{Service Choices Are Increasing for All Customers}

Although the restructuring of the natural gas industry started more than 10 years ago, it is far from complete. By 1995, large segments of the gas industry had measurable cost reductions as a result of the introduction of competitive market forces into the industry's operations. Average inflation-adjusted gas prices have fallen for all types of consumers. Electric utility purchases show that prices to this group have fallen by more than a third between 1990 and 1995. However, residential and commercial customers, most of whom still purchase bundled gas services from regulated franchised distribution companies, on average experienced relatively modest real price declines of about 10 percent.

These residential and small commercial customers are only now beginning to have the benefits of competitive supply choices. State efforts to provide smaller residential and commercial customers service choice by providing access to unbundled gas services are gaining momentum. Many States are actively examining or implementing some form of small customer unbundling program, which will give smaller customers of local distribution companies (LDCs) access to competitive gas markets already enjoyed by their larger customers. Some regulatory agencies have begun to reduce the threshold volume of gas consumption needed to qualify customers for LDC transportation-only services. They are initiating experiments to encourage smaller customers, even residential users, to aggregate into groups and exercise choice in gas markets.

\section{Electric Power Restructuring Will Change the Market for Natural Gas}

With the issuance of Order 888 in April 1996, regulatory oversight of the electric power industry is changing and, like the restructuring of the natural gas industry, will provide more choice for buyers and sellers of electric power. As in the gas markets, the first retail electricity consumers to have choices of suppliers will be high-volume customers. If market pricing significantly lowers electricity prices to these users, it could lead to the substitution of electricity for gas in industrial processes and undercut gas sales to manufacturers. In many other uses such as residential service, however, electricity is about four times more expensive than gas before adjustments for conversion efficiency. Opportunities for electricity to attract new customers or to displace existing gas sales in these markets are less likely given the wide gas-price advantage.

Other aspects of electric restructuring may imply a closer relationship in the future for both industries. Innovative developments in the gas industry during the past 10 years foretell some of these changes. Gas marketers have reformed gas supply relationships. Many of these same marketers are moving into the new electricity markets. In an effort to create integrated "energy" markets, as opposed to continuing separate, isolated markets, gas and electric companies are forming mergers and strategic alliances to give customers menus that allow buyers to bridge the differences between the industries. The electric business also appears to have caught the attention of the financial community. The development of financial instruments already used in the gas industry, such as spot, forward, futures, and options contracts, are being taken as models for electricity. These financial markets may help integrate the energy markets. 


\section{Figure 1. Increased Price Volatility Has Become Common in the Gas Industry}

Wellhead prices vary greatly between months and years ...



... and changes in daily spot prices at the Henry Hub

can be extreme

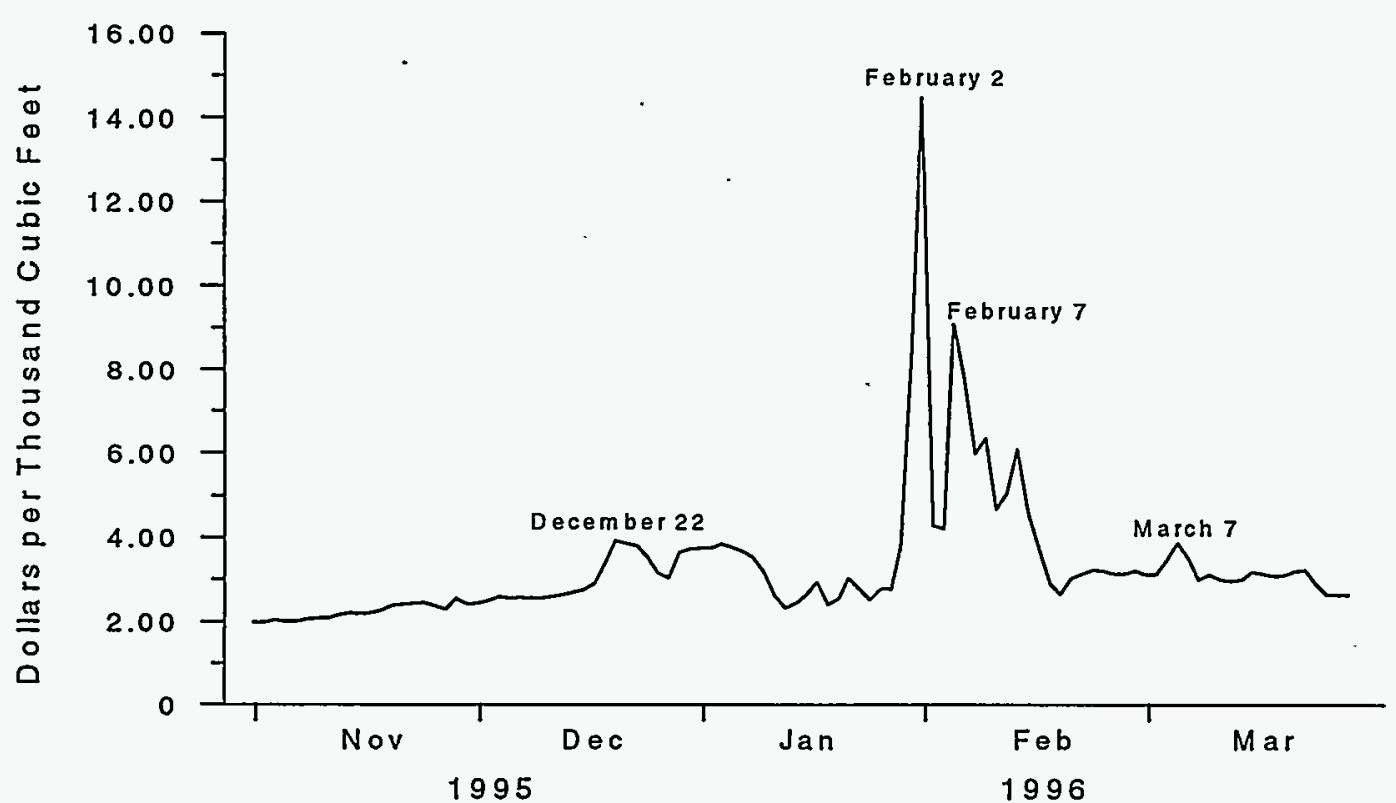

Notes: All prices are in nominal dollars. In the wellhead price graph, the labeled months are the month of the maximum and minimum prices in each year.

Sources: Wellhead Prlces: Energy Information Administration. 1991-1992-Historical Monthly Energy Review, 1973-1992. 1993-Natural Gas Monthly (March 1996). 1994-August 1996-Natural Gas Monthly (November 1996). Henry Hub Spot Prices: Pasha Publications, Inc., Gas Daily. 


\section{Data Trends: Wellhead and Spot Prices}

After a steep decline in 1995, natural gas spot and average wellhead prices moved sharply higher in 1996. Wellhead prices in 1995 averaged $\$ 1.55$ per thousand cubic feet (Mcf), down 16 percent from the 1994 level of $\$ 1.85$ per Mcf. In Jaly and August 1995, prices bottomed out for the year at $\$ 1.43$ per Mcf and then climbed to $\$ 1.84$ per Mcf in December. Prices rose even higher in January 1996 and have stayed above the December 1995 value throughout 1996. The particularly high price of $\$ 2.35$ per Mcf in July 1996 was in part due to strong demand for gas from storage customers who found their stocks badly depleted after the cold winter of 1995-96 and continued cold weather in early spring 1996.

Daily spot prices at the Henry Hub, a major exchange point for natural gas in South Louisiana, reached record levels during 1996. On February 2, 1996, some buyers paid more than $\$ 15.00$ per Mcf, and the median price for the day was about $\$ 14.00{ }^{2}$ The sharp rise and fall in price around this date indicates the phenomenal short-term price volatility in the natural gas marketplace. This volatility also surfaced in late November 1996 when prices at many trading locations and the Henry Hub futures market increased by more than $\$ 1.00$ within one week. In fact, spot prices for December 1996 are likely to be between 25 to 50 percent higher than the December 1995 values. It is increasingly apparent in the gas market that wellhead prices no longer exhibit any systematic changes between years, daily price volatility is significant, and natural gas prices are becoming ever more difficult to predict.

- Average annual wellhead prices in recent years have exhibited no obvious trend between years. Wellhead prices averaged $\$ 1.55$ per Mcf in 1995 , which is the lowest annual value since 1979 and well below the peak during the 1980's of $\$ 2.66$ per Mcf in 1984 ( $\$ 3.77$ in 1995 dollars). The mild 1994-95 winter, combined with plentiful supplies and relatively weak demand to refill storage reservoirs, contributed to the low price. Thus far in the 1990's, the differences between annual average prices have been as high as $\$ 0.30$ per Mcf (nominal), or about $\$ 6$ billion when expressed in terms of recent domestic production.

- The wide variations in wellhead prices from month to month since 1991 (Figure 1) suggest that those sellers who can quickly bring additional gas supplies to market have much to gain when prices rise. Since 1991 , monthly changes in wellhead prices have at times been large and almost always difficult to predict based on historical data. ${ }^{3}$ In addition, it is difficult to predict which month will have the lowest or highest prices during the year. The lowest monthly price occurred in February twice, yet it also occurred in the summer (1991 and 1995 ) and in the fall (1994). The highest monthly prices fell in three different seasons during this 5-year period. For 1996, preliminary estimates through August are all above the 1995 high of $\$ 1.84$ in December. These higher prices were driven, in part, by persistently colder-thannormal temperatures in the heating season and relatively high storage injection levels during the nonheating season.

- Spot prices at the Henry Hub varied widely between days during the 1995-96 heating season. During December 1995, spot prices increased $\$ 1.36$ in less than 10 days, from $\$ 2.44$ to $\$ 3.80$ per Mcf (Figure 1). Prices rose in response to colder-than-normal temperatures, lower-than-normal storage levels, and uncertainty about expected demands during the winter holiday season. ${ }^{4}$ Prices stayed high until mid-January when they dropped by more than $\$ 1.00$ in just a few days to settle at $\$ 2.19$ per Mcf. Spot prices rose again in late January. By February 1, 1996, prices were above $\$ 4.00$ per Mcf and stayed above $\$ 4.00$ until February 19. With this extreme short-term price volatility, the inherent risk in holding stocks is great, but so are the opportunities if companies stay current on price fluctuations and maintain flexible operating and contracting practices.

- The unpredictability of price provides a constant challenge to the industry. Many companies have reduced the amount of working gas they have in storage sites, especially relative to current demand. Technologies have allowed companies to reduce the amount of gas they have in storage at any point in time yet still maintain deliverability. This change in industry practice increases price uncertainty during periods of consistently colderthan-normal temperatures, as in the 1995-96 heating season. However, increased use of salt storage and new technologies, such as the use of horizontal wells in conventional oil and gas storage reservoirs, enable the industry to bring larger amounts of incremental supplies of gas to markets sooner than in the past. In addition, the industry is better able to tradeoff higher gas prices with lower prices for transportation and storage service or vice versa. ${ }^{5}$ The industry is also able to reduce price risk by using futures contracts and other financial instruments. ${ }^{6}$ 
Figure 2. A Second Futures Market Began Trading in August 1995

\section{Prices on both futures markets became more volatile in mid-December 1995}

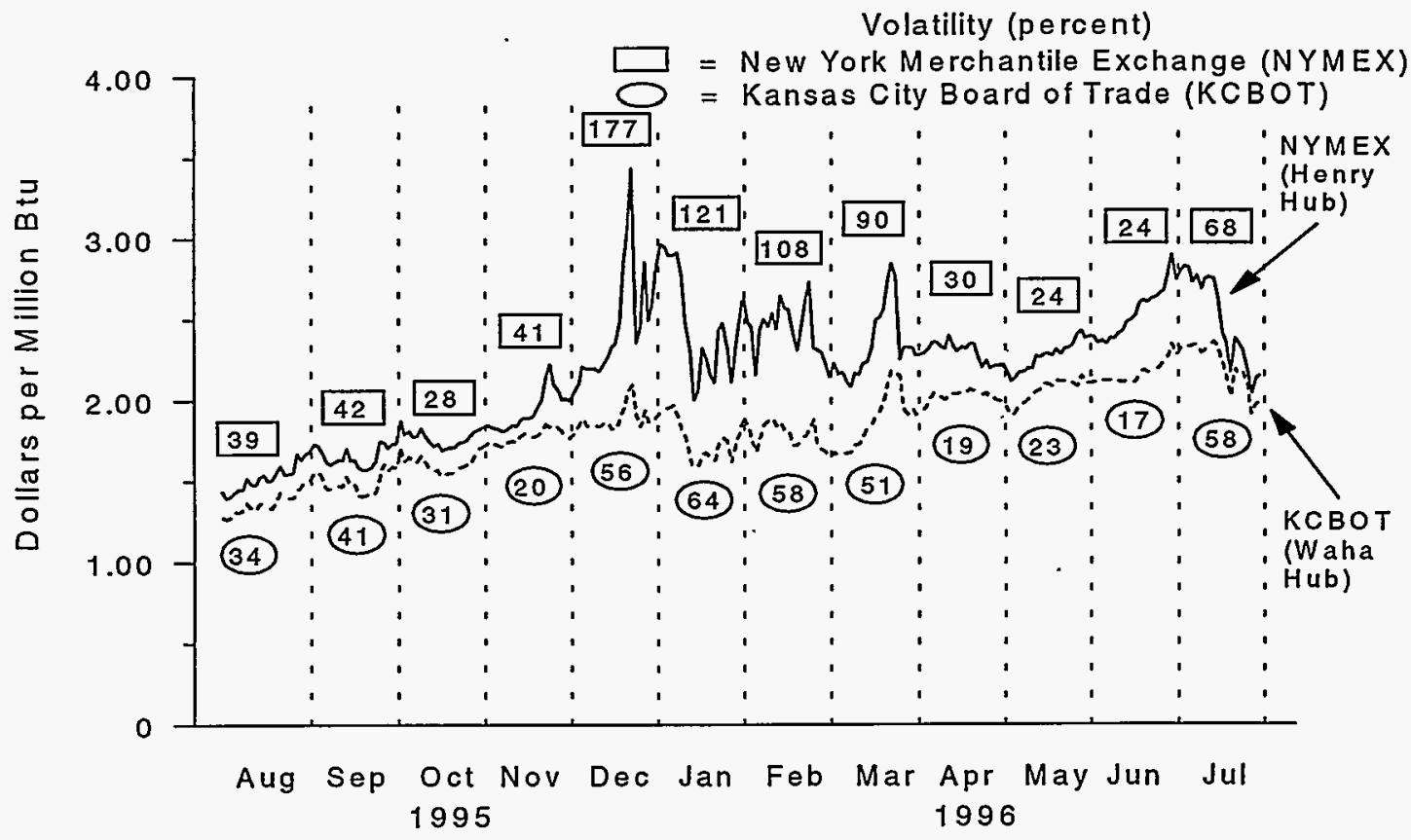

This increased volatility was coupled with increased trading on the NYMEX futures and options markets

Futures Markets

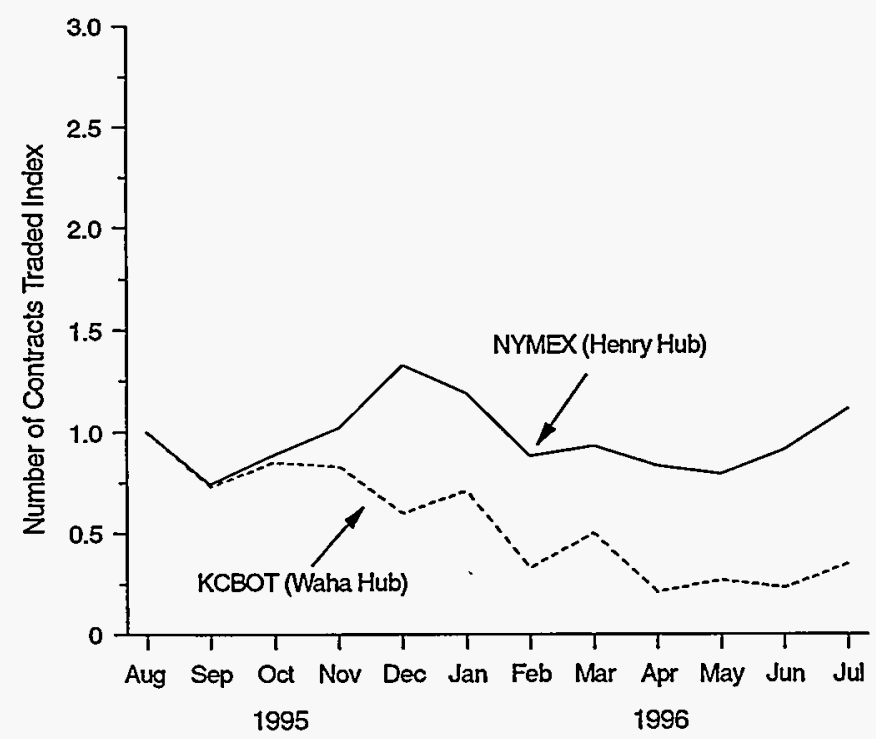

Options Markets

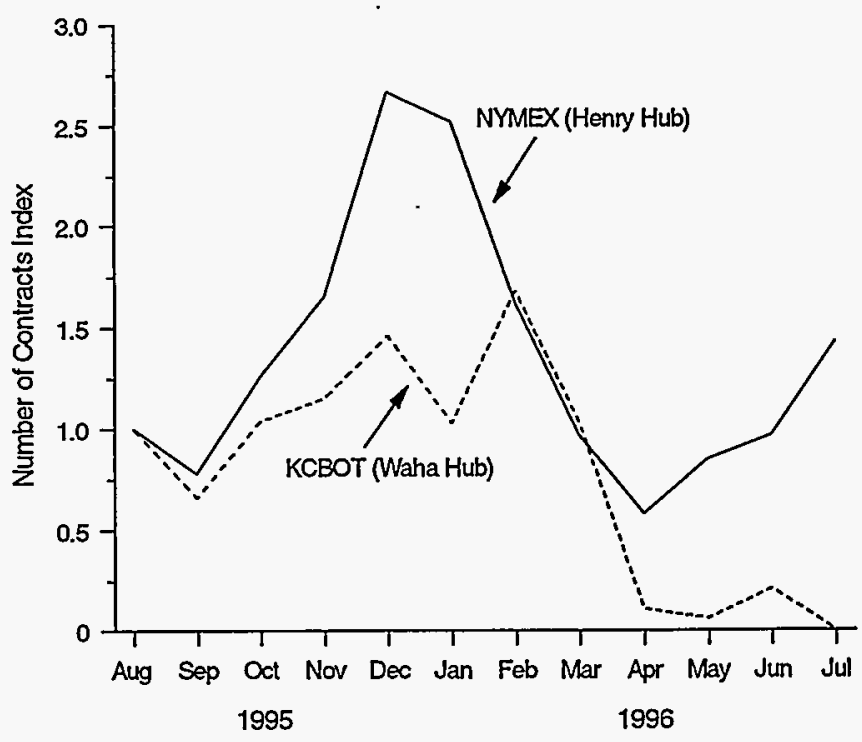

Note: In the price graph, "Volatility" is the annualized standard deviation of daily price changes expressed in percentage terms. The data are annualized by multiplying the standard deviation by the square root of 250 , the number of trading days in a year.

Source: Energy Information Administration, Office of Oil and Gas, derived from Commodity Futures Trading Commission, Division of Economic Analysis. 


\section{Data Trends: Futures and Options}

The high variability in natural gas supply prices and the large differences between eastern and western spot markets led to the establishment of a new futures contract in August 1995 by the Kansas City Board of Trade (KCBOT) for delivery though the Waha Hub in West Texas. The well-established New York Mercantile Exchange (NYMEX) futures contract for delivery at the Henry Hub in Louisiana is more closely connected to eastern consuming markets. In June 1996, NYMEX opened a competing western contract for delivery through the Permian Basin Pool, also in West Texas. Another NYMEX futures contract also began trading the last week of September 1996 for delivery in Alberta, Canada, to correlate more closely with Canadian spot prices and the U.S. markets served by Canadian natural gas.

The different prices and trading volumes of the Henry Hub and Waha Hub futures contracts since August 1995 (Figure 2) highlight the differences in eastern and western markets, particularly during the $1995-96$ winter. At that time, cold weather and low storage levels in the East raised concern about supply deliverability, whereas temperatures in western markets tended to be above normal and storage levels were "normal." In general, the Henry Hub contracts had much higher prices and higher price variability, which was coupled with a higher volume of trade. The Henry Hub and Waha markets for options contracts, which provide rights to buy or sell a futures contract, both had substantial activity.

- Prices for the nearby contract (the one next to expire) on both the NYMEX Henry Hub and KCBOT Waha Hub futures markets rose from August through December 1995, but the increase was greater for the Henry Hub contract. Futures prices at the Henry Hub doubled from $\$ 1.42$ per million Btu on August 2 to $\$ 2.87$ on December 27. In contrast, futures prices at Waha increased by only 51 percent, from $\$ 1.29$ to $\$ 1.95$ per million Btu. Besides differences in weather and storage levels, the lower prices for the Waha contract reflect the western market's access to relatively low-cost Canadian gas.

- The Henry Hub futures prices were more volatile than the Waha Hub prices, but both contracts had greater volatility than most other commodity contracts. Monthly annualized price volatility, which is a measure of the average variability in percentage changes in price between days, ${ }^{6}$ reached a peak of 177 percent during December 1995 (Figure 2) for the NYMEX Henry Hub contract and ranged from 56 to 64 percent for the KCBOT contract between December and February. This large price volatility or risk reflects the price changes in the related spot markets and explains the importance to the natural gas industry of financial instruments for bringing price risk under control.

- The Henry Hub contract reached an all-time peak of almost 100,000 contracts traded during December 1995 , reflecting the large volumes of gas subject to price risk. Futures trading and outstanding futures contracts are often highest when market deliveries are at their highest levels, because the amount of commodity at risk is greatest. Gas delivery levels during January are usually 75 percent greater than levels during the summer months and greater than levels in any other month. In fact, monthly deliveries of natural gas for the 1995-96 heating season reached a peak of 2.4 trillion cubic feet in January 1996. Trading for the January 1996 contract closed on December 21, 1995.

- The volume of trade in the KCBOT futures contract declined from November 1995 through March 1996. Part of this decline was due to above-normal temperatures in much of the West and adequate storage levels. Moreover, the percentage of contracts taken to delivery was generally high, which reduced the volume of trade. Deliveries amounted to about 12 percent of the volume of trade in March 1996 and were above 2 percent in several other months. Comparable figures for the NYMEX contract were less than 0.3 percent.

- High price volatility also contributed to substantial activity in the options markets during the 1995-96 heating season. On the KCBOT market, 315 options contracts were traded in September 1995. Trade peaked at 806 contracts in February 1996 and in March was still above August and September levels. The NYMEX options market reached a peak of almost 20,000 contracts traded in December 1995, and levels in March 1996 were also higher than in September. Moreover, the number of NYMEX options contracts (open. interest) is often more than 30 percent of the number of futures contracts, which is higher than in most other commodity markets.

- In 1995 , the options markets grew at a faster pace than the futures markets. Costs associated with taking a position in the options market are easier to estimate than are costs associated with the futures market. When the price of a futures contract exhibits increased volatility, the amount of down payment (margin) to maintain a position in the futures market also increases. In contrast, the cost associated with the options market is fixed at the time of purchase. ${ }^{7}$ Also, unlike futures, options allow sellers to protect themselves from a fall in price while experiencing gains from price increases. 


\section{Figure 3. Natural Gas Supply Activities Continue at a Strong Pace}

\section{Natural gas production recovers in 1996}

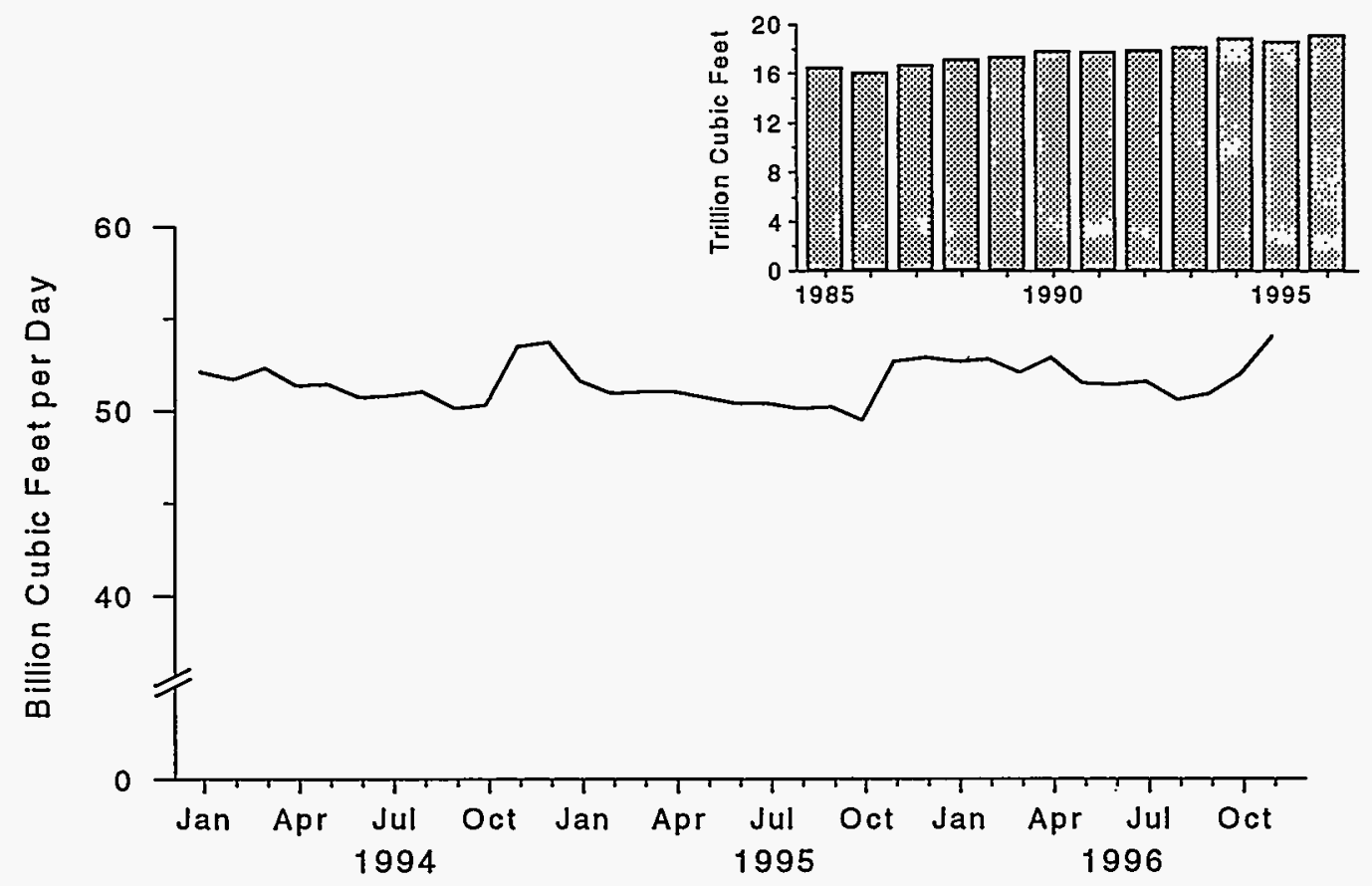

Natural gas well completions respond to higher prices in recent months

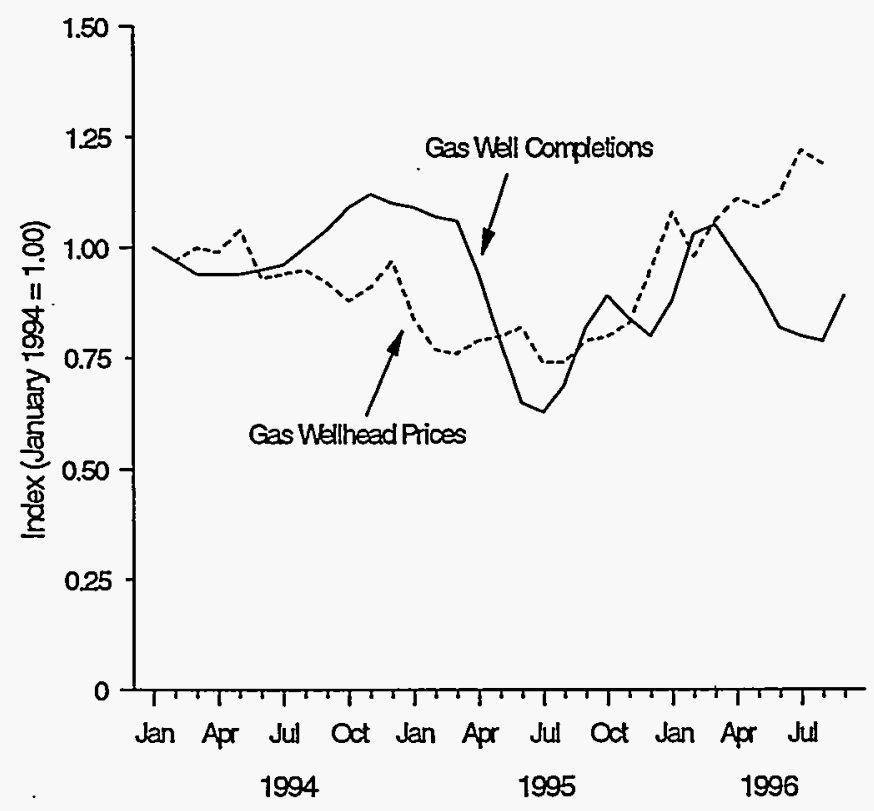

Rotary rig count shows industry preference for gas completions

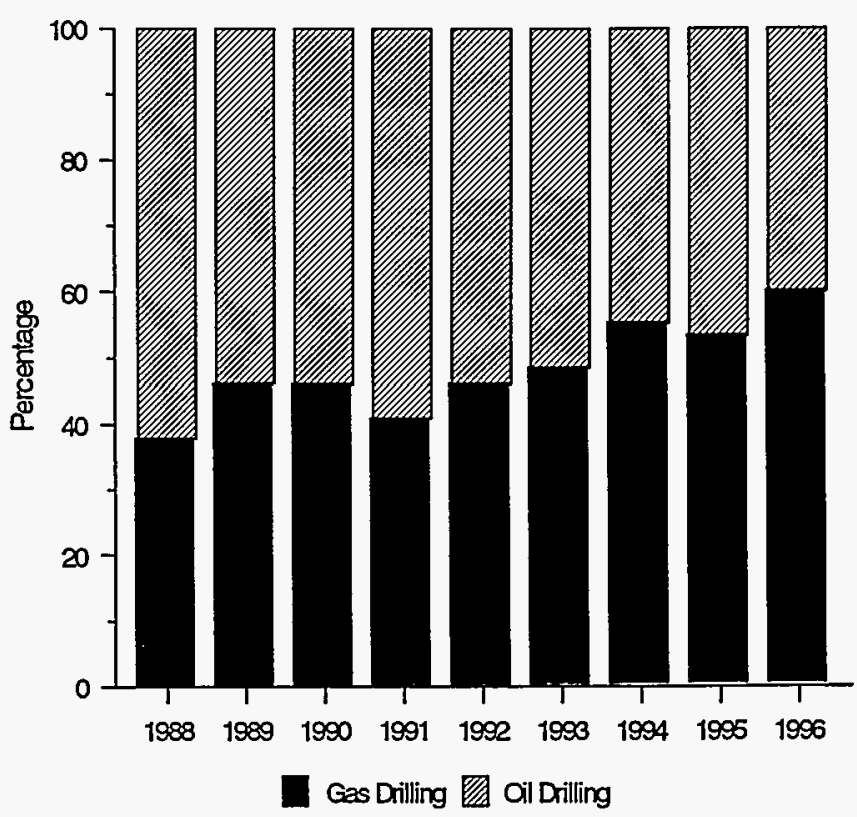

Source: Energy Information Administration (EIA), Office of Oil and Gas. Natural Gas Production and Wellhead Prlces: Natural Gas Monthly (November 1996). 1996 gas production is estimated from year-to-date data for 1994, 1995, and 1996. Gas Completlons: Three-month moving average derived from data published in the Monthly Energy Review (October 1996). Rigs: Monthly Energy Review (October 1996). 1996 value is the average through September. 


\section{Data Trends: Gas Production}

The response of gas producers to regulatory change has been a long-term increase in production even as wellhead prices have declined. The performance of the U.S. gas industry in 1995 reflected a continuation of that trend as production remained strong despite a sizeable decline in price. The success of domestic producers in recent years is in itself a significant factor that contributes to the prevailing low gas prices. This performance is expected to continue for at least the next few years with greater efficiency and continuing innovations in technology.

- Natural gas production in 1996 is flowing at a rate expected to be the highest yearly volume since 1981 . Cumulative production in 1996 exceeds the comparable volumes in both 1994 and 1995. Dry marketed production fell from 18.8 trillion cubic feet (Tcf) in 1994 to $18.6 \mathrm{Tcf}$ in 1995 (Figure 3). The production decline in 1995 is particularly striking given that productive capacity remained steady or increased, as indicated by the growth in proved reserves (see p. 9). Production during 1995 declined in the face of continued growth in imports and lesser volumes injected into storage compared with 1994. Increased deliveries to consumers and a greater need for replenishing storage have increased gas consumption in 1996, resulting in higher gas production while the average 1996 wellhead price through August has risen to $\$ 2.14$ per thousand cubic feet (Mcf), which is 38 percent above the 1995 price of $\$ 1.55$ per Mcf.

- The largest production increases for $\mathbf{1 9 9 5}$ occurred in Colorado and New Mexico, with incremental production gains of 64 and 69 billion cubic feet (Bcf), respectively. These gains are due in part to the maturation or initiation of coalbed methane recovery projects and the expansion of transportation capacity to support marketing the larger volumes. Production actually declined in the offshore Gulf of Mexico despite continued development of several 'large, deep water projects. The declines are attributable to the relatively weak market for domestic gas production in 1995. Despite its 1995 performance, the Gulf of Mexico, especially in deep waters, ${ }^{8}$ is expected to be a major growth area for U.S. natural gas production in the future.

- Natural gas well completions are up 9 percent from levels during the same period in 1995. Gas well completions in the first 9 months of 1996 have responded to the rise in wellhead prices (Figure 3). Gas completions for 1995 were only 7,428, reflecting a drop of more than
1,500 from the prior year. This decline was driven by the fall in wellhead prices in 1995, which reached the lowest annual average (in constant dollars) since 1976. Exploratory gas well completions in 1995 increased for the third consecutive year. The fraction of gas well drilling directed toward exploration has risen in recent years to levels last seen in the first half of the 1980's. These trends are important to the industry's attempts to replace proved reserves, which is a key element in the Nation's productive capacity.

- Recent technological research is expected to improve production performance from the reservoir. Improved placement of the wells based on three-dimensional (3D) seismic technology has reduced the occurrence of costly dry holes and increased well performance in terms of both flow rates and ultimate recovery. Innovative thinking regarding 3D applications has led to "4D" reservoir monitoring, which uses 3D images from separate time periods to enhance understanding of reservoir flow characteristics and hence production performance. Additional work is directed at 4D applications in real time to improve production operations further. ${ }^{9}$ Another technique with great promise is crosswell seismology, which can produce detailed 2D pictures of the area between two wells. The advantage of crosswell seismology lies in the significantly enhanced resolution of the data. ${ }^{10}$ It offers operators the ability to improve production by better understanding the reservoir performance characteristics and structure. Recent design and methodology improvements are expected to lower costs in the future, which will contribute to further success of crosswell seismology.

- The share of rotary rigs in operation that are directed toward natural gas has been at record levels in recent years. Rotary rigs utilized in gas well drilling in 1996 are 60 percent of total rigs (Figure 3). This record share is 58 percent more than the 38-percent share recorded in 1988 , the first year in which rotary rigs were reported by well type. As rigs increasingly were directed toward gas targets, the mixture of successful well completions shifted until gas completions exceeded oil completions for the first time in 1993. This differential is striking because oil completions were more than double the number of gas completions as late as 1987. The preference for gas drilling is likely to continue in the near term, although the number of gas wells per rig declined slightly in 1994 and 1995. 


\section{Figure 4. Natural Gas Resources Are Heavily Centered Around the Gulf of Mexico}

\section{Texas, Louisiana, and the Offshore Gulf of Mexico are major supply sources}

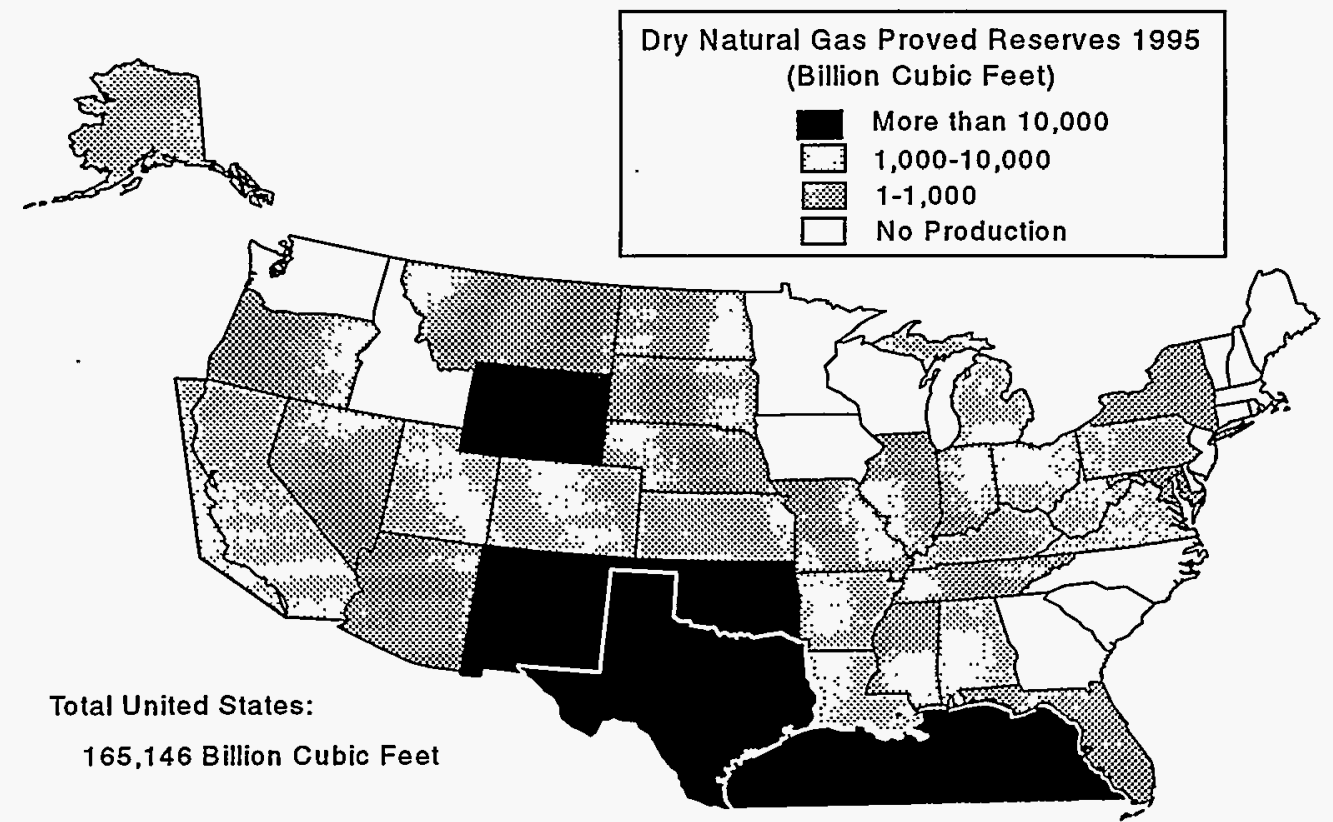

\section{Larger volumes of gas resources are recoverable at higher unit costs}

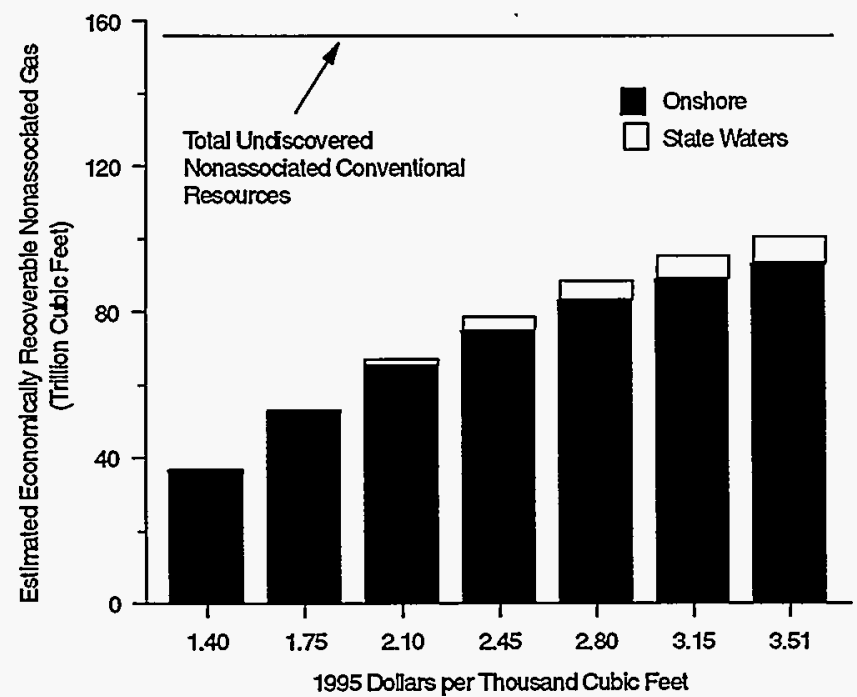

Remaining undiscovered gas fields are expected to be mainly in the Gulf Coast area

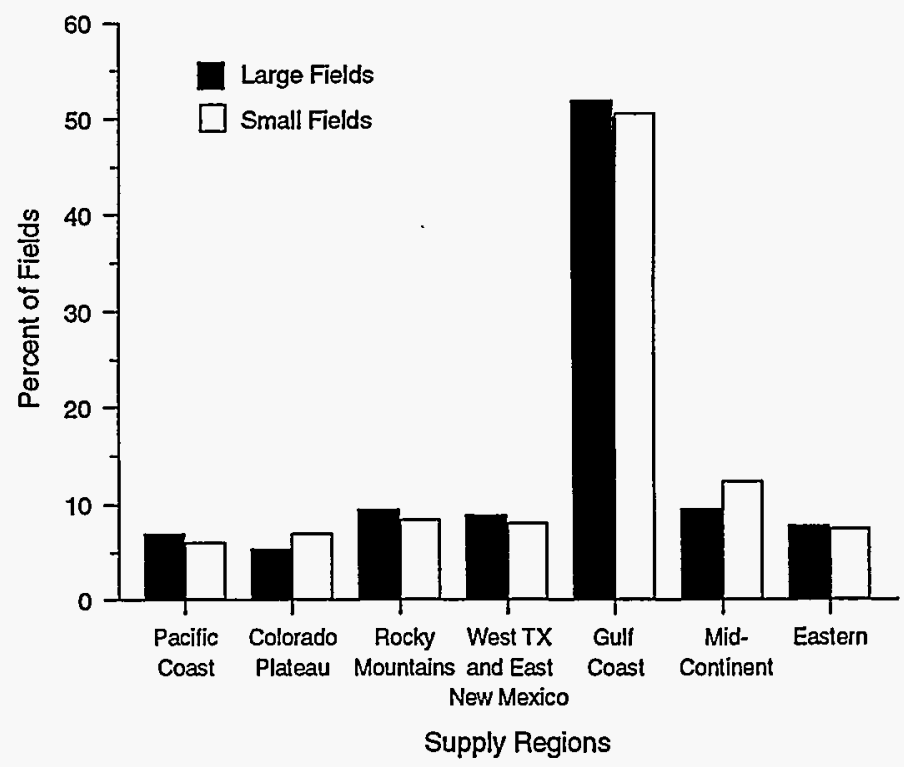

Notes: The lower left graph shows the marginal unit costs associated with recovery of the entire estimated resource volume. Thus, it is a cumulative figure that includes volumes recoverable with unit costs up to and including the stated value. The unit costs do not incorporate the dynamics of discovery, development, and production that are necessary to bring the gas to the market. This static, time-independent assessment of natural gas stocks does not show volumes that necessarily can be expected to flow to market at equivalent prices. The lower right graph shows gas field counts for the onshore lower 48 States and State waters. There are an estimated 2,812 undiscovered large gas fields (at least 1 million barrels of oil equivalent) and 35,427 small gas fields as of January 1, 1994. See Appendix A for map of supply regions.

Sources: Energy Information Administration (EIA), Office of Oil and Gas. Proved Reserves: derived from EIA, Advanced Summary U.S. Crude Oil, Natural Gas, and Natural Gas Liquids Reserves: 1995 Annual Report (October 1996). Recoverable Resources and Remalning Undlscovered Flelds: derived from U.S. Geological Survey, "Economics and Undiscovered Conventional Oil and Gas Accumulations in the 1995 National Assessment of U.S. Oil and Gas Resources: Conterminous United States," Open-File Report 95-75H (1996). 


\section{Data Trends: Reserves and Resources}

Natural gas proved reserves, from which production flows to market, are an important indicator of future gas production potential." Proved reserves are replenished from the natural gas resources that exist as unproven volumes in already known fields or in currently undiscovered fields. Estimates of undiscovered recoverable gas resources are uncertain and continue to be the object of considerable study because of their importance to any future energy outlook. ${ }^{12}$

- Dry natural gas proved reserves increased by 1.3 trillion cubic feet (Tćf) in 1995-the first consecutive increase in year-end reserves in 28 years. Proved reserves of dry natural gas in the United States as of December 31, 1995, were $165.1 \mathrm{Tcf},{ }^{13}$ up $2.7 \mathrm{Tcf}$ from the total in 1993. A major share of gas proved reserves are located in the Gulf Coast area, with Texas, Louisiana, Mississippi, Alabama, and the Federal offshore containing $79.3 \mathrm{Tcf}$, more than half the proved reserves for the lower 48 States (Figure 4). Other key States, with at least $7 \mathrm{Tcf}$ or more, include the traditional major producing States of New Mexico, Oklahoma, Kansas, and Colorado. A State of growing significance is Wyoming with $12.2 \mathrm{Tcf}$ in proved reserves, which ranks it fourth among the onshore lower 48 States.

- Overall, reserve additions of 19.3 Tcf were sufficient to replace 107 percent of production. The net increase in proved reserves for the lower 48 States measured $1.5 \mathrm{Tcf}$, however, this gain was partially offset by a 0.2 Tcf decline for Alaska. Total discoveries ${ }^{14}$ of 11.0 Tcf were down from the 1994 quantity but were still 14 percent higher than the prior 10-year average. Wyoming had the largest gain in reserves of any State or region, with an increase of $1.3 \mathrm{Tcf}$, a 12-percent increase over the 1994 level. Wyoming includes reserves in conventional formations, tight gas formations, and coalbed methane deposits. Important contributions to proved reserves were from large gas accumulations discovered in deep water areas in the Gulf of Mexico, as well as other discoveries in onshore areas of Texas and Colorado. Recovery from coalbed methane deposits, located principally in New Mexico, Colorado, Alabama, and Virginia, has grown sharply in recent years. Coalbed methane production increased again in 1995, more than offsetting the slight decline in 1994. Coalbed methane reserves comprise over 6 percent of 1995 gas reserves and 5 percent of gas production.

- More than half the estimated nonassociated natural gas resources are expected to be producible at up to \$2.10 per thousand cubic feet. Undiscovered technically recoverable conventional natural gas resources in the onshore lower 48 States are estimated at 139.5 Tcf for nonassociated gas and $31.4 \mathrm{Tcf}$ for associated gas. ${ }^{15}$ State water regions off the lower 48 States are expected to contain $16.4 \mathrm{Tcf}$ of nonassociated gas and 3.1 Tcf of associated gas. ${ }^{16}$ Not all technically recoverable resources, however, are likely to be economic to recover. The U.S. Geological Survey (USGS) has developed estimates of economically recoverable oil and gas resources. In nonassociated gas accumulations with unit costs of discovery, development, and production up to $\$ 2.45$ per thousand cubic feet, ${ }^{17}$ there are an estimated $75 \mathrm{Tcf}$ in the onshore States and 4 Tcf in State waters (Figure 4).

- Roughly 94 percent of expected remaining undiscovered oil and gas fields in the lower $\mathbf{4 8}$ States, including State waters, are small fields with conventionally recoverable volumes of less than 1 million barrels of oil or 6 billion cubic feet of gas. Remaining undiscovered oil and gas fields are estimated at almost 90,000 , with about 5,500 large (at least 1 million barrels of oil equivalent) and 84,000 small fields. The relatively high proportion of small fields has important implications for future gas recovery. These fields present technological challenges in both discovery and recovery. Further, as the number of remaining large fields in a region declines, there is a lower expected return for all remaining prospects, regardless of size. Eventually, the economic attractiveness of exploring for conventional deposits is directly affected because the remaining, smaller targets may not offer sufficient returns to offset exploration costs including dry holes. Most of the gas is estimated to occur as nonassociated gas, with roughly half the large and small fields located in the Gulf Coast region (Figure 4). ${ }^{18}$

- The Minerals Management Service (MMS) estimates remaining technically recoverable gas resources in the Federal Outer Continental Shelf (OCS) at 268 Tef. The new MMS estimates reflect more recent geophysical, geological, technological, and economic data and the impact of an enhanced methodology. ${ }^{19}$ This analysis shows significantly greater volumes for the OCS regions off the Pacific Coast, the Atlantic Coast, and Alaska when compared with earlier estimates (1987). The expected gas recovery volume from the Gulf of Mexico OCS reflects more optimism even though the new estimate of $95.7 \mathrm{Tcf}$ is $7.6 \mathrm{Tcf}$ less than the figure published earlier, because the reduction is less than the $27 \mathrm{Tcf}$ that was converted from unproven resources to proved reserves subsequent to the prior assessment. 


\section{Figure 5. Canadian Imports Dominate U.S. International Gas Trade}

\section{U.S. imports of Canadian gas occur increasingly under short-term contracts}

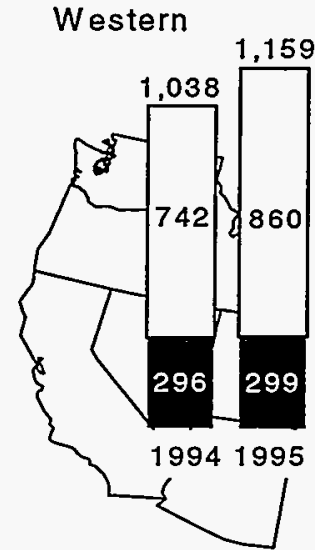

Imports of Canadian Gas (billion cubic feet)

Long-term

Short-term

Midwest

Central

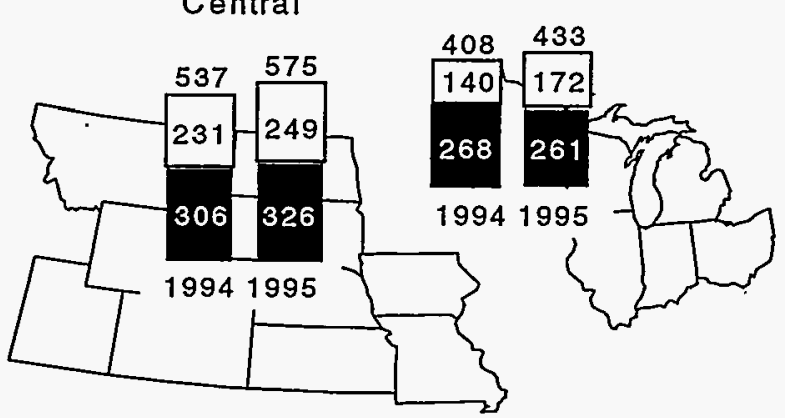

Share of 1995 Canadian Imports



Lower LNG imports reflect Algeria's renovation of liquefaction plants


$\mathrm{LNG}=$ Liquefied natural gas .

Notes: Short-term imports are those made under purchase arrangements of 2 years' or less duration; long-term imports are for longer than 2 years. Regional import volumes are the sums of volumes imported into each region through the border points in the region. The index of imports of Canadian gas was constructed using daily average volumes for the months shown. 1996 data are preliminary.

Sources: Energy Information Administration (EIA), Office of Oil and Gas. Long-term and Short-term Canadlan Gas Impoits: derived from import and export data from U.S. Department of Energy, Office of Fossil Energy. Indices of U.S. Average Wellhead Prices, Canadlan Gas Import Volumes and Border Prices, and Cumulative LNG Import and Export Volumes: derived from Natural Gas Monthly (November 1996). 


\section{Data Trends: International Trade}

Total imports of natural gas continued their steady climb of the past 9 years, increasing 8 percent to 2.8 trillion cubic feet (Tcf) in $1995 .{ }^{20}$ Liquefied natural gas (LNG) exports remain steady, while LNG imports are expected to increase to levels of a decade ago. Some major developments include:

- Pipeline imports from Canada continued to dominate external sources of U.S. supply, accounting for 99 percent of 1995 total imports. Imports of Canadian gas increased by 10 percent in 1995 , reaching $2.8 \mathrm{Tcf}$. The share of total U.S. consumption provided by imported Canadian gas increased for the ninth year in a row, to 13 percent. ${ }^{21}$ The average border price for Canadian gas declined for most of the past 2 years, although it recovered somewhat in the fourth quarter of 1995 , following the trend in U.S. wellhead prices (Figure 5). The annual average price for Canadian gas at the border decreased markedly between 1994 and 1995, dropping 20 percent to $\$ 1.48$ per thousand cubic feet (Mcf).

- Short-term imports accounted for 50.4 percent of total 1995 imports from Canada, exceeding long-term imports for the first time. The trend to short-term imports reflects a growing preference for more marketresponsive arrangements. Short-term imports reached 1.4 Tcf in 1995, accounting for 85 percent of the increase over 1994 imports from Canada. The average border price was $\$ 1.18$ per Mcf for short-term imports and $\$ 1.79$ per Mcf for long-term imports. ${ }^{22}$ Moving along the U.S.Canadian border from west to east, the relative proportion of short- and long-term imports changes from predominantly short term in the Western Region to predominantly long term in the Northeast (Figure 5). ${ }^{23}$

- The Western Region continues to receive the largest share of Canadian gas-41 percent of total 1995 imports from Canada. Western. Region imports, at 1,159 billion cubic feet $(\mathrm{Bcf})$, were nearly double the 649 Bcf imported into the Northeast, the next most highly served region. The Western Region had the largest share of the 1995 increase in imports of Canadian gas, receiving $120 \mathrm{Bcf}$, or 47 percent of the increase. At 26 Bcf, the Midwest had the smallest share, 10 percent.

- The growth of imports from Canada likely will be stunted by the lack of available pipeline capacity to move gas into the United States. Indeed, preliminary data for the first 9 months of 1996 show gas imports from Canada down about 2 percent from the year-earlier period. Capacity utilization on pipelines serving all export and import points averaged 87 percent in $1995,{ }^{24}$ and it was highest during the winter months. Pipeline capacities at major border points are tighter still. Utilization rates range from 89 percent at Sumas, Washington in the Western Region, to 100 percent at Waddington, New York on the Iroquois pipeline in the Northeast. Utilization rates at major export points into the Central and Midwest regions were 98 and 97 percent, respectively. Pipeline capacity constraints are hampering the ability of Canadian producers to move gas from the major producing areas in British Columbia and Alberta to U.S. Midwest and Northeast markets. These constraints have contributed to an excess of Canadian productive capacity and to the disparity in U.S. prices between eastern and western markets. A number of pipeline construction projects have been proposed to address this problem (Appendix $G$ ). ${ }^{25}$

- Exports to Mexico have fallen recently, but might increase as a result of the recent explosion at a Mexican gas-processing plant. By late 1995, Petroleos Mexicanos (PEMEX), the State-owned oil and gas production company, had reduced imports of U.S. gas by boosting its production from a decade-long average of 3.6 Bcf per day to about 4.2 Bcf per day. ${ }^{26}$ Exports of U.S. gas to Mexico during the first 6 months of 1996 fell by 64 percent from the level for the same period a year earlier. Conversely, U.S. imports of Mexican gas during the same period rose from $0.3 \mathrm{Bcf}$ to $9.6 \mathrm{Bcf} .{ }^{27}$ However, PEMEX's near-term production goal of 5 Bcf per day by the year 2000 suffered a major setback with the July 1996 explosion at a major gas-processing plant in southern Mexico, which destroyed almost 1.5 Bcf per day, or about 33 percent, of Mexico's gas-processing capacity. ${ }^{28}$ While some of the capacity has since been restored, expectations are for Mexico to increase imports of U.S. gas to make up the continuing shortfall.

- LNG imports from Algeria fell to a 7-year low of $\mathbf{1 8}$ Bcf in 1995, but are beginning to recover (Figure 5). ${ }^{29}$ LNG imports fell because Sonatrach, Algeria's Stateowned oil and gas company, initiated a multi-year renovation project in 1994 to restore its liquefaction plants to their original capacities. Project completion is scheduled for 1997, but import volumes have increased in 1996, because renovation work to date has returned export capacity to pre-renovation levels. Also, the Maghreb-Europe pipeline, connecting Algerian gas fields to markets in Spain and Portugal, should be completed in October 1996. This should free up the LNG capacity that has been used to serve Spain, Sonatrach's second-largest LNG customer. 


\section{Figure 6. Interregional Pipeline Capacity Increased Only 1 Percent in 1995}



But planned construction projects could increase interregional capacity 7 percent by 1999

\begin{tabular}{|c|c|c|c|c|c|c|c|c|c|c|c|c|c|c|}
\hline \multirow{3}{*}{ Reglon } & \multicolumn{7}{|c|}{ Enterlng the Reglon ${ }^{a}$ (MMcf/d) } & \multicolumn{7}{|c|}{ Within the Reglon (MMcf/d) . } \\
\hline & \multirow{2}{*}{$\begin{array}{c}\text { Existing } \\
\text { Capacity } \\
1995\end{array}$} & \multicolumn{5}{|c|}{ Scheduled Additions to Capacity ${ }^{c}$} & \multirow{2}{*}{$\begin{array}{c}\text { Percent } \\
\text { Change } \\
\text { from } \\
1995\end{array}$} & \multirow{2}{*}{$\begin{array}{c}\text { Exlsting } \\
\text { Capacity } \\
1995\end{array}$} & \multicolumn{5}{|c|}{ Scheduled Additlons to Capaclty } & \multirow{2}{*}{$\begin{array}{c}\text { Percent } \\
\text { Change } \\
\text { from } \\
1995\end{array}$} \\
\hline & & 1996 & 1997 & 1998 & 1999 & Total & & & 1996 & 1997 & 1998 & 1999 & Total & \\
\hline Western ................ & 10,080 & 0 & 0 & 0 & 0 & 0 & 0 & 26,088 & 0 & 12 & 0 & 0 & 12 & 0 \\
\hline Southwest ............. & 2,523 & 0 & 480 & 0 & 0 & 480 & 20 & 57,127 & 600 & 3,005 & 0 & 0 & 3,605 & 6 \\
\hline Central .................. & 12,676 & 169 & 0 & 1,437 & 0 & 1,606 & 13 & 37,405 & 388 & 1,509 & 4,274 & 0 & 6,171 & 16 \\
\hline Midwest ................. & 24,632 & 0 & 716 & 1,155 & 1,200 & 3,071 & 12 & 48,666 & 46 & 986 & 1,407 & 4,800 & 7,239 & 15 \\
\hline Northeast ............ & 12,159 & 25 & 112 & 178 & 400 & 715 & 6 & 45,837 & 75 & 1,046 & 2,404 & 1,250 & 4,775 & 9 \\
\hline Southeast .............. & 21,586 & 0 & 145 & 0 & 0 & 145 & 1 & 72,550 & 0 & 625 & 1,239 & 1,000 & 2,864 & 1 \\
\hline Total .................. & 83,656 & 194 & 1,453 & 2,770 & 1,600 & 6,017 & 7 & 287,673 & 1,109 & 7,183 & 9,324 & 7,050 & 24,666 & 9 \\
\hline 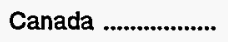 & 2,409 & 200 & 0 & .0 & 0 & 200 & 9 & NA & NA & NA & NA & NA & $\cdots$ & - \\
\hline Mexico ..................... & 889 & 0 & 322 & 300 & 500 & 1,122 & 120 & NA & NA & NA & NA & NA & -- & - \\
\hline
\end{tabular}

'Includes only the sum of capacity levels for the States and Canadian Provinces bounding the respective region.

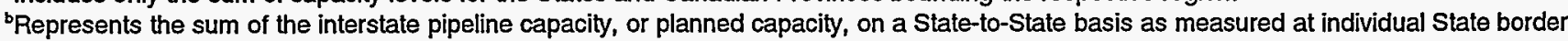
crossing points. Does not include projects which are entirely within one State. Gulf of Mexico projects are considered within the Southwest or Southeast region.

"New capacity has been counted in only one region even though some projects may cross regional boundaries. In the case of a new line, the additional capacity has been included within the region in which it terminates; for an expansion project, it is included in the region where most of the expansion effort is focused.

Exp $=$ Expansion. MMcf/d = Million cubic feet per day. $N A=$ Not available.

Sources: Capaclty: Energy Information Administration (EIA), EIAGIS-NG Geographic Information System, Natural Gas Pipeline State Border Capacity Database, as of August 1996. Capacity Additlons: Federal Energy Regulatory Commission, Natural Gas Act Section 7(c) Filings, "Application for Certificate of Public Convenience and Necessity," and various natural gas industry news sources. 


\section{Data Trends: Natural Gas Pipeline Expansions}

The limited number of major pipeline expansions during 1995 reflects, in part, the ample availability of pipeline capacity in most parts of the national network. Interregionally, overall pipeline capacity increased by only 803 million cubic feet (MMcf) per day, represented by six projects, a 1-percent increase over the 1994 level. $^{30}$ Interstate capacity ${ }^{31}$ increased by a relatively low 3,008 MMcf per day with the completion of an additional eight projects (Figure 6). ${ }^{32}$ The trend in new construction has been to refine and expand locally to attract and hold customers. Other important improvements during 1995 included projects that increased pipeline linkups at "hub" sites and enhanced deliverability at strategic points along a number of pipeline systems.

- Three new interstate pipelines were placed in service in 1995: the Tuscarora pipeline (110 MMcf per day) serving northern California and the Reno area of Nevada; the Crossroads pipeline (250 MMcf per day) serving northern Indiana and western Ohio; and the bidirectional Bluewater pipeline (250 MMcf per day) transporting gas between Michigan and Ontario, Canada.

- Two interstate expansion projects were completed that serve the growing gas markets of the Southeast. Completion of the Transco Southeast expansion (115 MMcf per day) offers increased deliverability to customers in North Carolina. Completion of Florida Gas Transmission's (FGT) current expansion brings additional supplies to Florida from the Texas/Louisiana area and, in particular, from the Mobile Bay offshore area. The 535 MMcf per day expansion increases FGT's capacity into Florida to 1,475 MMcf per day. FGT is now studying the market feasibility of further expanding the eastern portion of its system and may file for a Phase IV project sometime in 1996.

- Several intrastate pipeline projects were completed to improve access to hubs and pipeline interconnections. For example, the TECO pipeline linkup between its western and east Texas lines provides a direct connection to services at its Waha and Katy Interchange Hubs (see Chapter 3). TECO now can transport up to $300 \mathrm{MMcf}$ per day between the two hubs, providing a much needed service to customers wanting to move Permian and eventually San Juan Basin supplies to eastern and Midwestern markets.

- An existing capacity bottleneck in the San Juan Basin area was reduced somewhat in 1995 with the completion of EI Paso's San Juan project (300 MMcf per day). This expansion not only increases the amount of production that may now exit the area but also supports the future completion of expansions eastward toward the Waha and Permian Hub areas. Currently, productive capacity in the San Juan area exceeds pipeline capacity exiting the area.

- During 1995 and early 1996, several pipeline companies reevaluated their market requirements and, as a result, either downsized, postponed, or canceled projects. For example, the Mayflower project, designed to expand deliverability off the Iroquois system to Massachusetts, was canceled because of insufficient customer support. Downsized projects include revision of the Transcolorado pipeline project to construct only the southern leg (in New Mexico) in 1997 and postpone the remainder of the system until additional pipeline capacity is built in the area to move supplies to eastern markets.

Proposed expansion projects continue to concentrate on removing some system bottlenecks and redirecting excess supplies to additional higher-value markets. The sustained cold weather in the Midwest and East during the 1995-96 heating season intensified interest in developing plans to move more western supplies eastward (see Appendix G). If all proposed projects were completed, interregional capacity would increase 7 percent by 1999 (Figure 6).

- Projects to expand Canadian supply deliverability dominate current proposals. Two projects in particular stand out. The first is the Maritimes \& Northeast project that would, for the first time, move gas from Nova Scotia to the U.S. Northeast ( $400 \mathrm{MMcf}$ per day). The second is the Alliance project that would expand deliverability (proposed 1,200 MMcf per day) from the supply-rich fields in British Columbia to the Midwest Region (Illinois).

- Several additional proposals address the issue of increasing capacity from the Rocky Mountain and San Juan Basin (southern Colorado/northern New Mexico) areas and moving greater volumes eastward to the Midwest and Northeast regions. Among these are expansion of the Trailblazer system out of Wyoming and northern Colorado by 105 MMcf per day with a link to an expansion of Natural Gas Pipeline Company of America's Amarillo line toward the Midwest market. In addition, Transwestern Pipeline Company has filed for a $170 \mathrm{MMcf}$ per day expansion and flow redirection on its line eastward from the San Juan Basin area. El Paso Natural Gas Company has also filed to expand its deliverability from the San Juan Basin to the eastern portion of its system and the strategic Waha area of West Texas by 180 MMcf per day. 


\section{Figure 7. High-Deliverability Storage Grew in Capacity and Usage in 1995}

\section{New salt cavern storage represented 65 percent of deliverability added in 1995}

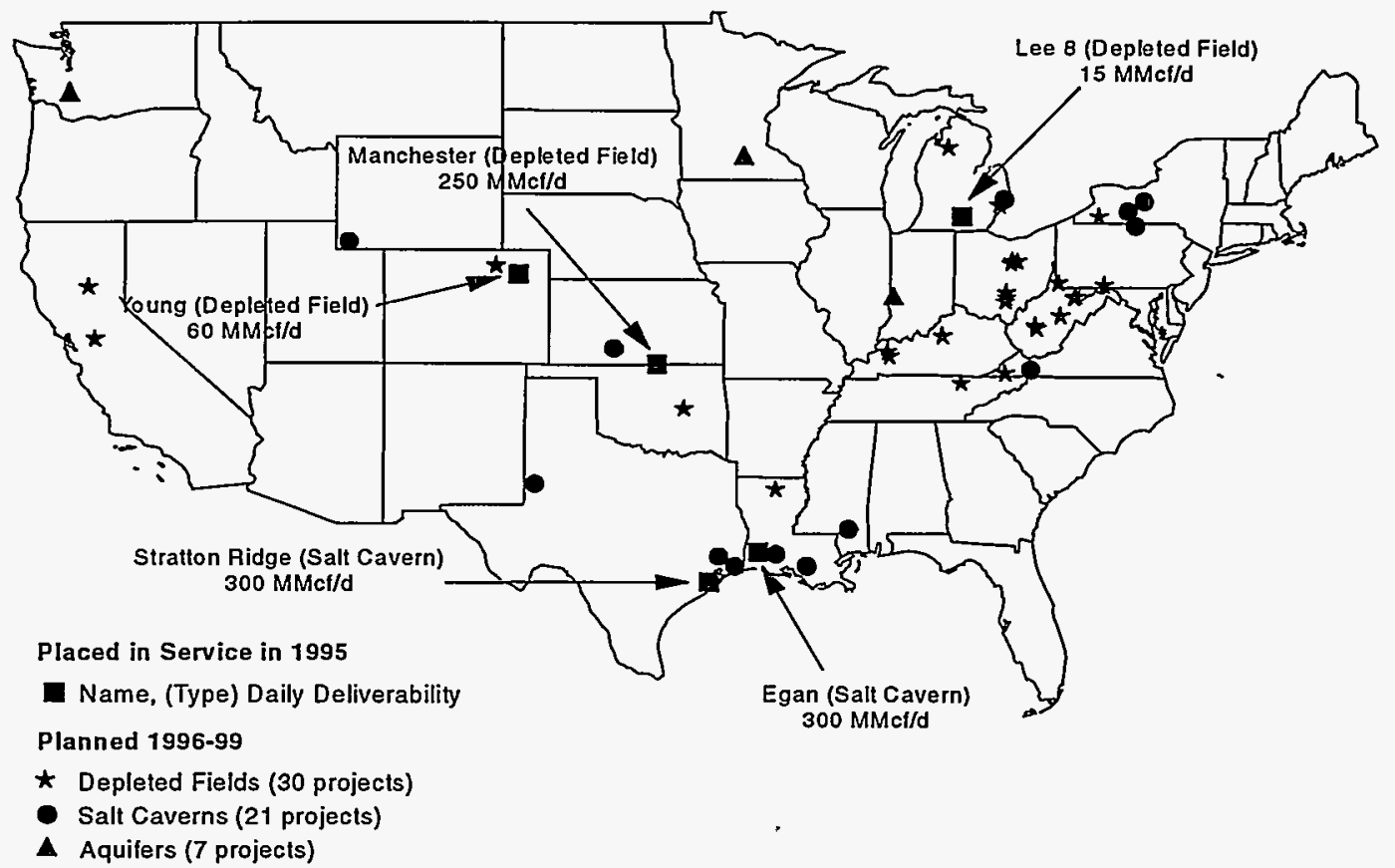

Salt cavern cycling during the heating season increased from 0.53 in $1991-92$ to 1.14 in $1995-96$



MMcf/d = Million cubic feet per day.

Notes: Mapped symbols represent sites. One site may have several projects (phases) associated with it. A heating year is from April of one year through March of the next year; for example, heating year 1991-92 is April 1991 through March 1992.

Sources: Storage SItes: Energy Information Administration (EIA), EIAGIS-NG Geographic Information System, Planned Underground Storage Database, as of July 1996; Salt Cavern Cycles: Form EIA-191, "Underground Gas Storage Report." 


\section{Data Trends: Underground Natural Gas Storage Developments}

Entering the 1995-96 heating season (November 1 through March 31), underground natural gas storage deliverability in the United States was 2 percent greater than at the same time the previous year (see Appendix F). Some of the additional capability represented startups of high-deliverability (salt cavern) storage associated with expanding market center operations (see Chapter 3). Its availability during the extreme cold spells in January and February 1996 was probably a key factor in meeting increased demands during the period.

Working gas levels at the end of March 1996 were very low, 755 billion cubic feet. ${ }^{34}$ As a consequence, storage refill activity through September 1996 was 20 percent higher than during the same period in $1995 .{ }^{35}$ Nevertheless, the Energy Information Administration estimates that by the start of the 1996-97 heating season, working gas levels were about 2.8 trillion cubic feet, 7 percent lower than the previous year. This total, however, appears sufficient to meet anticipated needs, based on the amount of net withdrawals required to meet demand during the past three heating seasons $-2 \mathrm{Tcf}$ in 1995-96, 1.8 Tcf in 1994-95, and 2.3 Tcf in 1993-94. ${ }^{36}$

Several factors have contributed to the current status of the U.S. natural gas storage industry:

- Storage has become a popular commodity in today's market. It is offered by many market center operators and marketers as a multipurpose resource, such as to support short-term gas loans, gas balancing, and peaking services. Of the 39 market center operations in the United States and Canada, 26 offer storage as a major service.

- Two of the five underground storage sites brought in service in 1995 were high-deliverability sites (Figure 7). In addition, expansions were completed at 4 of the 17 existing high-deliverability sites. Although the 2 new high-deliverability sites represented only 30 percent of the added working gas capacity, they accounted for 65 percent ( 600 million cubic feet per day) of new daily withdrawal capability. The significance of these additions is not merely the absolute volume, but rather that this type of storage may be quickly cycled-that is, its inventory may be fully depleted and refilled as rapidly as once a month, while conventional storage may be cycled only about once during the 5-month heating season.

- The utilization of high-deliverability storage has changed significantly in recent years. Before 1993, this type of storage was often used and marketed in the same manner as conventional storage. Operators leased storage capacity to customers who used it primarily as seasonal backup supply rather than as peaking or short-term swing supply. Since 1991, the average cycling at these sites during the heating season has increased from about 0.53 cycles to about 1.14 in the 1995-96 season (Figure 7). For those sites associated with market centers, the average number of cycles during the 1995-96 heating season was a significantly higher 1.45 , reflecting the more intensive use of these facilities.

- Drawdowns from base gas inventory at a number of storage sites during the past heating season, particularly in the Northeast and Midwest, raised some concerns about the need to build new storage. The percentage of total base gas inventory withdrawn, 1.7 percent, was well above the 1.0 percent withdrawn during the very cold 1993-94 heating season. However, the volume withdrawn was only 72 billion cubic feet, ${ }^{37}$ which amounts to only 2.7 percent of total gas withdrawals during the heating season. ${ }^{38}$

The success of underground storage operations during the past two heating seasons and the more efficient use of existing storage will probably affect plans for proposed storage projects. Most of the new proposals announced during the past 12 to 24 months have been expansions to existing sites. In addition, several projects have been postponed or redesigned in response to changed shipper needs, market demand, or market center efficiencies.

- The current list of proposed projects (through July 1996) has dropped to its lowest level since the Energy Information Administration began tracking in $1993 .^{39}$ Planned projects through 1999 currently total 58 , about a third less than the number planned in $1994 .^{40}$ Proposed increases to daily deliverability would amount to 9,936 million cubic feet (MMcf), well below the $20,746 \mathrm{MMcf}$ per day planned as recently as October 1994. This change reflects the completion of approximately 12 new sites and 14 expansion projects since then and plans for only 7 additional new proposals. ${ }^{41}$ The majority of the planned increases in deliverability and working gas capacity is still in the form of salt cavern storage, but now most of these (14) are expansions to recently completed projects.

- A significant increase in daily deliverability is planned to be put in place in the Northeast and Midwest regions at a number of conventional (depleted field) storage sites owned by Columbia Gas Transmission Company. Columbia will be improving facilities at 13 underground storage sites and increasing daily deliverability by $326 \mathrm{MMcf}$ by the end of 1998 . Working gas capacity will essentially remain the same. 


\section{Figure 8. Service Selection and Costs Have Changed in the Natural Gas Transmission Market}

\section{Choices of delivery services have changed}

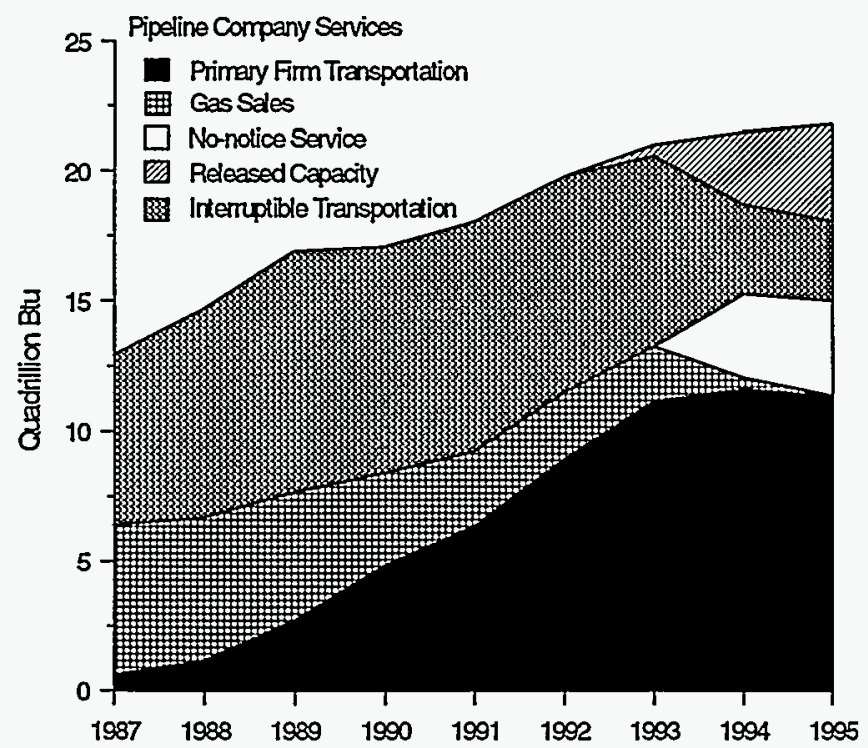

\section{Marketers' selection of transportation} services is the most diversified

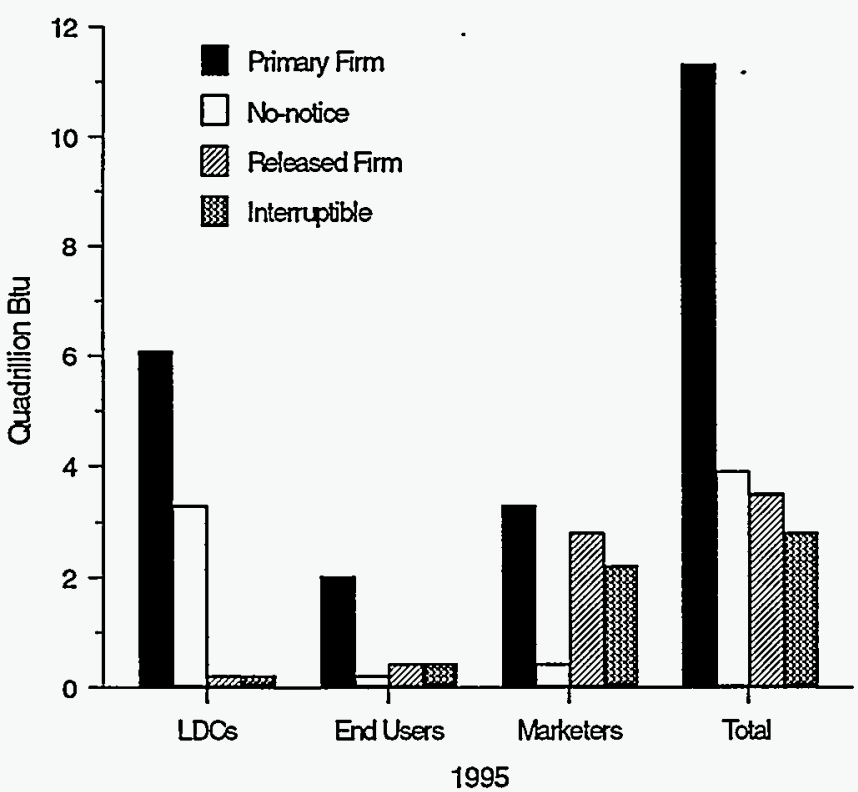

Interstate pipeline companies' share of the industrial market may be leveling off

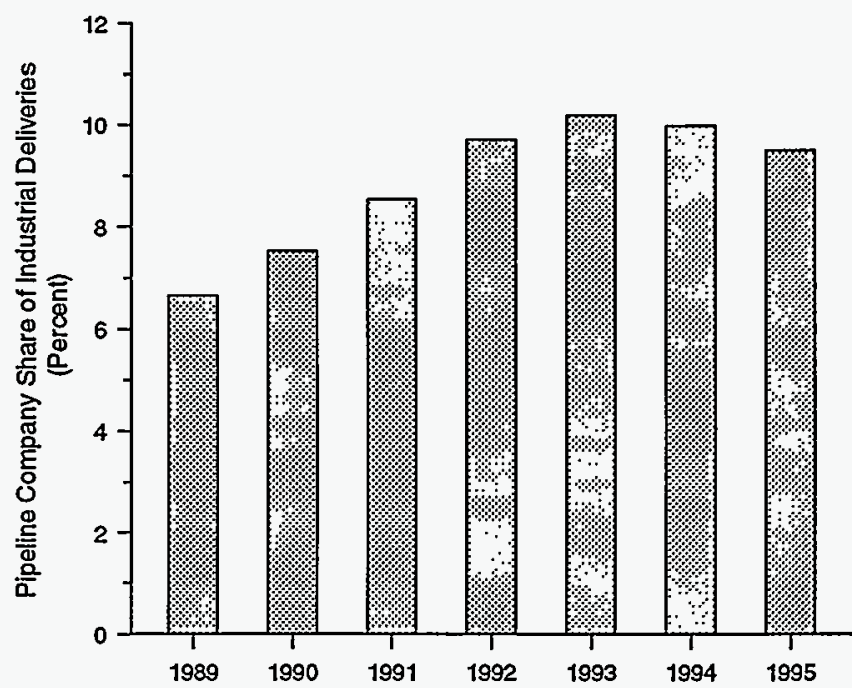

\section{Annual natural gas transmission and distribution costs have declined for most end-use sectors}

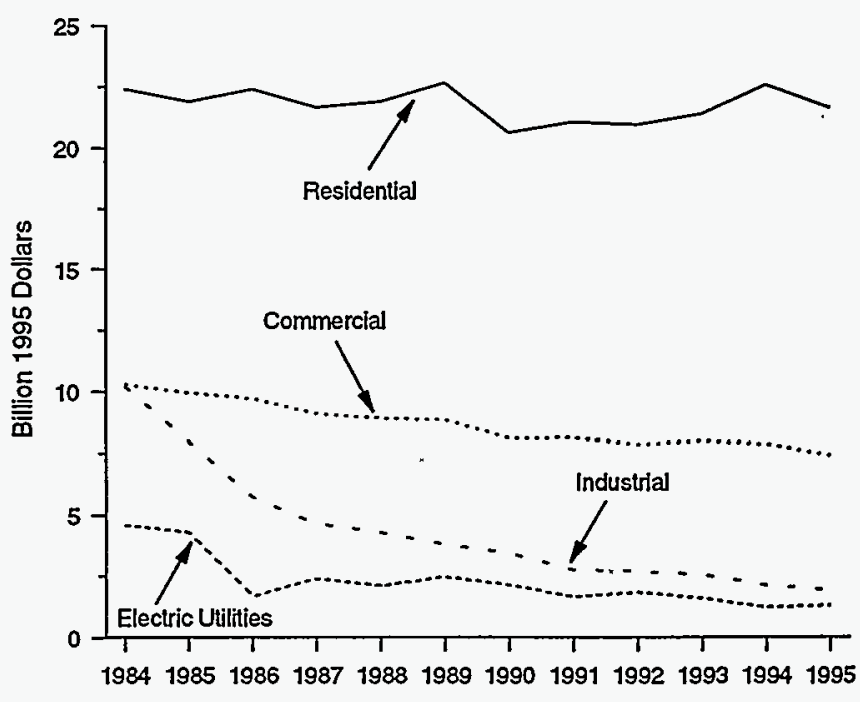

LDC $=$ Local distribution company.

Notes: The commercial and industrial transmission and distribution costs reflect end-use prices for onsystem sales only. The onsystem share of industrial deliveries was 75 percent in 1984 and 24 percent in 1995. The onsystem share of commercial deliveries was 100 percent in 1984 and 77 percent in 1995. Values expressed in 1995 dollars based on chain-weighted gross domestic product (GDP) deflator from the U.S. Department of Commerce, Bureau of Economic Analysis.

Sources: Dellverles: Interstate Natural Gas Association of America (INGAA), Gas Transportation Through 1995 (September 1996). PIpeline Company Share: Energy Information Administration (EIA), Office of Oil and Gas, derived from Form ElA-176, "Annual Report of Natural and Supplemental Gas Supply and Disposition." Transmission and DIstrlbution Costs: ElA, Office of Oil and Gas, derived from: 1984-1986-Natural Gas Annual 1988 (October 1989; 1987-1990-Natural Gas Annual 1991 (October 1992); 1991-1995-Natural Gas Annual 1995 (November 1996). 


\section{Data Trends: Service Selection and the Transportation Market}

The interstate natural gas pipeline industry completed the shift to nonmerchant services in 1995 , and a similar switch from sales to transportation service has gained momentum in retail markets. Annual transmission and distribution costs, which declined almost 3 percent in real terms between 1994 and 1995, also appear to have declined for most end-use sectors. One uncertainty for the industry is the future role of long-term transportation arrangements in consumers' service portfolios. The availability of alternatives to long-term, firm transportation services, such as market area storage, may lead to future reductions in capacity commitments and to the emergence of additional challenges for the industry in marketing capacity and the pricing of services.

- In 1995, interstate pipeline company firm services (primary firm transportation, no-notice service, and released capacity) dominated gas deliveries, while pipeline company sales were virtually nonexistent ${ }^{41}$ and interruptible transportation continued to decline (Figure 8). Firm transportation services represented 86 percent of gas deliveries in 1995, up from 82 percent in 1994. Although the 1995 total gas volume delivered to market was about the same as its 1994 level, data show that use of released capacity and no-notice service increased. ${ }^{42}$ Primary firm transportation service continued to represent just over 50 percent of deliveries to market in 1995. The decline in shippers' use of interruptible transportation that began in 1990 continued into 1995. Compared with 1994, interruptible transportation volumes fell by 11 percent in 1995, from 3.4 trillion cubic feet ( $\mathrm{Tcf}$ ) to $3.0 \mathrm{Tcf}$. Interruptible transportation represented 14 percent of total volumes delivered for market in 1995.

- The interstate pipeline companies' expansion into the industrial retail market may be leveling off. Interstate pipeline companies increased their share of deliveries to industrial customers from 6.6 percent in 1989 to 10.2 percent in 1993 (Figure 8). In 1994 and 1995, however, the share dropped slightly to 10.0 and 9.5 , respectively. Nevertheless, deliveries per industrial customer increased from 1,087 million cubic feet in 1994 to 1,245 million cubic feet in 1995.

- Marketers appear to select the most diversified portfolio of interstate pipeline company services, transporting about equal amounts using primary firm, released firm, and interruptible transportation (Figure 8). Local distribution companies (LDCs) and end users, on the other hand, continue to use primary firm transportation as their principal means of transportation. As a result of their service selections, marketers accounted for 80 percent of all volumes transported under released capacity in. 1995 (see Chapter 2). LDCs accounted for 54 and 85 percent of the primary firm and no-notice transportation volumes, respectively, in 1995.

- Companies that provide local delivery services (local companies $)^{43}$ have also witnessed a shift from sales to transportation service by their customers. Deliveries to end users by local companies in 1995 increased by 3 percent over 1994 levels, ${ }^{44}$ while transportation deliveries to end users increased by more than 5 percent to 8.1 Tcf. Concurrently, gas sales by local companies, which represent over half of their deliveries, increased by 1 percent to $9.9 \mathrm{Tcf}$ in 1995. Transportation accounted for over 74 and 67 percent of deliveries by local companies to industrial and electric utility customers, respectively. This compared with 23 percent to commercial customers and negligible transportation to residential customers. Although sales dominated local company deliveries to residential customers, that situation may change as States accelerate their efforts to provide residential customers access to unbundled gas service (see Chapter 6).

- Annual transmission and distribution costs, which exclude commodity costs, declined in real terms from $\$ 35$ billion in 1994 to $\$ 34$ billion in 1995. These costs apply to all gas deliveries to the electric utility sector and onsystem sales to residential, industrial, and commercial customers. ${ }^{45}$ Deliveries to these customers increased by more than 2 percent during the same period. ${ }^{46}$ Compared with 1994, each customer group except electric utilities saw a decrease in total and per unit costs for transmission and distribution service (Figure 8). ${ }^{47}$ The industrial sector had the largest decrease in transmission and distribution costs, 5 percent, while commercial and residential consumers each had decreases of 3 percent. Costs to electric utilities increased by 14 percent.

- Market and regulatory changes are leading to expanded use of alternatives to long-term firm transportation (such as market area storage and hub services) and a reduction in transportation capacity reserved on interstate pipeline companies. To date, the reduction or "turnback" of capacity has been limited to a few pipeline companies serving the Midwest and West. By the end of 2001, contracts covering 50 percent of capacity will have expired, providing shippers an opportunity to revise their capacity commitments. The extent and implications of a reduction in capacity reservations presents a number of cost allocation and operational challenges and is an emerging concern for the industry (see Chapter 2). 
Figure 9. End-Use Consumption of Natural Gas Increases as Prices Fall

Electric utility consumption increased

7 percent in 1995

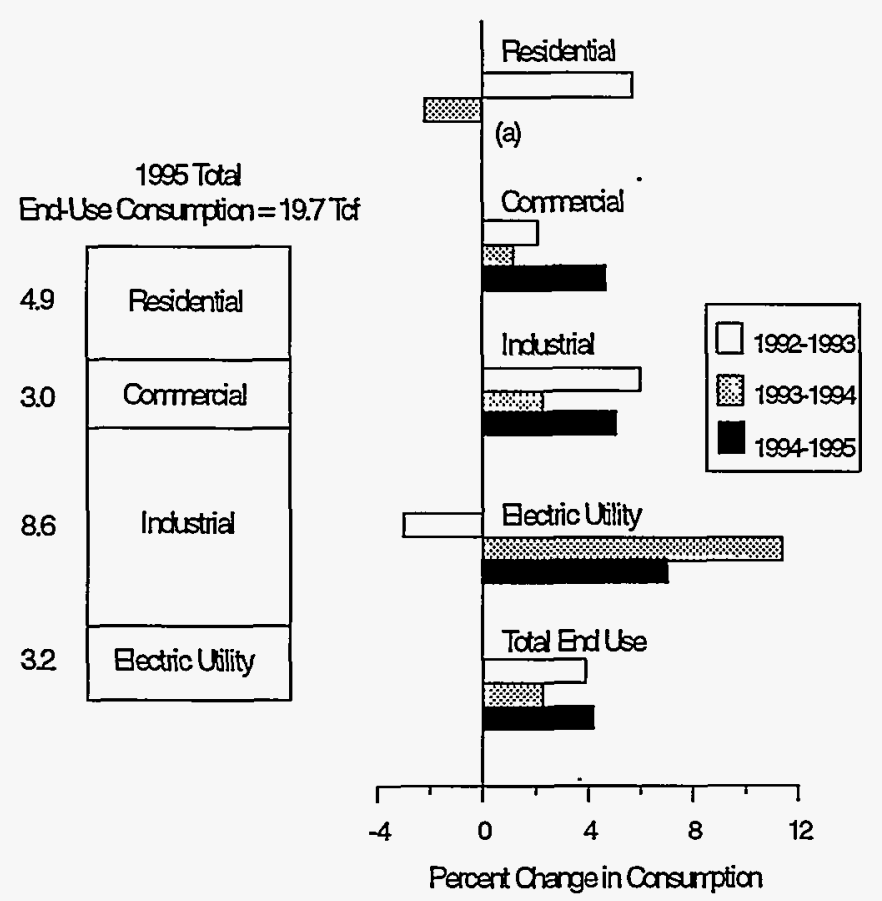

\author{
Real prices declined 8 to 14 percent \\ in 1995
}

End-Use Prices

(Dollars per Thousand Cubic Feet)

\begin{tabular}{lcccc}
\hline Year & \multicolumn{5}{c}{$\begin{array}{c}\text { Onsystem } \\
\text { Residential }\end{array}$} & $\begin{array}{c}\text { Onsystem } \\
\text { Commercial }\end{array}$ & $\begin{array}{c}\text { Electric } \\
\text { Industrial } \\
\text { Utility }\end{array}$ \\
\hline & \multicolumn{5}{c}{ (nominal dollars) } \\
1993 & 6.16 & 5.22 & 3.07 & 2.61 \\
1994 & 6.41 & 5.44 & 3.05 & 2.28 \\
1995 & 6.06 & 5.05 & 2.71 & 2.02 \\
& \multicolumn{5}{c}{ (real 1995 dollars) } \\
1993 & 6.46 & 5.47 & 3.22 & 2.74 \\
1994 & 6.57 & 5.57 & 3.13 & 2.34 \\
1995 & 6.06 & 5.05 & 2.71 & 2.02 \\
\hline
\end{tabular}

Fuel prices to electric utilities have declined and converged during the past decade
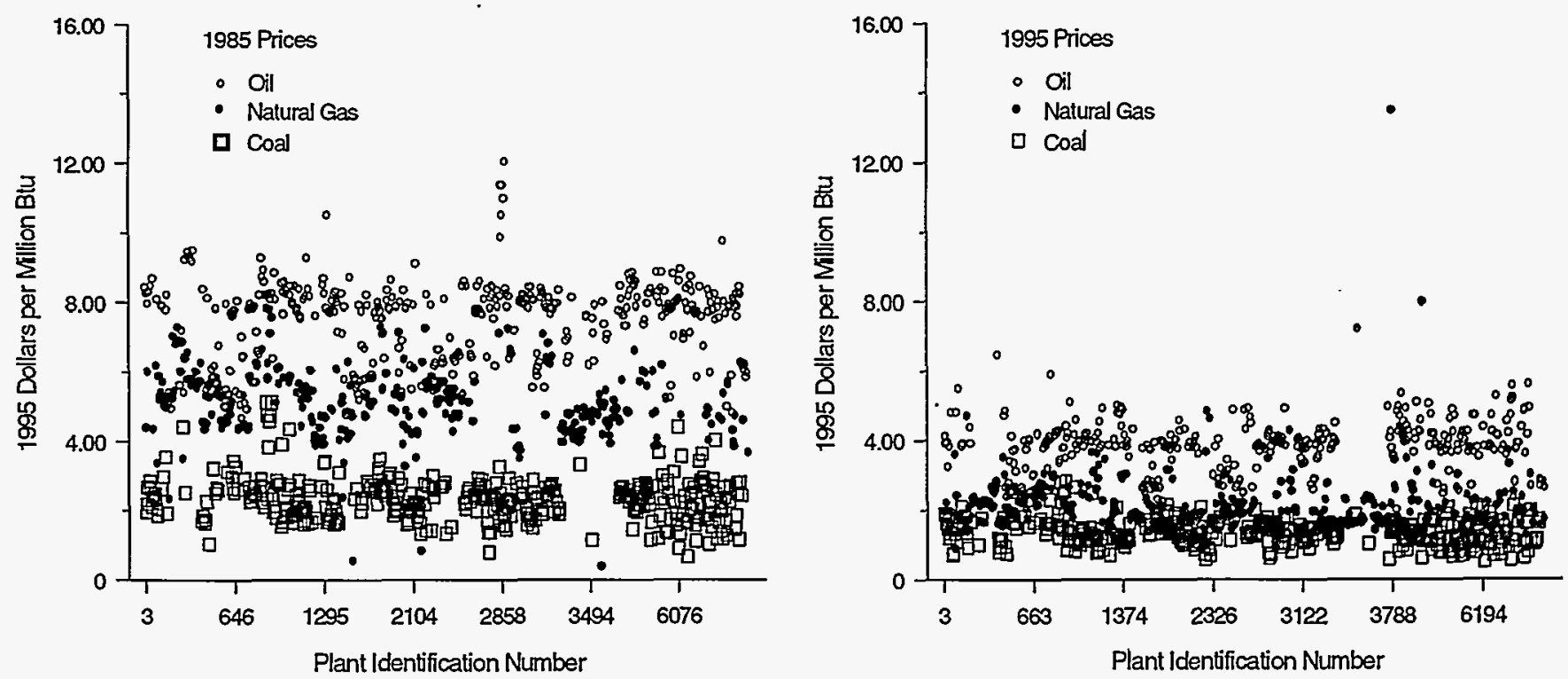

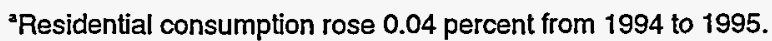

$\mathrm{Tcf}=$ Trillion cubic feet.

Source: Energy Information Administration. Volumes and Prices by Sector: Natural Gas Annual 1995 (November 1996). Prices by Plant Identification Number: Office of Integrated Analysis and Forecasting, derived from Federal Energy Regulatory Commission Form 423, "Monthly Report of Cost and Quality of Fuels for Electric Plants." 


\section{Data Trends: End-Use Consumption and Prices}

End-use consumption of natural gas in 1996 continues to move higher than 1995 levels, averaging 3 percent above 1995 consumption through November. There were strong increases in the residential and commercial sectors because of colder-than-normal weather in early 1996. In contrast, electric utility consumption dropped by 9 percent during the first 11 months of 1996 after posting strong growth the year before. The overall increase in consumption to date follows a 4percent rise in end-use consumption from 1994 to $1995 .{ }^{48}$ End-use consumption of natural gas increased in 1995 to 19.7 trillion cubic feet (Tcf), only 220 billion cubic feet short of the historical high recorded in $1972 .{ }^{49}$ Demand was spurred by widespread economic growth during the year, resulting in consumption increases of 4 percent or more in the commercial, industrial, and electric utility sectors compared with 1994 (Figure 9). In nominal terms, average prices in all sectors fell from 5 to 11 percent between 1994 and 1995. Preliminary data for the first 11 months of 1996 show price increases in all sectors.

- Residential and commercial consumption during the first 11 months of 1996 was 9 percent higher than in the same period of 1995 as cold weather increased demand for natural gas for space heating. Cumulative consumption from January through April 1996 exceeded the 1995 level by 13 and 15 percent, respectively, in the residential and commercial sectors. The weather was particularly cold in early spring. In March 1996, heating degree days were 14 percent colder than normal, and 27 percent colder than in March 1995. The estimated average price of natural gas from January through August 1996 is $\$ 6.16$ per thousand cubic feet (Mcf) in the residential sector and $\$ 5.26$ per Mcf in the commercial sector. For residential users, this is almost no change from that of the same period in 1995, while this is 3 percent higher for commercial users.

- Industrial consumption of natural gas for the first $\mathbf{1 1}$ months of 1996 was 2 percent higher than in the same period of 1995, while consumption by electric utilities dropped by 9 percent. Both sectors have seen large increases in the price of natural gas during 1996. For industrial users, the January-through-August average price is $\$ 3.30$ per Mcf in 1996, 26 percent higher than in 1995. For electric utilities, the average price of natural gas for January through July (the latest month available) is $\$ 2.69$ per Mcf in 1996,35 percent higher than in 1995.

- In 1995, commercial consumption rose 5 percent, while residential consumption barely increased over the 1994 level. Residential consumption increased less than one-half percent to $4.9 \mathrm{Tcf}$ in 1995 , but was still slightly below the recent high in 1993. In November 1995, heating degree days were 13 percent colder than normal for the Nation, but the weather was generally warmer than normal during the other heating months of the year. ${ }^{50}$ This dampened residential demand for gas even though new construction added to the housing stock. Sixty-six percent of new single-family homes constructed in 1995 were heated by gas. ${ }^{51}$ Commercial consumption increased during the year in part because low interest rates contributed to economic growth. Both residential and onsystem ${ }^{52}$ commercial prices fell in 1995, after rising by 4 percent in each sector in 1994. The average residential price was $\$ 6.06$ per Mcf, which is 5 percent below the price in 1994. The average commercial price fell 7 percent during the same period, reaching $\$ 5.05$ per Mcf for 1995 .

- Industrial consumption of natural gas grew 5 percent in 1995 , reaching $8.6 \mathrm{Tef}$. This continues the increase in consumption seen in this sector since the late 1980's and is only 109 billion cubic feet short of the historical high in 1973. Gas consumed by industrial cogenerators and nonutility generators (NUGs) is included in the data for this sector. In 1995, NUGs consumed 4.0 Tef of natural gas-nearly double the amount in $1994 . .^{53}$ The average price of natural gas to onsystem industrial users declined 11 percent in 1995 to $\$ 2.71$ per Mcf.

- Electric utility consumption of natural gas rose 7 percent in 1995 to $3.2 \mathrm{Tcf}$, while the average price in this sector fell by 11 percent. This strong growth occurred without the prolonged outages at nuclear plants or low hydroelectric production that helped to spur the 11-percent increase in consumption during 1994. The average price of gas to electric utilities was $\$ 2.02$ per Mcf in 1995, down $\$ 0.26$ from the level in 1994 .

- Competition to serve the electric utility market during the past decade has added to the price pressure on most major fuels used in this sector. Data are available on the price of coal, natural gas, and oil used in more than 600 electric utility generation plants (Figure 9). ${ }^{54}$ These data show a general stratification of prices by fuel in 1985, with the price (in 1995 dollars) of coal generally in the range of $\$ 1$ to $\$ 4$ per million Btu, gas in the $\$ 4$ to $\$ 7$ range, and oil in the $\$ 6$ to $\$ 9$ range. By 1995 , the prices of all three fuels had declined, with coal still generally the cheapest. Oil and gas prices have fallen greatly, however, becoming more competitive with each other and with coal. By 1995, the prices paid by electric utilities for each of the three fuels were generally below $\$ 4$ per million Btu. 


\section{Figure 10. How the Restructured Industry Responded to Recent Periods of Severe Winter Weather}

\section{Both winters had extended periods of extremely cold weather}

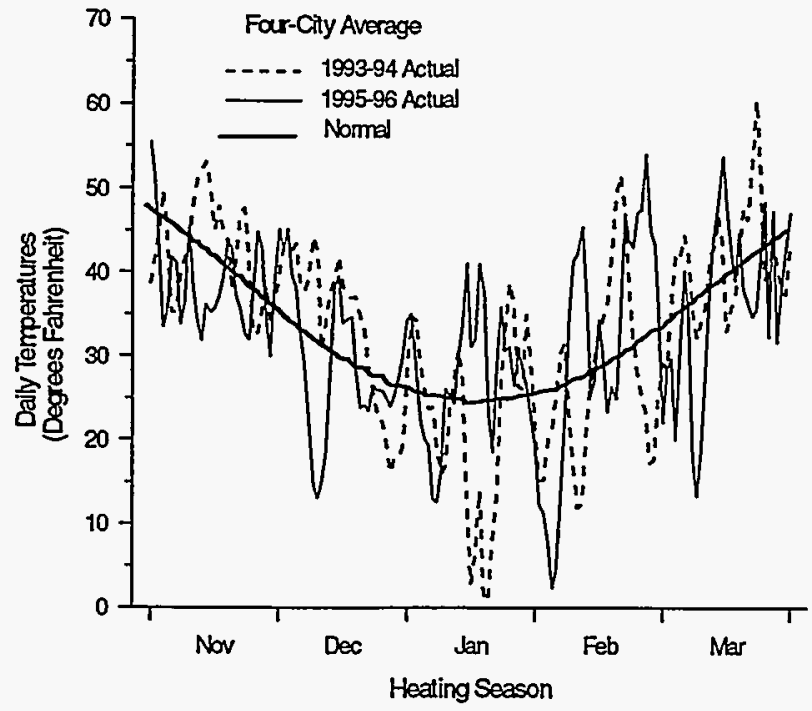

\section{Working gas levels reached several historical lows}



Natural gas price markets reacted differently during the two severe weather periods
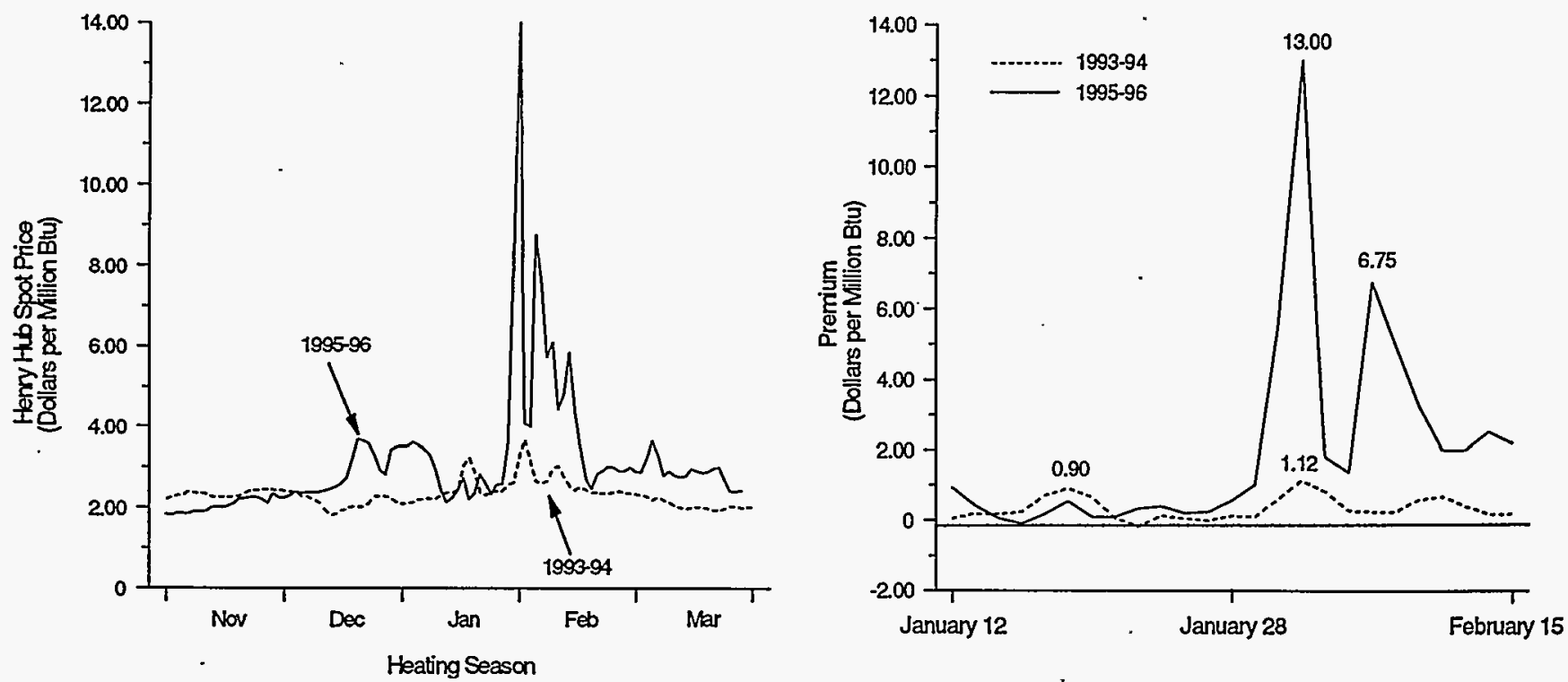

Bcf $=$ Billion cubic feet.

Notes: Temperatures are the average of temperatures for Chicago, Kansas City, New York, and Pittsburgh. The premium is the difference between the spot price and the New York Mercantile Exchange (NYMEX) nearby month futures price, both at the Henry Hub.

Sources: Energy Information Administration (EIA), Office of Oil and Gas. Temperatures: derived from National Oceanic and Atmospheric Administration, National Climatic Data Center. Working Gas in Storage: EIA, Form EIA-191, "Underground Gas Storage Report." Premium: derived from Spot Prices-Pasha Publications, Inc. Gas Daily and Futures Prices-Commodity Futures Trading Commission, Division of Economic Analysis. 


\section{Key Issues: Dealing with Cold Weather}

The past decade has seen many changes in the natural gas industry. A good measure of whether the industry has retained its capability for reliable service after restructuring is to observe how it operates under stress. The highest and most variable demands for natural gas usually occur during the heating season (November through March) when periods of abnormally cold weather occur. Two recent periods of severe winter weather offer an opportunity to observe how various segments of the natural gas industry operated.

The industry's operational systems were tested during the winters of 1993-94 and 1995-96. Low storage levels in November 1995 and persistently cold weather kept working gas in storage at low levels throughout the 1995-96 heating season. ${ }^{55}$ This led to great price uncertainty and to some of the highest gas prices ever recorded (Figure 10). Unusually cold temperatures in February 1996 extended into the producing regions, disrupting some supply activities for a day or two. Many pipeline companies reported record demand levels over the period.$^{56}$ In contrast, the 1993-94 heating season (the first season under Order 636) had only one sustained period of extremely low temperatures. Record cold weather east of the Mississippi in mid-January 1994 led to record levels of natural gas consumption. Several interstate pipelines and local distribution companies met or exceeded record weekly throughput. ${ }^{57}$ Storage withdrawals for January 1994 were nearly 800 billion cubic feet (Bcf), the second-highest record for any month. ${ }^{58}$ This level was not exceeded in 1995-96, but persistent cold weather and low storage throughout the season led to much larger price increases than in 1993-94.

- Great demands were placed on natural gas storage resources. At the beginning of November 1995, less than 3.0 trillion cubic feet (Tcf) of working gas was in storage. This was only the second time in 15 years that working gas levels were this low at the beginning of the heating season. By the end of December, working gas reached a 20-year low for the month of 2,153 Bcf (Figure 10). Preliminary data indicate that a record $2,691 \mathrm{Bcf}$ of gas was withdrawn from storage during the 1995-96 heating season as cold weather continued throughout the period. Both natural gas production and imports from Canada were at expected levels; but without any significant increases from totals the previous winter. Thus, the management of storage was crucial as the industry successfully met the high, weather-driven demand of the season. Storage levels were also below 3.0 $\operatorname{Tcf}(2,978 \mathrm{Bcf})$ at the start of the 1993-94 heating season, but temperatures were near normal in November and December. The severe cold later in the 1993-94 season resulted in near record storage withdrawals of 792 Bcf in January and 567 Bcf in February.
- Natural gas prices reacted to the abrupt and intense increases in demand during the cold periods of both heating seasons. During the winter of 1995-96, prices skyrocketed on the spot market as buyers rushed to meet the peaking demands of their customers. At the Henry Hub in Louisiana, prices were above $\$ 15.00$ per million Btu (MMBtu) on Friday, February 2, prior to the coldest weekend of the year (Figure 10). Reports in the trade press indicated that some industrial gas consumers paid more than $\$ 45.00$ per MMBtu in Chicago in order to avoid pipeline imbalance penalties of over $\$ 60.00$ per MMBtu. ${ }^{59}$ The spot price for February 1996 averaged a record high of $\$ 4.41$. The sharp price movements during this period indicate how the low storage levels and elevated demand created an atmosphere of price uncertainty. In 1994, the period of severe weather was of similar duration, 7 to 10 days, and also concentrated in the eastern part of the country. But the price movements at the Henry Hub were dramatically different. In January 1994 , spot prices were around $\$ 2.25$ per MMBtu before the cold spell, and by the fourth day of the severe.cold had reached a high of $\$ 3.25$. (Prices reached $\$ 3.70$ on February 2, 1994, during a 2-day cold snap.) Another difference was that very few imbalance penalties were imposed on gas buyers in 1994, perhaps because it was the industry's first experience in dealing with cold weather while operating under Order 636.

- The large difference between spot and futures prices showed how valuable it was to own gas during the stressful periods of both heating seasons. The "premium," or the difference between the Henry Hub spot price for short-term (1- to 3-day) delivery and the futures price for deliveries the next month, becomes higher when temperatures are colder than normal. This indicates the value of having gas available for immediate delivery rather than at a future time. ${ }^{60}$ In 1994 , the premium reached $\$ 0.90$ per MMBtu on January 19 , but was less than $\$ 0.06$ two days later. The highest premium of the season was $\$ 1.12$ on February 2, falling to $\$ 0.28$ on February 4. The more volatile spot prices in the 1995-96 heating season resulted in many more instances of extremely high premiums. The premium began to increase on January 30 , when it was at $\$ 0.57$ per MMBtu; by February 1, it was $\$ 5.50$ as the cold weather arrived. It reached its highest level on February 2, a startling $\$ 13.00$ per MMBtu. The premium was down to $\$ 1.36$ in 2 days, but then spiked again at $\$ 6.75$ per MMBtu and stayed well over $\$ 2.00$ until the futures market for March delivery closed on February 23. 


\section{Table 1. The Top Natural Gas Marketers Will Change After Mergers}

Top 10 Natural Gas Marketers in 1994

\begin{tabular}{c|l|c|l}
\hline \multicolumn{2}{|c|}{ Marketing Company } & \\
\cline { 1 - 2 } Rank & \multicolumn{1}{|c|}{ Name } & $\begin{array}{c}\text { Average Daily Sales } \\
\text { (Bcf/d) }\end{array}$ & \multicolumn{1}{|c}{ Parent Company } \\
\hline 1 & Amoco Canada Petroleum Co., Ltd & 5.4 & Amoco Corporation \\
\hline 2 & Natural Gas Clearing House & 3.7 & BP Gas and NOVA Corporation \\
\hline 3 & Associated Gas Services & 3.6 & Panhandle Eastern \\
\hline 4 & Western Gas Marketing Ltd. & 3.2 & TransCanada PipeLines Limited \\
\hline 5 & Enron Capital \& Trade Resources Corp. & 3.0 & Enron Corporation \\
\hline 6 & Chevron Natural Gas Services, Inc. & 2.9 & Chevron USA \\
\hline 7 & Coastal Gas Marketing Co. & 2.7 & Coastal Corporation \\
\hline 7 & Mobil Natural Gas, Inc. & 2.7 & Mobil Oil Corporation \\
\hline 9 & Exxon Co., USA & 2.1 & Exxon Corporation \\
\hline 10 & Texaco Natural Gas & 2.0 & Texaco Inc. \\
\hline
\end{tabular}

\section{Estimated Sales After Mergers}

\begin{tabular}{|c|c|c|c|}
\hline \multicolumn{2}{|c|}{ New Marketer } & \multirow[b]{2}{*}{ Merging Marketers } & \multirow[b]{2}{*}{$\begin{array}{l}\text { Merger } \\
\text { Status }\end{array}$} \\
\hline Company Name & $\begin{array}{c}\text { Estimated } \\
\text { Average Daily Sales' } \\
\text { (Bcf/d) }\end{array}$ & & \\
\hline Natural Gas Clearing House & 10.0 & $\begin{array}{l}\text { Chevron Natural Gas Services, Inc. I } \\
\text { Natural Gas Clearing House }\end{array}$ & Completed \\
\hline PanEnergy & 7.6 & $\begin{array}{l}\text { Mobil Natural Gas, Inc. / Associated Gas } \\
\text { Services }\end{array}$ & Completed \\
\hline To be announced & 7.0 & $\begin{array}{l}\text { Coastal Gas Marketing Co. / West Coast } \\
\text { Energy Services }\end{array}$ & Pending \\
\hline To be announced & 6.5 & $\begin{array}{l}\text { Tenneco Energy Resource / El Paso } \\
\text { Energy Corporation }\end{array}$ & Pending \\
\hline Coral Energy Resource & 4.5 & Shell Gas Trading / Tejas Gas Corporation & Completed \\
\hline
\end{tabular}




\section{Key Issues: Mergers and Acquisitions in the Gas Industry}

Restructuring and increased competition in the natural gas industry have created new opportunities for companies that in turn have resulted in numerous mergers and acquisitions. In a competitive industry, companies seek to increase market share and also diversify into profitable new lines of business. A company with high costs or burdensome debt might find itself vulnerable to acquisition, while other companies may merge to build on strengths that are considered unique to each company. Through mergers and acquisitions, companies attempt to add value by: (1) penetrating new markets and offering new services; (2) avoiding new investments by gaining access to new facilities; (3) cutting costs by eliminating duplicate services; (4) reducing overall management costs; and (5) establishing credibility and name recognition with customers.

- Consolidation heats up among gas marketers. In January 1996, Chevron Corporation and Natural Gas Clearing House announced a merger of their gas gathering, marketing, and processing businesses, which would create the Nation's largest marketer. The new corporation's sales would average more than 10 billion cubic feet per day, about 14 percent of North American natural gas consumption. ${ }^{61}$ Other large marketer mergers are also either under negotiation or have recently been completed (see Appendix A). In such mergers, producers gain access to new markets and marketing expertise, while marketers gain access to relatively secure gas supplies. Also, marketers anticipate new gas marketing opportunities as State regulators begin to allow retail competition in local distribution. ${ }^{62}$ Potential customers could increase from a few thousand large industrial and commercial customers to millions of residential users (see Chapter 6).

- Recently completed and proposed mergers will reduce the number of major marketers and increase market share for the largest companies. In 1994, Amoco was the leading gas marketer, averaging almost 5.4 billion cubic feet (Bcf) per day in sales, and Natural Gas Clearing House was second with sales of $3.7 \mathrm{Bcf}$ per day (Table 1) ${ }^{63}$ In 1997 , the leading marketers will likely have double the sales of the largest marketing companies in 1994. The top 10 marketers in 1994 accounted for 31 Bcf in average daily sales, approximately 42 percent of U.S. daily consumption. After the planned mergers, this volume would represent sales of the four largest marketers.
- Smaller marketers will still play a vital role despite these mega-mergers. Market niches exist to aggregate small customer loads for larger marketers and also to aggregate gas production from small producers. For example, Tulsa-based. Nimrod Natural Gas recently formed an alliance with Chevron to market Chevron's gas in the Chicago area. Despite these opportunities, smaller marketers will probably find themselves under increasing economic pressure as margins they earn from buying and selling gas become squeezed by the entry of large firms into the market.

- More utilities combine forces to offer both gas and electric service. Since January 1, 1995, a number of gas and electric utilities have announced plans to merge their operations (Appendix A). For example, Baltimore Gas and Electric (BG\&E) plans to merge operations with Potomac Electric Power Corporation (PEPCO). BG\&E provides gas and electric service to the city of Baltimore and 10 surrounding Maryland counties. PEPCO provides electric service to Washington, D.C. and two surrounding Maryland counties. The companies estimate that over 10 years they could save $\$ 1.3$ billion from the elimination of duplicate services, the adoption of centralized purchasing, and reduction of management costs. ${ }^{64}$

- Natural gas and electric utilities are merging to cut costs, expand their service territories, and to offer new multi-fuel services. Many utilities believe that their knowledge of power and gas delivery systems places them in a unique position to compete with marketers for sales customers. They anticipate that as unbundling continues in retail gas and power markets, the best opportunities for profits will be in natural gas and electricity sales rather than in providing only transportation services.

- Merging utilities are closely scrutinized by State public utility commissions. In most States, utility mergers are subject to approval by the regulatory commissions. Specific criteria that regulators consider when deciding whether to approve a merger are: the effect on costs and rate levels, the proposed corporate structure, the reasonableness of the purchase price, and the existing competitive environment. 


\section{Table 2. Interest Grows in Alternative Transportation Rate Design}

\section{Alternative Transportation Rates for Interstate Pipeline Companies}

\begin{tabular}{|c|c|c|c|c|}
\hline \multirow[b]{2}{*}{ Rate Design Method } & \multirow[b]{2}{*}{$\begin{array}{l}\text { Degree of } \\
\text { Competition }\end{array}$} & \multirow[b]{2}{*}{$\begin{array}{l}\text { Basis of } \\
\text { Service Rates }\end{array}$} & \multicolumn{2}{|c|}{ Rate Limits } \\
\hline & & & Upper & Lower \\
\hline Traditional Cost of Service & Low & $\begin{array}{l}\text { Estimated Annual Operating } \\
\text { Expenses plus Return on Investment }\end{array}$ & $\begin{array}{l}\text { Maximum Filed } \\
\text { Tariff Rate }\end{array}$ & $\begin{array}{l}\text { Minimum Filed } \\
\text { Tariff Rate }\end{array}$ \\
\hline Market-Based & High $^{1}$ & $\begin{array}{l}\text { Customer Driven/ } \\
\text { Rates for Competing Services }\end{array}$ & Market Determined & $\begin{array}{l}\text { Variable Cost of } \\
\text { Providing Service }\end{array}$ \\
\hline \multicolumn{5}{|l|}{ Negotiated/Recourse } \\
\hline Negotiated & Moderate ${ }^{2}$ & $\begin{array}{l}\text { Individually Negotiated } \\
\text { with Each Customer }\end{array}$ & $--^{3}$ &.$-^{3}$ \\
\hline Recourse ${ }^{4}$ & Low & Traditional Cost-of-Service Rate & $\begin{array}{l}\text { Maximum Filed } \\
\text { Tariff Rate }\end{array}$ & $\begin{array}{l}\text { Minimum Filed } \\
\text { Tariff Rate }\end{array}$ \\
\hline Incentive-Based & -- & Agreed upon Benchmarks ${ }^{5}$ & $-\circ$ & - \\
\hline
\end{tabular}

\section{Companies that Have Filed for Negotiated/Recourse Transportation Rates}

\begin{tabular}{lc|l|l}
\hline \multicolumn{1}{c|}{ Company Name } & FERC Docket No. & Date Filed & Status \\
\hline NorAm Gas Transmission Company & RP96-200 & April 1, 1996 & Conditionally Accepted \\
Colorado Interstate Gas Company & RP96-190 & April 15, 1996 & Conditionally Accepted \\
Northern Natural Gas Company & RP96-272 & June 7, 1996 & Conditionally Accepted \\
Tennessee Gas Pipeline Company & RP96-312 & July 16, 1996 & Conditionally Accepted \\
Koch Gateway Pipeline Company & RP96-320 & July 31, 1996 & Conditionally Accepted \\
Florida Gas Transmission Company & RP96-330 & August 2, 1996 & Conditionally Accepted \\
National Fuel Gas Supply Corporation & RP96-331 & August 2, 1996 & Conditionally Accepted \\
Transcontinential Gas Pipe Line Corp & RP96-359 & August 30, 1996 & Pending \\
CNG Transmission Corporation & RP96-383 & September 13, 1996 & Pending \\
Columbia Gas Transmission Corporation & RP96-390 & September 25, 1996 & Pending \\
Columbia Gulf Transmission Company & RP96-389 & September 25, 1996 & Pending \\
East Tennessee Natural Gas Company & RP97-13 & October 1, 1996 & Pending \\
Midwestern Gas Transmission Company & RP97-14 & October 1, 1996 & \\
\hline
\end{tabular}

'The Federal Energy Regulatory Commission will measure a pipeline company's market power using the Hirschmann-Herfindahl Index (HHI). While the HHI will indicate if a pipeline company has enough market power to suppress competition, the company's HHI level will not be the deciding factor for determining if market-based rates are appropriate. Market-based rate applications by companies with an HHI measurement greater than 0.18 will be more closely reviewed.

2Negotiated/Recourse rates may be an alternative when market-based rates are inappropriate.

${ }^{3}$ Negotiated rates may exceed maximum filed rates or be less than minimum filed rates.

${ }^{4}$ A pipeline company's recourse rates will be its effective cost-of-service rates.

${ }^{5}$ Benchmarks may include: average of rates charged by other companies in region, reduction in operating expenses, increased customer satisfaction.

-Although the 1992 Policy Statement on Incentive Regulation (61 FERC 161,168 ) required that rates under incentive regulation be no higher than they would have been under traditional cost-of-service regulation, FERC has eliminated this requirement from its current incentive rate ovaluation criteria.

$--=$ Not applicable. FERC $=$ Federal Energy Regulatory Commission.

Sources: Alternative Transportation Rates: Energy Information Administration, Office of Oil and Gas, derived from: Federal Energy Regulatory Commission orders and Commission Issuance Posting System. Negotlated/Recourse Rate Filing: Foster Associates, Inc., Foster Natural Gas Report, No. 2100 (October 3, 1996). 


\section{Key Issues: Transportation Regulatory Actions}

The natural gas industry has witnessed major regulatory and legislative changes during the past several years. Some of the changes have allowed market forces to govern rate and. service levels in areas of the industry where standard regulatory oversight was previously required. Recent regulatory actions have continued to expose more elements to market forces and have increased the options for interstate pipeline companies and shippers.

- The Federal Energy Regulatory Commission (FERC) has established its evaluation criteria for marketbased, incentive, and negotiated/recourse rates for transportation service. FERC issued the policy statement on ratemaking alternatives in recognition that additional rate design flexibility may be needed in the restructured environment. ${ }^{65}$ For instance, pipeline companies may need rate design flexibility to market excess capacity and recover costs associated with unsubscribed or "turned-back" capacity (see Chapter 2). Market circumstances are an important indicator of which type of alternative rate design method would be appropriate (Table 2). FERC will evaluate requests for alternative rates on a case-by-case basis.

Pipeline companies appear to favor the negotiated/recourse method of the three alternatives to cost-of-service rates. As of October 1, 1996, 13 pipeline companies have filed for negotiated/recourse rates (Table 2). Most of the filings for negotiated/recourse rates have been conditionally accepted by FERC. The negotiated/recourse rate falls between market and costof-service rates in terms of how the rate is determined. A customer may "negotiate" a transportation rate with the pipeline company, or as a "recourse" choose to pay the effective cost-of-service rate. Although some issues still need to be resolved, it appears that the industry is embracing the concept of flexibility in rates.

- Negotiated terms for pipeline company services may be another way of increasing flexibility in the transportation industry. In addition to its policy statement on ratemaking alternatives, FERC has. established a proceeding in which it will consider a proposal to allow pipeline companies to negotiate service terms and conditions. Negotiating terms and conditions may allow pipeline companies to tailor services to meet their customers' specific needs. Various sectors of the industry have asked FERC to ensure that pipeline companies do not enhance services to flexible customers at the expense of the remaining customers. Some generic benchmarks, with respect to pipeline company terms, may be required to keep a degree of standardization across the industry. In addition, an expedited complaint process may be needed so that affected customers can avoid excessive hardships.

- In addition to rate and tariff flexibility, FERC is providing pipeline companies flexibility with respect to access to markets. In a January 31, 1996, order, FERC clarified that Order 636 does not prohibit interstate pipeline companies from obtaining capacity on other pipelines. ${ }^{66}$ FERC stated that "to continue a prohibition on acquiring capacity on other pipelines may limit the flexibility that all industry segments may need to meet changing market demands." FERC will continue to review pipeline company requests on a case-by-case basis giving particular attention to four items: (1) pipeline company control of capacity and supply sources, (2) the rate impact on the acquiring pipeline company's customers, (3) preferential treatment of pipeline company marketing affiliates, and (4) integration of acquired capacity into open access systems.

FERC perceives at least two benefits of pipeline companies holding capacity on other pipelines. First, it would allow the pipeline companies to provide shippers access to new supply and market areas. Second, it would reduce the administrative burden of shippers having to deal with several pipeline companies to secure the flow path they desire. Opponents of FERC's position believe that pipeline companies may use the capacity to exercise monopoly power while charging the cost of the capacity to core customers.

- FERC has issued a Notice of Proposed Rulemaking to improve the operation of the capacity release mechanism and increase released capacity's value as a means of transporting gas. ${ }^{67}$ In the notice, FERC proposes to discontinue the current bidding requirements in an effort to end the uncertainty and delay some replacement shippers have experienced before they may use the released capacity.$^{68} \mathrm{FERC}$ is also proposing to remove the price cap for released, interruptible, and short-term firm capacity when releasing shippers and pipeline companies can demonstrate that they are unable to exercise market power. In addition to making these services more comparable, removing the price cap will enable releasing shippers and pipeline companies to sell the capacity at market prices. Releasing shippers may also be able to recover more of their firm capacity costs, making the secondary market more attractive (see Chapter 2). 


\section{Figure 11. New Deep Water Fields Are Highly Productive}

Average discovery size in deep waters dwarfs discoveries anywhere else in the lower 48



Deep water fields yield a major portion of associated-dissolved gas in new fields



Total associated-dissolved gas for discoveries during 1990-1994 is 143 billion cubic feel.

Water depth records for producing projects have increased rapidly

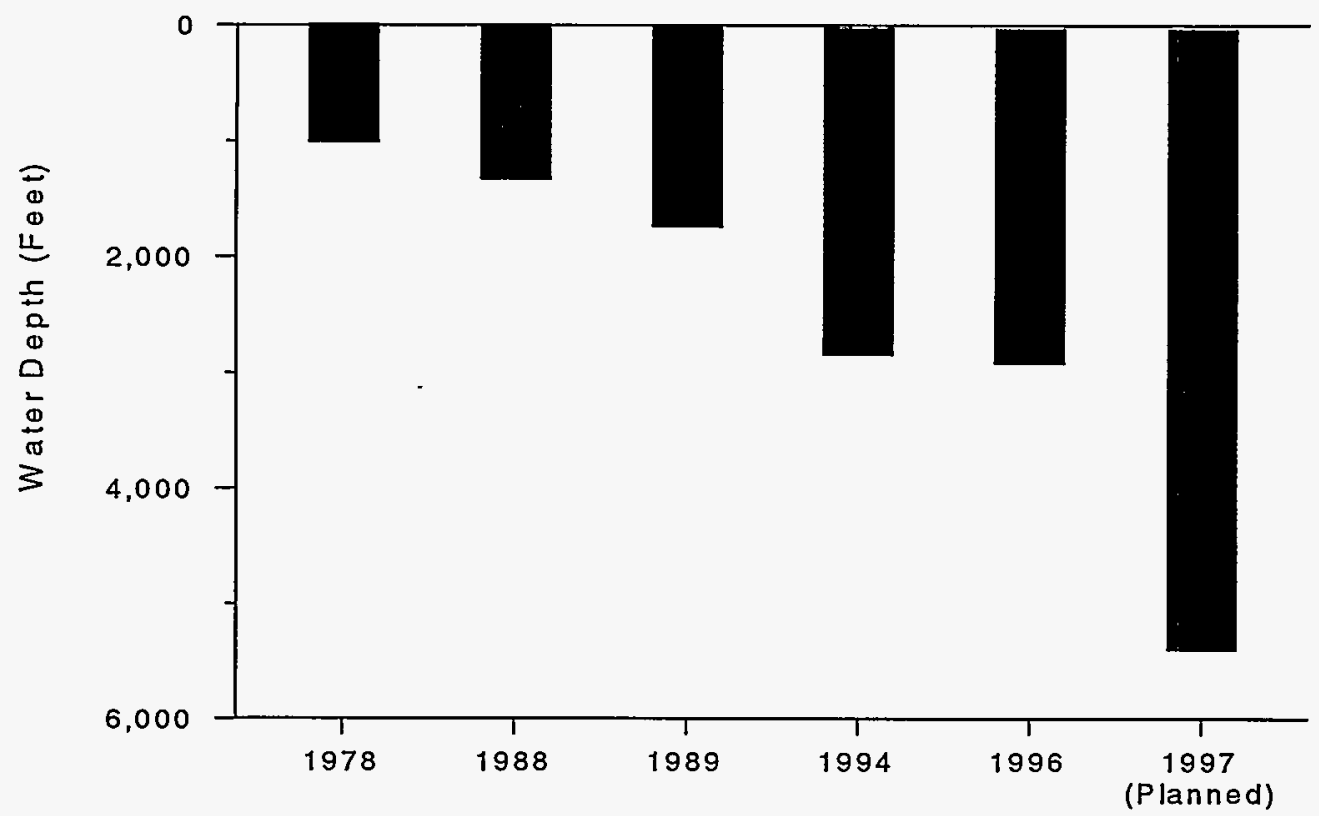

Notes: Average discovery size (top left graph) does not include liquids in gas fields. New field discovery data for the top two figures are for discoveries made during 1990 through 1994.

Sources: Energy Information Administration (EIA), Office of Oil and Gas. Average Discovery Size and Assoclated-Dissolved Gas in New Fields: Form ElA-23, "Annual Survey of Domestic Oil and Gas Reserves." Water Depth Records: Oil and Gas Journal (November 13, 1995$)$, p. 32. 


\section{Key Issues: Offshore Deep Water Development}

Deep water regions ${ }^{69}$ of the Gulf of Mexico are a prime growth area for domestic gas production. Productivity in these areas is the highest in the lower 48 States, but development had been inhibited because of relatively low prevailing gas prices and technical difficulties. The current outlook for deep water supplies from the Gulf of Mexico is encouraging because of technological improvements and the royalty relief program instituted in late 1995 by the Department of the Interior, both of which have lowered unit costs of exploration and development.

- The average size of new field discoveries in the deep water Gulf of Mexico from 1990 through 1994 was 60 billion cubic feet, vastly exceeding that of any other area of the lower 48 States. Deep water gas discoveries were three times the estimated recovery of shallow Gulf fields and at least six times the average field size discovered in any onshore region of the lower 48 States (Figure 11). The new oil fields in deep water contain substantial gas volumes. The associated-dissolved (AD) gas in these fields is estimated to be 59 billion cubic feet, or 41 percent of all $A D$ gas in lower 48 new field discoveries from 1990 through 1994 (Figure 11). In contrast, the gas field discoveries in the deep Gulf during this period yielded only 3.5 percent of gas volumes discovered in lower 48 gas fields.

- Technology is the driving factor that determines the development of deep water gas projects. Deep water operations have benefited greatly from technology advances since the late 1980's such as three-dimensional (3D) seismic survey techniques and subsea completion technology. Use of 3D seismology is attractive for its capacity to limit costly dry holes and optimize well placement within the reservoir. A recent test demonstrated the use of satellites to transmit large volumes of information quickly for rapid analysis of $3 D$ seismic data, which improves data collection by directing the seismic vessel to rework targets or move to another site. This enhancement in the 3D process offers the opportunity to save money and acquire better quality information. ${ }^{70}$ More accurate and reliable data tend to encourage investment because uncertainty is reduced.

Remotely operated subsea completions allow companies to transport gas from deep water fields back to producing platforms in shallower water that serve as centralized processing and gathering facilities. These "tie-back" arrangements enhance project economics by allowing producers to maximize utilization of existing on-site equipment and enhance economic returns by avoiding large expenditures for additional platforms and production equipment at the deep water locations. The importance of acquiring better technology for deep water activity is underscored by the alliances forming in the industry: Shell has a technology exchange agreement with Petroleo Brasileiro AS of Brazil, and Mobil is working with .Norwegian companies on a new subsea completion system for water depths exceeding 8,000 feet.

- Deep water projects continue to come on line each year and add to the growing infrastructure as well as the record of success. Deep water projects are extending into deeper and more distant locations in the Gulf of Mexico as evidenced by the evolving water depth records (Figure 11). In 1988, the Bullwinkle project came in at a depth of 1,350 feet, followed in 1989 by Joliet at 1,760 feet. These achievements were eclipsed with the Auger project in 1994 at 2,860 feet. The Mensa project, slated for initial production in 1997, will dwarf all of these with a water depth of 5,400 feet. This shift to ever greater depths is especially striking given the difficulties caused by increasing pressure and falling temperatures.

Deep water projects also are being connected, or tied back, at increased distances to producing platforms in shallower water. The first instance of remote subsea production with a significant tie-back occurred with the Tahoe project in 1994 with a 12-mile tie-back. Shell's new Popeye project is a major step in the evolution of this approach. The Popeye field, in 2,000 feet of water, will be tied back over 24 miles to the Cougar platform in 350 feet of water, which will make it the longest tie-back from a subsea well. The Popeye project is serving as a testing ground for technology planned for the Mensa project, which is located in 5,400 feet of water with a planned 68-mile tie-back. The increasing reach of remote operations is an important aspect of the planning and design stage for development of new fields, which will increase the complexity of long-term project planning and investment decisionmaking.

- The Minerals Management Service's (MMS) new royalty relief program contributed to a record-setting Gulf of Mexico lease sale. The Deep Water Royalty Relief Act passed in late 1995 exempts deep water projects from Federal royalties on the first portion of production according to a sliding scale. ${ }^{71}$ Royalties paid in the Federal offshore area typically are up to 17 percent of the gross value of production. The new royalty relief program apparently stimulated activity in the April 1996 lease sale for the Central Gulf of Mexico. The 1,381 bids received by MMS were a record count. Top bids, totaling more than $\$ 520.9$ million, were received for 924 tracts. ${ }^{72}$ 


\section{Figure 12. Electronic Communication Services Have Increased}

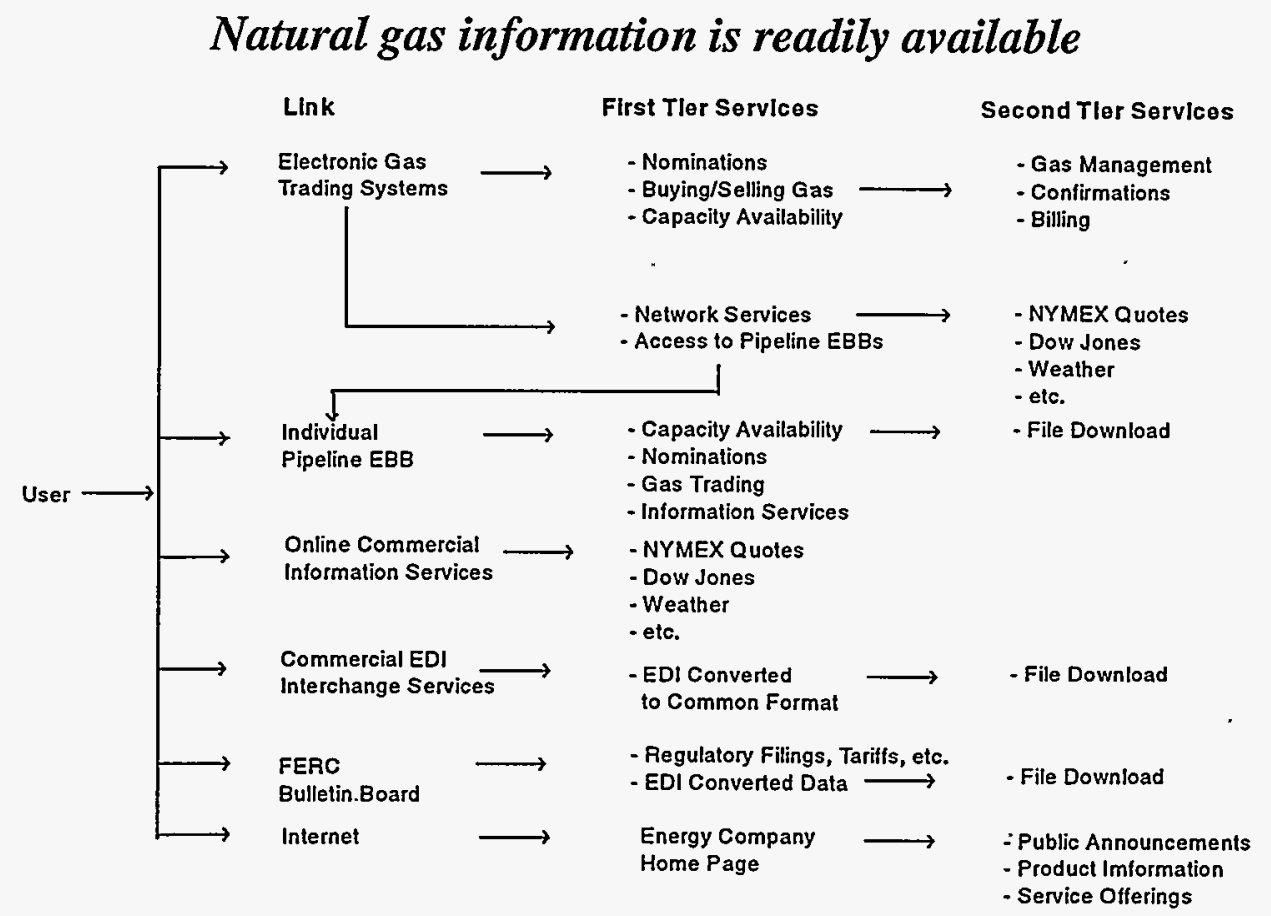

Gas trading is simplified by user-friendly programs

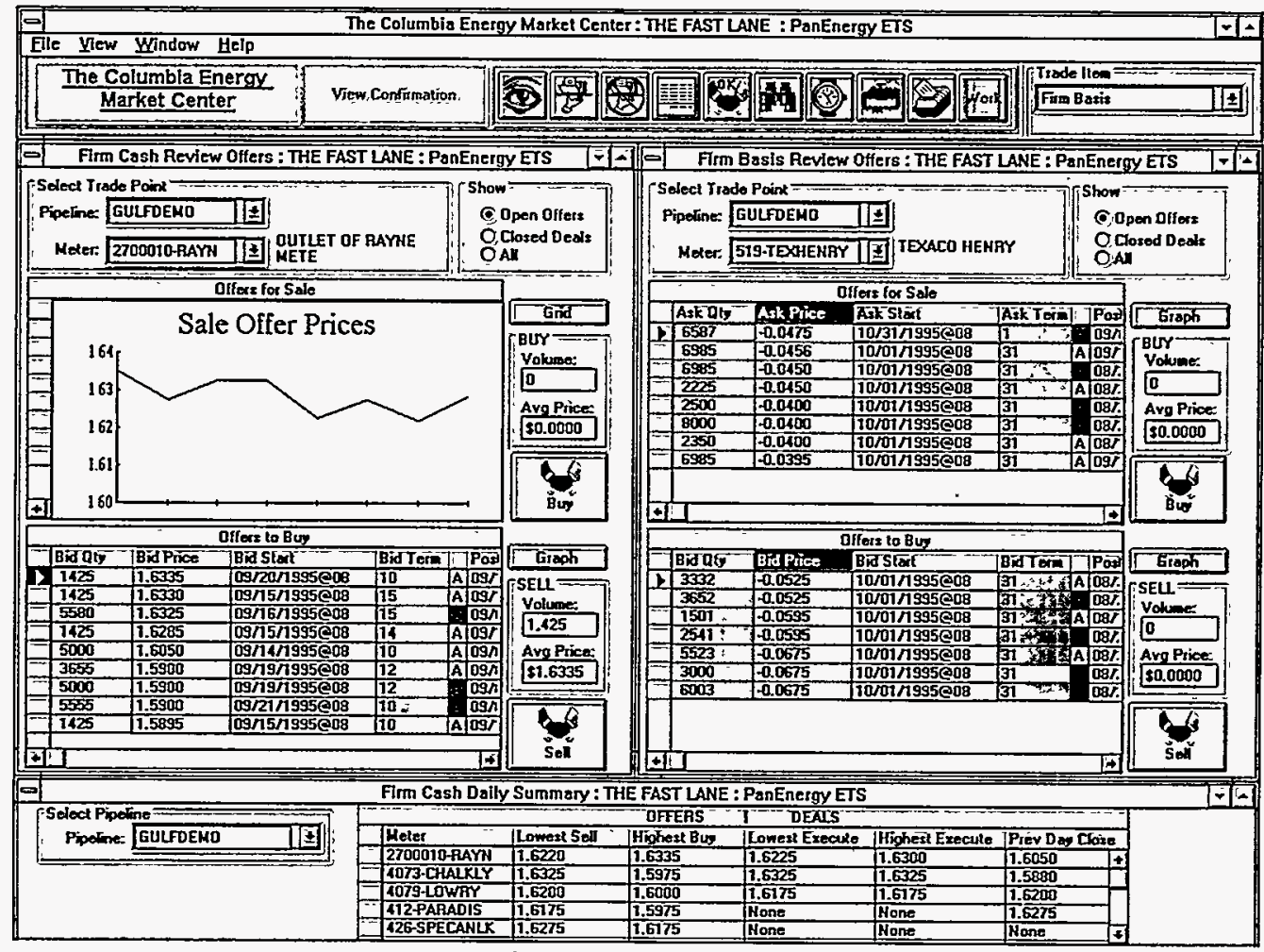

EBB = Electronic bulletin board. NYMEX = New York Mercantile Exchange. EDI = Electronic data interchange. FERC = Federal Energy Regulatory Commission.

Sources: Flow Chart: Energy Information Administration (EIA), Office of Oil and Gas. Computer Screen: Altra Energy Technologies. 


\section{Key Issues: Importance of Electronic Information}

The integration of computers and electronic communications with the transacting of business in the natural gas industry expanded rapidly during 1995 and early 1996 . As recently as 1994, pipeline company electronic bulletin boards (EBBs) were extensively criticized for their complexity, slow speed, and operational problems. The current EBBs, however, are easier to use and more readily accessible. In addition, the electronic trading system concept for the industry has become much more developed with several full service systems that offer greater reliability and ease of use (Figure 12).

- The new commercial electronic trading systems reflect the need for a single tool that provides access to market information during business transactions. All of the major new or improved systems allow a customer remote access to their network via computer and, once linked, a number of optional services. These services include access to diverse information sources such as New York Mercantile Exchange (NYMEX) quotes, network E-Mail, other EBB operations, or alternatively to gas trading operations. Trading systems enable customers to buy and sell volumes and pipeline or storage capacity, as well as to conduct other trading activities, including billing, title transfers, and other administrative and accounting tasks (Figure 12).

- Three new commercial electronic trading systems have been introduced since late 1994. Currently, the most frequently used system is Altra Streamline, which was introduced in April 1995. It is used at eight natural gas market centers in the United States and three in Canada. Daily trading volumes at these centers range from 10 to 200 million cubic feet. Through its network, users can also access selected information (capacity release, operational flow orders, and notices of outages) from 45 pipeline company EBBs. Channel 4, the second most used system (four existing and two planned market centers), was introduced in 1994. Quick Trade, which began trading in early 1996, currently is operational at three market centers and 28 trading points on six pipeline systems. Several other commercial systems are available, although they are not as well known. A few natural gas market centers operate their own customized services.

- The electronic data interchange (EDI) system for capacity release is being tested and improved. Order 636 required each interstate pipeline company to maintain a certain minimum set of information for capacity release transactions. However, the 65 pipeline company EBBs have quite different content level and vary widely in ease of access and use. This variability was the driving force behind FERC's decision to implement standard electronic data formats in the EDI system for capacity release data. Even with the common EDI format, however, there still was inconsistency in how different pipeline companies provided the information. FERC has spent considerable effort to ensure that the EBB and EDI data are consistent. The problems of data discrepancies and differing formats also have resulted in action on the part of the industry to develop standards.

- The Gas Industry Standards Board (GISB), a voluntary organization that comprises all segments of the natural gas industry, has been working to develop standards for electronic business transactions. In March 1996, 248 business standards were proposed, covering nomination, confirmations, allocating and measuring of flowing gas, invoicing and statements of account, electronic delivery arrangements, and capacity release. The industry approved 140 of these in April 1996 and submitted them to FERC in response to FERC's Advance Notice of Proposed Rulemaking (RM96-1) ${ }^{74}$ FERC adopted the 140 standards on July 17 , 1996. Some pipeline companies are required to implement the standards by April 1, others by May 1, and all by June 1, 1997.

- The Internet is being used by the natural gas industry mainly as an advertising medium to publicize specific company services. Users can typically find information about a company's capabilities on its "home page" and order services, but are unable to obtain "real-time" information. Having learned from the problems resulting from the differing electronic systems in the natural gas industry, FERC has mandated that electric power companies use a network that is accessible to all power companies. As a result of that April 1996 mandate, a limited access, electric power internet is being established, using existing Internet software and dedicated servers (see Figure 13).

- GISB's Future Technology Task Force has proposed that all jurisdictional pipeline companies place capacity release and other EBB information on the public Internet. On September 30, 1996, the task force recommended that FERC approve adoption of 10 new electronic delivery mechanism standards and require all transportation service providers and their trading partners to have standardized transaction datasets by April 1997. Information currently on EBBs would become available on each company's Internet home page. 


\section{Figure 13. Electric Restructuring Begins in Earnest}

\section{FERC has issued orders to open electric transmission access}

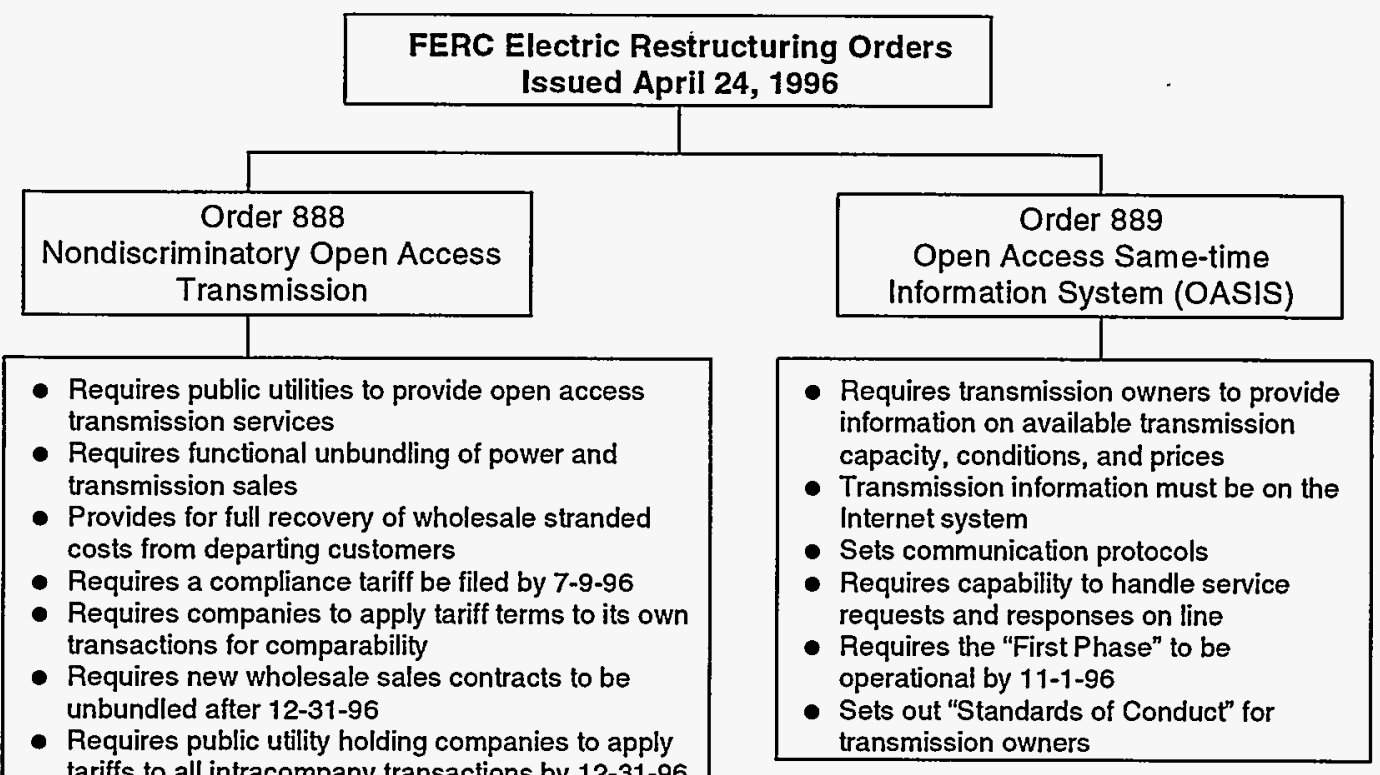

tariffs to all intracompany transactions by 12-31-96

- Proposes replacing compliance tariffs with capacity reservation tariffs by 12-31-97

\section{Residential consumers pay about four times more for electricity than gas ${ }^{1}$}

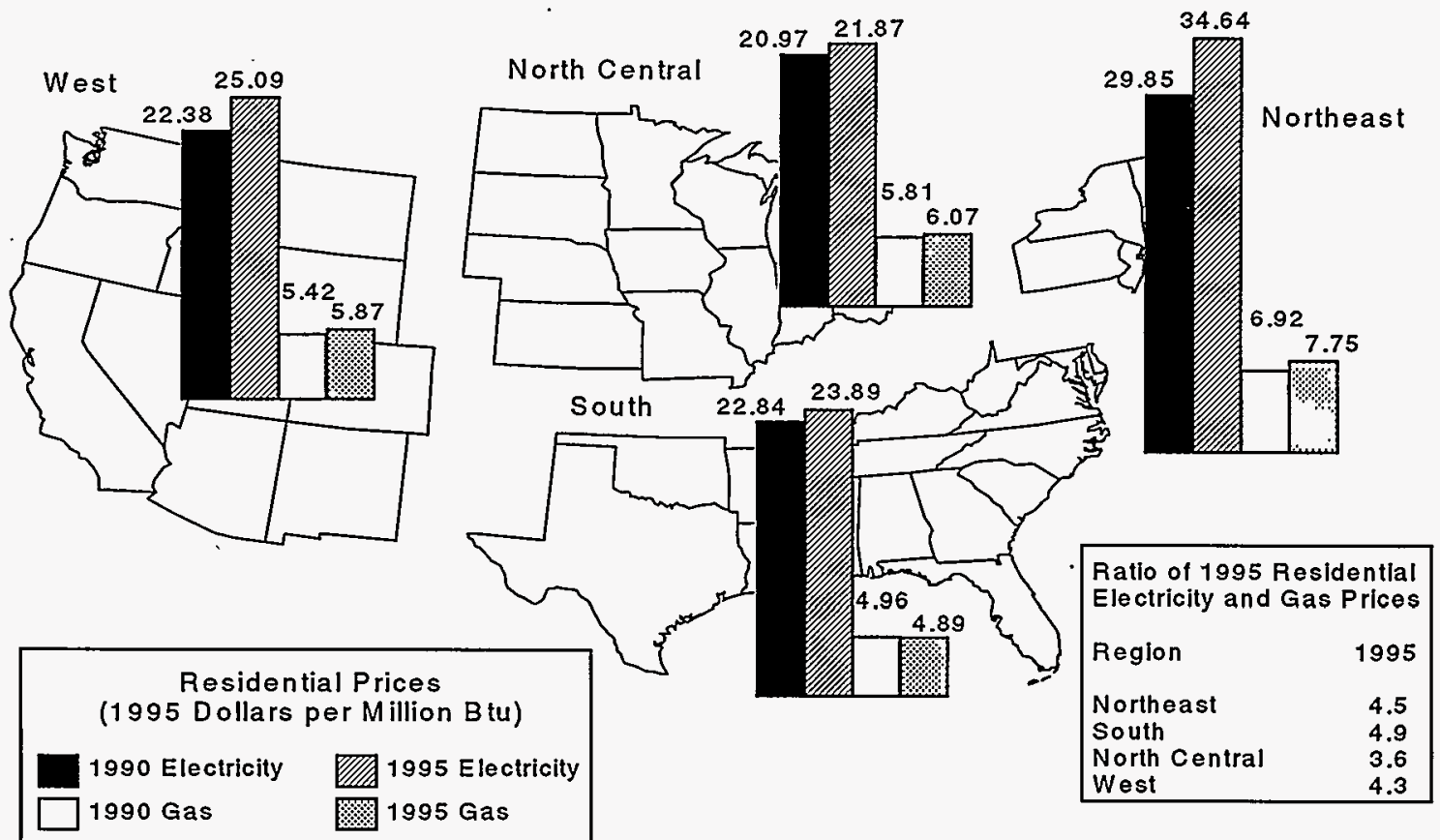

'In choosing fuels, consumers consider relative energy conversion efficiencies when comparing fuel prices. Energy efficiencies vary depending on the process, equipment, and pattern of use. Therefore, price adjustments are made for each type of energy application.

FERC $=$ Federal Energy Regulatory Commission.

Note: Values expressed in 1995 dollars based on chain-weighted gross domestic product (GDP) deflator from the U.S. Department of Commerce.

Sources: Energy Information Administration (ElA), Office of Oil and Gas. Electrlcity Prices: derived from Electric Power Annual 1996 (July 1996) and Electric Sale and Revenue, 1990 (November 1991). Gas Prices: derived from Natural Gas Annual 1995 (November 1996). 


\section{Key Issues: Electric Restructuring and the Gas Industry}

The restructuring of the electric utility industry will open a new and challenging era of changes in energy industries. These changes are likely to affect not only the demand for natural gas for power generation but also the organization of the energy supply industries and conditions under which gas competes directly with electricity for end-use sales. The time table and the final results remain uncertain today; however, current activities do provide some insights into the transition.

- The Federal Energy Regulatory Commission (FERC) has followed through on the 1992 Energy Policy Act by requiring transmitting electric utilities to provide open access transmission services. Order 888, the open access rule, is similar to Order 636 that encouraged gas pipeline companies to become open providers of gas transportation services. As it did in the gas industry, FERC will require transmission-owning utilities to separate power sales functionally from the provision of transportation services. In a companion rule, Order 889 , FERC set ground rules for the establishment of an electronic communications system to inform potential transmission customers of the availability and conditions of the transmission network (Figure 13).

- Many of the forthcoming changes in the electric industry will follow the pattern set earlier by the natural gas industry; however, differences in the traditional organization of the two industries cause new problems. Two differences that affect the pattern of restructuring are the degree of vertical integration and the amount of overvalued assets on regulated companies' books, commonly referred to as "stranded costs."74 Traditionally, different companies own and operate each stage of the natural gas industry. For example, there are separate production, transmission, and distribution companies. But in the electric industry, multiple stages of the industry are controlled under one firm, from power generation through final distribution. This vertical integration complicates restructuring in several ways. Most noticeably, it results in splitting regulatory oversight for the different stages in a single company between Federal and State governments. This split jurisdiction is a major consideration in resolving the stranded costs problem. Estimates of potential stranded costs of electric utilities run as high as $\$ 300$ billion. $^{75}$ FERC has determined that electric utilities are entitled to full recovery of the costs incurred to serve wholesale customers that are under Federal jurisdiction. ${ }^{76}$ However, currently about 85 percent of stranded costs fall under State jurisdiction. ${ }^{77}$ This past summer, legislation was introduced to give FERC authority over retail access if it is not competitive by December $15,2000 .^{78}$
- The amount, proportion, and means of recovering stranded costs will determine just how soon competition reaches electricity markets. If stranded costs are large and they must be recovered from customers rather than shared between customers and the utility companies, few customers will be able to change suppliers. Instead, retail customers will stay with their traditional utility supplier until stranded costs are nearly paid off. ${ }^{79}$ Thus, the rate at which competition becomes established in retail markets will be tied to the way stranded costs are resolved.

- Other aspects of electric restructuring may imply a closer and more favorable future for both industries. Innovative developments in the gas industry during the past 10 years foretell some of these changes. Gas marketers have reformed gas supply relationships. Many of these same marketers are moving into the new electricity markets (see p. 23). Indeed, the largest gas marketer, Enron, is also now the country's largest electricity marketer. Enron has also proposed buying a major electric utility, Portland General. Although this is a merger between a major gas player and an electric utility, it is only one in the rush of recent merger proposals that have involved electric utilities. In an effort to create integrated "energy" markets as opposed to continuing separate, isolated markets, other gas and electric companies are also forming mergers or strategic alliances to give customers menus that allow buyers to bridge the differences between the industries. The electric business also appears to have caught the attention of the financial community. The development of financial instruments already used in the gas industry, such as spot, forward, futures, and options markets, are being taken as models for electricity. ${ }^{80}$ These financial markets are probably the best means of bringing about the integration of energy markets.

- In electricity as in gas, the first retail consumers to have choice among suppliers will be the high volume customers. These customers tend to be very price sensitive. If market pricing significantly lowers electricity prices to these users, it could lead to the substitution of electricity for gas in industrial processes and undercut gas sales to manufacturers. However, in many other uses such as residential service, electricity is about four times more expensive than gas before adjustments for conversion efficiency (Figure 13). ${ }^{81}$ Opportunities for electricity to attract new customers or to displace existing gas sales in these markets are less likely given the wide gas-price advantage. 


\section{Chapter 1 Endnotes}

1. In general, prices are presented in nominal dollars for short-term, such as monthly, comparisons. For longer term comparisons over several years, such as in Chapter 5, prices are presented in real 1995 dollars using the chain-weighted gross domestic product (GDP) price index from the U.S. Department of Commerce, Bureau of Economic Analysis.

2. Spot prices are more commonly given in dollars per million Btu. In this section, spot prices were converted to dollars per thousand cubic feet, using the factor of 1,028 Btu per cubic foot, to aid in comparison of spot and wellhead prices.

3. During the second half of the 1980 's, monthly average wellhead prices tended to rise throughout the fall and early winter, peak in January, and then fall until mid or late summer. This pattern has not held true during the 1990's, yet a 3-month pattern from December through February did develop wherein prices fall from the December level through February of the next year. However, the pattern occurred at very different levels of price in each year. Also, monthly price movements during the other months in those years were quite varied. Preliminary estimates indicate that even this shorter term monthly price pattern did not occur from December 1995 through February 1996.

4. By historical standards, stocks of gas were very low during the 1995-96 heating season, but stocks of substitute sources of energy such as oil and propane were also low. These low levels for stocks contributed to great price uncertainty.

5. For example, a customer will pay more for gas if it is able to get transportation at a discount. Thus, the final price of gas to an end-use customer may be influenced by whether a pipeline system used to transport the gas is operating near full capacity because this would affect the cost of transportation on that system. Moreover, if a pipeline is operating at or near full capacity, a company may hurriedly complete a deal and pay more for gas than it would otherwise in order to reserve sufficient space on the pipeline system.

6. Interestingly, because futures and options contracts enable a buyer and a seller of gas to obtain protection from current price increases, buyers and sellers have the choice to use such markets to protect their capability to make needed investment decisions instead of subjecting themselves to the challenges posed by the current uncertainty in gas prices.

7. More precisely, volatility is defined as the standard deviation of percentage price changes. The computed number is usually annualized. Thus, when daily price changes are used as primary data, the standard deviation is multiplied by the square root of 250 , which is the number of trading days in a year.

8. The price of the options contract at the time it is sold is influenced by the volatility of the futures price. The higher the volatility, the higher the price of the options contract.

9. Deep water refers to water depths of 200 meters or more. Additional discussion of gas developments in the deep water regions can be found in a separate section of this chapter.

10. Additional information regarding this technology can be found in "Production Operations Moving to 5-D," The American Oil and Gas Reporter (February 1996).

11. Energy Information Administration, Office of Oil and Gas, "Crosswell Seismology-A View from Aside," draft paper (October 1996).

12. Proved reserves of natural gas are the estimated quantities that analysis of geological and engineering data demonstrate with reasonable certainty to be recoverable in future years from known reservoirs under existing economic and operating conditions.

13. Undiscovered resources are located outside oil and gas fields in which the presence of resources has been confirmed by exploratory drilling, and thus exclude reserves and reserve extensions; however, they include resources from undiscovered pools within confirmed fields to the extent that such resources occur as unrelated accumulations controlled by distinctly separate structural features or stratigraphic conditions. Technically recoverable resources are those volumes producible with current recovery technology and efficiency but without reference to economic viability. Economically recoverable resources 
are those volumes considered to be of sufficient size and quality for their production to be commercially profitable by current technologies, under specified economic assumptions.

14. All proved reserves estimates cited in this section are from the Energy Information Administration, Advance Summary, U.S. Crude Oil, Natural Gas, and Natural Gas Liquids: 1995 Annual Report, DOE/EIA-0216(95)Advance Summary (Washington, DC, October 1996).

15. Total discoveries are calculated as the sum of new field discoveries, new reservoir discoveries in old fields, and extensions.

16. Nonassociated natural gas is natural gas not in contact with significant quantities of crude oil in a reservoir. Associated gas is the volume of natural gas that occurs in crude oil reservoirs either as free gas (associated) or in solution with crude oil (dissolved).

17. The estimated recovery volume data from the U.S. Geological Survey are for conventional resources in undiscovered gas and oil fields in onshore and State offshore areas of the conterminous United States. Thus, the estimates exclude substantial gas volumes that are expected to be recoverable from either unconventional resources, such as coalbed methane gas, or gas in the deep water areas of the Gulf of Mexico.

18. Unit cost estimates are based on an assumed 12 percent after-tax rate of return.

19. See Appendix A for a map defining the U.S. Geological Survey regions. These regions are aggregations of geological provinces, so they do not relate reliably to other regions discussed elsewhere in this report.

20. U.S. Department of the Interior, An Assessment of the Undiscovered Hydrocarbon Potential of the Nation's Outer Continental Shelf, OCS Report MMS96-0034 (Washington, DC, June 1996).

21. Unless otherwise specified, all statistics cited in this section are contained in or derived from Energy Information Administration, Natural Gas Monthly, DOE/EIA-0130(96/11) (Washington, DC, November 1996).

22. Energy Information Administration, Natural Gas Monthly, DOE/EIA-0130(96/11) (Washington, DC, November 1996); Monthly Energy Review, DOE/EIA-0035(96/10) (Washington, DC, October 1996).

23. Data on short- and long-term imports came from U.S. Department of Energy, Office of Fossil Energy, Natural Gas Imports and Exports, First Quarter Report, 1996, DOE/FE-0347-1 (Washington, DC, undated), pp. I-ii. Prices are expressed in the report in terms of dollars per million Btu. These were converted to dollars per thousand cubic feet by applying the conversion factor 1,021 Btu per cubic foot for gas imported from Canada.

24. Regional import statistics were derived from import data from the U.S. Department of Energy, Office of Fossil Energy.

25. Pipeline utilization data are from Natural Resources Canada, Natural Gas Division, Canadian Gas Exports in the U.S. Market: 1995 Evaluation \& Outlook, March 1996 (Ottawa, Ontario, Canada, undated), pp. 10-11.

26. Expansion planning by Canadian (and U.S.) pipeline companies has been made more difficult in the past several years as the U.S. gas industry has been restructured. While pipeline companies were demanding long-term commitments from shippers to reduce the financial risks involved in pipeline construction projects, which are usually very expensive and can take years to complete, producers and others have declined such commitments. This reflects customers' general preference for short-term deals. As a consequence, a consortium of Canadian producers announced plans to build its own pipeline-the "Alliance" project, which would run from northeastern British Columbia through production areas in Alberta and on to the Chicago area. This initiative has drawn competitive responses from a number of pipeline companies, which have proposed additional projects to increase deliverability of Canadian gas. into the United States.

27. U.S. Department of Energy, Office of Fossil Energy, Natural Gas Imports and Exports, Fourth Quarter Report, 1995 (Imports and Exports Fourth Quarter 1995), DOE/FE-0336-4 (Washington, DC, undated), p. vi.

28. Energy Information Administration, Natural Gas Monthly, DOE/EIA-0130(96/11), p. 15. 
29. Energy Information Administration, Office of Integrated Analysis and Forecasting.

30. U.S. Department of Energy, Office of Fossil Energy, Imports and Exports Fourth Quarter 1995, p. vii.

31. Interregional projects included only one new pipeline, the bi-directional Bluewater pipeline between Michigan and Ontario, Canada, with a capacity of 250 million cubic feet per day (MMcf/d). The rest were expansion projects, including the Florida Gas Transmission expansion at $373 \mathrm{MMcf} / \mathrm{d}$ from Louisiana to Alabama, the Tennessee Gas Pipeline Company's Niagara Import Point expansion (92 MMcf/d), and the Northwest Pipeline Phase II expansion (120 MMcf/d), which added only 21 $\mathrm{MMcf} / \mathrm{d}$ at the Canadian border crossing. The others were minor projects such as the Texas Eastern Pipeline expansion from Lebanon, Ohio to the New Jersey/New York area (45 MMcf/d) and the Northern Natural IA-Il expansion of $22 \mathrm{MMcf} / \mathrm{d}$. Between 1990 and 1994, interregional capacity increased by 10 billion cubic feet per day or by almost 14 percent. In 1992, 3,635 million cubic feet, or 5 percent of new capacity was added interregionally. During 1994 and 1995, additions to interregional capacity fell significantly.

32. Represents the sum of additional capacity as measured at each State-to-State crossing point for all pipeline projects shown on Figure 6. As can be seen on the map, several completed projects transited multiple States.

33. Compared with 1992 and 1993, additions to interstate capacity during 1994 and 1995 also fell significantly. On a State-toState basis, interstate pipeline capacity increased by more than 10 percent with the largest increase also in 1992, a 4-percent change for 1992 and 1993.

34. See Energy Information Administration, Natural Gas Monthly, DOE/EIA-013(96/09) (Washington, DC, September 1996).

35. Based on net injections of 1,895 billion cubic feet between April 1 and September 30 in 1996, compared with 1,581 billion cubic feet for the same period in 1995. Calculated on the basis of injections only, the percentage increase was 13 percent between the two periods, 2,208 versus 1,951 billion cubic feet.

36. For the combined Eastern and Midwestern regions of the country, which depend upon underground storage to supplement natural gas supplies during often cold winters, EIA estimates that working gas levels at the start of the 1996-97 heating season will reach more than 1.7 trillion cubic feet. The estimate represents about 86 percent of total working gas capacity in these regions and about 94 percent of the average amount of working gas in storage at the beginning of the past three heating seasons.

37. From an operational standpoint, dipping into base gas in the short term is not detrimental and is considered normal practice at some underground storage sites, particularly late in the heating season. Just how much of the base gas inventory may be withdrawn without consequences depends upon the type of reservoir (aquifer and some water-driven reservoirs may be adversely affected if base gas is withdrawn) and the design specifications of the facilities.

38. Some of the increase in base gas dipping can also be attributed to the fact that FERC has allowed base gas inventory levels to be adjusted upward at a number of sites over the past several years, thus decreasing overall working gas capacity levels. Consequently, part of what is now being reported as base gas withdrawals was once within the working gas envelope.

39. See Energy Information Administration, "The Expanding Role of Underground Storage," Natural Gas Monthly, DOE/EIA013(93/11) (Washington, DC, November 1993). In mid-1993, 68 proposed underground natural gas storage projects, to be completed between 1993 and 1996, had been announced or filed with the Federal Energy Regulatory Commission. Not all of these projects were implemented during the proposed time frame. Some were postponed or canceled. Of the 36 new sites proposed for development through 1995, 26 were completed and placed in service. Because a number of sites were abandoned during the same period and base gas inventory levels were adjusted at some existing sites, actual working gas capacity dropped slightly from 3,848 to 3,828 billion cubic feet from 1993 through 1995 . However, because many of the new sites were high-deliverability, salt cavern storage sites, total daily deliverability increased 5,967 million cubic feet per day, or 9 percent.

40. See Energy Information Administration, The Value of Underground Natural Gas Storage on Today's Natural Gas Industry, DOE/EIA-0591 (Washington, DC, March 1995), Appendix B, Table B1. 
41. Ten storage projects proposed to be implemented during 1994 or 1995 were canceled during the period.

42. Survey information collected by the Interstate Natural Gas Association of America (INGAA) as well as the Energy Information Administration (EIA) shows negligible sales by interstate pipeline companies in 1995. EIA data show that a small volume ( 13 billion cubic feet) of gas was sold by interstate pipeline companies in 1995, which represented only 0.2 percent of deliveries to end users.

43. While specific tariff provisions vary by pipeline company, no-notice service is generally a combination of storage and firm transportation services used to supply additional service upon the shipper's request. No-notice service is used to re-create the quality of service customers previously received through pipeline company sales service. It allows shippers to use their full capacity commitment without advanced scheduling. Local distribution companies frequently supplement their transportation portfolio with no-notice service in order to provide the most reliable service to their high priority customers. Released capacity and no-notice service represented 15 percent ( 3.3 trillion cubic feet (Tcf)) and 18 percent ( $4 \mathrm{Tcf}$ ), respectively, of total gas deliveries to market in 1995, a 15-percent and 29-percent increase over their respective 1994 levels. Energy Information Administration, Office of Oil and Gas, derived from Interstate Natural Gas Association of America, Gas Transportation Through 1995 (September 1996).

44. Largely made up of local distribution companies (LDCs), local companies also include intrastate pipeline companies and producers who deliver gas directly to end users.

45. Energy Information Administration, Office of Oil and Gas, derived from Form EIA-176, "Annual Report of Natural and Supplemental Gas Supply and Disposition."

46. The term "onsystem" refers to volumes and revenues associated with gas sold and delivered by the same entity.

47. In 1995, onsystem sales to commercial and industrial customers represented 77 percent and 24 percent of total deliveries, respectively, compared with 79 percent and 25 percent, respectively, in 1994. Total deliveries represent the total volume of gas delivered to consumers, including sales to and transportation for consumers. Onsystem deliveries to residential, commercial, and industrial customers, and total deliveries to electric utilities increased from 12.185 trillion cubic feet (Tcf) in 1994 to $12.434 \mathrm{Tcf}$ in 1995, an increase of 2 percent. Energy Information Administration, Office of Oil and Gas, derived from Natural Gas Annual 1995, DOE/EIA-0131(95) (Washington, DC, November 1996).

48. Between 1994 and 1995 , the unit transmission and distribution cost for residential, commercial, and industrial sales decreased by 3.4 percent, 4.6 percent, and 5.7 percent, respectively. The unit transmission and distribution cost for total deliveries to electric utilities increased by 7 percent. Energy Information Administration, Office of Oil and Gas, derived from Natural Gas Annual 1995 (November 1996).

49. Unless otherwise stated, annual data in this section come from Energy Information Administration (EIA), Natural Gas Annual 1995, DOE/EIA-0131(95) (Washington, DC, November 1996), Table 1, and monthly data come from EIA, Natural Gas Monthly, DOE/EIA-0130(96/11) (Washington, DC, November 1996), Tables 3 and 4.

50. Data on natural gas consumption are available beginning in 1930. In $1972,19,880$ billion cubic feet of natural gas was consumed by end users.

51. Heating degree days are gas home customer-weighted heating degree days provided in Energy Information Administration, Natural Gas Monthly, DOE/EIA-0130(95/04) and (96/04) (Washington, DC, April 1995 and 1996), pp. 71 and 72 in both issues.

52. Gas used in new homes included both natural gas and liquefied petroleum gas. U.S. Department of Commerce, Bureau of the Census, Housing Completions Report 1995, C22/96-6 (Washington, DC, June 1996), p. 8, Table 7A.

53. Energy Information Administration price data are for onsystem sales only in the residential, commercial, and industrial sectors. Virtually all residential consumption is through onsystem sales, thus residential prices represent total deliveries in this sector. The proportion of consumption that is onsystem in the commercial and industrial sectors has generally declined in recent years. In 1995, 77 percent of commercial consumption was onsystem, while only 24 percent of industrial 
consumption was onsystem. The price of gas to electric utilities covers virtually all gas deliveries in this sector, whether onsystem or offsystem.

54. Energy Information Administration, Form EIA-867, "Annual Nonutility Power Producer Report."

55. In this discussion, the fuel prices at each plant represent the average price for each type of fuel used at the plant. For example, a plant may use some residual and some distillate fuel oil to ignite coal. The price data would then include an average coal price and an average oil price for this plant.

56. Temperature data are the mean average daily temperatures in Kansas City, Missouri; Chicago, Illinois; Pittsburgh, Pennsylvania; and New York, New York. These cities were selected because they are representative of large gas markets in the areas affected by cold weather in both heating seasons.

57. Michigan Consolidated had its highest deliveries of gas in 20 years. ANR Pipeline experienced its most consecutive days (6) of over 5 billion cubic feet of throughput. Natural Gas Pipeline of America had its highest throughput in 15 years.

58. Several local distribution companies reported gas use that was 60 percent higher than normal for a day in January. Twelve pipeline companies met or exceeded record weekly throughput and eight pipeline companies set records for daily throughput.

59. Records on monthly storage withdrawals begin in September 1975. The highest monthly withdrawal was 805 billion cubic feet in December 1989.

60. Pasha Publications, Inc., Gas Daily (February 6, 7, and 9, 1996); and Gas Daily's NG (April 1996). Imbalance penalties are extraordinary tariffs that a pipeline operator may impose on a transportation customer when that individual or organization fails to have the contracted volume in the pipeline's system at the agreed-upon time (usually a daily measure).

61. For further discussion of the premium, see Energy Information Administration, The Value of Underground Storage in Today's Natural Gas Industry, DOE/EIA-0591 (Washington, DC, March 1995), Chapter 2.

62. Pasha Publications, Inc., Gas Daily (January 23, 1996).

63. The citygate is the point at which the local distribution company takes receipt of gas.

64. Ben Schleisinger \& Associates, Directory of Natural Gas Marketing Service Companies, 9th Ed. (1995).

65. Company applications to the Federal Energy Regulatory Commission.

66. Federal Energy Regulatory Commission, Docket No. RM95-6, Alternatives to Traditional Cost-of-Service Ratemaking for Natural Gas Pipelines (January 31, 1996).

67. Texas Eastern Transmission Corporation, Docket No. CP95-218 (January 31, 1996).

68. Federal Energy Regulatory Commission, Docket No. RM96-14-000, Secondary Market Transactions on Interstate Natural Gas Pipelines (July 31, 1996).

69. Bidding is required for all releases exceeding 31 days with rates less than the maximum tariff rate, and for rollovers of 31 days or less with rates less than the maximum tariff rate.

70. Deep water in the context of this report refers to water depths of 200 meters (roughly 656 feet) or greater.

71. Oil Daily, "Industry Takes Satellite out for Test Drive to Transmit Offshore Seismic Data to Land" (February 24, 1996) (http://www.newspage.com...223203.4od.tod00000.htm). 
72. The Act pertains to projects in the Western and Central Planning Areas of the Gulf of Mexico and the portion of the Eastern Planning Area encompassing whole lease blocks lying west of 87 degrees, 30 minutes West longitude. Under the provisions of the Act, royalty payments are waived on the first 17.5 million barrel-of-oil-equivalent (BOE) produced in 200-400 meter waters, 52.5 million BOE in 400-800 meter waters, and 87.5 million BOE in water depths beyond 800 meters. (The 200, 400 , and 800 meter thresholds are approximately $656,1,312$, and 2,625 feet.) This waiver is suspended in any year during which crude oil prices exceed $\$ 28.00$ per barrel or natural gas prices exceed $\$ 3.50$ per million Btu.

73. These data are drawn from two articles: Dallas Morning News, "Deep-water oil lease bids surge" (April 26, 1996); and Natural Gas Week, "Royalty Relief, New Technology Spur Record-Setting Lease Sale" (April 29, 1996).

74. Foster Associates, Inc., Foster Natural Gas Report, No. 2075 (Washington, DC, April 11, 1996), p. 27.

75. Stranded costs are the value of utility activities that regulators allowed or even required companies to undertake that exceed the value that would be assessed to the activities in a competitive market.

76. Stranded cost estimates range from zero to about $\$ 300$ billion, but industry supporters generally use estimates of about $\$ 135$ billion.

77. Wholesale customers will be required to arrange to repay costs stranded on their behalf in order to gain access to the transmission network. The Federal Energy Regulatory Commission regulates about 15 percent of investor-owned electric utility revenues.

78. Debates on the disposition of State jurisdictional stranded costs are currently under way. Several States are experimenting with retail access programs modeled on programs to allow competing gas service.

79. H.R. 3790, The Electric Consumers Power to Choose Act of 1996. Committee review and floor debate have not yet occurred.

80. One example of the extent of the stranded costs problem is especially important to the gas industry. Many electric utilities want to include the excess cost of Public Utility Regulatory Policies Act of 1978 (PURPA) qualifying facility (QF) contracts in stranded costs. PURPA required electric utilities to purchase electricity generated by QFs at the utility's avoided cost. In many States, avoided costs were set by administrative studies based on past utility-plant construction costs and expectations for escalating oil prices. These contracts allow QFs to sell power at prices that exceed current cost estimates. Since a majority of the power sold under these contracts is from gas-fired facilities, gas demand for nonutility generation could decline if electric utilities are not allowed to recover the cost of these contracts from final customers.

81. Building on its successful innovation in gas markets, the New York Mercantile Exchange (NYMEX) introduced electricity futures contracts for two separate West Coast markets in the spring of 1996. Progress in electricity futures trading is slow because of the lack of well-developed spot markets against which futures prices could be leveraged.

82. Detailed information about the specific energy-consuming activity and equipment would be needed to make efficiency adjustments for more direct price comparisons. 



\section{Changes in Firm Transportation Capacity Contracting}

Shippers in today's natural gas market are under increasing pressure to manage their gas supply and transportation portfolios efficiently to reduce costs. When possible, they are choosing some of the new services that compete with primary firm transportation services offered by interstate pipeline companies, such as high-deliverability storage, "high quality" interruptible capacity, released capacity, and market center services.

Under Order 636, the "restructuring rule" issued by the Federal Energy Regulatory Commission (FERC) in April 1992, firm sales entitlements of pipeline companies' customers were converted to firm transportation rights. However, Order 636 provided little opportunity for customers to reduce their firm commitment levels. ${ }^{1}$ With the changes in rate design, development of new services, and the ability to identify the cost of each component of natural gas service, customers are finding that the long-term contracts entered into years earlier may no longer reflect current market conditions. In addition, demand has not increased as much as expected in some areas because of changes in regional economies, as well as increases in energy efficiencies and greater conservation efforts. Consequently, available firm capacity exceeds customers' requirements along some pipeline routes.

The cost of firm transportation has also become more expensive for some shippers because of the current rate design method. Order 636 changed the way rates are calculated by requiring pipeline companies to use the straight fixed-variable rate design, which increases the costs of reserving capacity but lowers the variable cost of the gas transported. Shippers whose peak-period needs for capacity are very high compared with their average needs are particularly affected by this change.

Some shippers have reduced their capacity costs by using the capacity release market, which was established under Order 636. This market allows shippers to resell unused firm transportation capacity as long as rates do not exceed the maximum regulated rate. ${ }^{2}$ In practice, however, most capacity rights have been traded at substantial discounts, which limits the market's effectiveness in offsetting the high costs of

\footnotetext{
'Order 636-A did permit firm customers to reduce or terminate capacity entitlements if another customer contracted for and assumed liability for the cost of the capacity or the pipeline company assumed responsibility for the capacity and associated costs. Federal Energy Regulatory Commission, Order 636-A, 57 F.R. 36128 (August 12, 1992).

${ }^{2}$ The Federal Energy Regulatory Commission issued a Notice of Proposed Rulemaking on July 31,1996 , which proposes to remove the price cap on released capacity provided the releasing shipper can demonstrate that it does not exercise market power (Docket No. RM96-14).
}

reserving firm capacity. The market also has been hindered by its somewhat cumbersome posting and transaction procedures. In some cases, shippers instead repackage unneeded capacity with another service and sell rebundled services outside their usual market area (the "gray market").

Because the capacity release and gray markets have not solved the long-term problem of excess capacity commitments, some shippers have "turned back" all or part of their capacity commitments when these contracts come up for renewal. This has significant implications for the natural gas market and raises a number of issues for shippers, pipeline companies, and regulators.

The extent and implications of a reduction in the amount of capacity reserved is an emerging concern for the transportation industry. Turnback of pipeline capacity, which was limited to two U.S. geographic regions (West and Midwest) in 1995 and 1996, could increasingly become a nationwide challenge. Between April 1, 1996, and December 31,2001 , contracts covering 51 percent of transportation capacity (under contract as of April 1, 1996) will expire. In monetary terms, the potential impact of capacity turnback is significant. If pipeline companies are unable to remarket 20 percent of the capacity expiring through 2001, for example, it would represent at least a $\$ 686$ million reduction in annual pipeline revenues. ${ }^{3}$

Pipeline cost recovery is a major concern in this circumstance. Increasing rates to remaining customers is not a viable solution since this would lead to even further reductions in capacity reservations. Such rate increases would make it difficult for pipeline companies in competitive markets to attract new customers and may drive their current customers to other transporters, services, and service providers.

Capacity turnback may signify a period of adjustment for the transportation market similar to the transition from long-term to short-term and spot contracts that occurred in the wellhead market for gas in the 1980's. Over the long term, the current

\footnotetext{
${ }^{3}$ The $\$ 686$ million annual reduction in pipeline company revenues was estimated using the amount of capacity due to expire through the year 2001 and firm transportation tariff rates for a sample of 44 interstate pipeline companies. In order to estimate the minimum revenue impact of contracts that are not renewed, it was assumed that the lowest firm transportation rate for each pipeline company would apply to the full expiration amount. Transportation rates were taken from H. Zinder \& Associates, Summary of Rate Schedules of Natural Gas Pipeline Companies (March 15, 1996). The product of the transportation rates and capacity expirations was multiplied by 0.2 to estimate the annual reduction in pipeline company revenues for 20 percent of contracted capacity.
} 
changes may lead to the development of alternative products to current transportation services. Other possibilities include a spot market for transportation, increased commoditization of capacity, and the development of financial instruments for the transportation market.

This chapter focuses on the development of excess capacity commitments by shippers and the potential implications of capacity turnback for the transportation market. The chapter also discusses the use and effectiveness of the secondary capacity market for reducing capacity commitments and costs. In addition, it quantifies the potential for capacity turnback and examines three cases of large turnbacks that occurred in 1995 and 1996 to assess pipeline company approaches, financial impacts, and evolving regulatory policy.

\section{Factors Leading to Excess Capacity Commitments}

Industry restructuring, deregulation of the wellhead market, availability of new competing services, as well as changes in gas supply, regional economies, and system deliverability are contributing factors to a reduced need for long-term firm capacity reservations (see box, p. 41).

\section{Regulatory Changes}

Until the mid-1980's, all interstate natural gas pipeline companies were primarily gas merchants, combining gas sales with transportation. They would purchase natural gas from producers, transport it largely along their own proprietary pipeline system, and resell the rebundled product to local distribution companies (LDCs) and other large customers. The prices paid by customers reflected the cost of gas and all services required for delivery. This institutional structure, together with the relatively concentrated nature of the interstate pipeline industry, meant that each producer could sell gas to a limited number of buyers (pipeline companies). Moreover, LDCs and large end users usually had limited options in terms of the number of pipeline companies from which they could purchase gas. ${ }^{4}$

Under this market structure, interstate pipeline company rates were regulated by $\mathrm{FERC}$, and distribution rates charged by LDCs to move gas from the citygate to end users were regulated by State regulatory agencies. ${ }^{5}$ Traditionally,

\footnotetext{
'Small end users, such as residential customers, had no choice but to purchase gas from LDCs.

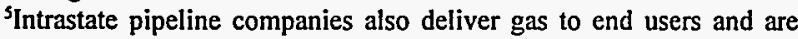
governed by State regulatory agencies.
}

pipeline companies and LDCs are allowed to charge prices that recover all reasonable costs of delivering gas to their customers. In practice, most of the costs fall on the captive customers who have no other options for obtaining gas service. Also, regulators have traditionally required LDCs to purchase sufficient pipeline capacity to meet their maximum seasonal requirements for firm sales service. Under these circumstances LDCs tended to enter into long-term firm transportation contracts with pipeline companies, which both parties perceived would reduce contract management costs, protect their capital investments, reduce deliverability uncertainties, and lock-in price terms. Both the industry and regulators believed that long-term contracts would provide the stability and service reliability necessary for investment in a capital-intensive industry.

Long-term security came at a cost, usually to the captive customers of pipeline companies and LDCs. Capacity commitments and gas flows were based largely on moving gas along proprietary systems. Many customers paid maximum regulated rates for their gas service. There was little opportunity for savings from rerouting the flow of gas, moving gas from one system to another, and entering into alternative contract vehicles. LDCs were required to reserve sufficient capacity to meet their maximum loads, although this meant that for the rest of the year they were paying for unused capacity and passing these costs to their customers.

FERC restructured interstate pipeline company services during the 1980's and early 1990's and transformed the way the industry operates. Among other things, FERC abolished pipeline company bundled services; adopted a uniform transportation rate design method; and established a secondary market for storage and pipeline capacity. Under the new market structure, natural gas customers can build and manage a portfolio of supply, storage, and transportation services that best meets their needs.

Concurrent with Federal regulations, State regulators offered incentives for LDCs to increase efficiency and reduce operating costs. A number of States established incentive-rate mechanisms that allowed LDCs to keep a portion of any savings derived from managing their gas supply and transportation portfolios more efficiently. As States unbundle LDC sales and transportation for smaller customers, LDCs may face increased pressure to reduce their service costs (see Chapter 6).

A direct consequence of industry restructuring and regulatory reform is that the mix of various natural gas services has changed. New services that compete directly with long-term capacity are commonplace compared with just a few years ago. Market hubs offer an array of services that allow shippers to "park" and reroute gas to bypass system bottlenecks. New storage and liquefied natural gas (LNG) 


\section{Factors Leading to Capacity Turnback}

\section{Industry Restructuring}

- Increased options for shippers to ship gas.

- Shippers reduced use of sales service.

- New market center services and improved grid integration.

- Increased use of high-deliverability and market area storage.

- Improved access to U.S. and Canadian suppliers.

\section{Regulatory Reform}

- Capacity reservation is more expensive for low load customers under the new straight fixed-variable rate design.

- Price offsets from releasing excess capacity onto the capacity release market are limited (rate cap and large discounts).

- Incentive rate programs established by states that encourage LDCs to cut costs.

\section{Competition}

- Shippers are under pressure to reduce costs to remain competitive.

- Development of downstream alternatives to firm transportation.

- Expansion of pipeline and storage capacity.

\section{Other}

- Changes in regional economies result in lower than expected gas demand.

facilities give shippers additional access to gas sources to meet peak-day requirements. LDCs can now substitute a mix of high-deliverability storage, short-term firm transportation, interruptible transportation, released capacity, and gray market transportation for long-term firm transportation (FT).

With cost-conscious shippers seeking cheaper alternatives to expensive FT capacity, a number of specific conditions have made long-term firm capacity contracts increasingly unattractive. For example, the cost of reserving pipeline capacity is more expensive. FERC Order 636 requires interstate pipeline companies to develop rates using a straight fixed-variable method. This new tariff design made it more expensive for most gas shippers to reserve pipeline capacity, but lowered the usage charge for transported gas. This change especially affects low-load-factor customers (customers whose ratio of annual gas throughput to reserved capacity is low) who must reserve sufficient pipeline capacity to meet seasonal peak demand. Low-load-factor customers now pay significantly more to transport gas because of the higher capacity reservation fee, even though the usage fee paid for the actual quantity of gas shipped has declined.

LDCs who must reserve enough capacity to meet peak demand during cold winters are examples of low load customers that are hurt by the change to straight fixedvariable rates and therefore may seek alternative arrangements to long-term firm transportation. For example, a 1995 Energy Information Administration report found that low-load-factor customers of a sample of U.S. pipeline companies consistently had changes in rates between 1991 and 1994 that were less advantageous than for the high-loadfactor customers. ${ }^{6}$ For some LDCs, the cost of reserving firm pipeline capacity has also increased because of discounts given to other customers. FERC permits pipeline companies to discount prices for competitive services in order to retain customers and to recover the revenue reduction from remaining firm customers.

For many firm capacity holders, releasing unused firm transportation (FT) capacity on the secondary market generally does not offset the expense of reserving the capacity. FERC Order 636 established a secondary or capacity release market that enables shippers to resell their excess FT capacity. Depending on the price for the released. capacity, this mechanism had the potential to offset the expense of reserving long-term FT capacity. Because of the cumbersome nature of this market and the low prices received for released capacity, however, shippers have released only small amounts of capacity and at prices that do not offset

\footnotetext{
'Energy Information Administration, Energy Policy Act Transportation Study: Interim Report on Natural Gas Flows and Rate, DOE/EIA-0602 (Washington, DC, October 1995), p. 48. The study found that for customers with low load-factors, two-thirds of sampled pipeline companies had rate increases between 1991 and 1994. Further, for each company in the sample, the increase was larger in both absolute and percentage terms for the lowload-factor ( 40 percent) customers than for those with a 100-percent load factor.
} 
reservation costs. Consequently, shippers are looking for other alternatives to deal with unused, long-term FT capacity.

\section{Changes in Regional Economies}

Expected increases in gas demand and the need for operational flexibility led to a 14-percent increase in interregional pipeline capacity between 1990 and $1994 .{ }^{7}$ Of the total 10.4 billion cubic feet per day of pipeline capacity added during this period, 3.7 billion cubic feet per day was new capacity built to import gas from Canada to the Northeast, Central, and Western United States.

Much of the new pipeline capacity was built on the premise that natural gas markets would expand at a much faster pace than has proved to be the case. Although U.S. gas demand increased at an average annual rate of more than 3 percent between 1986 and 1995, growth was lower than expected because of increases in energy efficiency, greater conservation efforts, relatively slow growth in gas use by energy-intensive industries and electric utility generators. As a result, excess pipeline capacity has developed in some regional markets, contributing to the risk of capacity turnback by gas shippers who now have more transportation options.

In California, new pipeline capacity was built by Pacific Gas Transmission Company and Kern River Transmission Company to ship relatively inexpensive natural gas from Canada and the U.S. Rockies. Pipeline capacity into the Western Region, primarily designed to increase access to Canadian supplies, increased by 41 percent between 1990 and 1994. As a result, LDCs and other pipeline customers have begun to relinquish capacity on the older pipelines, which access more expensive production from the Permian Basin of Texas and the Anadarko Basin of western Oklahoma, as their contracts expire. One indication of the growth of excess capacity in the Western Region is the fact that the pipeline capacity utilization rate declined from 84 percent in 1990 to 71 percent in $1994 .^{8}$

\section{Short-Term Solutions to Excess Capacity Commitments}

There are three methods currently available to shippers who wish to reduce their capacity costs:

\footnotetext{
'Energy Information Administration, Energy Policy Act Transportation Study: Interim Report on Natural Gas Flows and Rates, p. 32.

${ }^{8}$ Energy Information Administration, Energy Policy Act Transportation Study: Interim Report on Natural Gas Flows and Rates, p. 32.
}

- The capacity release market - wherein shippers may offer the rights to some or all of their firm capacity in exchange for revenue credits

- The gray market - wherein shippers may bundle their unneeded capacity with additional service and sell the rebundled package to others

- The turnback of capacity - wherein shippers, when their contracts expire, return or "turn back" all or part of their firm contracted capacity to the pipeline company.

The first two options are short-term solutions that are discussed in this section. The third is a permanent solution to excess capacity and is discussed separately later in the chapter.

\section{Capacity Release}

The release market offers several advantages for the selling or "releasing" shipper:

- Allows shippers to respond quickly to market changes. The capacity release market operates every business day, and releasing shippers are not required to provide excess lead time before posting their releases.

- Includes flexible terms with respect to amount of capacity and duration of release. A shipper may release all or only part of its capacity for as little as a day or as long as the duration of its contract with the pipeline company.

- Releasing shippers may set specific pricing terms, subject to the maximum regulated rate cap. They may request rates based on capacity reserved, capacity used, or rates that are indexed to a particular benchmark.

- Releasing shippers may reserve the right to recall the capacity. By placing a recall option on the released capacity, the releasing shipper avoids any risk to ongoing operations. The releasing shipper may reclaim the capacity from the replacement shipper when market or operating conditions reach a predetermined level.

The capacity release market also offers many advantages to "replacement" shippers who purchase the released capacity:

- Moderate lead time required. The acquisition of capacity on the release market requires very little lead time. This allows the replacement shipper to use the capacity release market to satisfy incremental loads 
economically instead of subscribing to firm capacity that may be underutilized.

- Flexible terms with respect to duration of contract. The replacement shipper can acquire capacity for the period it will be needed instead of being constrained by standard contract periods.

- Ability to obtain capacity. The replacement shipper is able to obtain firm capacity even when the pipeline is fully reserved.

- Released capacity is usually priced below tariff rates. The replacement shipper often can acquire released capacity at a fraction of the maximum regulated rate.

However, the capacity release market has some significant drawbacks that can more than offset the advantages and could present obstacles for both releasing and replacement shippers. The disadvantages include:

- Some of the electronic bulletin boards (EBBs), through which the release market is accessed, are cumbersome. Released capacity is posted on pipeline company EBBs, each of which can have a different user interface. Therefore, shippers would need to learn the operating methods of several EBBs to access a desired flow path.

- Coordination of multiple contracts may be difficult. A replacement shipper wishing to acquire several segments (parcels) of released capacity to ensure access to a specific supply area might not be able to close deals simultaneously. The shipper might have to acquire the desired segments of capacity in a piecemeal fashion. If the shipper fails to acquire a critical segment of capacity, then the acquired segments could be of less use. ${ }^{9}$

- Released capacity rates are less than tariff rates for firm capacity. During the nonheating season when capacity is plentiful, rates are well below tariff rates. Even during the heating season, the price for released capacity is capped at the maximum tariff rate. ${ }^{10}$ Therefore, on average, releasing shippers might receive

\footnotetext{
"The capacity release procedures, adopted by the Federal Energy Regulatory Commission (FERC) in its Order 587, may help alleviate the coordination problem. Beginning April 1, 1997, pipeline companies must establish procedures to process capacity release transactions within one hour of receipt if the transaction is a prearranged deal, not subject to bidding, and within one day if the deal is subject to bidding. FERC Docket No. RM96-1000 (July 17, 1996).

${ }^{10}$ On July 31, 1996, FERC issued a Notice of Proposed Rulemaking that proposes to remove the price cap on released capacity provided the releasing shipper can demonstrate that it does not exercise market power (Docket No. RM96-14).
}

only a fraction of the amount they paid for the capacity, which might provide only a partial offset for the cost of reserving firm capacity.

- Released capacity may be unavailable. Particularly during peak periods, released capacity might not be available or offered for release.

\section{Activity in the Capacity Release Market Continues to Grow}

The release market has grown steadily in terms of capacity traded, indicating that shippers are becoming experienced in capacity trading. When capacity held by replacement shippers is considered over entire heating and nonheating seasons, two patterns emerge. First, the overall amount of capacity held by replacement shippers has increased year to year. The amount of capacity held by replacement shippers during the 12 months ended March 31, 1996, was 5.8 trillion cubic feet, or 59 percent more than the 3.2 trillion cubic feet held for the 12 months ended March 31, 1995.

The increase in release activity was mirrored in the heating (November through March) and nonheating (April through October) seasons (Figure 14)." Although the growth in capacity held by replacement shippers during the heating seasons slowed from its initial pace, there was still a significant overall increase between the 1994-95 and 1995-96 heating seasons (Figure 15). The amount of capacity held by replacement shippers during the 1994-95 heating season was 1,587 billion cubic feet (Bcf), over two and onehalf times the 1993-94 level. The capacity held by replacement shippers during the 1995-96 heating season increased to 2,451 Bcf, which is 54 percent higher than the 1994-95 level. The capacity held during nonheating seasons also grew. Capacity held during the 1995 nonheating season was 3,324 Bcf, representing a 63-percent increase over the amount held during the 1994 nonheating season.

The amount of capacity held by replacement shippers during the heating and nonheating seasons may indicate that many holders of firm capacity are using the release market to shed unneeded capacity year-round. The level of capacity held by replacement shippers represents a significant amount of interstate pipeline capacity. As much as 23 percent of the

\footnotetext{
"The total volume of released capacity held by replacement shippers during a season is the sum of the capacity effective on each day of the season. For example, if a 60-day contract for $Z$ thousand cubic feet per day is effective within a season, then the sum of capacity held for the season would include $\mathrm{Z}$ thousand cubic feet 60 times for that contract. If that 60-day contract were only effective, for example, for the last 20 days of the season, then the sum for the season would include $Z$ thousand cubic feet 20 times, and the sum for the next season would include $Z$ thousand cubic feet 40 times for that contract.
} 
Figure 14. Seasonal Capacity Held by Replacement Shippers, November 1993 - March 1996

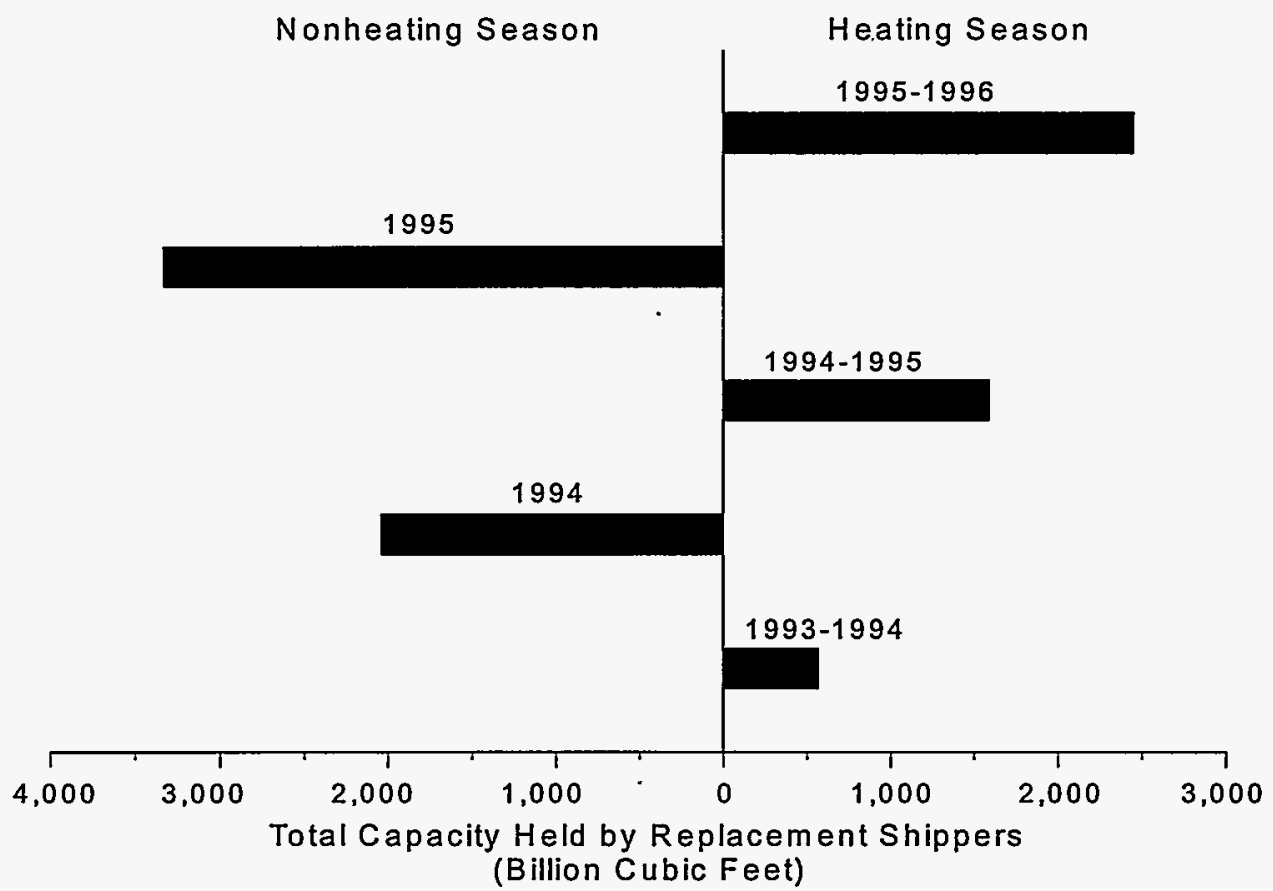

Note: The nonheating season extends from April through October, and the heating season is from November through March.

Sources: Energy Information Administration, Office of Oil and Gas, derived from: November 1993 - July 1994: Pasha Publications, Inc. July 1994 - March 1996: Federal Energy Regulatory Commission, Electronic Data Interchange (EDI) data.

Figure 15. Index of Capacity Held by Replacement Shippers During Heating Seasons

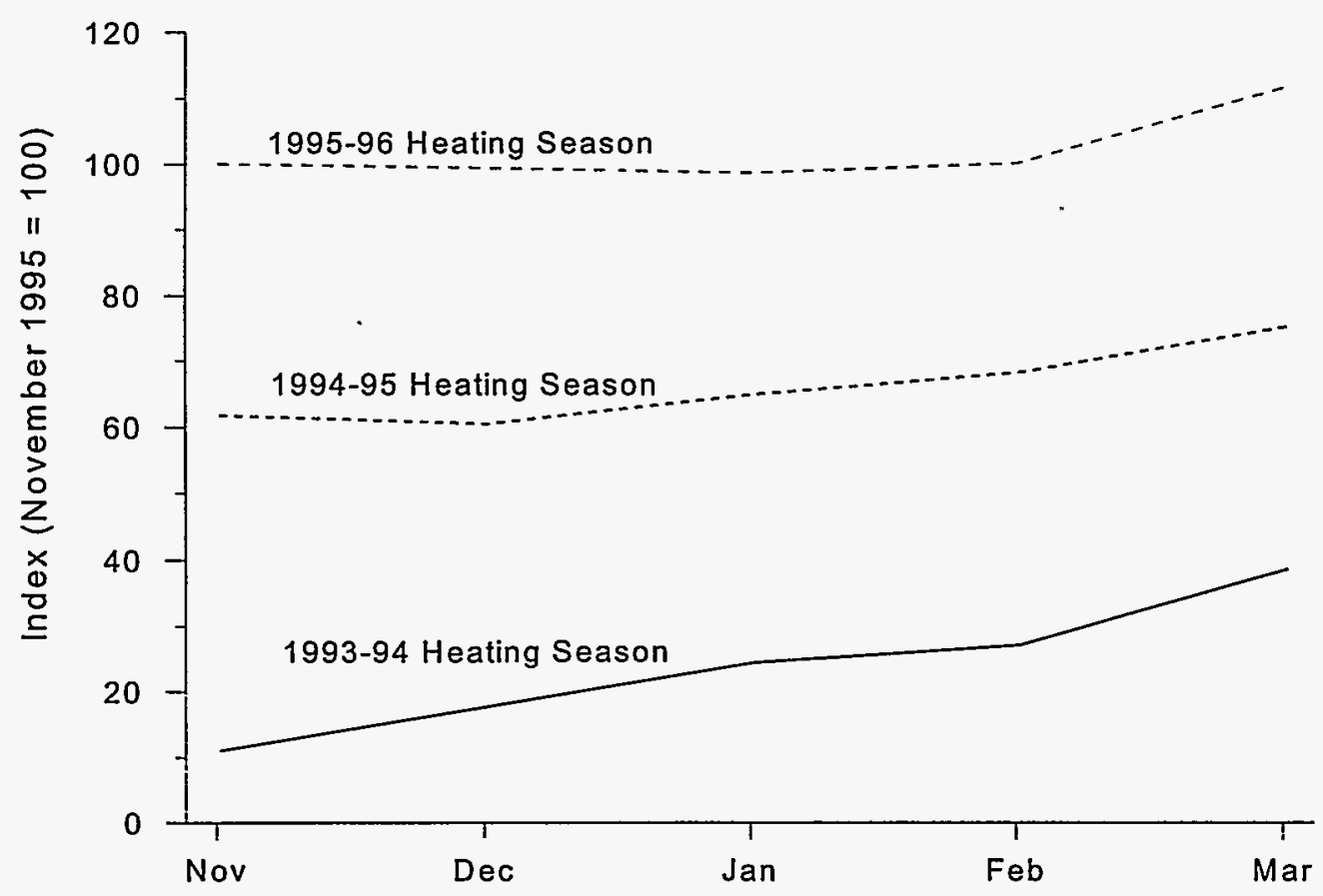

Sources: Energy Information Administration, Office of Oil and Gas, derived from: November 1993 - July 1994: Pasha Publications, Inc. July 1994 - March 1996: Federal Energy Regulatory Commission, Electronic Data Interchange (EDI) data. 
deliveries to end users could have moved using released capacity during the 1995-96 heating season. The fact that a large amount of capacity is available for release during the peak season also indicates that shippers are holding a substantial amount of unneeded capacity.

The second pattern that can be seen in the capacity release market is the distinct seasonal patterns of capacity held by replacement shippers (Figure 16). ${ }^{12}$ The daily amount of capacity held by replacement shippers generally grows from the beginning of the nonheating season until it peaks just before the beginning of the heating season. Then the amount of capacity held gradually falls until the middle of the heating season when it begins to climb again. The downturn in capacity held by replacement shippers may be due to releasing shippers retaining their capacity rights until they are more certain what their own needs will be.

The sharper downturn experienced during the 1995-96 heating season may have been caused by the colder weather in the 1995-96 heating season compared with the 1994-95 heating season..$^{13}$ During the 1995-96 heating season, consumption and capacity utilization increased, leaving less capacity available for shippers to release (see Chapter 1). Unusually low levels of working gas in storage heading into the 1995-96 heating season also may have been a factor in the sharper decline in capacity held by replacement shippers. ${ }^{14}$

An important feature of the capacity release program is that the releasing shipper may include with the release a provision that allows the shipper to recall the capacity. About 63 percent of the capacity held between April 1, 1995 and March 31, 1996 had recall provisions. Unfortunately, no data are available on the amount of capacity that has actually been recalled once the replacement contracts became effective. Such data would be very useful in understanding how the industry is using the capacity release market, especially during times of extremely cold weather such as the 1995-96 heating season.

\footnotetext{
12The amount of capacity held by replacement shippers on any day is the sum of all capacity for which a contract is effective on that day. For example, if a contract for $\mathrm{X}$ million cubic feet of released capacity was effective March 1-March 31, 1996, then X million cubic feet from this contract would be included in the total, daily capacity held for March 1-March 31, 1996. See Appendix B for a description of the data sources and methodology used to calculate the amount of capacity held by replacement shippers.

${ }^{13}$ The 1995-96 heating season was 15 percent colder than the 1994-95 heating season as measured by heating degree days. Energy Information Administration, Natural Gas Monthly, DOE/EIA-0130(96/04) (Washington, DC, April 1996).

${ }^{14}$ Working gas was 2,495 billion cubic feet (Bcf) in August 1995 and 2,802 Bcf in September 1995. These were the lowest levels for these months since 1976.
}

There is evidence that indicates replacement shippers are using the capacity release market as a rapid response source of capacity. Of the capacity traded since November 1, 1993, 90 percent became available for use by replacement shippers within 2 weeks of the contract award date. For the released capacity under contracts in effect during the 1995-96 heating season, 90 percent of the awarded capacity was under contracts that became effective within the.first 2 weeks after they were awarded. Also, 79 percent of the capacity awarded was under contract for terms of 31 days or less. This, along with the increase in capacity held by replacement shippers during the last 2 months of the heating season, implies that there was sufficient excess capacity for new releases to occur, even though 65 percent of the capacity held by replacement shippers that season was subject to recall.

\section{Revenues from Capacity Release Activity Have Also Increased}

Revenues generated from released capacity total $\$ 1.2$ billion for transactions between November 1993 (when the program began) and March 1996. Generally, the trend in revenue received from released capacity has paralleled the trading activity of the release market. Total revenue from released capacity increased by 81 percent, from $\$ 388$ million for the 12 months ended March 31,1995 , to $\$ 702$ million for the 12 months ended March 31, 1996. ${ }^{15}$ In comparison, total transportation and distribution revenues for 1995 were approximately $\$ 32$ billion. ${ }^{16}$

Capacity release revenues received during the heating season and nonheating season also rose. Total revenue from released capacity doubled between the 1993-94 and 1994-95 heating seasons, from $\$ 78$ to $\$ 173$ million, and doubled again to $\$ 392$ million during the $1995-96$ heating season. The revenue from released capacity during nonheating seasons increased by 44 percent, from $\$ 215$ million in 1994 to $\$ 309$ million in 1995.

While the increase in release activity was partially responsible for the growth in revenues, it appears that the average price for capacity traded during the heating season has also increased. The average monthly price for released capacity during the heating season increased by 47 percent, from $\$ 3.31$ per thousand cubic feet (Mcf) in the 1994-95 heating season to $\$ 4.87$ per Mcf in the 1995-96 heating season. In contrast, the average monthly price of capacity released during the

\footnotetext{
${ }^{15}$ All the revenue and volume calculations have been performed assuming no recall and 100-percent load factor. In other words, it is assumed that the total capacity awarded will be used by the replacement shipper (see Appendix E).

${ }^{16}$ Unless noted otherwise, dollar amounts are stated in nominal terms.
} 
Figure 16. Capacity Held by Replacement Shippers, November 1993 - March 1996

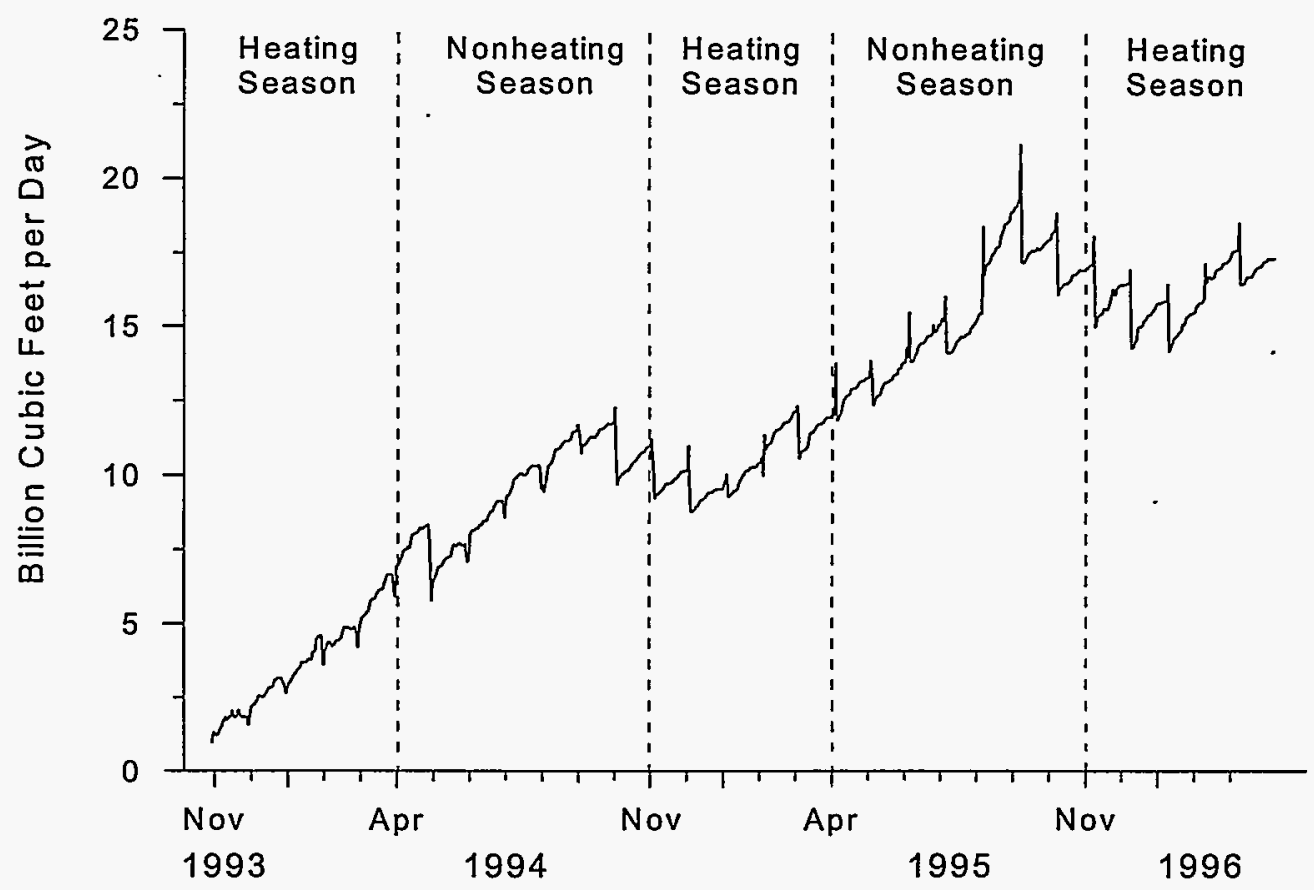

Sources: Energy Information Administration, Office of Oil and Gas, derived from: November 1993 - July 1994: Pasha Publications, Inc. July 1994 - March 1996: Federal Energy Regulatory Commission, Electronic Data Interchange (EDI) data.

nonheating season has declined by 12 percent, from $\$ 3.21$ per Mcf in 1994 to $\$ 2.83$ per Mcf in 1995. This reduction possibly is the result of the increased availability of capacity during the nonheating season in 1995-96 and the relatively high storage levels at the end of the 1994-95 heating season that lessened the need to build storage inventories during the nonheating season.

The increase in the average price for released capacity during the heating season can be the result of several factors. First, the increase in capacity held by replacement shippers may indicate that more shippers are looking to the capacity release market to satisfy their transportation requirements. This boost in demand for released capacity could be pushing up the price. Second, weather conditions may be influencing the average price of capacity. The average rate was lowest in the 1994-95 heating season when the winter was mildest, and the average rate was highest in the 1995-96 heating season during the prolonged cold winter.

The average term of the contract duration for the released capacity has grown for contracts that became effective during the heating season, from 60 days in 1994-95 to 90 days in 1995-96. This could indicate that the released capacity is more valuable. It may also indicate that releasing shippers have an improved understanding of the extent of their excess capacity or have alternative methods of meeting loads. Much of the increase in contract duration was due to several longterm releases of capacity. Nevertheless, the median contract term for the past two heating seasons increased from 29 days in 1994-95 to 31 days in 1995-96.

The increase in average rates resulted in heating season revenues exceeding the nonheating revenues for the first time during the 1995-96 period. The 1995-96 heating season revenues were over 27 percent greater than the nonheating season revenues, although the heating season is only 5 months long compared with 7 months for the nonheating season.

Notwithstanding the increase, average rates for released capacity are still well below maximum tariff rates. The rates were discounted, on average, 65 percent from the maximum rates during the 1995-96 heating season, and 83 percent during the 1995 nonheating season. Although the average discount amount has declined compared with the previous seasons ( 82 percent and 92 percent for the 1994-95 heating and 1994 nonheating seasons, respectively), it appears that the capacity release market still does not fully compensate releasing shippers for their firm capacity costs. FERC's recent 
proposals to change the secondary market ${ }^{17}$ may affect the rates for released capacity in the future (see Chapter 1).

\section{Regions Have Quite Different Capacity Release Markets}

The trends in the capacity release market for some regions differ markedly from the national trends. For example, the national release market, on average, experiences more activity and higher prices during the heating season, but not all regions experience the activity increase during that season. The Southeast and Southwest regions may be driven by summer consumption for cooling rather than the winter heating demand. Also, the level of trading in these regions is an order of magnitude less than the level in other regions. Nevertheless, capacity release revenues increased for the 1995-96 heating season in all regions except the Southeast compared with the 1994-95 heating season (Figure 17). The Midwest Region had the largest percentage increase, with 1995-96 heating season revenues that were five times the revenues for the previous heating season. The 1995-96 heating season revenues were twice the comparable 1994-95 levels for each other region except the Southeast and Southwest.

The average prices for released capacity also increased in most regions between the 1994-95 and 1995-96 heating seasons. The increases ranged from 4 percent in the Central to 124 percent in the Midwest. The Southwest and Southeast Regions experienced price declines between the 1994-95 and 1995-96 heating seasons. However, the Southwest had unusually high prices during the 1994-95 heating season. The lowest monthly price for released capacity was in the Southeast Region at $\$ 1.68$ per thousand cubic feet (Mcf). ${ }^{18}$ All other regions had monthly prices between $\$ 4.13$ and $\$ 5.45$ per Mcf during the 1995-96 heating season (Table 3). The Midwest commanded the highest average monthly price for released capacity at $\$ 5.45$ per Mcf.

The dramatic increase in rates for released capacity during the 1995-96 heating season may have been the result of several factors, including the cold weather during that period and the change in some characteristics of the released capacity. As mentioned earlier, most regions experienced colder-than-

\footnotetext{
${ }^{17}$ Federal Energy Regulatory Commission, Notice of Proposed Rulemaking, Secondary Market Transactions on Interstate Natural Gas Pipelines, Docket Nos. RM96-14-000 and RM96-14-001 (July 31, 1996).

${ }^{18}$ The price levels for capacity release traded between 1994 and 1995, presented in this report, differ from those published by the Energy Information Administration in Natural Gas 1995: Issues and Trends, DOE/EIA-0560(95) because of reporting errors in the Pasha data for several pipeline companies. For this report, the errors in the Pasha data have been revised and data from the Federal Energy Regulatory Commission, provided by the pipeline companies via electronic data interchange, are used whenever possible.
}

normal weather during the 1995-96 heating season. Overall the 1995-96 heating season was 3 percent colder than normal and 15 percent colder than the previous heating season, as measured by heating degree days. ${ }^{19}$ This prolonged cold weather may have caused some shippers to refrain from releasing capacity on the market, thus reducing the supply of released capacity and driving up the price.

Shippers have been releasing capacity for longer periods, thereby increasing the value of the capacity to some shippers. The longer periods may indicate that shippers have become more experienced in managing system requirements and more aware of the costs associated with unused capacity. The average term of a contract for released capacity varies widely across regions, but in all six regions the average term increased between the 1994-95 and 1995-96 heating seasons. The Midwest and Southeast regions had the lowest average term of 51 and 52 days, followed by the Central and Northeast at 71 and 82 days, and then the Western Region at 183 days. The Southwest had no transactions initiated during the 1995-96 heating season. The average contract term increased from the 1993-94 heating season to the 1994-95 heating season for the Central and West regions, but decreased for the other four regions.

In addition to releasing capacity for longer terms, shippers overall have been placing recall restrictions on lesser amounts of released capacity. This may be another indicator of shipper experience in the market and their confidence that the capacity will not be needed during the release period. Thus, the quality of the released capacity has increased. During the 1993-94 heating season, all released capacity was subject to recall. By the 1994-95 heating season; however, the amount of capacity subject to recall ranged from 98 percent in the Southeast to 36 percent in the West (Table 3). Even the Northeast Region, where the most release activity occurred, had only 74 percent of its transactions subject to recall. The amount of released capacity subject to recall increased somewhat in the Central and West regions during the 1995-96 heating season, whereas it declined in all other regions.

While the low price for released capacity is advantageous to replacement shippers, it is a big disadvantage to releasing shippers who wish to mitigate the high cost of reserving firm capacity. Released capacity rate discounts averaged 65 percent during the winter of 1995-96. That high discount is significant, as it occurred in the winter months when capacity generally is most highly valued. ${ }^{20}$ As a result, the

\footnotetext{
${ }^{19}$ Energy Information Administration, Natural Gas Monthly, DOE/EIA0130(96/04) (Washington, DC, April 1996), Table 25.

${ }^{20} \mathrm{However}$, the amount of the discount varies with the time of year and the region in which the capacity is released.
} 
Figure 17. Heating Season Capacity Release Revenues by Region

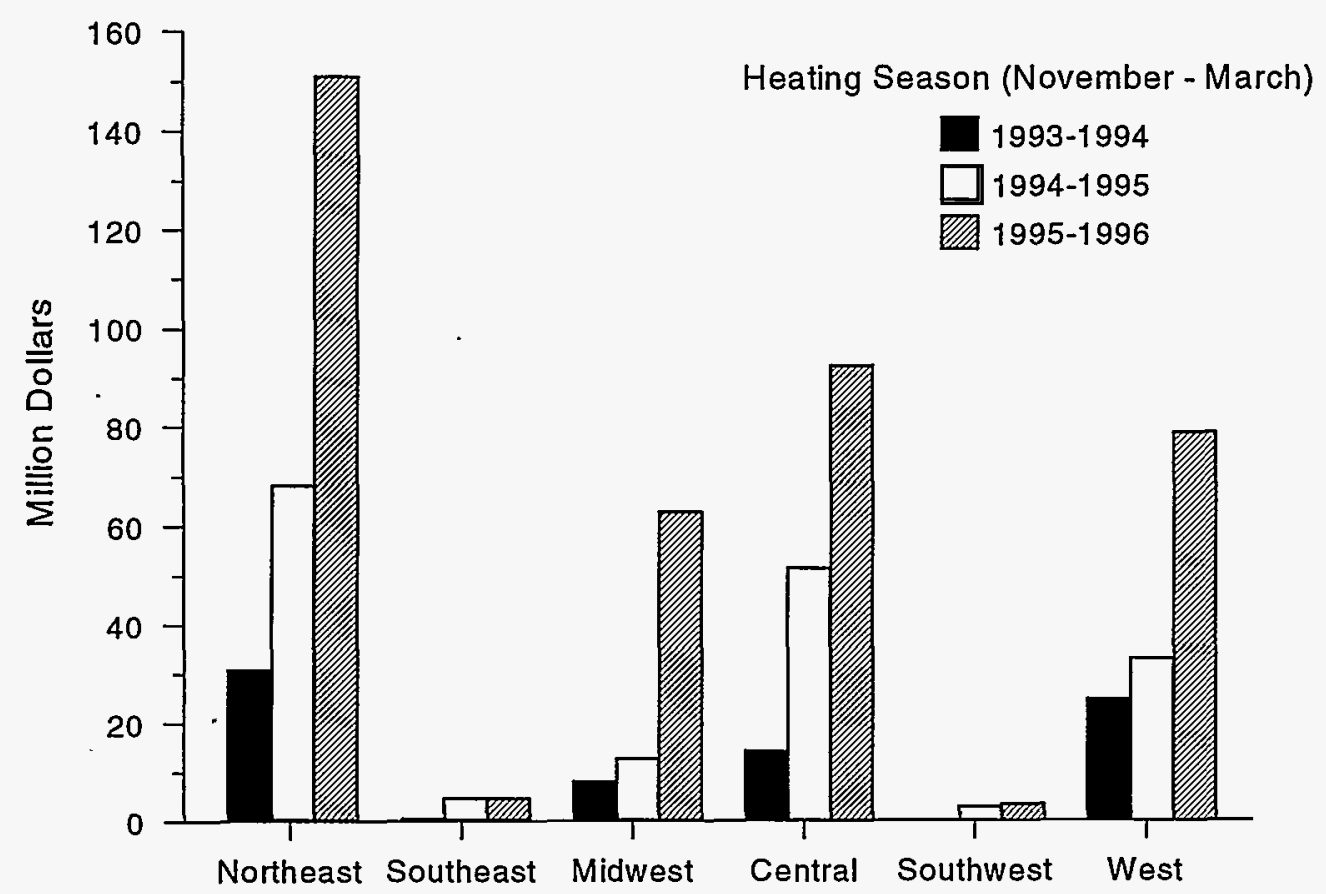

Sources: Energy Information Administration, Office of Oil and Gas, derived from: November 1993 - July 1994: Pasha Publications, Inc. July 1994 - March 1996: Federal Energy Regulatory Commission, Electronic Data Interchange (EDI) data.

release market in the past has been limited in its ability to offset the cost of reserving capacity. ${ }^{21}$

\section{The Gray Market}

Shippers with excess capacity can avoid some disadvantages of the capacity release market by participating in the gray market. Through gray market transactions, LDCs and marketers bundle their excess capacity with other services (such as gas sales) and sell the packaged service. The significance of activity in the gray market is difficult to quantify because of the lack of data on these transactions. In the case of an LDC, it may involve a sale to an offsystem customer. One advantage claimed for the gray market is that it is unregulated and therefore not subject to FERC's posting requirements or price caps. Therefore, shippers can avoid the burdens of completing and posting transactions on the EBBs. In addition, releasing shippers may be able effectively to earn prices above maximum regulated rates on the gray market.

\footnotetext{
${ }^{21}$ Some pipeline companies are proposing reservation charge mechanisms that may raise the effective rate cap on released capacity during winter periods. Foster Associates, Inc., Foster Natural Gas Report, No. 2078 (Washington, DC, May 2, 1996), p. 7.
}

Not all shippers, however, are positioned to sell their excess capacity on the gray market. To sell capacity on the gray market successfully, a shipper must be able to repackage the capacity with another desired service and be able to reach prospective customers. The shipper may not have excess gas or other services that it could economically bundle with excess capacity. Or the shipper may have a combination of services but not be able to deliver these services to the willing buyer. Buyers of gray market services usually are located outside the seller's traditional service area. If the buyer and seller cannot connect at an interchange, the transaction might not take place. Therefore, the gray market might not be an effective solution for all shippers with unused firm transportation capacity.

The capacity release and gray markets may provide only partial or short-term relief from the cost of holding long-term firm capacity. However, by selling capacity on these markets, the shipper may discover that it can release the unused capacity during peak periods without degrading its service. The shipper can confirm the true level of its firm capacity requirements without risking severe operational or economic penalties. Shippers can thereby better plan the level of capacity held in their firm transportation contracts that they can turn back. 
Table 3. Regional Characteristics of Released Capacity, November 1993 - March 1996

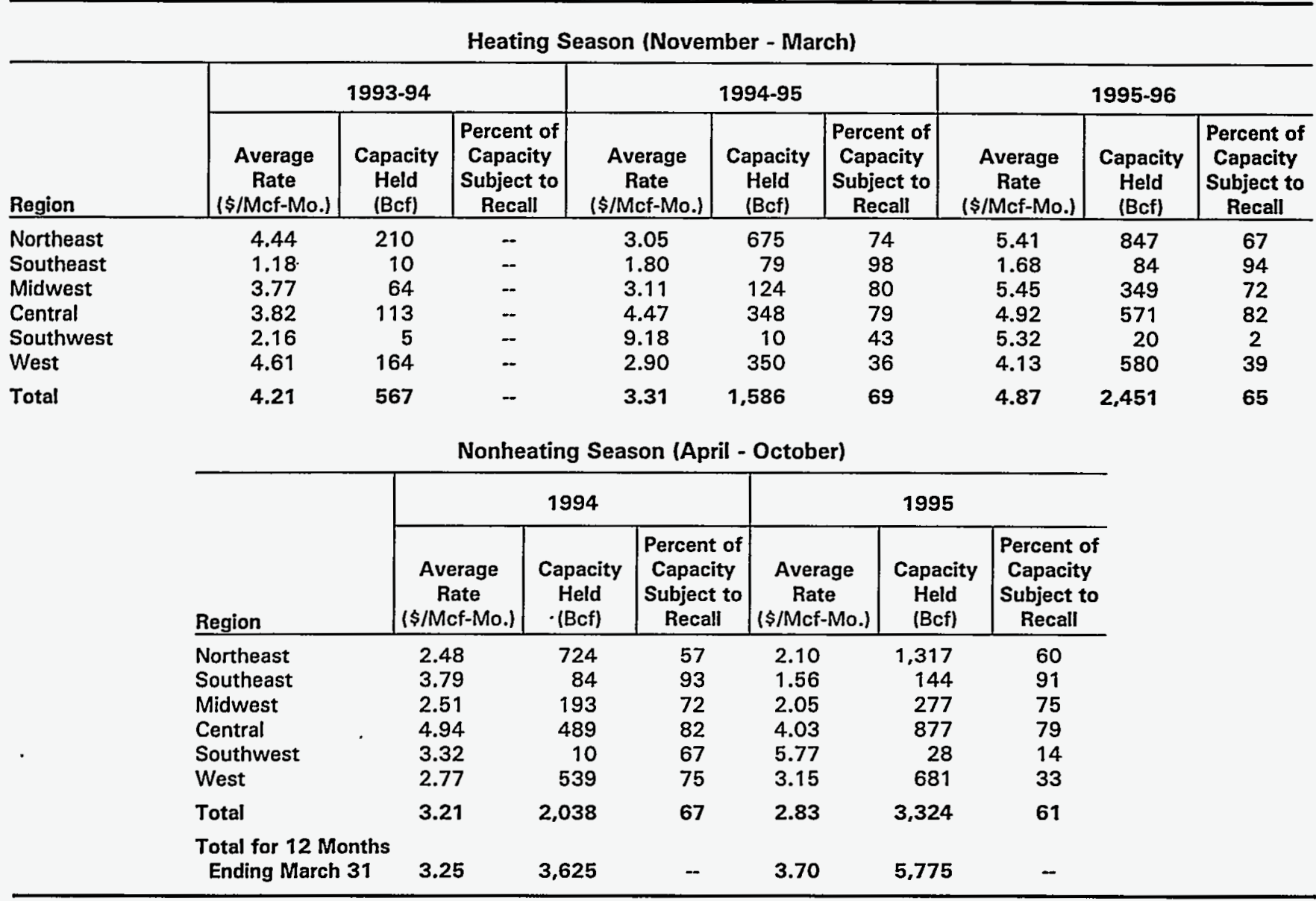

$\$ /$ Mcf-Mo. = Dollars per thousand cubic feet per month. Bcf $=$ Billion cubic feet. $--=$ Not applicable.

Note: See Appendix $D$ for a list of the pipeline companies and commitments included in the sample.

Sources: Energy Information Administration, Office of Oil and Gas, derived from: November 1993 - July 1994: Pasha Publications, Inc. July 1994 - March 1996: Federal Energy Regulatory Commission, Electronic Data Interchange (EDI) data.

For example, Southern California Gas Company (SoCal) has been an active releasing shipper on the El Paso Natural Gas Company (EI Paso) and Transwestern Pipeline Company (Transwestern) systems since the capacity release program began in November 1993. In fact, the awards of SoCal's released capacity represented between 24 and 46 percent of its total commitments on El Paso's system during the 1994-95 heating season. ${ }^{22}$ This clearly indicates that SoCal had a significant amount of unused capacity during this period (Figure 18). Once a shipper identifies the existence of yearround excess capacity, it may decide to reduce its contracted capacity at the expiration of its contract with the pipeline company.

\footnotetext{
${ }^{22}$ Average monthly award capacity for March 1995 and November 1994 of 345 and 668 million cubic feet, respectively, divided by SoCal's pretumback contract demand of 1,450 million cubic feet.
}

\section{Capacity Turnback: Realigning Contracts with Requirements}

The reduction or returning of capacity to the pipeline company at the expiration of the contract, also called capacity turnback, severs the contractual ties and obligations between the shipper and the pipeline company. However, turnback is not inevitable when a contract expires. For instance, the shipper may enter into a new contract for the same amount of capacity under the "right of first refusal" if the shipper is willing to pay the maximum rate or the shipper and pipeline company may negotiate a new contract with alternative terms and prices.

To date, there have been only three cases of significant turnbacks of capacity: El Paso Natural Gas Company (EI Paso) and Transwestern Pipeline Company (Transwestern) in the West and Natural Gas Pipeline Company of America 
Figure 18. Southern California Gas Company Activity on El Paso Natural Gas Company System



Sources: Energy Information Administration, Office of Oil and Gas, derived from: Capacity Awards November 1993 - July 1994: Pasha Publications, Inc. July 1994 - March 1996: Federal Energy Regulatory Commission (FERC), Electronic Data Interchange (EDI) data. SoCal Proposed Turnback: El Paso Natural Gas Company, FERC Docket No. RP95-363. SoCal Contracted Capacity Before Turnback: El Paso Natural Gas Company, FERC Docket No. RP95-363, Statement G-6. After Turnback: FERC Index of Customers data for April 1, 1996, FERC Bulletin Board (August 28, 1996).

(NGPL) in the Midwest. These cases provide insights into the difficulties associated with turnbacks. Since the cases are localized in only two geographic regions, however, it is unclear whether they are anomalies or indicate a fundamental shift in the industry much like the take-or-pay situation of the mid-1980's. The operational, economic, and legal issues that arise from turnbacks create problems that have no simple solutions. There are two major areas of concern in a turnback case: (1) the apportionment of costs and (2) the implications for pipeline operations.

The cost impact of a turnback can be significant for both the pipeline company and the remaining shippers. For the Transwestern, El Paso, and NGPL systems, annual revenue reductions were estimated by the companies to be $\$ 51, \$ 140$, and $\$ 60$ million, respectively, assuming that the pipeline companies are not able to remarket any of the turnback capacity. The magnitude of these costs makes their distribution among the stakeholders (pipeline company, decontracting shippers, and remaining customers) a serious issue. Allocating the cost of turnbacks to the remaining firm customers may be inappropriate because these customers would pay higher rates without a corresponding increase in the quality of service. In addition, passing turnback costs directly to remaining shippers may inspire additional turnbacks as shippers would try to avoid increases in their capacity reservation fees. Although the cost of a turnback may be associated with one or more decontracting customers, requiring these customers to shoulder all turnback costs could create a barrier that in turn could discourage a competitive market. For example, a shipper may decide to renew the contract to avoid turnback charges. If, on the other hand, pipeline companies are required to absorb these costs, they will be subject to increased business risks and less likely to build new facilities in the future.

Capacity turnbacks can present operational problems to participants. Depending on the amount and location of the turnback, it can affect service on other segments of the pipeline system and necessitate changes in the operation of the pipeline that could lead to increased pipeline costs. If service to a specific delivery point is severely reduced, the pipeline company might have to increase linepack dramatically to transport gas beyond that point. The pipeline company's operational options can be limited because a shipper who decontracts only a portion of its capacity has the right to select its receipt and delivery points, as provided for in Order 636 . Therefore, while shutting down facilities to a particular supply area might balance operational and contracted capacity, this might also restrain 
interstate commerce and prevent buyers and suppliers from reaching each other.

Several means of resolving these issues have been pursued. Some pipeline companies initially have sought solutions through rate increases or litigation. In the large turnback cases that have transpired thus far, FERC has favored negotiation between the pipeline company and its customers in lieu of litigation. Although the large cases of capacity turnback have been localized with respect to geographic regions, they provide a view of the general problems and approaches to capacity turnback that indicate how the industry and regulators will accommodate the effects of changes in capacity commitments.

\section{The Experiences from Large Turnback Cases}

The significant cases of capacity turnback to date have occurred in only two regions of the United States: the West (Transwestern Pipeline and El Paso Natural Gas) and the Midwest (Natural Gas Pipeline Company of America). These cases demonstrate an important characteristic of capacity turnback - the combination of factors that lead to turnbacks can be concentrated in a specific market. For example, the turnbacks on Transwestern and El Paso are primarily because of stepdowns, or reductions, in the amount of firm contracted capacity by California customers. These turnbacks represented 18 percent of the respective total capacity commitments on the Transwestern and El Paso systems. Transwestern experienced a 457 billion Btu per day reduction effective November 1, 1996. El Paso faces a reduction in firm capacity contracts of 1.5 trillion Btu per day effective between January 1, 1996, and January 1, 1998 (Table 4).

Transwestern ultimately reached a settlement agreement with its customers (Table 4) that provides for sharing of the turnback cost between the pipeline company and its customers over a 5-year period. At the end of the 5 years, Transwestern will assume full responsibility for any revenue shortfall from the turnbacks. The settlement also provides rate certainty for the shippers. Transwestern's shippers will pay negotiated rates that include an annual escalation factor. Transwestern also receives a stable revenue stream under the agreement, since the settlement participants have extended their firm contracts for 10 years. This will give Transwestern time to develop marketing strategies for uncommitted capacity including marketing to new areas and developing competitive rate methods. To combat the downturn in the California market, the pipeline company is expanding its facilities in the San Juan production basin to offer better access to eastern market centers. El Paso has filed a similar settlement, which is awaiting FERC approval. In addition, El Paso has agreed to acquire Tenneco's energy division, thus allowing for geographical extension of its pipeline system. ${ }^{23}$

The turnback case in the Midwest was a result of certain NGPL customers relinquishing 600 billion Btu per day of capacity effective December 1, 1995. The capacity reductions represent almost 17 percent of NGPL's total capacity commitments. ${ }^{24}$ If the cost of the turnback were passed through to customers, it would contribute to a 50 to 60 percent increase in firm transportation rates. ${ }^{25}$ NGPL also reached a settlement with its customers under which it assumed responsibility for about 80 percent of the revenue loss resulting from the relinquished capacity. As a part of the agreement, FERC allows NGPL to consider alternative rate designs, such as a departure from straight fixed-variable rates.

These cases indicate that pipeline companies and shippers are addressing three areas to mitigate the impacts of capacity turnbacks.

- Negotiating acceptable cost-sharing procedures and rate levels.

- Pipeline companies are moving to new markets with greater growth potential.

- Developing plans for competitive rate strategies for the unused capacity.

In the future, additional turnbacks on Transwestern, El Paso, and NGPL are possible. For instance, while Transwestern's settlement locks in a large portion of its capacity commitment for the next 10 years, it did not resolve all of its potential capacity turnbacks. Approximately 25 percent $(634,612$ million Btu per day) of Transwestern's total firm capacity commitments will expire during 1996 (Figure 19). Most of these contracts are short-term (less than one year) and rollover contracts. The next significant firm capacity contracts will not expire until the year 2000. While there is no indication that these expiring contracts will result in a turnback, strengthening of California's economy and Transwestern's eastern market link to the Waha Hub may absorb a portion of

\footnotetext{
${ }^{23}$ El Paso Energy Corporation, Press Release (June 19, 1996).

${ }^{24}$ The 17-percent reduction is based on the difference between NGPL'S July 11, 1995 filing, which showed the firm customers' market area peakperiod contract demand to be 3,845 billion Btu, and its August 18, 1995 filing showing a projected contract demand of 3,201 billion Btu. Federal Energy Regulatory Commission, Order Following Technical Conference, Natural Gas Pipeline Company of America, Docket Nos. RP95-326-000 et al (October 11, 1995).

${ }^{25}$ In addition to turning back capacity, some of NGPL's customers changed their service paths, opting for service zones with lower rates. Federal Energy Regulatory Commission, Order Following Technical Conference, Natural Gas Pipeline Company of America, Docket Nos. RP95326-000 et al (October 11, 1995).
} 
Table 4. Capacity Turnbacks in the U.S. Western Region

\begin{tabular}{|c|c|c|c|c|c|c|c|}
\hline Company & $\begin{array}{c}\text { Pre-turnback } \\
\text { Contracted } \\
\text { Capacity } \\
\text { (MMBtu/d) }\end{array}$ & $\begin{array}{l}\text { Turned-Back } \\
\text { Capacity } \\
\text { (MMBtu/d) }\end{array}$ & $\begin{array}{l}\text { Effective } \\
\text { Date }\end{array}$ & $\begin{array}{c}\text { Revised } \\
\text { Contracted } \\
\text { Capacity }^{2} \\
\text { (MMBtu/d) }\end{array}$ & $\begin{array}{c}\text { Potential } \\
\text { Revenue } \\
\text { Impact }^{3} \\
\text { (million dollars) }\end{array}$ & $\begin{array}{c}\text { Settlement } \\
\text { Revenue } \\
\text { Impact } \\
\text { (million dollars) }\end{array}$ & $\begin{array}{l}\text { Other } \\
\text { Terms }\end{array}$ \\
\hline Transwestern Pipeline & & & & & & $35.7^{4}$ & \\
\hline $\begin{array}{c}\text { Decontracting Customers } \\
\text { Southern California Gas }\end{array}$ & 963,281 & 457,281 & $11 / 1 / 96$ & 506,000 & 22.3 & $9.1^{4}$ & (a) \\
\hline $\begin{array}{l}\text { Remaining Customers } \\
\text { Settlement Participants } \\
\text { Others }\end{array}$ & $\begin{array}{l}650,000 \\
923,667\end{array}$ & -- & -- & $\begin{array}{l}650,000 \\
923,667\end{array}$ & 28.7 & $6.2^{4}$ & (a) \\
\hline Total & $2,536,948$ & 457,281 & - & $2,079,667$ & 51.0 & 51.0 & - \\
\hline \multicolumn{8}{|l|}{ El Paso Natural Gas } \\
\hline $\begin{array}{l}\text { Decontracting Customers } \\
\text { Gas Co. of NM } \\
\text { Southern California Gas } \\
\text { Pacific Gas and Electric }\end{array}$ & $\begin{array}{r}71,618 \\
1,493,500 \\
1,174,200\end{array}$ & $\begin{array}{r}41,200 \\
309,000 \\
1,174,200\end{array}$ & $\begin{array}{l}4 / 1 / 96 \\
1 / 1 / 96 \\
1 / 1 / 98\end{array}$ & $\begin{array}{r}30,418 \\
1,184,500 \\
-\end{array}$ & $\begin{array}{r}1.5 \\
58.6 \\
--\end{array}$ & $\begin{array}{l}-- \\
-- \\
-\end{array}$ & $\begin{array}{l}- \\
-\end{array}$ \\
\hline $\begin{array}{l}\text { Remaining Customers } \\
\text { Settlement Participants }\end{array}$ & $1,616,609$ & - & -- & $1,616,609$ & 79.9 & -- & - \\
\hline Total & $4,355,927$ & $1,524,400$ & - & $2,831,527$ & 140.0 & $140.0^{5}$ & - \\
\hline
\end{tabular}

'Transwestern: FERC Index of Customers for April 1, 1996. El Paso: FERC Docket No. RP95-363, Statement G-6.

${ }^{2}$ Pre-Turnback contracted capacity less decontracted capacity.

${ }^{3}$ Total annual revenue shortfall allocated among settlement customers based on revised contracted capacity.

${ }^{4} T$ total annual revenue shortfall of $\$ 51$ million allocated between Transwestern and SoCal and Settlement Participants on the basis of settlement-sharing mechanism (70 percent, 18 percent, and 12 percent, respectively). Current customers share the costs equally (50/50) with Transwestern in the first year and then 25 percent of the annual costs are recovered by the current customers for each of the next 4 years. In the sixth year, Transwestern absorbs 100 percent of the costs. Under an alternative option, current customers take a 30.67 percent share of the revenue shortfall for the entire 5 years. If it selected the second option, SoCal's share would be the amount for SoCal derived under the first option less the total amount due from the other customers. The costs are allocated among customers on the basis of their mainline transmission capacity billing determinants as of November 1, 1996.

${ }^{5} \mathrm{EI}$ Paso filed a comprehensive settlement on March 29, 1996, which, as of October 15, 1996, has not been approved. The settlement would establish rates, subject to an annual inflation adjustment, effective through 2005 . Under the proposed settlement, El Paso would assume responsibility for 65 percent of the fixed costs associated with the capacity turnbacks. SoCal and PG\&E would pay the largest portions of the customers' turnback responsibility.

${ }^{a}$ Customer contracts are extended until 2006. Negotiated rates take effect on November 2, 1996, and include an automatic annual escalation in base rates. Effective November 1,1998 , current customer settlement base rates will increase annually by 60 percent of the increase in the implicit price deflator to the gross domestic product.

MMBtu/d = Million Btu per day.

Sources: Energy Information Administration, Office of Oil and Gas, derived from: Transwestern Pipeline Company: Federal Energy Regulatory Commission (FERC) Docket No. RP95-271 et al. El Paso Natural Gas Company: FERC Docket No. RP95-363, Foster Associates, Inc., Foster Natural Gas Report (April 11, 1996) and FERC Index of Customers for April 1, 1996 (August 28, 1996).

the decontracted amount or prevent it from being decontracted in the first place.

The pipeline industry is alert to the threat posed by capacity turnbacks and is responding with new marketing and cost reduction strategies. In general, turnbacks can be expected togrow in regions where shippers have a variety of options and alternatives to long-term firm transportation.

\section{Capacity Turnback: Opportunities and Expectations}

Shippers will have significant opportunities to change their transportation contracts through the year 2001 when contracts covering approximately 51 percent of firm transportation capacity are scheduled to expire. ${ }^{26}$ At that time, they will be able to turn back all capacity reserved or negotiate a new

\footnotetext{
${ }^{26} \mathrm{Absent}$ a contract rollover in which the terms and conditions of the original contract may be renewed by the shipper for a predetermined period of time.
} 




Source: Energy Information Administration, Office of Oil and Gas, derived from Federal Energy Regulatory Commission (FERC) Index of Customers data for April 1, 1996, FERC Bulletin Board (August 28, 1996).

contract that may include revised contract terms for capacity reservations. Under the assumption that all expiring contracts lead to turnback of all reserved capacity, a review of current contracts can provide an upper bound on the potential amount of capacity that could be turned back to transporters. It is important to note that expirations are a measurement of the maximum potential turnback. Shippers may instead resubscribe (e.g., negotiate a new contract) for all or part of the capacity reserved in the expiring contract.

This section identifies the potential for turnback in the transportation industry by examining the amount of capacity currently reserved under firm contracts and the expiration of those contracts over the next 15 to 30 years. The maximum amount of capacity that can be turned back is the amount associated with an expiring contract. The expiration of a contract generally provides the shipper its first opportunity to reduce firm contracted capacity.

\section{Capacity Reservations in 1996 Totaled More than 100 Trillion Btu per Day-A Significant Increase from 1990 Levels}

As of April 1, 1996, reservations for transportation capacity in the United States totaled 107.4 trillion Btu per day
(Table 5) for the 63 interstate pipeline companies reporting to FERC on the Index of Customers survey. ${ }^{27}$ These companies accounted for more than 90 percent of interstate throughput in 1995. Total capacity reservations represent the amount of capacity that shippers could have used for firm transportation services on April 1, 1996, under the terms and conditions of their contracts. This figure may not equal capacity reservations on other days of the year because some contracts may include service levels that vary throughout the year.

If shippers fully utilized their reserved capacity and if the April 1, 1996, daily reservation amount were the same throughout the year, total throughput for firm services would total 39.2 quadrillion Btu per year, far in excess of the 18.7 quadrillion Btu of firm transportation throughput and the 24.4 quadrillion Btu of total throughput reported by the pipeline

\footnotetext{
${ }^{2}$ Beginning April 1, 1996, interstate pipeline companies are required to report information to FERC on all existing contracts for firm transportation and storage service. This Index of Customers includes a snapshot of information on those contracts that are active on the first day of the quarter including: shipper name, capacity reserved, and beginning and end date of the contract. The pipeline companies are required to file these data quarterly. As of August 28, 1996, 63 interstate pipeline companies provided useable information to FERC. Information on additional pipeline companies are expected to be available in the future.
} 
Table 5. Current Capacity Commitments and Cumulative Expirations by Region and Period (Billion Btu per Day)

\begin{tabular}{lcrrrrrr}
\hline & $\begin{array}{c}\text { Commitments } \\
\text { as of }\end{array}$ & \multicolumn{7}{c}{ Cumulative Capacity Expirations } \\
\cline { 2 - 7 } Region & April 1, 1996 & $\mathbf{1 9 9 7}$ & $\mathbf{2 0 0 1}$ & $\mathbf{2 0 0 5}$ & $\mathbf{2 0 1 0}$ & $\mathbf{2 0 2 0}$ & $\mathbf{2 0 2 5}$ \\
\hline Central & 14,447 & 6,112 & 9,180 & 12,018 & 13,444 & 14,447 & 14,447 \\
Midwest & 27,376 & $\mathbf{8 , 6 4 1}$ & 19,132 & 24,046 & 25,684 & 27,145 & 27,376 \\
Northeast & 37,642 & $\mathbf{3 , 2 4 8}$ & 12,124 & 27,891 & 31,770 & 37,642 & 37,642 \\
Southeast & 4,964 & 465 & 2,520 & 3,309 & 4,214 & 4,961 & 4,964 \\
Southwest & 6,235 & 2,523 & 5,828 & 6,221 & 6,221 & 6,235 & 6,235 \\
West & 16,717 & 4,442 & 5,457 & $\mathbf{9 , 3 8 5}$ & 14,195 & 15,488 & 16,717 \\
$\quad$ Total & $\mathbf{1 0 7 , 3 8 1}$ & $\mathbf{2 5 , 4 3 2}$ & 54,240 & $\mathbf{8 2 , 8 7 0}$ & $\mathbf{9 5 , 5 2 8}$ & $\mathbf{1 0 5 , 9 1 8}$ & $\mathbf{1 0 7 , 3 8 1}$ \\
\hline
\end{tabular}

Note: Totals may not equal sum of components because of independent rounding.

Source: Energy Information Administration, Office of Oil and Gas, derived from Federal Energy Regulatory Commission (FERC) Index of Customers data for April 1, 1996, FERC Bulletin Board (August 28, 1996).

industry for $1995 .^{28}$ The primary reason for this difference is that shippers requiring high-priority firm services typically reserve sufficient capacity to satisfy their peak-period demands but they do not use all of it during the nonpeak period. Pipeline companies must stand ready to provide service up to the reserved amount under firm contracts, even though their customers may not actually request transportation of that amount of gas.

Customer commitments for firm services by interstate pipeline companies in 1996 have grown significantly since 1990 , the prior year for which comprehensive data are available. For a sample of pipeline companies that represent 92 percent of capacity commitment in 1996, capacity reservations were 26 percent $^{29}$ higher in 1996 than the 77.7 trillion Btu per day of firm commitments in 1990 (Figure 20). Over 87 percent of current capacity commitments are under longer term contracts (more than 1 year) and over two-thirds exceed 5 years in duration (Figure 21).

Three factors, in particular, have contributed to the increase in capacity commitments:

- Increased gas consumption. Total end-use consumption of natural gas in the United States in 1995 was 19.7

\footnotetext{
${ }^{28}$ Derived by Energy Information Administration, Office of Oil and Gas from: Interstate Natural Gas Association of America, Gas Transportation Through 1995 (Washington, DC, September 1996), Tables A-1 and A-4. Total delivered for market (21.765 quadrillion Btu times percentage firm services (52 percent plus 17 percent plus 17 percent) equals 18.7 quadrillion Btu for 1995 .

${ }^{29}$ Derived by Energy Information Administration, Office of Oil and Gas from: Capacity and Service on the Interstate Natural Gas Pipeline System 1990, DOE/EIA-0556 (Washington, DC, June 1992); and Federal Energy Regulatory Commission (FERC) Index of Customers data for April 1, 1996, FERC Bulletin Board (August 28, 1996).
}

trillion cubic feet, a 17-percent increase over the 1990 level.

- Increased pipeline capacity. U.S. pipeline capacity increased by 13 percent between 1990 and 1995.

- Increased preference for firm rather than interruptible services. Many shippers have shifted to firm service from interruptible service. Firm services represented 86 percent of the gas delivered to market by interstate pipeline companies in 1995, up from 49 percent in 1990.

Not surprisingly, two of the geographic regions that posted significant increases in pipeline capacity over the period, the Northeast and the West, also showed the largest increase in reservations for the companies included in the sample. Pipeline company commitments for firm service in the Northeast showed the largest increase, 8.6 trillion Btu per day, followed by the Western Region, which increased 4.0 trillion Btu per day or 46 percent since 1990 (Table 6). Also noteworthy is the 31-percent increase in firm commitments in the Southeast between 1990 and 1996. The regional estimates were developed by assigning each pipeline company's contracts to the geographic region corresponding to its principal service area as indicated by historical delivery patterns..$^{30}$ (See Appendix $G$ for definition of the regions used and more information on capacity commitments.)

\footnotetext{
${ }^{30}$ These regional estimates are approximate because of the lack of contract information on service location.
} 
Figure 20. Pipeline Capacity Under Firm Contract in 1990 and 1996 for a Sample of Interstate Pipeline Companies

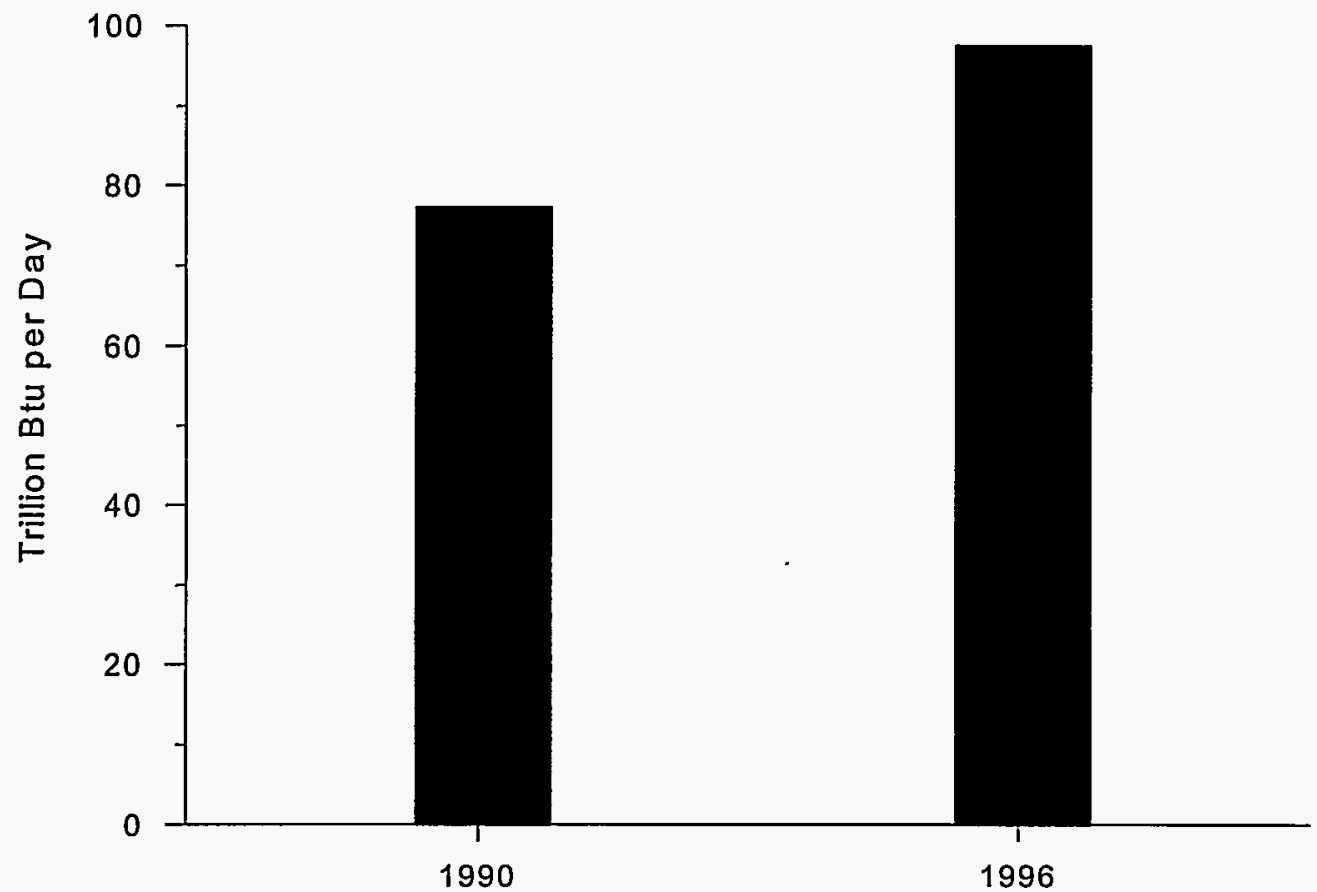

Note: See Appendix $D$ for a list of the pipeline companies and commitments included in the sample.

Sources: Energy Information Administration (EIA), Office of Oil and Gas, derived from: 1990: EIA, Capacity and Service on the Interstate Natural Gas Pipeline System 1990 (June 1992); 1996: Federal Energy Regulatory Commission (FERC) Index of Customers data for April 1, 1996, FERC Bulletin Board (August 28, 1996).

Figure 21. Firm Transportation Capacity as of April 1, 1996, Grouped by Length of Contract

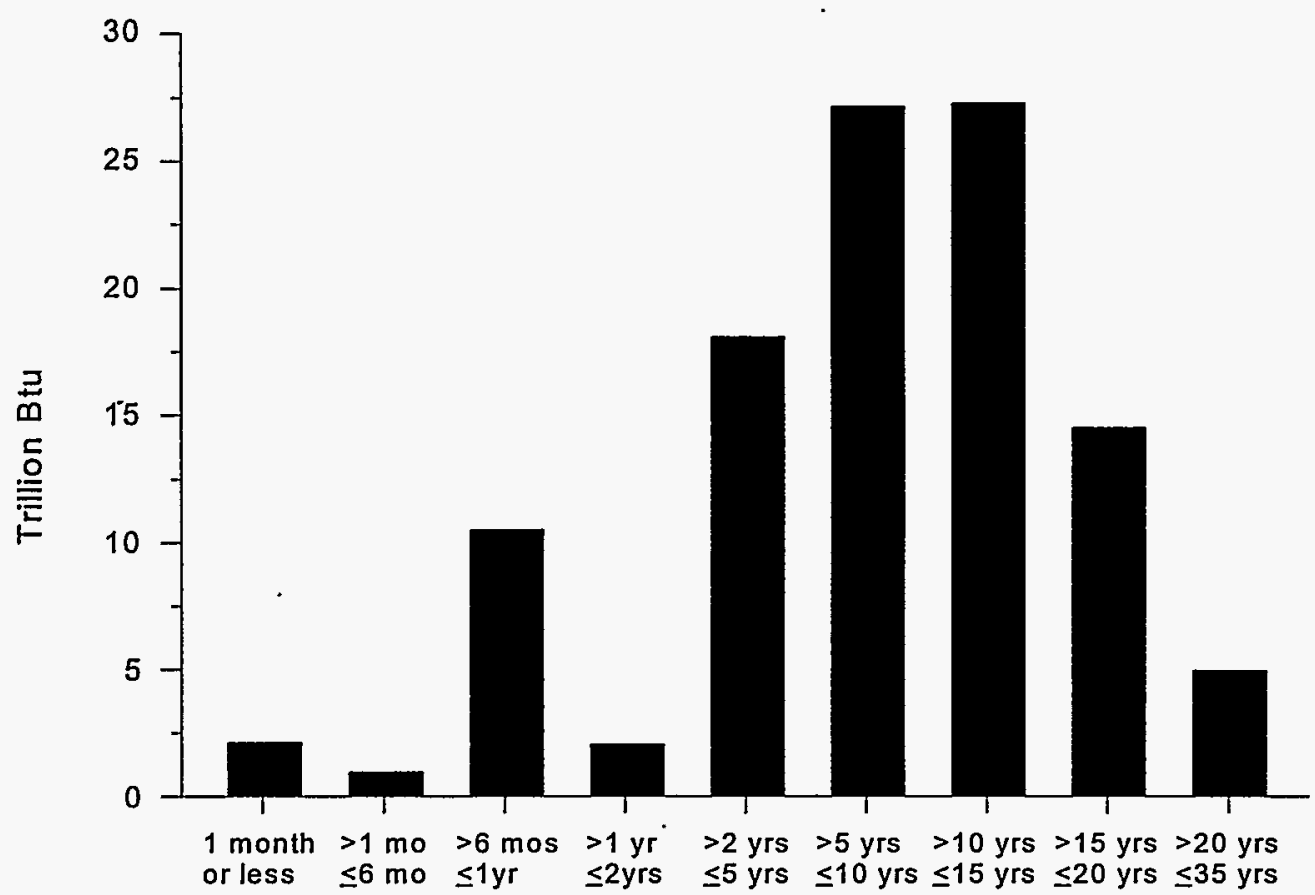

Source: Energy Information Administration, Office of Oil and Gas, derived from Federal Energy Regulatory Commission (FERC) Index of Customers data for April 1, 1996, FERC Bulletin Board (August 28, 1996). 
Table 6. Transportation Capacity Under Contract in 1990 and 1996 for a Sample of Interstate Pipeline Companies, by Region (Million Btu per Day)

\begin{tabular}{l|c|r}
\hline \multirow{2}{*}{ Region } & \multicolumn{2}{|c}{ Firm Capacity Commitments } \\
\cline { 2 - 3 } Central & 1990 & \multicolumn{1}{c}{1996} \\
Midwest & $12,211,680$ & $14,209,661$ \\
Northeast & $21,313,790$ & $24,453,615$ \\
Southeast & $27,910,940$ & $36,482,322$ \\
Southwest & $3,766,710$ & $4,935,744$ \\
West & $3,646,200$ & $5,224,234$ \\
Total & $8,850,790$ & $12,895,685$ \\
\hline
\end{tabular}

Note: See Appendix $D$ for a list of the pipeline companies and commitments included in the sample.

Sources: Energy Information Administration (EIA), Office of Oil and Gas, derived from: 1990: EIA, Capacity and Service on the Interstate Natural Gas Pipeline System 1990 (June 1992); 1996: Federal Energy Regulatory Commission (FERC) Index of Customers data for April 1, 1996, FERC Bulletin Board (August 28, 1996).

\section{Contracts Representing 89 Percent of Current/y Reserved Capacity Will Be Up for Renewal Between 1996 and 2010}

Between 1996 and 2010, transportation contracts representing a total of 89 percent of currently ${ }^{31}$ reserved capacity in the United States will come up for renegotiation or expiration (Table 4). The pace of those expirations varies over time (Figure 22). For most years, expirations account for less than 5 percent of current reservations. However, the years 1996, 2000 , and 2004 will be particularly active, when 16,12 , and 12 percent, respectively, of currently contracted capacity will expire (Figure 23). The short-term period, through 1997, will be active as almost one-fourth of contracted capacity will be up for renewal, including rollovers and short-term (less than 1 year) contracts each of which account for approximately 5 percent of current reservations. An additional 27 percent of currently contracted capacity will expire in the mid-term period 1998 through 2001, which will bring cumulative expirations to just over one-half of current commitments. Between 2002 and 2010, contracts covering an additional 39 percent of current capacity reservations will be up for renewal. Finally, although most contracts will expire before 2010,11 percent of capacity is under contracts that continue after 2010 and in some cases through 2025.

\section{Over the Mid Term, Contract Expirations Vary Considerably by Region, but the Long-Term (2010) Outlook Is Similar for Each Region}

The schedule (or profile) of contract expirations over time also varies by region (Figure 24). Although there is

\footnotetext{
${ }^{31}$ As of April 1, 1996
}

considerable variation in the quantity of cumulative capacity expirations in the short and mid term (through 2001), for each region the pattern of extensive contract turnovers or expirations by 2010 is similar and in the range of 85 to 100 percent of existing contracts (Figure 25). In the short term, shippers on pipelines that principally serve the Central and Southwest regions will see the most expirations, over 40 percent of capacity under existing contracts. In contrast, pipeline companies in the Northeast and Southeast will have contracts covering only about 9 percent of their current reservations expire while companies in the Midwest and West expect between 27 to 32 percent of their capacity reservations to expire over the short term. As an aside, it should be noted that these expirations are based on contracts that were in effect as of April 1, 1996, and therefore would include any capacity reductions, changes, rollovers, or renegotiations made prior to that date. As noted earlier, pipeline company information is the basis for these regional totals, which show enormous variation. For instance, at least 11 pipeline companies, such as Northern Border (Central Region), Granite State Gas Transmission, Inc. (Northeast Region), and several pipeline companies in the West, have no contracts expiring through $1997 .^{32}$ In contrast, almost a dozen companies principally in the Central and Midwest regions, including Michigan Gas Storage, $\mathrm{K} \mathrm{N}$ Interstate Gas Transmission, and Williston Basin Interstate Pipeline

\footnotetext{
${ }^{32}$ Including Cove Point LNG, MIGC, Inc., Mobile Bay Pipeline, OKTex Pipeline, Pacific Gas Transmission Company, Pacific Interstate Offshore Company, Paiute Company, Riverside Pipeline, and Tuscarora Gas Transmission Company.
} 
Figure 22. Expiration of Firm Transportation Capacity Under Contract as of April 1, 1996

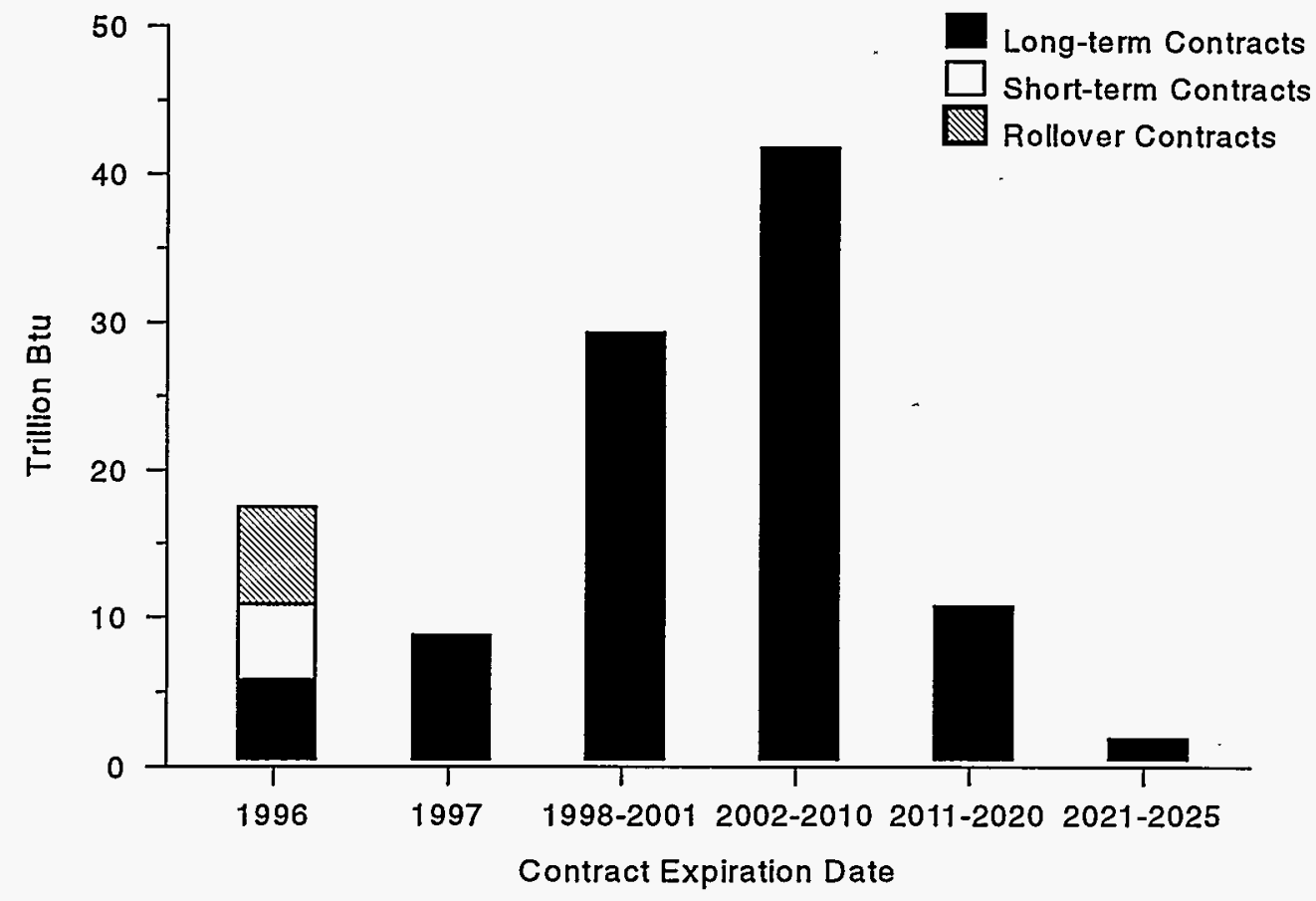

Source: Energy Information Administration, Office of Oil and Gas, derived from Federal Energy Regulatory Commission (FERC) Index of Customers data for April 1, 1996, FERC Bulletin Board (August 28, 1996).

Figure 23. Annual and Cumulative Expirations of Firm Transportation Capacity, 1996-2025

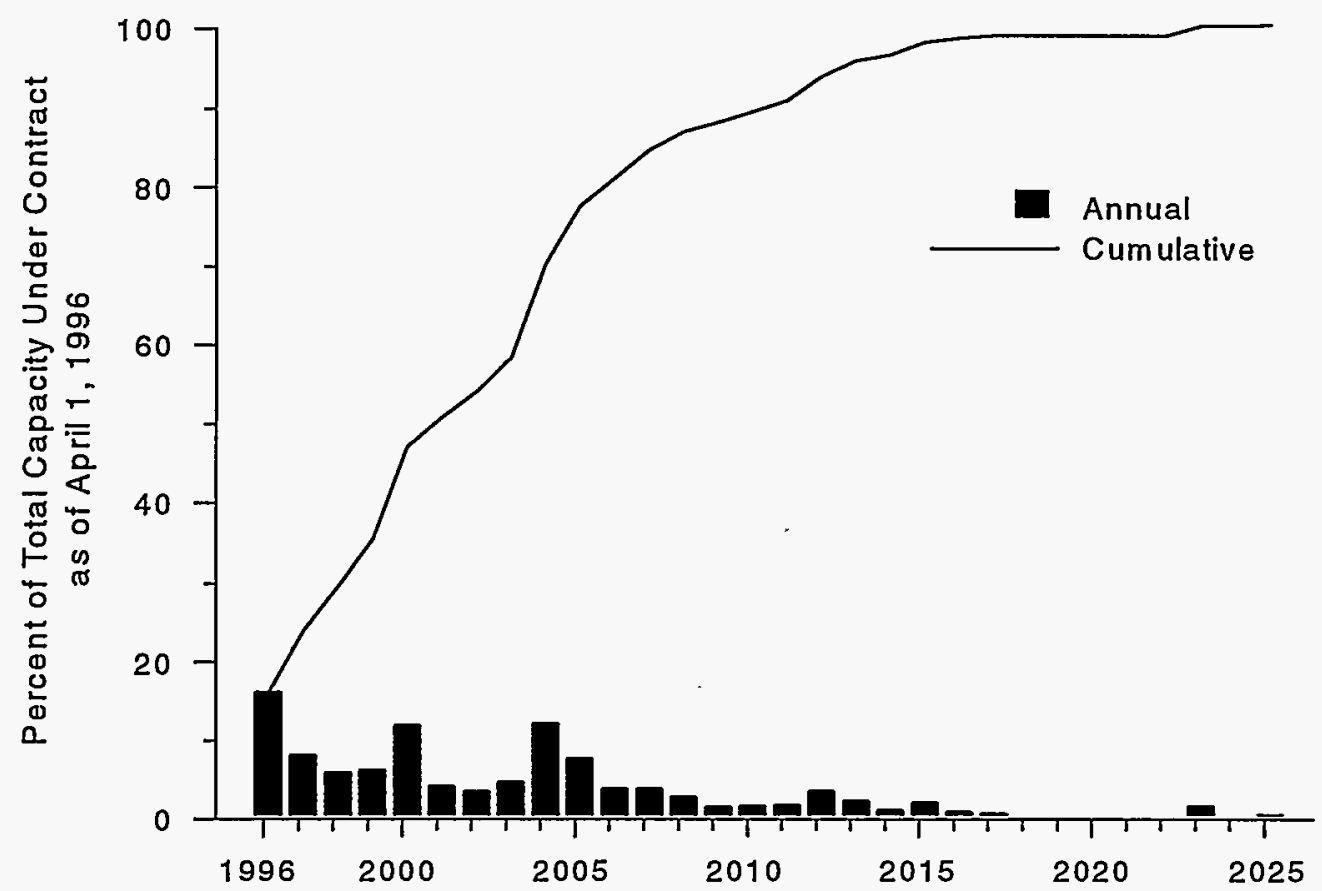

Source: Energy Information Administration, Office of Oil and Gas, derived from Federal Energy Regulatory Commission (FERC) Index of Customers data for April 1, 1996, FERC Bulletin Board (August 28, 1996). 
Figure 24. Regional Exposure to Capacity Expirations, 1996-2025 (Trillion Btu)

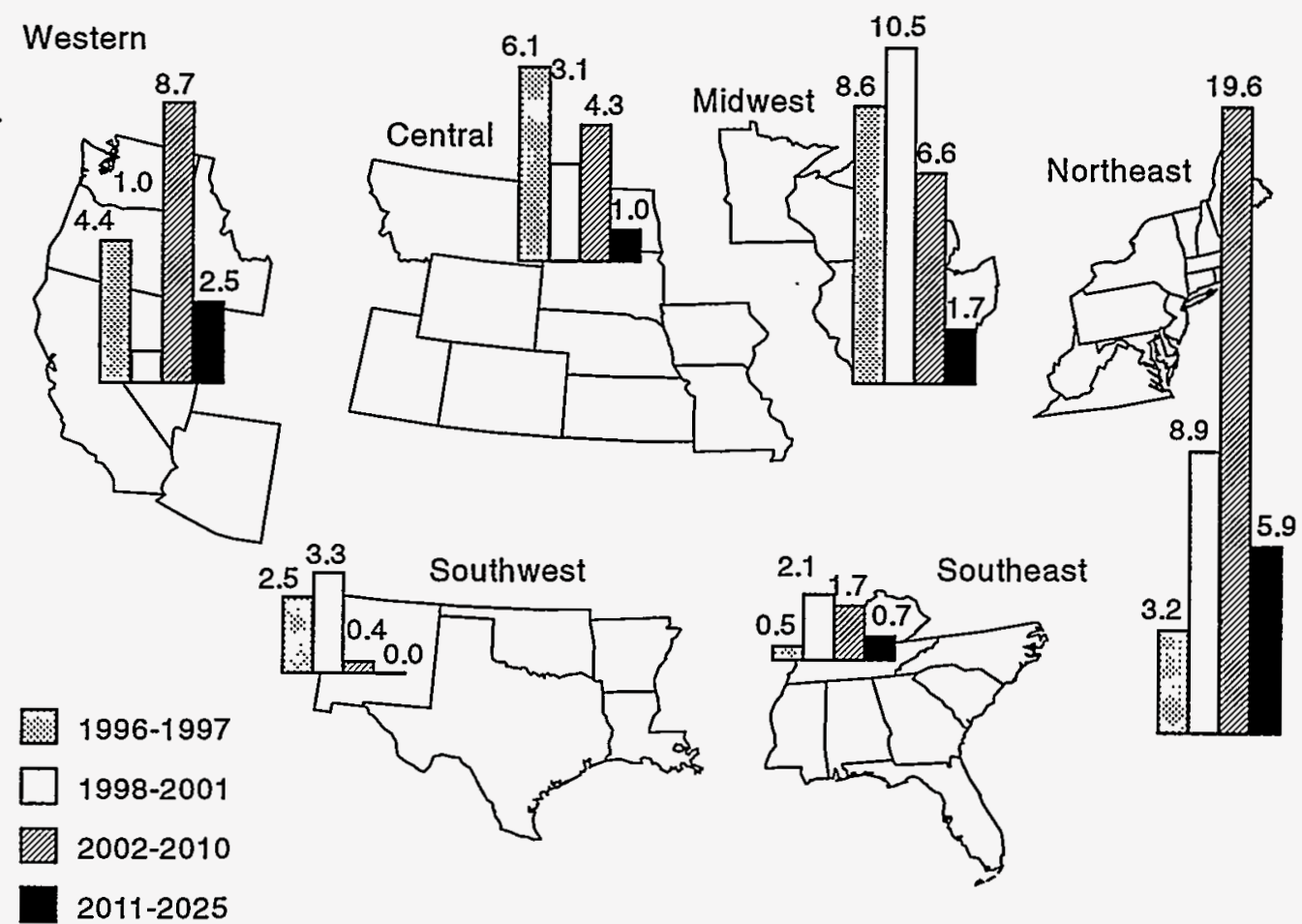

Capacity Associated with Expiring Firm Transportation Contracts by Region (Million Btu)

\begin{tabular}{l|r|r|r|r}
\hline Region & $1996-1997$ & $1998-2001$ & \multicolumn{1}{c}{ 2002-2010 } & \multicolumn{1}{c}{ 2011-2025 } \\
\hline Central & $6,111,633$ & $3,067,964$ & $4,263,969$ & $1,003,859$ \\
Midwest & $8,640,978$ & $10,491,173$ & $6,552,234$ & $1,691,382$ \\
Northeast & $3,248,228$ & $8,875,327$ & $19,646,885$ & $5,871,170$ \\
Southeast & 465,373 & $2,054,247$ & $1,694,176$ & 749,833 \\
Southwest & $2,523,256$ & $3,304,974$ & 392,403 & 14,500 \\
West & $4,442,041$ & $1,015,271$ & $8,737,494$ & $2,522,509$ \\
\hline
\end{tabular}

Source: Energy Information Administration, Office of Oil and Gas, derived from Federal Energy Regulatory Commission (FERC) Index of Customers data for April 1, 1996, FERC Bulletin Board (August 28, 1996).

Company, have more than three-fourths of existing contracts expiring by the end of $1997 .^{33}$

Based solely on contract expirations, the Southwest, Central and Midwest regions have the greatest potential for significant capacity turnbacks between 1996 and 2001 (Table 5, Figure 25). By 2001, the cumulative expirations since
April 1, 1996, will total a substantial 93 percent in the Southwest, 64 to 70 percent in the Midwest and Central regions, 51 percent in the Southeast, and only 33 percent in the Northeast and West. Expirations of contracts in the West are lower than in other regions because a significant number of contracts to transport gas from the Southwest to California were renegotiated in 1995 and 1996 and are not due to expire

${ }^{33}$ Additional pipeline companies with three quarters or more of existing contracts expiring by the end of 1997 include: Trailblazer Pipeline Company, Crossoads Pipeline Company, Carnegie Interstate Pipeline Company, Kentucky West Virginia Gas Company, NORA Transmission Company, High Island Offshore System, Ozark Gas Transmission System, and Sabine Pipeline Company. 
Figure 25. Expirations of Firm Transportation Capacity Under Contract as of April 1, 1996, by Region
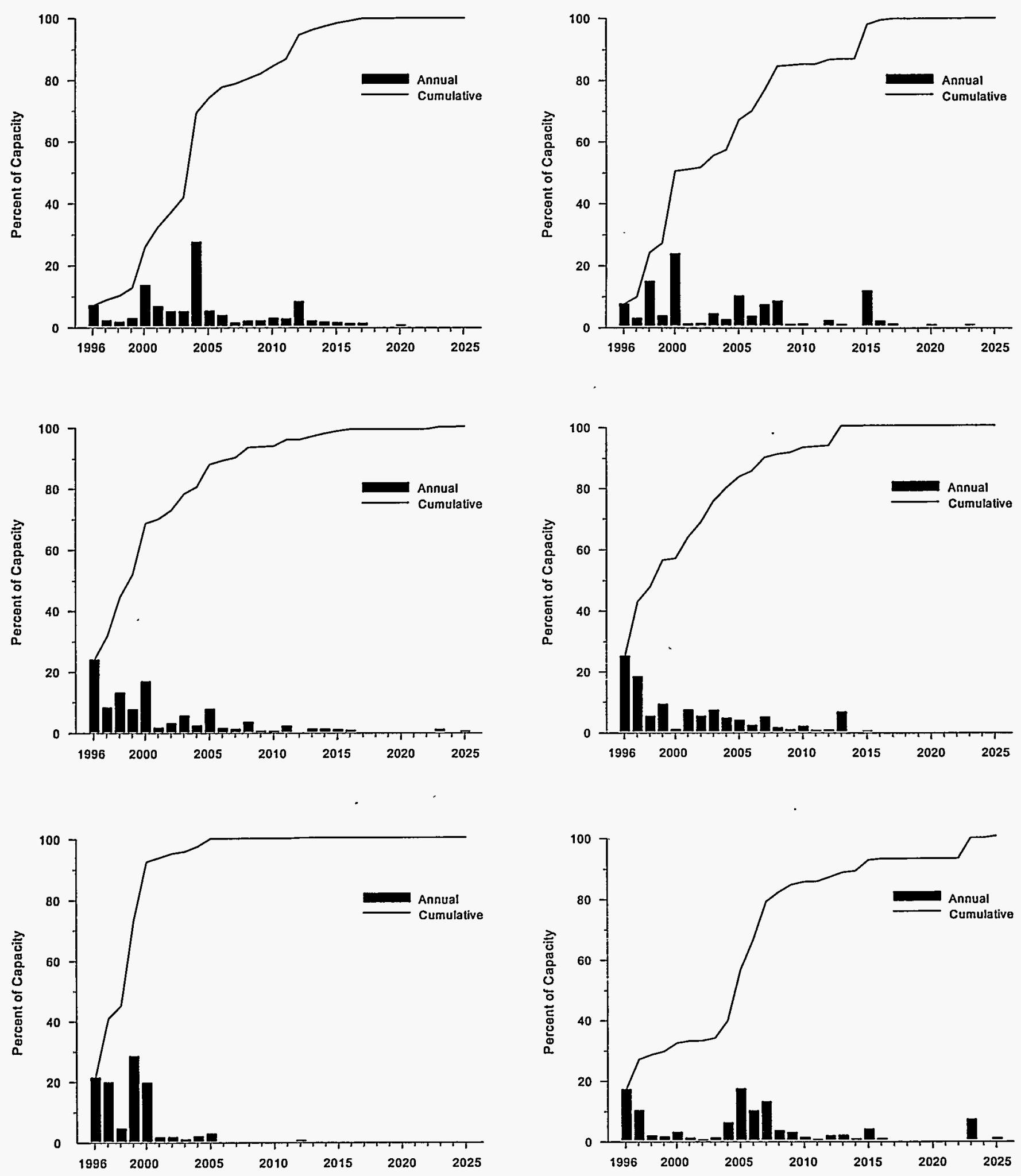

Source: Energy Information Administration, Office of Oil and Gas, derived from Federal Energy Regulatory Commission (FERC) Index of Customers data for April 1, 1996, FERC Bulletin Board (August 28, 1996). 
for several years. ${ }^{34}$ Incidentally, in the years from January 1998 through December 2001, the Southeast is the region with the largest share of contract expirations, with over 40 percent of its contracts with pipeline companies serving the region due to expire. Between 2001 and 2010, expirations in the Northeast and West exceed 50 percent of current reservations, bringing cumulative expirations up to approximately 85 percent of 1996 reservations in those regions-this is comparable to the levels in other regions.

Between 1996 and 2001, over half ${ }^{35}$ of the interstate pipeline companies will have more than three-fourths of their current contracts expire. For example,all firm contracts with Koch Gateway, which serves the Southwest Region, will expire by 1999. Additional companies with a significant portion of their contracts expiring between 1997 and 2001 include Questar, Company of America, which had capacity turned back when some contracts expired in 1996, will see a significant amount of additional expirations in 1998 and again in 2000 . This will bring the company's total expirations in 2001 up to 94 percent of the 1996 capacity reservation levels. In contrast, for approximately one-third of the companies with contracts that generally exceed 10 years in duration, significant expirations are postponed until 2001 or later. ${ }^{36}$ In addition, several companies that together serve a broad geographic area will have limited vulnerability to capacity turnback until after 2010 compared with other pipeline companies. For example, 60 percent of capacity currently reserved on Algonquin Gas Transmission Company is under contracts that are not due to expire until after $2010 .{ }^{37}$ Pacific Gas Transmission Company will have 40 percent of its transportation contracts expiring after 2020. ANR Pipeline Company holds the current record for the longest contract term; it has one small-volume transportation contract that will expire in 2025.

\section{Industry Expectations for Capacity Turnback}

Two surveys were conducted by the industry to assess expectations about capacity turnback. The Interstate Natural

\footnotetext{
${ }^{34}$ To date, the Western Region, which includes California, has led the other regions in terms of potential for capacity turnback. However, a number of large capacity contracts have already expired or have been renegotiated, with extended terms. These expired contracts were not in place on April 1, 1996, and therefore are not included in FERC's Index of Customers data, which present a snapshot of active contracts as of April 1, 1996.

${ }^{35}$ Represents 33 of the 64 interstate pipeline companies included in the Index of Customers data.

${ }^{36} \mathrm{C}$ mpanies with a significant amount of capacity expirations between 2001 and 2005 include National Fuel Gas Supply Corporation and Columbia Gas Transmission Corporation. Pipeline companies with significant capacity expirations between 2006 and 2010 include Kern River Gas Transmission Company, Northwest Pipeline Corporation, and Transcontinental Gas Pipeline Corporation.

${ }^{37}$ Additional companies include Pacific Gas Transmission Company, Williams Natural Gas Company, Texas Eastern Transmission Corporation, and Florida Gas Transmission Corporation.
}

Gas Association of America survey in March 1995 examined the expectations of a sample of 31 interstate pipeline companies regarding the amount of capacity likely to be turned back. ${ }^{38}$ In August 1995, the LDC Caucus survey looked into the expectations of a sample of 75 LDC shippers for future capacity reservations. ${ }^{39}$

Pipeline companies anticipate that 75 percent of capacity expiring under long-term contracts through 2002 will lead to long-term resubscriptions, although for a lesser term than under the expiring contract. Further, based on market characteristics, peak-day requirements, and communication with shippers, pipeline companies expect only a moderate decline in the demand for long-term firm transportation contracts during this period. This decline is expected to result in an increase in uncommitted capacity to 13 percent of capacity in 2002, up from 4 percent in 1994. Regionally, pipeline companies that serve the West expect to see the most significant increase in uncommitted capacity, from 1 percent in 1994 to 25 percent in 2002. All other regions, except the Rockies, also are expected to have increased levels of uncommitted capacity that will reach between 6 and 15 percent of current capacity in 2002.

The survey of local distribution companies, almost a third of which have connections to four or more interstate pipelines, presents a somewhat different outlook about the levels and locations of future capacity reservations. Whereas almost 30 percent of LDCs in the survey expect to increase their capacity reservations, approximately 45 percent expect to reduce their reservations by 5 percent to over 25 percent from 1995 levels. It is difficult to gauge the amount of capacity that could be affected, because the survey did not collect volumetric information. The survey also did not ask LDCs about the price at which they would renew their reservations. Nevertheless, it appears that LDCs expect to turn back more capacity than pipeline companies anticipate. Approximately two-thirds of large-volume LDCs (with throughput exceeding 300 million cubic feet per day) expect to reduce their capacity reservations.

Competition among pipeline companies may be a factor in future reductions in capacity reservations by LDCs. Almost two-thirds of the LDCs in the survey connected to four or more interstate pipelines (one-third of the sample) expect to reduce their capacity reservations and to enter into contracts

\footnotetext{
${ }^{38}$ The Interstate Natural Gas Association of America published the survey results in its September 1995 report, The Effect of Restructuring on Long-Term Contract For Interstate Pipeline Capacity.

${ }^{39}$ The LDC Caucus is a national organization of almost 200 local distribution companies that are members of the American Gas Association. The results of the survey as well as an analysis of other issues relating to unsubscribed pipeline capacity were published in the December 1995 report Future Unsubscribed Pipeline Capacity.
} 
with shorter terms. When the survey was conducted in August 1995 , the potential problem of unsubscribed capacity during the next 5 years appeared to be most significant in the West, followed by the Middle Atlantic and North Central East regions. The results for the Middle Atlantic States are in contrast to the pipeline company survey, which found that no significant reductions were anticipated by the pipeline companies serving that region.

A comparison of the two surveys with the contract expiration data presented in this chapter indicate that the Midwest and Central regions may be particularly vulnerable to capacity turnback through $2001 .^{40}$ The industry surveys indicate that both pipelines and local distribution companies expect a significant reduction in the long-term capacity commitments needed in the future. There will be ample opportunity to turn back capacity in the Midwest, as approximately 70 percent of currently reserved capacity is under contracts that will expire by 2001 .

\section{Future Challenges}

The changes that shippers are making to their long-term firm capacity contracts indicate a general shift in operating procedures for the transportation industry. The movement to tightly controlled, short-term capacity contracts will have an impact on interruptible transportation service, the secondary market for capacity, rates for firm capacity, and the perceived risk of pipeline company investments.

As shippers align their firm capacity contracts with their system requirements, interruptible transportation (IT) will be affected in two basic ways. First, if the pipeline company's system contains excess capacity as a result of shippers' turnbacks of firm capacity, interruptible transportation may become very reliable. If the pipeline company is unable to market the turned-back capacity, its system may operate below its potential during peak periods. Therefore, it is unlikely that interruptible service will need to be suspended because of capacity constraints. This could result in interruptible service that is essentially as reliable as firm service, making IT more valuable to shippers than it is now. Second, future tariff rates for transportation service, including

\footnotetext{
${ }^{10} \mathrm{There}$ are a number of limitations with this comparison. First, the industry surveys were done 1 to 2 years ago and may have become outdated. Second, because each of the studies uses different region classifications, aggregate regions (for the East, West, and Midwest/Central) were developed as part of this analysis to allow comparisons. In some cases, the mapping to aggregate regions required analyst judgment, and is therefore somewhat uncertain. Third, coverage of the three data sources varies. The contract information (Index of Customers) represents all existing contracts, whereas the other two studies are based on industry surveys of a sample of either LDCs or pipeline companies. In spite of these limitations, the comparison may be broadly indicative of industry expectations.
}

IT, may increase as some fixed costs that previously were recovered from capacity that now has been turned back are collected from remaining customers. ${ }^{41}$ However, depending on the competitive environment, some companies may be forced to discount IT rates.

Capacity turnbacks could affect the secondary market in one of several ways. First, the reduction in firm capacity held may reduce the quantity of capacity that is offered for release. However, turned-back capacity might not have been highly marketable to replacement shippers to begin with. Unless the turnback provides space on a desired segment of the pipeline, it may not materially affect the release market. Also, as discussed above, the excess system capacity could result in highly reliable interruptible transportation service that could compete with the secondary market.

The change in firm transportation contracting will challenge the current rate design practice for firm capacity charges. As discussed earlier, Order 636 mandated the use of the straight fixed-variable (SFV) method of rate design, which recovers all fixed costs in the reservation charge of firm transportation rates. On some systems, the SFV rate design may have created charges that exceed the shipper's valuation of the firm capacity. ${ }^{42}$ FERC recognizes that, in some cases, departure from SFV may be appropriate to make unsubscribed capacity more marketable..$^{43}$ Nevertheless, this does not address the price of the capacity that remains under contract to captive customers. In some cases, the alternative rate design methods described in FERC's January 31, 1996 Order (Chapter 1) can alleviate the value and price disparity of capacity. As pipeline companies develop innovative pricing methods, practices that charge varying rates for essentially the same services may need to be evaluated.

Further turnback of long-term firm transportation (FT) capacity by LDCs can be expected as the trend toward unbundling of LDC services to smaller customers gains momentum (see Chapter 6). As part of retail unbundling, some State regulators are requiring LDCs to assign the capacity they hold on pipelines to their customers. This will reduce LDC requirements for firm capacity and give LDCs less reason to renew their FT contracts when they come up for

\footnotetext{
A1 In the Transwestern and El Paso tumback examples, customers who were parties to the settlement are charged negotiated rates for the next 10 years. However, customers who were not parties to the settlement may face rate increases associated with the capacity turnback.

${ }^{42}$ The fact that, on average, rates for most released capacity are discounted at about 31 percent of the maximum rate level (Interstate Natural Gas Association of America, Capacity Release Activity in the First Three Quarters of 1994 (December 1994)) may also be an indication that reservation rates exceed the shipper's valuation of firm capacity.

${ }^{43}$ Federal Energy Regulatory Commission, Order Following Technical Conference, Natural Gas Pipeline Company of America, Docket Nos. RP95326, et al. (October 11, 1995), p. 11 .
} 
renewal. Moreover, as more LDCs exit the business of providing bundled sales service, they will have less need for long-term FT capacity. Competitive pressures may make long-term FT pipeline capacity an expensive option compared with other services offered to LDC transportation customers. The challenge for pipeline companies is to market capacity to existing customers as well as to other shippers who possibly have expanding markets.

The current changes in gas pipeline capacity contracting somewhat parallel the changes in gas supply contracting that occurred over a decade ago (see Chapter 4). Previously, the norm in gas supply contracting was the use of fixed-price, long-term contracts. The upstream deliverability surplus of the early 1980 's, along with open access in transmission and the development of the spot market in gas, contributed to the demise of this system. Specifically, industrial consumers could save hundreds of millions of dollars by purchasing gas on the spot market. Pipeline companies, however, who at the time were both sellers and transporters of the gas, were contractually obligated to pay for what were now largely unmarketable supplies of gas. The pipeline companies ultimately sought to free themselves from their contractual obligations by declaring force majeure and even bankruptcy. Since then, long-term fixed-price supply contracts have been largely abandoned by the industry.
In today's market for pipeline capacity, long-term contracts are not flexible enough to keep pace with changing market conditions. Instead of a gas productivity surplus (the gas bubble from the 1980's), there is now a pipeline capacity surplus in some areas. Shippers are now seeking to free themselves from inflexible long-term capacity contracts just as pipeline companies once sought relief from inflexible longterm gas purchase contracts. Some shippers are reducing the length of their contracts and expect that new contracts will have shorter terms than current contracts to enable them to respond better to market changes. ${ }^{44}$

As in the supply industry of a decade ago, the role of the spot market is a key factor in the changing market for pipeline capacity. In the case of gas supply, the emergence of spot supplies at prices below the previously established contracted prices effectively doomed the use of fixed-price long-term contracts. While it may be too early to predict with confidence, the emerging secondary or spot market for pipeline capacity may seriously undermine the practice of contracting for pipeline capacity for long periods of time at fixed prices. What could emerge is a system of rates that are based on market conditions as opposed to historical costs. Such a system may promote more options for shippers and provide opportunitites for pipeline companies. However, the increased opportunities may be accompanied by increased risk since market-driven pricing does not assure a profit. 


\section{The Emergence of Natural Gas Market Centers}

Several major commercial innovations have developed during the past 10 years in response to the restructuring of the U.S. natural gas industry. In the mid-1980's, the "marketer" segment of the industry emerged. Marketers exploited shortterm, open spot markets and more open transportation markets, and they effected exchanges of gas between buyers and sellers who never before had been brought together. Market conditions and regulatory reform in the late 1980's and early 1990's continued to bring about a more open market, not only for transportation but also for storage capacity rights. This evolution resulted in the development of capacity release markets, which supported the exchange of rights to transportation and storage by buyers and sellers of gas. More frequent trading in gas and rights to transportation and storage services by a diverse group of industry participants resulted in greater price volatility. This in turn led to the institution of a futures market where transparent price information could be found and contracts for controlling some of the price risks could be purchased.

The development of market hubs and centers is a recent innovation in the natural gas marketplace. (See box, p. 64 for a description of differences between hubs, market hubs, and market centers. ${ }^{45}$ ) They have been key features in the evolution of competitive markets in other industries such as air transportation. In the natural gas industry, market hubs and centers were the logical outgrowth of open-access restructuring, providing the place where many buyers and sellers can transact business and receive services.

These centers, supported in Federal Energy Regulatory Commission (FERC) Order $636,{ }^{46}$ were formed by companies that saw opportunities to provide new services to increase trade in gas and capacity across pipeline and storage systems and to meet the need for short-term balancing services formerly provided by pipeline companies under bundled service. Market centers combine features of recent commercial innovations in that they: (1) provide the means to increase short-term exchanges between parties, (2) provide short-term/short-haul transportation services that improve a company's capability to move gas between systems, and (3) offer a means to reduce price risk exposure. In particular:

\footnotetext{
${ }^{45}$ For simplicity, the term "market center" is used throughout the rest of the chapter to represent market hubs and market centers.

${ }^{46}$ While FERC Order 636 did not require the creation of market centers, it disallowed any efforts that would hinder their development. Order 636-B defined a market center as an area where (a) pipelines interconnect and (b) there exists or is a reasonable potential for developing a market institution that facilitates the free interchange of gas.
}

- Market centers have increased shippers' access to both long- and short-term gas supplies. Access to short-term supply is particularly important, especially for short-term adjustment of available supply with demand. At least 39 centers are operating in the United States and Canada, providing numerous interconnections and routes to move gas from production areas to markets.

- Market centers have access to 47 percent of working gas storage capacity in North America and are connected to practically all the high-deliverability storage facilities. Many physical services at market centers involve storage. The high-deliverability facilities are ideally suited for providing a variety of short-term services such as balancing, parking, and loaning.

- The availability of better price information and access to other buyers and sellers at market centers should provide a means of reducing price risk exposure. This is key because price risk for natural gas is greater than for any other major commodity. However, this capability is limited by the fact that public, real-time information on gas prices and the cost of nearby pipe and storage is available only for a few market centers.

- Active trade in the futures contract market has led to major development of the Henry Hub and Waha Hub market center areas. More than 25 pipeline systems have access to these market centers. In 1995, several hundred billion cubic feet of gas moved through the Henry Hub under a variety of hub services.

This chapter discusses the value of market centers in today's natural gas marketplace, highlighting their importance in capacity and financial transactions. The further development of an interconnected network of hubs seems likely as the industry increasingly looks for ways to make better use of existing pipe and storage capacity and to move gas from areas of ample supply and low prices to areas of greater demand and higher prices.

\section{Value of Market Centers}

When it issued Order 636, FERC recognized that the type of expertise developed over the years by pipeline companies to manage gas purchases and balance ever-changing user demand with supply would somehow have to be retained. As one solution, FERC promoted the development of the market center concept as a means and location to provide the new 


\section{Distinguishing Between Hubs, Market Hubs, and Market Centers}

Just what type of facility constitutes a natural gas market center, a market hub, or simply a hub operation? Applying the correct label to a specific site is often difficult. The answer often differs among operators themselves. The following definitions were developed to help categorize the distinct types of operations that usually are thought of as market centers and hubs. For convenience, the remainder of Chapter 3 will use the term "market center" for both market hubs and centers.

1. Hubs are operated as physical transfer points (often referred to as headers) where several pipelines are connected to a facility that permits the redirecting of gas volumes from one pipeline to another (Figure 26). Separate facilities for storage and gas plant processing may also be interconnected with the hub, but the hub operator usually does not handle a customer's relationship with these facilities. The operator merely routes a customer's gas volumes back and forth. Often such hubs are located in supply areas, receiving volumes and directing them forward to markets (Figure 26, E to F) with little or no bi-directional activity. A good example of a conventional hub is the Aqua Dulce Hub in southeastern Texas. This facility primarily offers pipeline interchange and transportation services.

2. Market hubs include the same types of activities as described above, except that the operator offers a number of expanded services that facilitate the buying, selling, and transportation of gas within the local facility. These services often include making arrangements for storage and plant processing services, peaking services, transfer of title for gas sales/purchases, anonymous gas trading (often handled via electronic gas-trading systems), in addition to wheeling (or transportation) of gas. As an adjunct to these services, the market hubs often include information services and electronic gas trading for their customers. Some market hubs have broadened their operations to become market centers. The Henry Hub in Louisiana and the several Katy hubs in eastern Texas are examples of market hubs. These facilities provide services such as parking and loaning of gas, balancing, and intra-hub transfers of gas, in addition to transportation and interchange services at a physical hub.

3. Market centers can operate almost independently of physical facilities. Often, however, they are associated with, and use, the physical infrastructure of one or more pipeline systems in the implementation of their operations and services (wherein the system(s) can function as one very large hub). Many centers are situated/structured so as to have broad access to other centers and to be easily accessed from many parts of the country. They can be used to access storage or arrange transportation from a supply area (receipt) to a customer's desired delivery point. At the same time, a center can provide the ancillary services a customer might need, such as short-term parking or gas borrowing/loaning, balancing services, etc. Two good examples of such operations are the Union Hub in Ontario, Canada, and the Columbia Market Center in the U.S. Northeast. Both centers support the interchange of gas for their customers via the many interconnections and delivery points on their associated pipeline systems, but neither center operates a physical hub.

Market centers also provide a location, or "market," where shippers and traders can buy and sell transportation, capacity, and natural gas itself. Some examples of how market centers may be used include:

A shipper with firm capacity on Pipeline A wants to deliver gas to an end user located off Pipeline B. The shipper can make arrangements to transfer the gas through the market center, with the center providing (de-)compression services if pipelines A and B operate at different pressures. Needed capacity on Pipeline B may be sought and acquired at the center if trading services (or traders) have such posted. Similarly, the shipper can use the center's services to revise its nominations (or temporarily release some capacity) on Pipeline A, with the center handling the administrative requirements, including confirmations, associated with the transactions. To cover any imbalances that might occur when the purchased production volume exceeds nominated capacity on Pipeline $A$, the shipper can execute an operational balancing agreement with the center.

A large end user or local distribution company with firm capacity on Pipeline $\mathbf{D}$ buys gas in an area serviced by Pipeline $\mathbf{C}$, which has only interruptible capacity available. The shipper can arrange to have supplies moved on Pipeline $C$ during nonpeak periods; any excess gas is injected into (high-deliverability) storage at the center. When the shipper experiences a sudden increase in demand, the center will provide the necessary incremental support from storage. If the shipper temporarily exceeds its storage inventory at the center, the center offers gas loaning, with the shipper responsible for replacement of the gas within a specified period. Similarly, storage withdrawal and loaning by the center can also be used to cover shortfalls when purchased production flowing into Pipeline $\mathrm{C}$ does not equal transportation nominations. Many centers also provide a real-time tracking service to notify shippers immediately when such imbalances are imminent. 
Figure 26. General Representation of a Hub Configuration

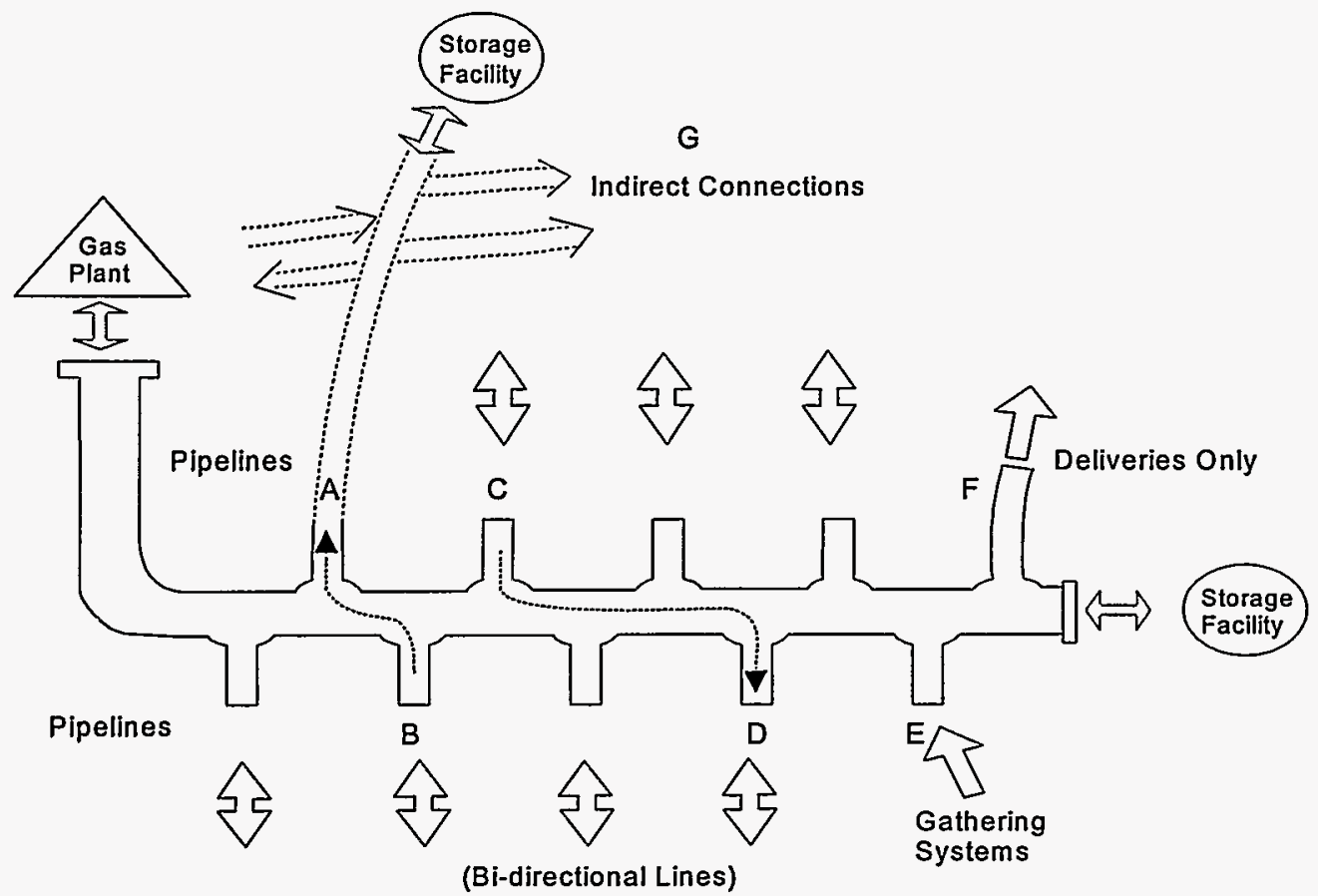

Source: Energy Information Administration, Office of Oil and Gas.

services that customers (now shippers) needed to manage their portfolios of supply, transportation, and storage. In addition, these locations would increase the potential number of exchanges across pipeline systems and permit a "market" to develop for the trading of natural gas volumes, storage, and pipeline capacity. Because services were priced separately, it was presumed that additional efficiencies would develop.

The location and form of these centers was to be left up to the industry and the marketplace to decide. A possible location for a market center was, of course, where a large number of pipelines already were interconnected and nearby storage facilities already existed. Such locations could be readily developed into trading centers where supplies from a number of sources could be aggregated or traded and where a large number of buyers could access supplies from multiple pipelines. Moreover, these exchanges would promote efficiency by encouraging greater utilization of the associated pipeline and storage systems throughout the year. Such facilities located in major producing areas would also help smooth production by providing a place to put gas readily when there was no immediate market for the gas. This would also promote productive efficiency since production costs are minimized by producing at a relatively steady rate.

The Nation's vast interstate natural gas pipeline system includes numerous pipeline interconnections. Most of these connections were developed singly as individual pipeline companies expanded their markets and supply sources and hooked up to system storage. Hub sites, with multiple interconnections, developed mainly around major gathering systems and in supply areas. Before the 1980's, pipeline interconnections were put in place as additional insurance to maintain the reliability of the system, to receive supply via a major trunkline, or to fulfill exchange gas commitments with other pipeline companies.

Until open access (1987), little value was to be gained from regularly using these connections. Moreover, such use was restricted by long-term contractual relationships along particular pipeline systems. Flexibility was often further constrained by the companies' unwillingness to release gas because arrangements with lenders required them to maintain specific amounts of dedicated reserves. Many interconnections were used only for emergency situations or when a pipeline company had an unexpectedly large need for gas.

The value of moving gas between pipeline systems and between pipeline and storage systems increased significantly in the 1980's and 1990's with development of interruptible, discount markets for rights to transmission capacity. Overall, these market developments expanded possible opportunities and thus encouraged choice. The challenge was to extend 
these choices to a large number of customers to enhance the competitiveness of the natural gas industry.

The market center provided a focal point and location where transparent and public spot markets could expand and further encourage improvements in the efficiency of exchange. This would take place by (1) enabling an increasing number of buyers to seek out the cheapest source of supply, (2) encouraging sellers to seek out the buyer who valued the gas commodity most, and (3) encouraging trading rights to transportation service.

In addition, access to storage interconnections increased the value of centers even further when customers of pipeline companies had to assume the responsibility for adjusting the amount of gas they received with the amount of gas they had reserved, or face imbalance penalties. The interconnections became even more valuable when they provided access to high-deliverability storage sites, which supported such needed services as short-term parking, loaning, swing supplies, and peaking.

The value of the location is also improved if it enables customers, or an administrator acting for customers, to reallocate gas and rights to transportation and storage services depending on the customers' current needs. Opportunities for reallocating these resources occur when customers' short-term needs vary in an unpredictable way. Situations can continually arise where one customer has an unexpected need for gas, and concurrently, another customer has an unexpected capability to release gas or rights to pipe and storage space.

However, the value of a location as a market center is reduced when customers' demands are influenced by the same forces in the same way. When customer demands on the system are very similar, the hub acts merely as a part of the pipeline system and not a trading center at which rights are exchanged to make fuller use of the system.

How well individual market centers, individually or collectively, have improved gas interchange and transportation flexibility is difficult to ascertain because of the lack of systematic and complete data on market center operations. Nonetheless, market centers have become a familiar and often a key feature in today's natural gas marketplace.

\section{Market Center Locations}

The market center segment of the natural gas industry has grown rapidly since industry restructuring. As of September 1996, approximately 39 market centers were operating in the
United States and Canada (Figure 27), with another 6 expected to be in operation by 1999. Most are located in the production areas of Texas and Louisiana, and 7 are in Canada. Of the 39 active sites, 27 began operating between 1994 and late 1996 (Table 7). A number of these market centers, however, have not yet attracted significant business.

Some market centers have extensive delivery capability. For example, many customers regularly conduct business at the Henry Hub in southern Louisiana through 12 interconnecting pipeline systems and 3 high-deliverability, directly accessible salt storage caverns (Table 8 ). The Henry $\mathrm{Hub}$ is accessible to major producers both onshore and offshore Louisiana where price and other relevant information is readily available via electronic and printed media. This hub and others in the producing areas help producers to smooth production.

The Henry Hub is also the delivery point for a New York Mercantile Exchange futures contract, which improves the value of this location as a market center. ${ }^{47}$ The ready availability of information on the price of gas and supporting services helps customers to become knowledgeable buyers and sellers. In addition, many different types of customers-producers, major industrial customers, and local distribution companies (LDCs) - use the Henry Hub. Because of this ready availability of information, the difference between the price that sellers are willing to take for their gas and the price that buyers are willing to pay is probably not great. Hence, it is relatively easy for these customers to agree on a price to complete a deal, which helps explain the large number of transactions. ${ }^{48}$

An important market center in the Northeast consuming region is the Ellisburg-Leidy Center in northern Pennsylvania, which has access to 32 storage reservoirs and also has electronic trading (Table 8). The continued success of this market center is, in part, based on the relative independence of customers' demands for gas, the variety of contract terms, and the ease of transferring the contract rights. If demands are relatively independent, then the exchange of gas and supporting services between customers could result in a reduction in the amount of pipeline service required to bring gas from major production areas to major consuming markets.

\footnotetext{
${ }^{47}$ The three other natural gas futures contracts also have delivery points in major producing areas. Two contracts have delivery points in West Texas: the Kansas City Board of Trade contract is through the Waha Hub and a NYMEX contract is through the Permian Basin Pool. A new NYMEX contract for delivery in Alberta, Canada, began trading in September 1996.

${ }^{48}$ Such a market frequently is referred to as a liquid market. Liquidity is often defined in terms of the smallness of the spread between bid and offer price and the number of trades.
} 
Figure 27. Locations of the Major Natural Gas Market Centers in the United States and Canada

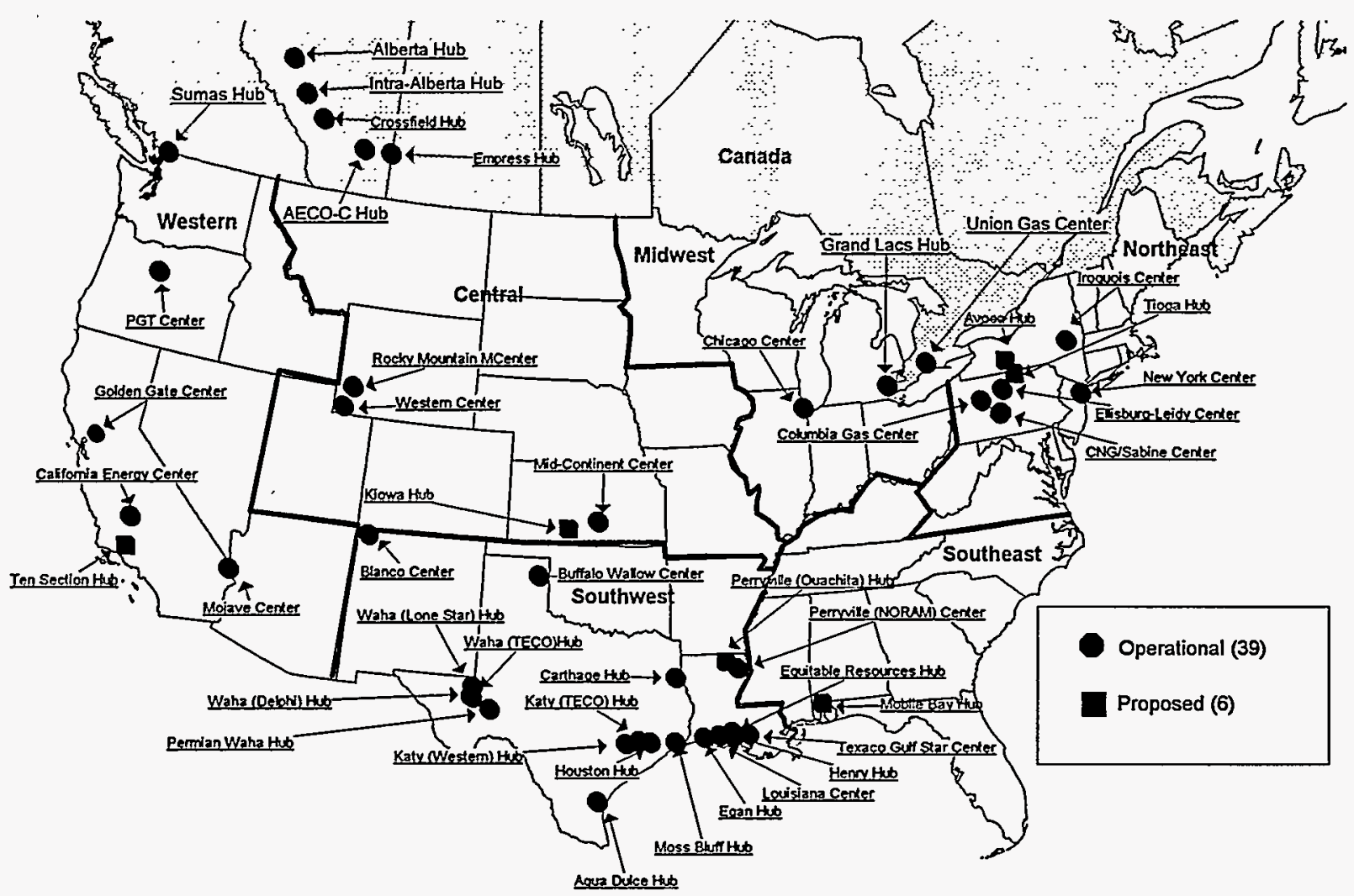

Source: Energy Information Administration, EIAGIS-NG Geographic Information System, Natural Gas Market Center/Hub Database, as of September 1996.

\section{Trade Between Market Centers}

The emergence of the natural gas market center within the North American natural gas pipeline network has facilitated the movement of natural gas from production and storage sites to customers needing gas. But as customers demand greater access to diverse supply sources, market center operators are having to develop improved interconnections and better ways to transact business. Creating closer business and physical relationships with other market centers is one way to improve service and attract customers. By examining the locations of a number of today's market centers, one can see how this trade occurs.

- The Waha area of West Texas has four market centers. These sites represent a total of 26 interconnections with a number of inter- and intrastate pipelines, many serving several of the sites. In addition to these four, the Buffalo Wallow Center, located to the north of Waha in the Texas Panhandle, also interconnects with many of the same pipelines that interchange in the Waha area. These ties permit the operator of the center to redirect its customer's needs either northward toward the Midwest or eastward depending upon market demands (Figure 28).

- The Katy area, in East Texas, also has several hubs that provide a direct link via several pipelines (Oasis, TECO, and Valero), with Waha area centers (Figure 28). In addition, the Valero pipeline system provides a link between the Waha area and the Carthage hub located northeast of the Katy area. The five Katy area hubs interconnect with at least 33 pipelines, including a number of the major interstate pipelines. For example, Texas Eastern Transmission and Tennessee Gas Pipeline companies, which are major transporters of gas to the Midwest and Northeast, have links with the Carthage Hub and several of the Katy area hubs. The large majority of interconnections, however, are between 


\begin{tabular}{|c|c|c|c|c|c|c|c|}
\hline \multirow[b]{2}{*}{ Item } & \multirow[b]{2}{*}{$\begin{array}{c}\text { Number } \\
\text { of } \\
\text { Operations }\end{array}$} & \multirow[b]{2}{*}{\begin{tabular}{|c|} 
Number \\
Reaching \\
Maximum \\
Capability in \\
Jan-Feb $1996^{1}$
\end{tabular}} & \multicolumn{5}{|c|}{ Storage Availability } \\
\hline & & & $\begin{array}{c}\text { Number of } \\
\text { Sites }\end{array}$ & $\begin{array}{c}\text { Total } \\
\text { Working Gas } \\
\text { (Bcf) }\end{array}$ & $\begin{array}{c}\text { Total Daily } \\
\text { Deliverability } \\
\text { (MṂcf/d) }\end{array}$ & $\begin{array}{l}\text { Salt/High- } \\
\text { Deliverability } \\
\text { Storage } \\
\text { (MMcf/d) }\end{array}$ & $\begin{array}{c}\text { Linepack } \\
\text { Used for } \\
\text { Parking and } \\
\text { Loaning } \\
\text { (number of } \\
\text { centers) }\end{array}$ \\
\hline \multicolumn{8}{|l|}{ Market Centers } \\
\hline Pre-1994 & 12 & 4 & 56 & 568 & 10,928 & 1,840 & 0 \\
\hline $1994-1996^{2}$ & 27 & 2 & 94 & 1,438 & 29,221 & 4,785 & $3^{3}$ \\
\hline Total Operational & 39 & 6 & 150 & 2,006 & 30,149 & 6,625 & 3 \\
\hline Proposed & 6 & - & 6 & 104 & 3,010 & 1,860 & -- \\
\hline $\begin{array}{l}\text { Total U.S./Canada Storage } \\
\text { (January } 1,1996 \text { ) }\end{array}$ & - & - & 414 & 4,306 & 77,697 & 10,004 & - \\
\hline
\end{tabular}

'Includes market centers that operated at their maximum (pipeline transfers or storage withdrawals) throughput capability sometime during the 2-month period.

${ }^{2}$ Does not include sites slated to be in operation after April 1, 1996.

${ }^{3}$ Approximately 560 million cubic feet of linepack, on average, is available for parking and gas loaning services at these market centers. Bcf = Billion cubic feet. MMcf/d = Million cubic feet per day. -- = Not applicable.

Sources: Energy Information Administration, EIAGIS-NG Geographic Information System, Natural Gas Underground Storage Database and Natural Gas Market Center/Hub Database (as of August 1996), compiled from industry trade press and filings with the Federal Energy Regulatory Commission.

pipeline systems, which play a major role in allowing shippers a large degree of flexibility in routing their gas.

- The two market centers in the Perryville area of northeast Louisiana (NORAM Transmission Company (operational) and Ouachita River Gas Storage Company (proposed)) have, or will have, arrangements in place to support trading with several of the Katy/Waha interconnections, as well as the Carthage Market Hub (Figure 28). The NORAM market center is not a hub, but it has a large number of receipt and delivery points on its system in the area that provide access to nine of the major interstate systems transporting gas north and east to major market areas. The NORAM center also provides shippers access to supplies located in the Anadarko and Acoma basins of Oklahoma. The Ouachita Hub will have many of the same interconnections with the interstate system, including the NORAM system, but will also provide storage and a number of other hub services.

- The Henry Hub, given its strategic location and its association with the NYMEX futures trading market, is directly linked with the Carthage hub as well as most of the Katy hubs. Shippers using the Henry Hub have access to major production areas for gas as distant as eastern Texas and as local as south Louisiana onshore and offshore gas production. The Henry Hub, via the many interstate and intrastate systems, handled several hundred billion cubic feet of gas in 1995 . The center also serves as the operational arm for the Texaco Market Center, which itself provides direct and indirect transportation ties with 26 inter- and intrastate systems.

- The Katy and Carthage area hubs also may soon be linked to pipeline(s) serving the Oklahoma Anadarko Basin production area. These market centers located in eastern Texas could benefit from increased access to the relatively lower priced production in the Anardarko area (Figure 28). Current area pipeline systems, with some improvements in interconnections, could direct some of their flows eastward: for instance, via the Transok Pipeline system onto the Ozark and NORAM Pipeline systems for routing to the Perryville centers in northern Louisiana. They could also route their flows through the Carthage hub located in southeast Texas, via the intrastate Texoma Pipeline system which runs from northeast Texas southward. Tejas Gas recently acquired the Transok system, perhaps in part with the intention of rerouting some of the Anadarko production to higher priced markets via current and future market center interconnections. ${ }^{49}$

The trading of gas between market centers occurs especially at those centers in the Texas and Louisiana producing areas. ${ }^{49}$ See "Tejas Gas Buys Transok," Gas Processors Report (Houston, TX,
une 3, 1996). 
Table 8. Operational Market Centers in the United States and Canada, September 1996

\begin{tabular}{|c|c|c|c|c|c|c|c|c|}
\hline $\begin{array}{l}\text { Region / } \\
\text { Market Center Name }\end{array}$ & State & $\begin{array}{c}\text { Year } \\
\text { Began }\end{array}$ & $\begin{array}{c}\text { Type of } \\
\text { Operation' }\end{array}$ & $\begin{array}{c}\text { Direct } \\
\text { Pipeline } \\
\text { Inter- } \\
\text { connects }\end{array}$ & $\begin{array}{c}\text { Maximum } \\
\text { Handling } \\
\text { Capability } \\
\text { (MMcf/d) }\end{array}$ & $\begin{array}{c}\text { Number } \\
\text { of Storage } \\
\text { Sites }^{3}\end{array}$ & $\begin{array}{l}\text { Type of } \\
\text { Storage } \\
\text { Sites }^{4}\end{array}$ & $\begin{array}{c}\text { Electronic } \\
\text { Trading } \\
\text { Available }^{5}\end{array}$ \\
\hline \multicolumn{9}{|l|}{ Southwest } \\
\hline Aqua Dulce Hub & $\mathrm{TX}$ & 1990 & Hub & 12 & 1,200 & 0 & None & No \\
\hline Blanco Market Center & NM & 1993 & System & 6 & 755 & 0 & None & EBB \\
\hline Buffalo Wallow Market Center & $T X$ & 1994 & System & 23 & 700 & 1 & Cavern & EBB \\
\hline Carthage Hub & $\mathrm{TX}$ & 1990 & Hub & 15 & 1,865 & 0 & Indirect & Yes \\
\hline Egan Hub & LA & 1995 & Hub & 6 & 1,100 & 1 & Cavern & EBB \\
\hline Equitable Resources Hub & LA & 1996 & Hub & 13 & 360 & 1 & Cavern & EBB \\
\hline Henry Hub & LA & 1988 & Hub & 12 & 2,015 & 3 & Cavern & Yes \\
\hline Houston Hub & $\mathrm{TX}$ & 1992 & Hub & 5 & 425 & 2 & Reservoir & Yes \\
\hline Katy (TECO) Hub & $\mathrm{TX}$ & 1995 & Hub & 9 & 500 & 0 & None & No \\
\hline Katy (Western) Hub & $\mathrm{TX}$ & 1993 & Hub & 12 & 800 & 2 & Reservoir & EBB \\
\hline Louisiana Market Center & LA & 1994 & System & 20 & 850 & 1 & Cavern & EBB \\
\hline Moss Bluff Hub & $\mathrm{TX}$ & 1994 & Hub & 6 & 900 & 1 & Cavern & EBB \\
\hline Permian Waha Hub & $\mathrm{TX}$ & 1995 & Hub & 10 & 800 & 1 & Cavern & Yes \\
\hline Perryville (NORAM) Center & LA & 1994 & System & 10 & 1,300 & 4 & Reservoir & Yes \\
\hline Texaco Star Market Center & LA & 1993 & System & 26 & 400 & 1 & Cavern & Yes \\
\hline Waha (Delphi) Hub & $\mathrm{TX}$ & 1995 & Hub & 4 & NA & NA & NA & EBB \\
\hline Waha (Lone Star) Hub & $\mathrm{TX}$ & 1995 & Hub & 5 & NA & NA & NA & EBB \\
\hline Waha (TECO) Hub & $\mathrm{TX}$ & 1995 & Hub & 7 & 500 & 0 & None & EBB \\
\hline \multicolumn{9}{|l|}{ Northeast } \\
\hline CNG/Sabine Market Center & PA & 1994 & System & 14 & 3,081 & 11 & Reservoir & EBB \\
\hline Columbia Gas Market Center & PA & 1995 & System & 12 & 7,074 & 43 & Reservoir & Yes \\
\hline Ellisburg-Leidy Market Center & PA & 1993 & System & 6 & 1,691 & 32 & Reservoir & Yes \\
\hline Iroquois Market Center & NY & 1996 & System & 5 & 1,100 & 0 & Linepack & EBB \\
\hline New York Market Center & NJ & 1993 & System & 4 & 451 & 6 & Mixed & EBB \\
\hline \multicolumn{9}{|l|}{ Midwest } \\
\hline Chicago Market Center & IL & 1993 & System & 5 & 3,435 & 8 & Mixed & Yes \\
\hline Grand Lacs Hub & MI & 1995 & System & 7 & 200 & 3 & Reservoir & EBB \\
\hline \multicolumn{9}{|l|}{ Central } \\
\hline Mid-Continent Market Center & KS & 1995 & System & 9 & 480 & 3 & Mixed & EBB \\
\hline Rocky Mountain Center & WY & 1995 & System & 3 & 740 & 8 & Reservoir & Yes \\
\hline Western Market Center & WY & 1995 & System & 6 & 1,800 & 10 & Reservoir & Yes \\
\hline \multicolumn{9}{|l|}{ Western } \\
\hline California Energy Market Center & $\mathrm{CA}$ & 1994 & System & 6 & NA & 5 & Reservoir & EBB \\
\hline Mojave Market Center & CA & 1996 & System & 4 & 400 & 0 & Linepack & No \\
\hline PGT Market Center & OR & 1994 & System & 4 & NA & 0 & Linepack & EBB \\
\hline \multicolumn{9}{|l|}{ Canada } \\
\hline AECO-C Hub & $A B$ & 1990 & System & 6 & 2,000 & 1 & Reservoir & Yes \\
\hline Alberta Center & $A B$ & 1996 & Hub & 1 & 500 & 1 & Reservoir & Yes \\
\hline Crossfield Hub & $A B$ & 1995 & Hub & 1 & 500 & 1 & Reservoir & Yes \\
\hline Empress Hub & $A B$ & 1986 & System & 3 & 6,200 & 1 & Reservoir & Yes \\
\hline Intra-Alberta Hub & $A B$ & 1994 & Hub & 3 & 12,000 & 4 & Reservoir & Yes \\
\hline Sumas Hub & $\mathrm{BC}$ & 1994 & Hub & 3 & 1,800 & 1 & Reservoir & Yes \\
\hline Union Gas Market Center & ON & 1985 & System & 5 & 4,000 & 1 & Aquifer & No \\
\hline
\end{tabular}

'A market center utilizing the interconnections of one or more pipeline systems for gas interchange purposes is categorized as a "system" operation, while one that uses a central (localized) interchange point is categorized as a "hub."

${ }^{2}$ Maximum volume that may be moved through the system or hub on a daily basis.

${ }^{3}$ Sites directly or readily accessible to operator.

${ }^{4}$ Reservoir represents depleted production field or reef storage site.

${ }^{5}$ An electronic trading system is either available at the center itself or the center is a trading point on one or more commercially available electronic trading systems. EBB indicates that the center at least has one electronic bulletin board service available.

$\mathrm{MMcf} / \mathrm{d}=$ Million cubic feet per day. EBB = Electronic bulletin board. NA = Not available.

Source: Energy Information Administration, ElAGIS-NG Geographic Information System, Natural Gas Market Center/Hub Database as of September 1996, compiled from various industry news sources, discussions with the industry, and filings with the Federal Energy Regulatory Commission. 
Figure 28. West Texas Market Centers Interplay with North and East Texas and Louisiana Market Centers

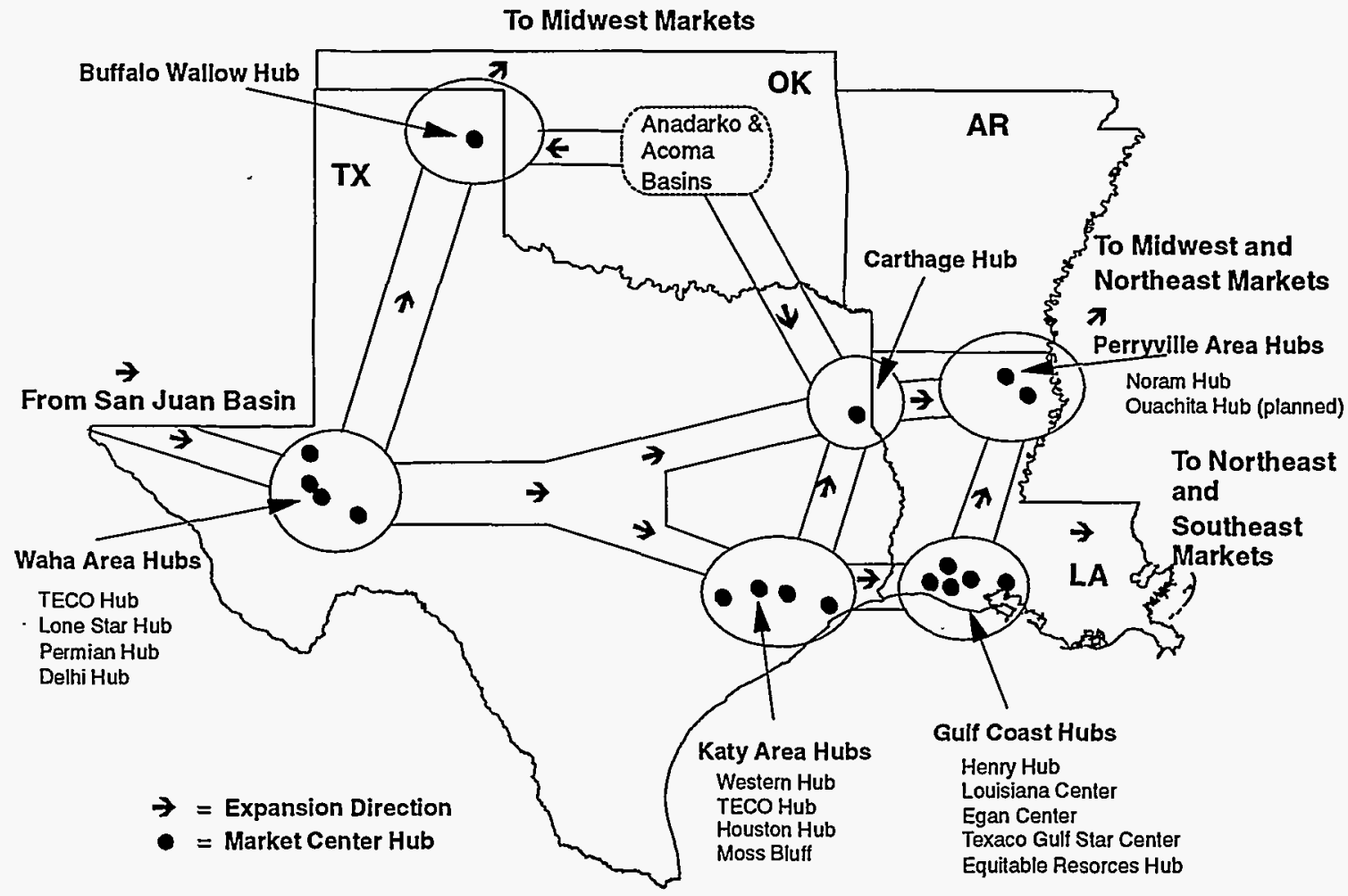

Note: Not all area pipelines are represented.

Sources: Energy Information Administration, EIAGIS-NG Geographic Information System, Natural Gas Market Center/Hub Database, Natural Gas Proposed Pipeline Construction Database, compiled from Federal Energy Regulatory Commission filings and various industry news sources, as of September 1996.

This trade is facilitated by the fact that several key market centers have ready access to incremental gas supplies from a wide variety of sources. This trade is well motivated by market centers with readily available price information. If this information indicates that the difference in the price of gas between market centers exceeds the cost of transporting the gas between these locations, then trading will occur if pipeline capacity is available to move this gas.

It is not surprising that market centers in Texas and Louisiana are continuing to improve their physical and business interconnections and to increase the number of exchanges. Increased trade and interconnections between centers could help to reduce the great price uncertainty currently associated with moving gas between major markets in the United States.

\section{Market Center Operations}

\section{Types of Services}

A number of market centers offer an extensive portfolio of services (see box, p. 71). Currently, however, many customers are choosing only a few of these services. Some of the more frequently used services are wheeling (transportation), parking, loaning, and storage (Table 9). Originally, the Henry Hub offered only transportation service, but recently it began to offer additional services that include parking (short-term storage service) and loaning of gas.

Wheeling, or transportation, is the main service currently provided by the majority of market centers. Two parties that exchange gas at a market center or move gas among pipeline systems via a market center generally require only transportation service. Salt dome storage type hubs are used to transport gas to and from hub interconnections and from one pipeline system to another. In many cases, they also are 


\section{Market Center and Hub Services}

The types of services offered by market centers and hubs vary significantly. No two operations are identical in the services offered, and in fact the features of similarly named services often differ in meaning and inclusions. The list below provides only some of the general types of services offered. Refer to Table 9 for the number of facilities that have offered the service (although the center may not currently be performing the transaction or the service named). The definitions were obtained from the Federal Energy Regulatory Commission's Office of Economic Policy.

Wheeling-Essentially transportation service. Transfer of gas from one interconnected pipeline to another through a header (hub), by displacement (including exchanges), or by physical transfer over the transmission of a market center pipeline.

Parking-A short-term transaction in which the market center holds the shipper's gas for redelivery at a later date. Often uses storage facilities, but may also use displacement or variations in line pack.

Loaning-A short-term advance of gas to a shipper by a market center that is repaid in kind by the shipper a short time later. Also referred to as advancing, drafting, reverse parking, and imbalance resolution.

Storage-Storage that is longer than parking, such as seasonal storage. Injection and withdrawal operations may be separately charged.

Peaking-Short-term (usually less than a day and perhaps hourly) sales of gas to meet unanticipated increases in demand or shortages of gas experienced by the buyer.

Balancing-A short-term interruptible arrangement to cover a temporary imbalance situation. The service is often provided in conjunction with parking and loaning.

Gas Sales-Sales of gas that are used mainly to satisfy the customer's anticipated load requirements or sales obligations to others. Gas sales are also listed as a service for any market center that is a transaction point for electronic gas trading.

Title Transfer-A service in which changes in ownership of a specific gas package are recorded by the market center. Title may transfer several times for some gas before it leaves the center. The service is merely an accounting or documentation of title transfers that may be done electronically, by hard copy, or both.

Electronic Trading-Trading systems that either electronically match buyers with sellers or facilitate direct negotiation for legally binding transactions. A market center or other transaction point serves as. the location where gas is transferred from buyer to seller. Customers may connect with the hub electronically to enter gas nominations, examine their account position, and access E-mail and bulletin board services.

Administration-Assistance to shippers with the administrative aspects of gas transfers, such as nominations and confirmations.

Compression-Provision of compression as a separate service. If compression is bundled with transportation, it is not a separate service.

Risk Management-Services that relate to reducing the risk of price changes to gas buyers and sellers, for example, exchange of futures for physicals.

Hub-to-Hub Transfers-Arranging simultaneous receipt of a customer's gas into a connection associated with one center and an instantaneous delivery at a distant connection associated with another center. A form of "exchange" transaction. 
Table 9. Service Profile of Operational U.S. and Canadian Market Centers

\begin{tabular}{|c|c|c|c|c|}
\hline \multirow[b]{2}{*}{ Types of Service } & \multicolumn{4}{|c|}{ Active Centers and Hubs Where Service Is: } \\
\hline & Offered & $\begin{array}{l}\text { Most Highly } \\
\text { Used }^{1.2}\end{array}$ & $\begin{array}{c}\text { Second Most } \\
\text { Highly Used }\end{array}$ & $\begin{array}{l}\text { Third Most } \\
\text { Highly Used }\end{array}$ \\
\hline Wheeling/Transportation & 34 & 13 & 6 & 3 \\
\hline Parking & 26 & 5 & 12 & 5 \\
\hline Loaning & 23 & 1 & 5 & 8 \\
\hline Title Transfer/Tracking & 22 & 0 & 1 & 1 \\
\hline Electronic and OtherTrading & 17 & 5 & 1 & 1 \\
\hline Buyer/Seller Matching & 15 & 4 & 1 & 1 \\
\hline Storage (Separate Service) & 12 & 6 & 2 & 3 \\
\hline Peaking & 8 & 1 & 0 & 2 \\
\hline Compression & 8 & 0 & 2 & 1 \\
\hline Balancing & 16 & 0 & 0 & 1 \\
\hline Risk Management & 5 & 0 & 0 & 0 \\
\hline Exchanges & 6 & 0 & 2 & 0 \\
\hline Hub-to-Hub & 2 & 0 & 0 & 1 \\
\hline Administration & 4 & 0 & 0 & $\cdot 0$ \\
\hline
\end{tabular}

${ }^{t}$ Based on volumes, number of transactions, or revenues generated, depending on the individual market center methodology for estimating overall business activity.

${ }^{2}$ Level of service information unavailable from 4 of the 39 market centers.

Sources: Energy Information Administration, EIAGIS-NG Geographic Information System, Natural Gas Market Center/Hub Database, as of September 1996, compiled from industry trade press, discussions with the industry, and filings with the Federal Energy Regulatory Commission.

used to arrange for the movement of volumes to the eventual delivery point. Thus, these hubs support exchanges simply through normal storage services.

Many of the recently opened market centers are gradually increasing their business, concentrating their major marketing efforts on the services that are reflected in the physical capabilities of their supporting systems. For instance, many centers with associated storage provide significant short-term parking, gas loans, and storage capacity brokering, while doing little business in the area of gas buying and selling.

Several operations specialize in arranging the movement of gas over an area. These centers may be considered to be market areas with several delivery points, pipeline interconnections, and/or storage sites. Their customers' needs change in ways that are difficult to predict. Thus, planned deliveries do not always equate well with actual requirements for these customers. These requirements need frequent adjustment and are well served by such systems.

A customer's use of a particular service is influenced greatly by the contract terms made available at the center. For example, if a customer needs gas and other service for only 4 days in the week, it would not release the rights for the other 3 days if the shortest term for wheeling service is one week. The shorter the term of the contract for the exchange of gas and rights to service, the greater the number of trades. Longterm, nonreleasable contracts for gas and related gas services, under which customers have highly variable demands for gas, imply underutilization of the service over an extended time period and full utilization for relatively short time periods. This is the opposite of the expected utilization of pipeline systems near market centers that serve as trading centers.

\section{Costs of Services}

The cost of doing business at a market center depends on the types of services used. Many of the services provided are essentially market based, that is, the charges are whatever the local market dictates. The prices of some services, such as transportation or storage-related services, however, are often governed by the Federal Energy Regulatory Commission or State utility commissions. ${ }^{50}$ Usually these rates are cost-ofservice based, that is, they are set at a level that is expected to generate enough revenues to allow the company to recover its expenses plus an allowed rate of return on assets used in producing the service.

\footnotetext{
${ }^{50} \mathrm{Most}$ of the 32 operational market centers in the United States operate under FERC jurisdiction and are governed by Natural Gas Policy Act (NGPA) Section 311 rates. Five operate under FERC Natural Gas Act (NGA) Section 7 authority. The remaining centers operate under their respective State jurisdictional agencies, all subject to cost-of-service tariffs.
} 
In other cases, the market center has been granted the authority to operate under a market-based rate structure entirely. ${ }^{51}$ Such exceptions have been granted when it has been proven to the satisfaction of FERC that the center (operator) does not, or will not, have excessive market power in the region. Currently, seven market centers are offering market-based rates for "hub services" although several are operating on a subject-to-refund basis pending final FERC approval.

Those market centers operating under cost-of-service rate structures, while they may not charge above the maximum set rate, are permitted to discount below the maximum charge. In today's market, competition has often forced center operators to discount the ceiling rate, except perhaps during peak demand periods for some short-term contracted services.

In some instances market centers can make up the lost revenues that result from discounting of regulated tariffs by selling interruptible service and by selling unregulated services. In general, the expenses incurred from providing transportation services are relatively less than those from operating the rest of the system. Furthermore, many market centers expect or hope to increase returns in the future if they gain approval for market-based pricing of their hub services. They also anticipate continued growth as the majority of the market centers have experienced growth rates of 30 percent or more per year since they began operating. Since they are not near capacity limits, the expectation of continued growth seems reasonable. ${ }^{52}$

Nevertheless, revenues generated by the large volumes flowing through the major market centers, even at highly discounted rates, can be significant. For instance, the Henry Hub moved several hundred billion cubic feet of gas through its facilities during 1995. Since the Henry Hub charges about 3 cents per million cubic feet to move gas through the hub, the revenues from this service alone were significant.

Another major cost issue is whether some market centers are underutilized because they are not using market-based rates. This makes it easier for companies to rationalize charging a lower summer rate than would otherwise be possible, because market-based rates allow companies to charge a higher rate in the winter when daily demand for gas is large and volatile.

\footnotetext{
stAll seven market centers located in Canada are permitted to charge market-based or negotiated rates. Canada has had market-based pricing since 1984. However, many contract rates are negotiated by a wholesaler, e.g., a distribution company, and individual customers, and the rates do not represent the price paid by customers over time for gas and other services because the needs of customers change in unexpected ways.

${ }^{32}$ In fact, a number of market center administrators have reported much higher growth rates, ranging from 50 to 300 percent annually in their second year of operation and beyond.
}

\section{Ease of Contracting Supports Trade}

An important characteristic of many successful markets is the ease and speed at which contracts can be finalized. For example, standardized contracts and preapproved credit or creditworthiness support the ease of trading and finalization of contracts. ${ }^{53}$

Market centers, to operate successfully, depend upon transaction volume, a relatively small spread between bid and offer prices (or liquidity), and minimization of transaction costs. One driving force for similarity of bid and offer prices is well-informed market participants. This highlights the importance of having contracts that can be easily understood with a limited number of key provisions.

Many market center providers have standardized contracts on hand for candidate customers. The advantage of a standardized contract is well understood and includes the minimization of transaction costs and a clear understanding of legal responsibilities.

\section{Key Role of Information}

\section{Electronic Trading}

Access to electronic gas trading (EGT) and electronic bulletin boards (EBBs) tends to be thought of synonymously with market center activity. Electronic trading provides the means by which centers can attract customers to broker their own gas trades, frequently in an anonymous environment.

Yet, not all operations currently make such services directly available to customers. According to available data, 17 of the 39 U.S. and Canadian centers can be accessed via one or more electronic trading systems (Table 9). The lack of such services reflects several business considerations. First, the amount of actual or potential trading may not support the investment needed to install an EGT system. Second, some market centers, without an EGT system, rely upon their own operations staff to carry out trades for their customers. Staff also provides many of the other administrative services such as title transfers and price discovery.

\footnotetext{
${ }^{53}$ Lines of credit, which are not generally used at market centers, are commonly used in related markets to expedite the completion of trades and, hence, the liquidity of the market. For example, the London Metals Exchange (LME) uses lines of credit. It is important to note that LME is largely made up of companies in the metals industry, much as one might expect market center participants to be made up of members of the gas industry, rather than members of the financial industry. Every day contracts for future and current delivery are traded on the LME as companies alter their competitive strategies in the metals market as economic conditions and their current situations change.
} 


\section{Price Information}

Price information is generally available to market center customers through electronic bulletin boards, electronic trading systems, or directly from center staff. Usually, however, this information is not publicly available. This lack of public information reflects the still low level of integration and interaction between centers.

Another reason for the lack of extensive electronic trading is the fixed cost associated with providing this information. For example, the technology required to support electronic trading requires new investment in equipment and people. Thus, the average cost of such information may be prohibitive unless the volume of trading is much greater than it is currently at many market centers.

Gas prices are also available through electronic services such as Bloomberg's and Reuter's data services and from the trade press at a fixed subscription cost. The drawback is that they may not be timely enough and may not be reliable. Some of these prices are not representative of completed deals. Instead they may represent an attempt by a company to influence market behavior. Moreover, the volumes of gas sold at different prices on spot markets on a particular day are often not known and may be small.

Price transparency, or the ability to identify quickly and accurately the cost of gas and other gas-related services at and near market centers, is crucial. At the Henry Hub, where price transparency is high, buyers appear willing to pay more, on average, than at nearby places with equal access to the same end-use markets but with less price transparency. ${ }^{54}$

The key with price transparency is to make public the price, quantity, and type of services received per transaction without revealing the parties involved in the transaction. Most successful markets with high trading volumes, such as the financial and commodity markets in the United States, provide full disclosure of price and other trading information.

Access to publicly available price data for the commodity and for available pipeline and storage space would encourage a variety of buyers and sellers with different needs to exchange gas and rights to ancillary services via market centers. All too often, however, the primary service provided by some market centers amounts only to conventional balancing services. In these instances, companies do not seek short-term gains by trading the gas commodity via a market center service. Indeed, activity at the market center is engaged in to sustain

\footnotetext{
${ }^{54}$ Of course, other factors may enter into this difference such as the liquidity of the market at the center and overall quality of hub service at the Henry Hub.
}

the operational and contractual integrity of gas delivery system not much different from the delivery system prior to Order 636.

\section{How Storage Supports Trade at Market Centers}

Access to storage is vital to many market centers, although it may not always be underground storage. Three centers support their parking and loaning services through linepacking on their supporting pipelines, and a few provide supplemental liquefied natural gas supplies to support their peaking service.

While a number of market centers have but one or two storage sites linked directly to their operations, many have access to multiple storage sites. Some market centers also have indirect access to storage because of contracts they have, or can readily acquire, for transportation service between storage sites and market centers.

An indicator of the importance of storage is that more than two-thirds of market centers have some form of access to storage. The total working gas capacity of accessible storage exceeds 2,006 billion cubic feet, or about 47 percent of all the working gas capacity in the United States and Canada. Expressed in terms of daily deliverability, this represents 30 billion cubic feet, or 39 percent of North American underground storage capability (Table 7). Practically all the salt storage sites are accessible to market centers.

Of course, not all of this capacity is accessible to the centers, because some of it is dedicated to selected high-priority customers such as distribution companies. The portion that is available to service new customers is often interruptible or releasable capacity within the storage site.

At least two salt storage sites, Egan and Moss Bluff, are specifically tied into hub operations. Two planned market centers, Tioga (PA) and Avoca (NY), have their market center operations developed around salt storage.

Regionally, underground storage availability to market centers depends upon the type of storage. Most of the underground storage in the production areas of the Southwest and Central regions is owned by independents or producers and is often open-access high-deliverability salt storage, most adaptable to the needs of market center operations.

Many of the proposed new underground storage sites over the next several years will be located in major production areas or in proximity to major market centers. Of the 45 storage sites 
planned for development or expansion, ${ }^{55} 11$ are located in the Southwest Region, and represent an additional 91 billion cubic feet of working gas capacity and 4.3 billion cubic feet per day of withdrawal capability. ${ }^{56}$ Of this total, seven are high-deliverability sites with a total of 3.2 billion cubic feet per day of withdrawal capability (see Appendix F). Existing oil and gas and even aquifer storage is being refurbished to increase flexibility and deliverability because customers are increasingly demanding flexibility and higher deliverability from their storage service contracts. However, such storage is still ideally obtained from salt dome storage tied to a market center.

In summary, many hubs are connected to seasonal storage and also to high-deliverability salt storage caverns or other flexible, high-deliverability reservoir sites. This is not surprising since salt storage caverns can serve as market centers if they are connected to a diverse group of suppliers and gas customers. Salt storage is ideally suited for satisfying both balancing needs and short-term strategic marketing objectives (to include arbitrage) by gas companies, and thus provides new choices for many gas customers.

\section{Value of High-Deliverability, Flexible Storage}

The value of having ready supplies of gas near a market center can be estimated by examining the difference in the current cash price of gas at the Henry Hub and the price of the most current natural gas futures contract being traded at the Henry Hub (Figure 29). This calculation is most relevant for market centers connected with high-deliverability, flexible storage near the Henry Hub. This calculation is convenient both because the futures price implicitly includes the cost of storage and the lost interest payments associated with having stored gas, and because it is difficult to obtain estimates of the cost of storing gas on a daily basis. The difference could be readily calculated for other market centers if reliable estimates of the daily cost of storage and gas were readily available. When the Henry Hub futures price is used, the difference represents the value that current supplies have relative to supplies a few weeks hence. This difference or premium is related to what economists refer to as a convenience yield. ${ }^{57}$

The current trade press cash price is an estimate of the price that a company could receive for stored gas today. The futures price is an estimate of the cost to replace the released gas in

\footnotetext{
${ }^{35}$ As of September 1996, 58 projects are actually planned but 19 of these projects represent phased development of single sites.

${ }^{8}$ It is important to note that working gas capacity statistics, as ordinarily reported, assume one cycle per year, which is possibly deceiving because they are capable of being cycled many times during the year. Effective capacity is the number of times cycled times the working gas capacity.

${ }^{57}$ The convenience yield or premium is the value after subtracting the influence of storage cost and the cost of money from the difference.
}

a few weeks. Thus, the difference in the two prices could be viewed as an indicator of the premium value of the stored gas near a market center when, for example, aggregate demand increases significantly.

When the difference between the spot and the futures price or the premium ${ }^{58}$ at the Henry Hub for the 1995-96 heating season is computed, it is found that it was positive throughout much of the heating season. At times, it was large and exceeded $\$ 1.00$. In fact, the average daily value of the premium at the Henry Hub was about $\$ 0.70$ per million Btu between November 1, 1995, and April 1, 1996. ${ }^{59}$ Even when the 13 largest differences were deleted from the data set and the average difference was recomputed, the average was still large at about $\$ 0.30$ per million Btu. Similar results were obtained for December-through-February price differences for the past several years. ${ }^{60}$

\section{Role of Market Centers in Managing Price and Volume Volatility}

\section{Volume Volatility}

As previously stated, exchanges of gas and pipe and storage space at market centers frequently can be viewed as satisfying unexpected changes in customer supply and demand volumes, especially demand. The average variability of these changes in volume is referred to as volume volatility. These unpredictable changes, especially when they accrue over time, are designated imbalances within the gas industry. Imbalances occur because the companies' needs for gas, storage, and pipe space differ from the amounts they have reserved. Thus, companies are often in a position where either they need to acquire such rights or they have unused rights to release for sale. Most companies can be viewed as alternating between a buyer and a seller of rights over time. For example, an LDC, which is ordinarily thought of as a buyer of gas at a market center or a buyer of center services such as parking, can be a

\footnotetext{
${ }^{58}$ For a further discussion of premiums, see Energy Information Administration, The Value of Underground Storage in Today's Natural Gas Industry, DOE/EIA-0591 (Washington, DC, March 1995. Also see John H. Herbert, "Improving Competitive Position with Natural Gas Storage," Public Utilities Fortnightly (Washington, DC, October 15, 1995).

${ }^{39}$ The distribution of the values for the premium was also skewed towards high values. Thus, the relative frequency of high values was much greater than the relative frequency of low values. The high values were associated with large and persistent drops in the temperature below normal levels. Similar results were obtained for the heating seasons in the past several years. Although the average value of the premium was not nearly as large, large values were observed and the distribution of the premium appeared to be skewed towards high values.

${ }^{60}$ See Energy Information Administration, Natural Gas 1994: Issues and Trends, DOE/EIA-0560(94) (Washington, DC, July 1994).
} 


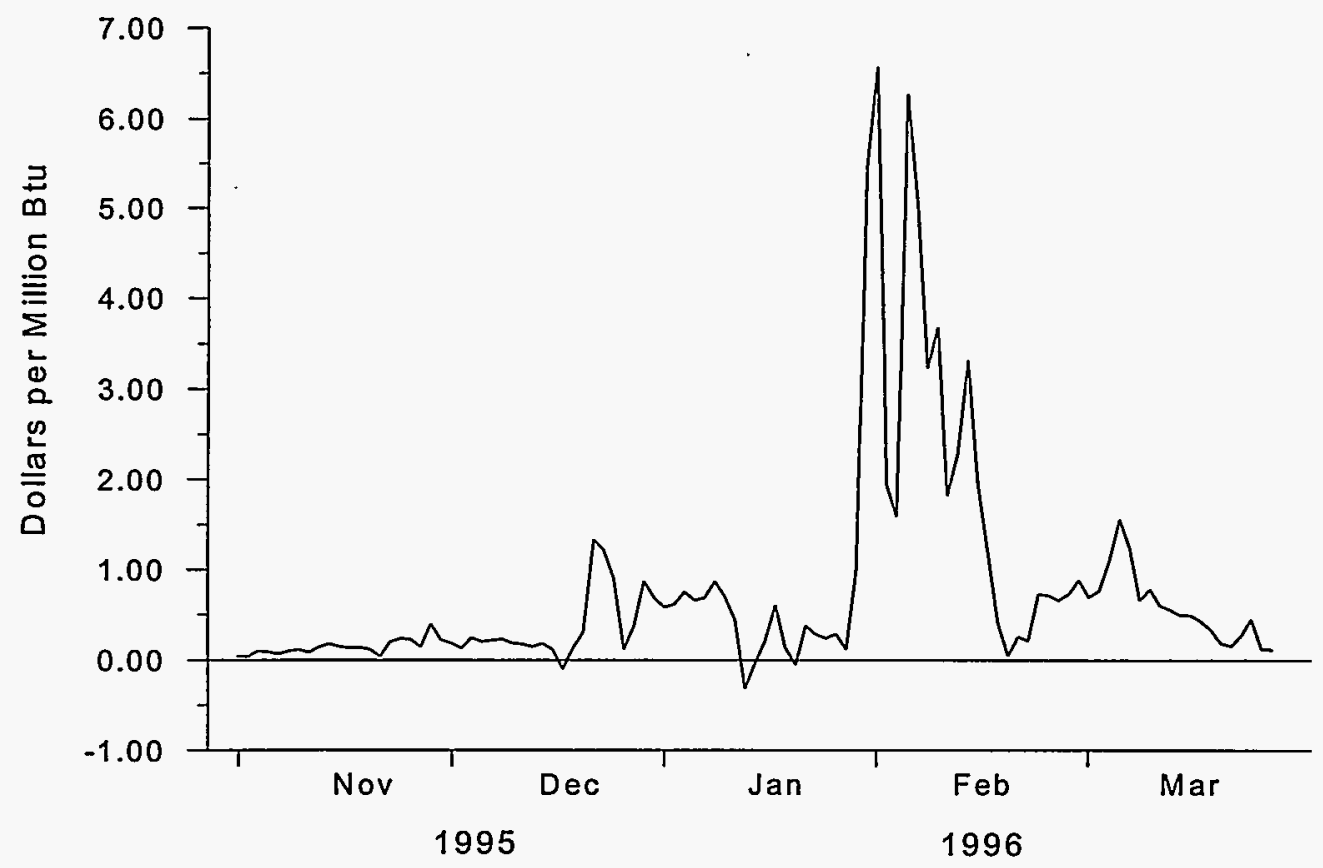

Sources: Cash: Pasha Publications, Inc., Gas Daily. Futures: Commodity Trading Commission, Division of Economic Analysis.

seller of gas if its needs for gas are less than its rights to gas. ${ }^{61}$ The LDC could release short-term gas to others via the shortterm transportation services offered by market centers when demand for gas declines from expected levels.

In principle, companies constantly have the capability to enter short-term exchanges at market centers. During any one week, a particular company could be a net seller of rights to gas, pipe, and storage space, and then in the next week be a net buyer. Interestingly enough, this type of constant buying and selling results in a smoothing out of natural gas costs for a company over time and may result in a reduction in price risk exposure.

For example, suppose an LDC has a contract to purchase 100 million cubic feet (MMcf) of gas in each of the next 3 months at $\$ 2.00$ per thousand cubic feet. During the period, however, the LDC sometimes needs less and sometimes more than 100 MMcf. For the sake of discussion it is assumed that this amount, on average, equals $20 \mathrm{MMcf}$. If prices rise above $\$ 2.00$ during the next 3 months, the LDC receives a return every time it sells gas into the market and it pays an additional cost every time it buys gas from this market. If the LDC's demand varies at an average of about 3.3 MMcf per day (the

\footnotetext{
${ }^{61}$ There are reports that several LDCs did in fact sell gas onto the market this past winter.
}

daily average of $100 \mathrm{MMcf}$ per month) during the time period, then the sum of the returns is likely to be similar to the sum of the incremental costs. If the LDC assumed only its traditional role as a buyer, it would incur additional costs each time its demands increased unexpectedly, without receiving any compensating revenues when its demands fell below reserved levels. By being both a buyer and a seller of gas, the LDC effectively fixes its cost near $\$ 2.00$ per thousand cubic feet.

Currently many companies try to control price risk exposure through a combination of a futures contract and a location basis swap. The futures contract is used to reduce the price risk associated with buying and selling the commodity. The swap contract is used to reduce the location price risk associated with taking the gas at a location other than the Henry Hub. ${ }^{62}$

There is a cost associated with using both of these financial instruments. Additionally, location basis risk or the price risk associated with taking gas at a location other than the Henry

\footnotetext{
${ }^{62}$ The price risk is due not just to variations in transportation cost between locations but to a myriad of factors such as physical and contractual constraints in moving gas between locations and in obtaining gas from different supply sources.
} 
Hub is difficult to control. ${ }^{63}$ Price risk control at the Henry Hub may also be difficult to obtain for some companies because of their timing of gas sales and purchases.

As market centers develop liquid markets with transparent prices for gas and for nearby pipe and storage capacity, a larger proportion of a company's exchanges could be accomplished at market centers. This could also attract additional customers. Hence, there would be less price risk exposure because the company would obtain more of its gas locally and avoid location basis risk. For example, buyers in local markets escape price risk caused by pipeline bottlenecks. Thus, some of a company's price risk exposure could be controlled through active participation at a market center, which would reduce the need for financial instruments. Moreover those companies that wish to hedge their price risk completely could enter into a swap arrangement written in terms of a market center price; or if an actively traded and liquid forward market develops at a market center, then they could buy and sell these contracts to hedge their price risk. ${ }^{64}$

Another direct way of receiving some price risk protection via a market center is through the active use of highdeliverability, flexible storage such as salt cavern storage and, in particular, through the joint use of conventional oil/gas storage with such salt storage. The company obtains this risk protection by moving gas from conventional storage to salt storage when space is available in a salt storage site during the winter time. Then, if gas prices or customers demands for gas increase, gas is released quickly from storage either for own use or for the use of another company.

When the customer uses the gas for its own use, it avoids the high cost of spot gas at the time. When the company provides gas to another company, it obtains a return as discussed previously. This type of behavior provides price protection to buyers only when prices rise. ${ }^{65}$ They also incur a cost equal to the cost of gas and the cost of money. However, it would seem prudent to consider such strategies because current spot prices have tended to move unexpectedly sharply upwards at different times during the past several heating seasons. ${ }^{66}$

\footnotetext{
${ }^{63}$ For examples and discussion, see John H. Herbert, "Gas Price Behavior: Gauging Links Between Hubs and Markets," Public Utilities Fortnightly (April 1, 1996), pp. 27-30.

"The shorter the term and the smaller the size of the contract, the greater chance that a liquid forward market will develop as long as transaction costs are kept low.

${ }^{65}$ In fact, there is a cost that can be calculated by examining the distribution of the relevant premium. This sort of calculation would be relatively straightforward for salt storage properties readily accessible to the Henry Hub.

"See Energy Information Administration, Natural Gas 1994: Issues and Trends, DOE/EIA-0560(94) (Washington, DC, July 1994).
}

\section{Reducing Price Risk Exposure - Market Center Versus Futures Market?}

As previously mentioned, the ready access to and release of gas via regular market center activity can provide price risk protection in markets near the centers. However, a view held by some in the gas industry is that the NYMEX Henry Hub futures contract market can also be used for price risk protection at a variety of locations scattered throughout the United States. Thus, why would a company incur the expense of attempting to control price risk exposure through market center activity when a market is already available that specializes in price risk protection? The reason for taking this additional measure is that price risk can be effectively hedged through a futures contract only if prices behave in a similar way at the location and at the Henry Hub and if spot prices and futures prices at the Henry Hub converge. ${ }^{67}$

One indication that futures contracts can be used to hedge price risk effectively at other locations is if futures prices change by, for example, $\$ 0.10$ per million Btu and then cash prices change, on average, by $\$ 0.10$ or by some other relatively constant amount. On average, changes in cash prices need to be highly correlated with changes in futures prices in order to hedge the price risk effectively with the futures contract. ${ }^{68}$

For many commodities, the difference in the cost of gas at different locations is explained by a relatively constant charge for transporting the commodity from a primary producing or storage area to a primary consuming area. If such conditions do not hold or if the relationship between futures and cash prices is complicated, then it is difficult to hedge price risk using a futures contract. ${ }^{69}$

It is possible to evaluate how difficult it might be to hedge price risk using a futures contract by examining the relationship between the futures market price at the close of trading of the futures contract and the bid week price at several major gas-consuming locations. Three locations were chosen for the analysis because of their importance as major consuming areas and because of their ready access to the Henry Hub: (1) the Appalachia region (near the Kentucky,

\footnotetext{
${ }^{67}$ For additional discussion, see J.H. Herbert and E. Kriel, "U.S. Natural Gas Markets - How Efficient Are They?" Energy Policy (January 1996). If the spot and futures prices do not converge, the calculation discussed previously becomes more difficult to justify because the magnitude of the nonconvergence (another type of basis risk) needs to be considered in the estimation.

${ }^{68}$ Another indication that futures contracts can be used to hedge price risk effectively is the occurrence of a relatively constant proportionate relationship between cash price and the futures price plus a constant difference.

${ }^{69}$ It may also be difficult or expensive to use options or swaps to hedge location basis risk completely.
} 
Ohio, West Virginia, and western Pennsylvania area) along the Columbia Gas System, (2) the New York citygate, and (3) the Chicago citygate. These three locations have good access via long-distance trunk pipelines to South Louisiana near the Henry Hub where deliveries through a futures contract take place. Hubs are also currently operating at these locations.

When the difference between the spot price at these three key locations and the Henry Hub futures price (at the close of trading for the futures contract) is examined (Figure 30), it is observed that the difference is not always positive or relatively constant. In fact, the difference in the price between Chicago and the Henry Hub can be positive as well as negative. The difference between the price for the Appalachian region and the Henry Hub has a winter/summer seasonality, yet the character of the seasonality varies between years. The magnitude of the difference in the New York price and the Henry Hub price also varies greatly, and high values can be seven times as great as low values. High or low values also tend to persist at times but not in a predictable way between years. Thus, it might be difficult to hedge price risk at these locations using a futures contract.

As previously stated, the futures contract market can provide an effective hedge if changes in the futures price are highly correlated with changes in the cash price. However, statistical analysis reveals that a large proportion of the variability in cash prices is left unexplained by changes in futures price at all locations. The most striking result is for Chicago where only 56 percent of the variability of changes in cash prices is explained by changes in futures prices. In Appalachia and New York, the variability is equal to 74 percent and 79 percent, respectively. Thus, the amount of price variability hedged through a futures contract may be poor for Chicago and limited for the other locations. ${ }^{70}$

\section{Future Challenges}

In just a few years, market centers have become a key component in the North American natural gas transmission and distribution network. The number of market centers has grown rapidly during the past 5 years, with 27 added since 1993. Today's market centers are structured and positioned to handle full-service marketing operations. They have made it

\footnotetext{
${ }^{70}$ The estimates are obtained using ordinary least squares. The change in gas price by location is regressed on changes in futures price at the Henry Hub. The data are for the period June 1990 through March 1996. Monthly data are from McGraw-Hill, Inc., Inside FERC's Gas Market Report (Washington, DC); and Oil Daily Company, Natural Gas Week (Washington, DC, June 1990-March 1996), various issues. The methodology is similar to that used in E.J. Brinkman and R. Rabinovitch, "Regional Limitations of the Hedging Effectiveness of Natural Gas Futures," Energy Journal, Vol. 16, 3 (1995), pp. 113-124.
}

easier for buyers to access the least expensive source of supply and helped sellers to allocate gas to the highest bidding buyer. Market centers also enable shippers to keep their receipt/delivery flows in balance and avoid paying penalties.

Market centers have led to the enhancement and expansion of a number of pipeline systems (see Appendix $G$ ) and the development of additional interconnections to expedite service. Such interconnections help level the flow of gas along pipeline systems throughout the year and thus reduce costs and encourage the redirection of flows when price disparities arise between various supply locations.

Nevertheless, most market centers are not operating near their full potential, even though they have expanded the number of services they offer and are doing increasing business. For instance, salt cavern storage sites associated with market centers are frequently less than 40 percent full, and the amount of withdrawals at these sites is rarely near upper limits from one week to the next. ${ }^{71}$ If these facilities were constantly being recycled (inventory turnover), they would be much closer to being full and the percentage amount full would usually change from one week to the next. In addition, the sum of injections and withdrawals for a week would be a significant percentage of total working gas capacity. Highdeliverability storage facilities offer the capability of taking advantage of trading opportunities provided by the great daily volatility in gas prices and in gas demand and by the daily and weekly imbalances experienced by many companies.

Other evidence that market centers are not being fully utilized is the size of the daily price spikes experienced this past winter. One of the primary functions of market centers should be to release additional gas to market when prices start to rise. This releasing of gas to market should tend to shave peak prices and thus eliminate extreme price peaks unless there is extreme stress on the system.

A major challenge facing the natural gas industry is to improve or create new services that will minimize or mitigate imbalance situations and their associated costs. These costs can be high in major consuming areas during peak usage periods. The expansion of market centers and trading services designed specifically to address the problem may be part of the solution. However, such services may not be able to address the problem fully, in part because of the special circumstances surrounding most imbalance situations, that is,

\footnotetext{
"Oil Daily Company, Natural Gas Week, "Salt Cavern Storage," (Washington, DC), various issues.
} 
Figure 30. Difference Between Futures Final Settlement Prices at the Henry Hub and Bid-Week Spot Prices at Selected Locations, June 1990 - March 1996

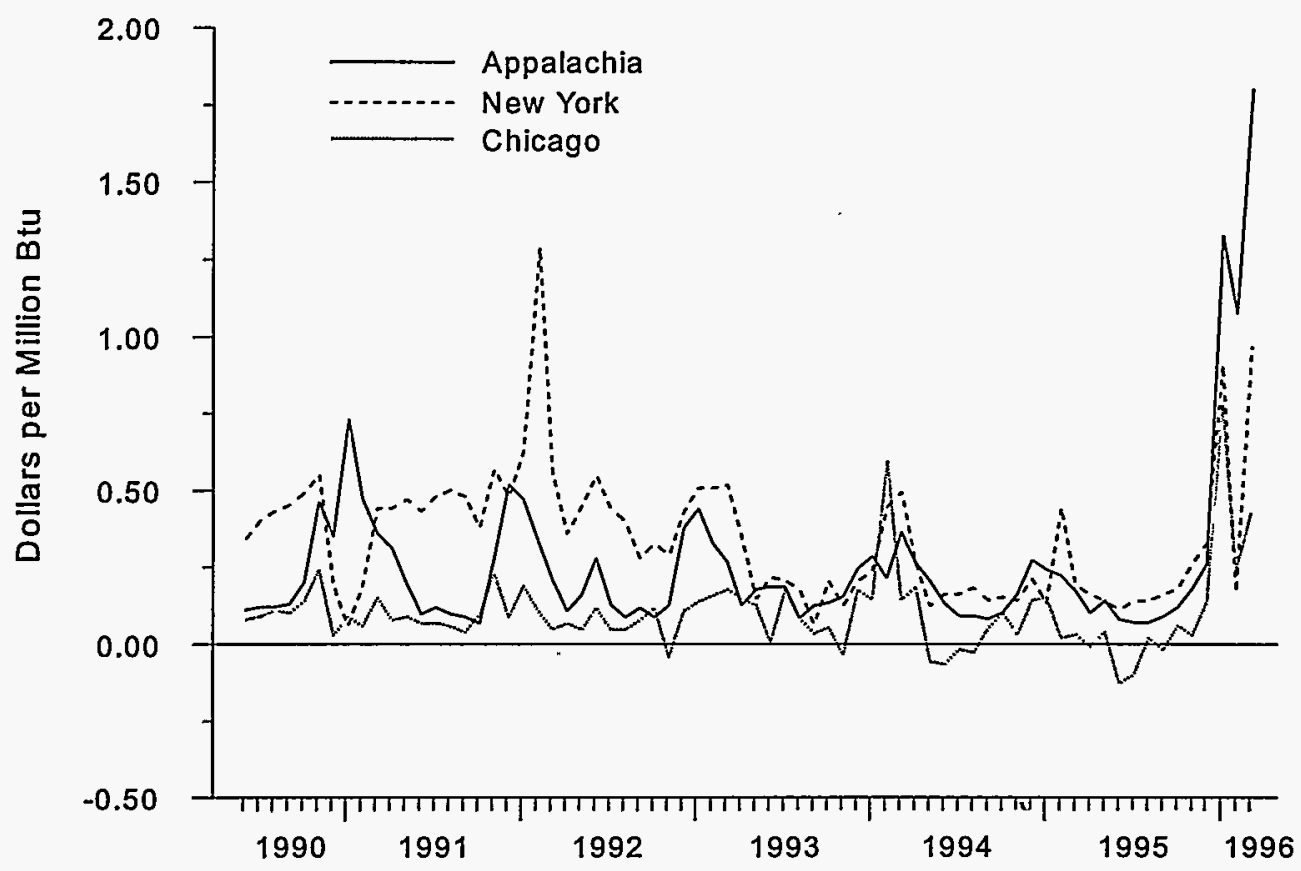

Note: Spot prices are the first of the month for the Appalachia region (Kentucky, Ohio, West Virginia, and western Pennsyivania) along the Columbia Gas Transmission system and the New York and Chicago citygates.

Sources: Spot Price: McGraw-Hill, Inc., Inside FERC's Gas Market Report. Futures Price: Commodity Futures Trading Commission, Division of Economic Analysis.

the restrictive delivery or receipt point conditions set forth in pipeline company "Operational Flow Orders."

Pipeline companies may impose penalties during a severe imbalance situation. However, the penalties are arbitrary and do not reflect precise market conditions. Moreover, the imposition of penalties frequently follows the period of greatest demand, which provides no motivation to reduce demand during the period of greatest demand. Furthermore, after the time of greatest demand, the dollar cost of the penalty will determine the natural gas price. A customer with a severe imbalance situation will be willing to pay a price for incremental supplies up to the cost of the imbalance penalty.

A possible solution could be the development of regional networks, electronic or otherwise, which would provide realtime information access to all affected parties. This would allow operational conditions and price information to direct the resolution of a potential imbalance before it becomes a

\footnotetext{
${ }^{72}$ Operational flow orders are put into effect by pipeline companies during periods of extreme demand or duress on the physical facilities of the system. These orders include specific limitations and conditions that a customer must adhere to during the period of enforcement, or face penalties.
}

problem. Regional networks would provide access to realtime pricing over a wider area. This should improve the trading and allocation of gas and rights to pipe and other services when demand has increased significantly. Thus, the market-determined price of these items could determine use of the pipeline system. Pipeline usage would have a greater chance of being reduced when demand was greatest, because prices would most likely be at their highest level at these times.

If regional markets were developed in major consuming areas, the opportunities to exchange gas should expand and improve the competitiveness of the market and thus support the use of market-based rates. Instead of a single provider allocating loaning services at a fee, gas would be allocated between end users exchanging rights to gas through market-determined prices (a center operator might receive a transportation fee that was indexed to a percentage of the cost of the gas). This would shift the proof of a competitive market from the number of alternative providers of hub-like services to the 
number of customers able to enter into free exchange at market centers. ${ }^{73}$

A significant shortcoming of many market centers is the unavailability of transparent, reliable, real-time price information. An improvement in price discovery could further the value and use of market centers by providing many other natural gas users with the type of information heretofore available only to the largest marketing companies and traders. This development could draw in more companies to engage actively in the gas marketplace and thus improve the overall efficiency of the gas industry.

Continued growth in market center use and operations depends to a great degree upon how these centers react to ever-changing market conditions. Further development of business interrelationships among market centers will most certainly support increased growth. Trade between centers can be expected to grow during the next several years as the interconnected network expands. There are several ways in which this trade might improve.

- Joint administration of hubs or joint ventures between companies that administer the center's business or operate the hubs. These endeavors would help consolidate operations and facilitate interhub trading and transfers.
- The use of the same electronic trading systems with expanded capabilities to accommodate intercenter tradingand services. Common trading software, combined with interhub business agreements, would attract customers, particularly those wishing to engage in risk management and price arbitrage.

- The creation of new market centers in strategic locations. As market demand and supply sources shift, new centers could be linked with existing centers that have complementary services.

Natural gas market centers have already demonstrated their value and importance to the smooth running of the Nation's transmission and distribution system. Doubtless, in the future, they will have to change further as the market continues to integrate and expand. Nonetheless, the reliability and transparency of price and other information will determine their value in allocating scarce supplies and in avoiding system bottlenecks.

\footnotetext{
${ }^{73}$ Most importantly, many customers would become sellers during one period and buyers during another, depending on their current imbalance situation.
} 


\section{Producers in Today's Competitive Market}

Natural gas producers have faced many difficulties in the past decade as the industry has shifted to a more flexible, competitive system from a highly regulated one in which virtually all phases of their operations were circumscribed by regulation. Strong regulatory oversight had generated an environment in which business activity conformed to a relatively inflexible, traditional pattern. The creative energy of the producing firms generally was directed toward resolving the technical difficulties of discovery and extraction, rather than addressing business concerns such as availability of transportation capacity and promoting gas sales through aggressive marketing. The continuing transition to today's more competitive natural gas industry has presented numerous choices and challenges to producers. Their response during this period generally has shifted the industry to a more dynamic, efficient mode of operation.

Federal regulations affecting the producing industry changed in two very fundamental ways in the past 10 years: wellhead price decontrol and open access transportation. ${ }^{74}$ Wellhead price decontrol, initiated in 1979 and completed in 1991, removed price constraints on interstate gas sales. Open access transportation, which was later enhanced by service unbundling, expanded the effective number of buyers in the wellhead market, thus transforming the structure from a monopsony to a highly competitive system. At the same time, the increase in potential buyers was mirrored in downstream markets as consumers suddenly enjoyed the benefits of access to a much broader set of suppliers, foreign as well as domestic. This led to intense sales competition among producers and with imported gas.

These changes resulted in the rapid evolution of producing firms as they changed contracting arrangements and practices in the field, as well as the nature of the firms themselves. The effects of regulatory change were exacerbated by the heightened competition caused by the drop in world oil prices and the rapid development of substantially improved exploration and production technology. Crude oil prices declined by 50 percent during the first half of 1986 , from $\$ 25.63$ to $\$ 12.83$ per barrel. ${ }^{75}$ The consequent competition

\footnotetext{
${ }^{74}$ Open access transportation in this chapter refers to the providing of transportation service as a separate service to customers on a first-come, first-served basis. Open access transportation is one of the "unbundled" services that had been provided by the pipeline companies on a combined basis, such as gas acquisition, storage, and load balancing. Open access transportation and unbundling thus eliminated the pipeline companies' role as the sole merchant-carriers of gas between producers and end-use markets.

${ }^{73}$ Based on composite refiner acquisition cost. Energy Information Administration, Historical Monthly Energy Review: 1973-1992, DOE/EIA0035(73-92) (Washington, DC, August 1994), Table 9.1.
}

from petroleum products strengthened the downward trend in average wellhead prices from the 3-year peak in 1982 to 1984 (after adjustment for inflation). Average wellhead gas prices (in constant 1995 dollars) fell 37 percent between 1985 and 1987 (Figure 31). The 9-year average from 1987 through 1995 of $\$ 1.95$ per thousand cubic feet (1995 dollars) is 43 percent below the 1985 level. $^{76}$

The intense competition confronting producers as a result of open access transportation and the lower price environment created a need for new strategies to handle changing conditions effectively. Some of the responses were:

- More use of short-term, market-oriented contracts and financial management tools to mitigate price risk. Producers' participation in the New York Mercantile Exchange (NYMEX) futures market accounted for 20 percent of the total during the first quarter of 1996.

- Changes in field practices to improve discovery and development operations. Costs have been reduced by consolidating operations, improving efficiency and productivity, and extensively using new technology. As one example, average discovery field size in the onshore Gulf Coast for the most recent 5 years is more than 50 percent greater than the average for the 1980's.

- Changes in corporate strategies to expand operations and capture economies of scale, attain a more secure position in gas markets, and position themselves for anticipated future conditions. Producers have combined forces with companies that are experienced in other aspects of natural gas supply and energy marketing so as to expand their marketing operations and benefit from new business opportunities.

This chapter discusses these changes in the producing industry and examines general trends in its operations and productivity in the context of the extensive regulatory and market changes during the past decade. The chapter also examines the extent of industry competition in the lower 48 States, the degree of interregional competition, and the impact of foreign trade.

\footnotetext{
${ }^{76}$ All gas prices are from the Energy Information Administration's Natural Gas Annual 1995, DOE/EIA-0131(95) (Washington, DC, November 1996).
} 
Figure 31. Natural Gas Wellhead Prices, 1980-1995

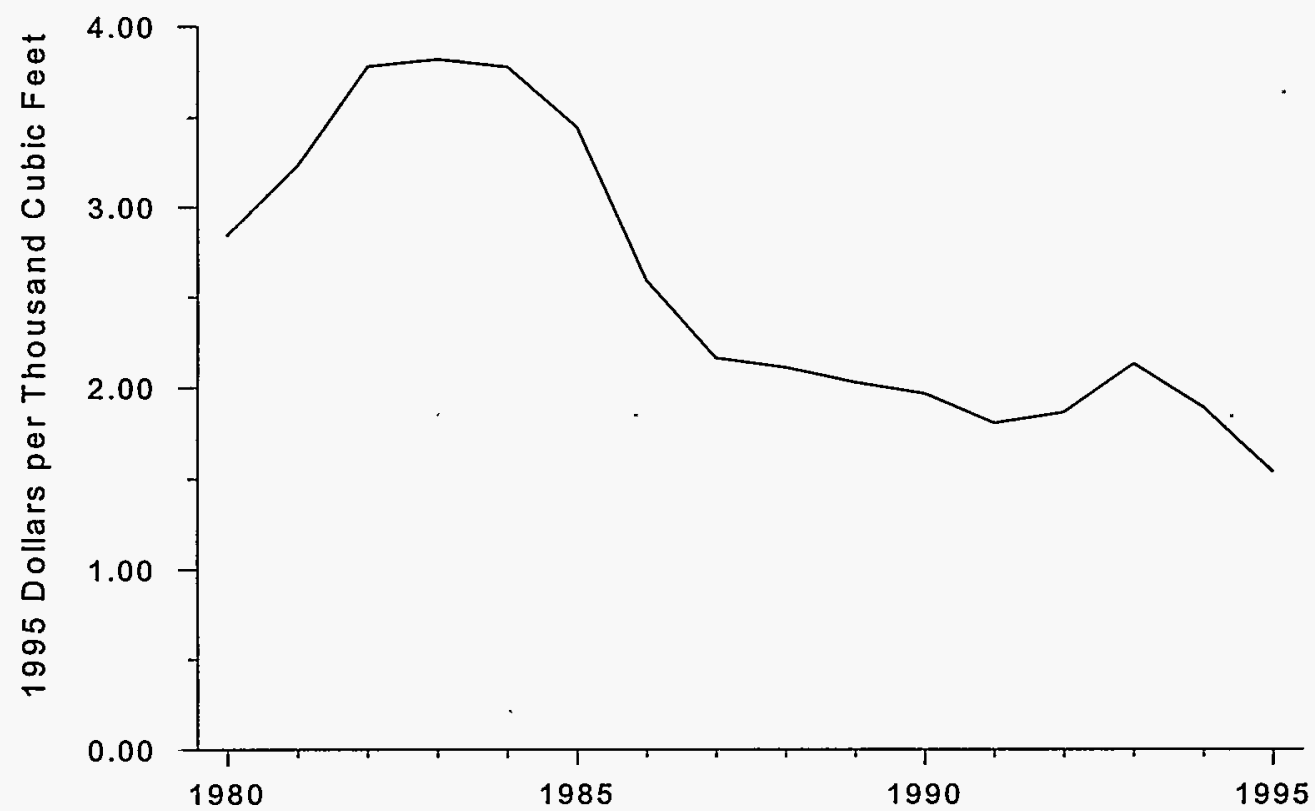

Note: Values expressed in 1995 dollars based on chain-weighted gross domestic product (GDP) deflator from the U.S. Department of Commerce, Bureau of Economic Analysis.

Source: Energy Information Administration. 1980-1990: Annual Energy Review 1995 (July 1996). 1991-1995: Natural Gas Annual 1995 (November 1996).

\section{A More Competitive Supply Industry and Wellhead Market}

The regulatory shift of pipeline companies from ownermerchants to open-access service providers expanded the effective number of potential customers for most producers. The benefits of reaching more customers for their supplies, however, did not necessarily work as producers expected. When open access transportation was achieved, the difficulty of confronting the pipeline companies' strong market power in transportation was replaced by the difficulty of facing the competitive pressure from producers across North America. The resulting competition placed downward pressure on wellhead prices, which was exacerbated by supply increases from expanded domestic and foreign supplies. In effect, a new set of difficulties for producers replaced the earlier one.

A key feature of competitive markets is an effective pricing mechanism that provides signals prompting appropriate responses by market participants. Short-term, marketresponsive contracts promote competitive behavior by reflecting the relative strength of supply or demand in a timely manner. This promotes efficiency in the allocation of industry resources into supplying gas to regional markets.

Regional gas prices serve as a signal for relative demand and supply conditions in each market. They also can indicate the degree of competition between markets. If gas markets are supported by an efficient infrastructure, consisting of the transmission network and institutional systems, regional demand and supply conditions will be interrelated. Market interrelatedness causes similar movements in prices although regional prices are not expected to be uniform. ${ }^{77}$ The correspondence in price changes at different locations can be measured by the statistical correlation between prices.

An analysis of spot prices at major trading locations in the United States and Canada (Figure 32) shows wide variations in the relationships between markets. ${ }^{78}$ Markets within the separate locations in the western, central, and eastern regions of the United States seem well interconnected. For example, the eastern markets (Katy in East Texas, Henry Hub in Louisiana, and Eastern Canada) have prices that are highly correlated (coefficients of 0.867 or more, Table 10). This tendency holds even for locations that are separated by

\footnotetext{
$n_{\text {For instance, prices in regions that are net importers of gas will tend to }}$ be higher than in regions that are net exporters. Nevertheless, to the extent that market institutions and the transmission infrastructure facilitate the movement of gas from one region to another, then supplies and demands in the different regions will be interrelated. Thus the prevailing price in one region will be affected by market conditions in other regions.

${ }^{78}$ Monthly spot price data (November 1993 through May 1996) for major North American trading locations were compiled and used to compute correlation coefficients, which range from 0.105 to 0.999 (Table 10). These figures ignore the simple 1.0 correlations for prices within each region.
} 
Figure 32. Lower 48 States Map Showing Reference Locations for Price Correlation Analysis

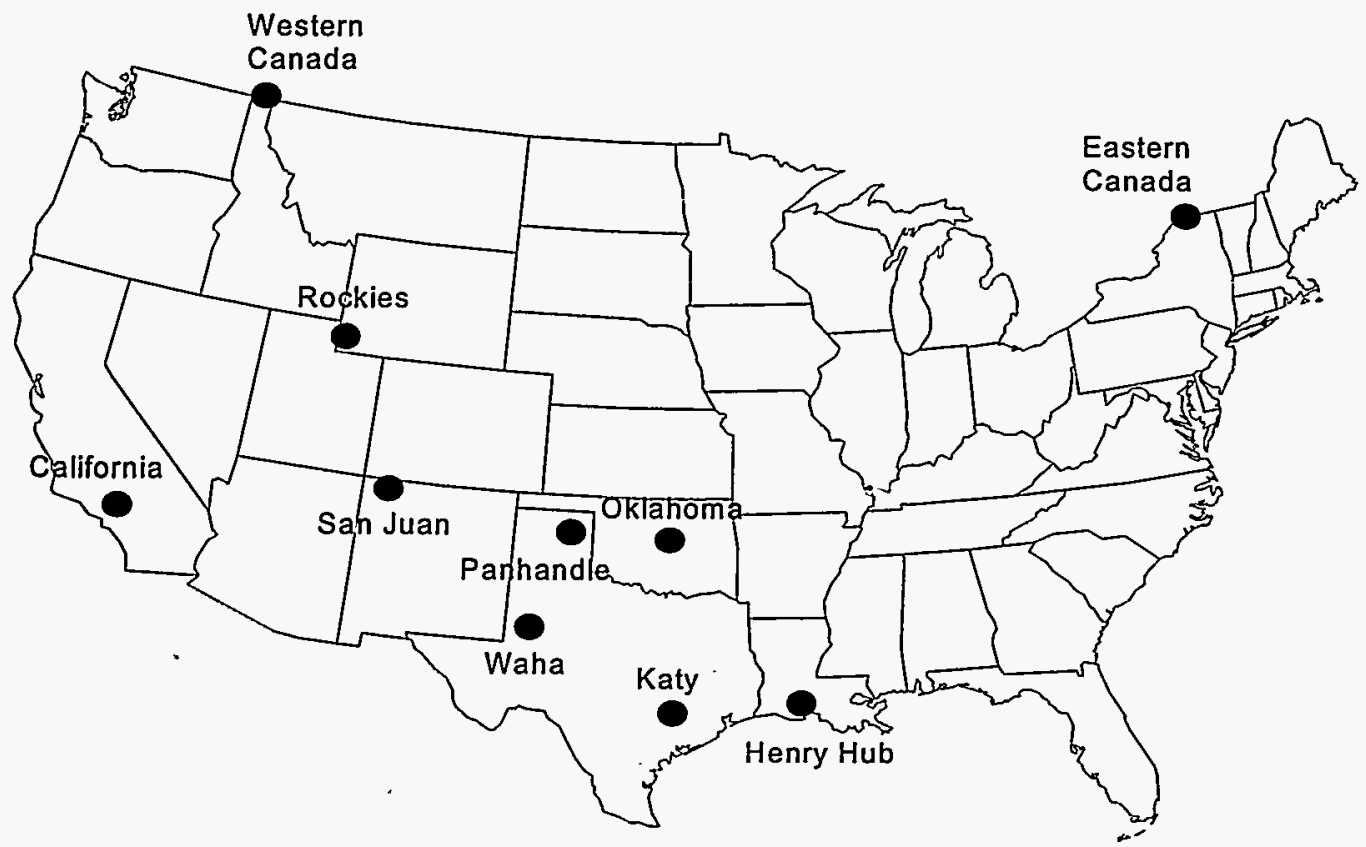

Source: Energy Information Administration, Office of Oil and Gas.

Table 10. Correlations Among Regional Spot Market Natural Gas Prices

\begin{tabular}{|c|c|c|c|c|c|c|c|c|c|c|}
\hline - & CA & WC & Rocky & SJ & Waha & Pan & OK & Katy & $\mathbf{H H}$ & EC \\
\hline \multicolumn{11}{|l|}{ Western Region } \\
\hline $\begin{array}{l}\text { California, Wheeling } \\
\text { Ridge (CA) }\end{array}$ & 1.00 & 0.96 & 0.97 & 0.98 & 0.69 & 0.66 & 0.67 & 0.32 & 0.29 & 0.11 \\
\hline $\begin{array}{l}\text { Western Canada, } \\
\text { Kingsgate (WC) }\end{array}$ & 0.96 & 1.00 & 0.95 & 0.98 & 0.73 & 0.71 & 0.72 & 0.40 & 0.38 & 0.20 \\
\hline $\begin{array}{l}\text { Rockies, } \\
\text { Kern River (Rocky) }\end{array}$ & 0.97 & 0.95 & 1.00 & 0.98 & 0.70 & 0.68 & 0.69 & 0.36 & 0.33 & 0.15 \\
\hline $\begin{array}{l}\text { New Mexico, } \\
\text { San Juan (SJ) }\end{array}$ & 0.98 & 0.98 & 0.98 & 1.00 & 0.70 & 0.68 & 0.69 & 0.36 & 0.33 & 0.14 \\
\hline \multicolumn{11}{|l|}{ Central Region } \\
\hline $\begin{array}{l}\text { West Texas, Waha } \\
\text { (Waha) }\end{array}$ & 0.69 & 0.73 & 0.70 & 0.70 & 1.00 & 0.98 & 1.00 & 0.82 & 0.81 & 0.63 \\
\hline $\begin{array}{l}\text { North Texas, } \\
\text { Panhandle (Pan) }\end{array}$ & 0.66 & 0.71 & 0.68 & 0.68 & 0.98 & 1.00 & 0.98 & 0.86 & 0.84 & 0.66 \\
\hline Oklahoma (OK) & 0.67 & 0.72 & 0.69 & 0.69 & 1.00 & 0.98 & 1.00 & 0.82 & 0.81 & 0.63 \\
\hline \multicolumn{11}{|l|}{ Eastern Region } \\
\hline $\begin{array}{l}\text { East Texas, } \\
\text { Katy (Katy) }\end{array}$ & 0.32 & 0.40 & 0.36 & 0.36 & 0.82 & 0.86 & 0.82 & 1.00 & 0.99 & 0.87 \\
\hline $\begin{array}{l}\text { So. Louisiana, } \\
\text { Henry Hub }(H H)\end{array}$ & 0.29 & 0.38 & 0.33 & 0.33 & 0.81 & 0.84 & 0.81 & 0.99 & 1.00 & 0.93 \\
\hline $\begin{array}{l}\text { Eastern Canada, } \\
\text { Waddington, NY (EC) }\end{array}$ & 0.11 & 0.20 & 0.15 & 0.14 & 0.63 & 0.66 & 0.63 & 0.87 & 0.93 & 1.00 \\
\hline
\end{tabular}

Note: The reported correlation coefficients were estimated based on monthly data over the period November 1993 through May 1996. Reference points for regional spot prices are shown in Figure 32.

Source: Energy Information Administration, Office of Oil and Gas. Derived from Gas Daily's reported monthly contract index prices, a measure of the weighted average cost of gas based on spot deals the week before the pipeline nomination period. In some cases, the analysis was based on pipeline-specific prices. These locations and the corresponding pipeline companies are: Western Canada, Pacific Gas Transmission; New Mexico, El Paso Natural Gas Company; Panhandle, Natural Gas Pipeline Company of America (NGPL); Oklahoma, El Paso Natural Gas Company; Katy, Transcontinental Gas Pipeline Corp. (Transco); and Eastern Canada, Iroquois Pipeline Company. 
considerable distances, such as the Henry Hub and Eastern Canada which are in the eastern region (a 0.925 price correlation). Market pairs in the western regions (California, Western Canada, the Rockies, and New Mexico) and the central regions (Waha, Panhandle, and Oklahoma) correlate even more strongly within each region, with coefficients of 0.952 or more.

The interregional correlations indicate a lower degree of competition than that within regions. In particular, the price correlations between the markets in eastern and western regions are 0.40 or less. For example, the correlations of the price in California with other prices in the West show the influence of its relation with the major supply areas of Western Canada, the San Juan basin, and the Rocky Mountains. The California price correlations with the central regions are less, at 0.657 to 0.685 , and are 0.321 and below for eastern locations, even Katy, Texas. Prices at the central regional markets generally correlate well with prices at all locations in both the eastern and western regions, being at least 0.633 in all cases.

The extent of price correlation between markets does not depend solely on distance. The prices at the Katy and Waha locations in Texas correlate strongly with each other at 0.822 , which is consistent with the relatively slight east-west distance between these two hubs. However, despite their proximity and close price correlation, a fundamental difference between the two markets is apparent in the significant difference of correlations between the Katy hub and points west of Waha. Whereas the correlations for the Waha hub price and the western markets range from 0.685 to 0.733 , the Katy hub has correlations of 0.397 or lower for the other four western points, indicating a lack of interrelatedness with those markets. The general division between eastern and western markets is exemplified by the low correlation coefficient of 0.201 between Western Canada and Eastern Canada.

Market integration has apparently improved in recent years, and regional clusters of markets across broad areas seem to be highly competitive, even between U.S. and Canadian markets. However, it is probably premature to conclude that a true North American market for natural gas has emerged in light of the seeming separation in competition between the eastern, central, and western regions. Besides the distance between markets, the degree of price correlation is affected by the nature of the infrastructure itself. These findings of generally competitive natural gas markets, although characterized by effective regional market separation, are consistent with the work of other analysts. ${ }^{79}$ The market imperfections indicated by the price analysis are a longer term challenge that is expected to be mitigated or resolved with further refinements to the structure, operations, and institutions as the industry evolves.

Short-term market challenges are a market reality since prices often fluctuate, sometimes quite rapidly and dramatically, as demand and supply conditions shift. The unbundling of transmission services altered the basic structure of markets between producers and end users. As the production and transmission segments of the gas supply process have become more competitive and decentralized, the number of transactions has multiplied. The overall decentralization of functions imposes a need for coordination of industry segments. For example, gas must be produced when wanted, and transportation capacity connecting through to the ultimate consumer must be available. There is the possibility of "coordination failure" in the sequential purchase of the gas commodity and gas transportation. The consequence of such failure would be "episodes of price volatility and unused transportation." ${ }^{980}$ Gas market institutions have been designed to avoid such coordination failures, but price fluctuations may arise anyway as the system confronts extraordinary stress. ${ }^{81}$

In response to the difficulties that arose with increased competition, producing firms adopted new and better ways of doing business. Changes extended to field operations, commercial activities in the marketplace, and the structure of the firm itself. The success of these actions and the expansion of gas imports combined to satisfy a growing gas market despite the shift to lower prices.

\section{Improved Operations: Contracting Changes}

Natural gas contracts at the wellhead establish the terms for initial sale of produced gas. The key provisions address the

\footnotetext{
${ }^{79}$ See for example, Canadian National Energy Board, Natural Gas Market Assessment: Price Convergence in North American Natural Gas Markets (December 1995).

${ }^{80}$ Arthur De Vany and W. David Walls, "Open Access and the Emergence of a Competitive Natural Gas Market," Contemporary Economic Policy, Vol. XII (April 1994), p. 92.

${ }^{81}$ The cold weather in January 1996 provides an example of short-term difficulties that cause variations in seasonal price patterns. Some transportation bottlenecks occurred that caused separation in the markets. Prices surged in Midwest and Northeast markets despite an apparent abundance of gas in areas such as Texas. At the same time, firm-service customers received their gas, so the markets appeared to operate as expected. It is expected that the economic opportunities posed by these bottlenecks and other industry performance inadequacies will motivate the industry to provide additional capability where needed, although lags in adjustment are expected.
} 
two main issues for performance under the contract: volumes and pricing. Typical contracts before regulatory reform were long-term business arrangements of 15 to 20 years, particularly for sales under interstate jurisdiction. Long terms for contracts were often required of interstate pipeline companies in order to obtain a certificate of public convenience and necessity from the Federal Energy Regulatory Commission (FERC), or its predecessor, the Federal Power Commission, to expand service and connect new customers.

The impetus of FERC orders during the 1980's and the intense competitive pressure of drastically reduced petroleum product prices in 1986 created strong forces for change in the natural gas contracts of the time. Despite the availability of certain pricing options that would establish a more market-responsive contract, most contracts did not utilize them. ${ }^{82}$ Discrepancies between contract prices and market prices were widespread in the mid-1980's. The increasingly competitive nature of the wellhead markets drove a need for commercial arrangements that were more flexible, so that participants could respond readily to changing market conditions.

Contracts today generally are short term, with flexible pricing and volumetric provisions. Even long-term contracts, which now extend for only 5 to 7 years, have considerable flexibility. These arrangements have the advantage of reducing transactions costs while maintaining an ongoing commercial relationship between buyer and seller. The increased flexibility allows transactions during the period of the contract to occur at prevailing market conditions. Thus, contract participants are not subject to performing under terms that were negotiated at the initiation of a contract many years earlier.

Price variation resulting from the flexible, market-based contracts raises uncertainty regarding the eventual prices that are realized under existing contracts. Price volatility made firms more aware of the need to manage increased price risk without entering again into long-term contracts with fixed terms. The need for a way to mitigate price risk led to the creation of a market for futures trading in natural gas, which opened for trading in April 1990. Prices determined on the futures market can be considered a clear indicator of prevailing market prices in order to establish prices as contracts are executed.

${ }^{82}$ Only 48 percent of 1984 production from wells drilled after passage of the Natural Gas Policy Act (NGPA) in 1978 flowed under contracts with market-out provisions. Thirty percent of the 1984 production from postNGPA wells flowed under contracts with neither market-out nor renegotiation clauses in effect. Energy Information Administration, $A n$ Analysis of Natural Gas Contracts, Vol. III: Contract Provisions Covering Production of New Gas, DOE/EIA-0505 (Washington, DC, May 1987), p. 32.
Futures trading meets the needs for a way to mitigate price risk and for a source of timely, reliable price information. However, futures trading does not eliminate price risk, and it is subject to risk in terms of expected volumes traded. If the actual volumes traded differ from the terms of the futures contract, the resulting profits and losses associated with any trade can be magnified. Nonetheless, futures trading has attracted traders of many types, including producers. The value of futures trading to producers can be inferred from their use of this trading option. Producers' participation in the natural gas futures market was 20 percent of the trading in the first quarter of 1996.

The response of the industry to the changing market seems to serve the industry and its customers well, but these institutional elements have not eliminated price variation. Price volatility has been a signature aspect of gas wellhead markets during recent years. In comparison with other commodities, natural gas prices remain extraordinarily volatile.

\section{Cost Containment: Changes in Field Operations}

Producers have made major strides in containing costs. Ways in which producers have improved their operations include redirecting their activities in the field and increasing productivity. Trends in costs and productivity show the impact of technology and improved efficiency on discovery and development activities.

\section{Redirection of Producer Supply Activity}

The reduced regulation of producers has allowed the market to establish competitive prices for gas supply activities at all stages in the delivery process. Prices distorted by regulation do not effectively direct industry resources to their most efficient applications.

The impact of drastically lower drilling levels caused by the falling prices after 1985 was mitigated by more efficient distribution of resources toward higher productivity locations and geologic settings. Drilling since the mid-1980's has been redirected toward those States that may be considered the more traditional gas suppliers: Texas, Louisiana, Kansas, Oklahoma, and New Mexico. Drilling also shifted to deeper, typically more productive strata. For example, the average depth of gas wells completed in the Permian Basin increased by 37.5 percent between 1987 and 1994 . The movement into deeper locations has higher associated costs, but the prospects are expected to provide greater volumetric returns that reduce unit costs and enhance expected profitability. 
Producer activity also has been redirected to more consolidated field operations and the more efficient use of available proved reserves. The number of fields operated by large operators fell steadily from 1988 to 1994 . The largest 10 producers in each year maintained their gas production levels (7.2 trillion cubic feet in 1994 compared with 7.1 trillion cubic feet in 1988), while the number of oil and gas fields operated by these firms declined by more than 50 percent. ${ }^{83}$ Despite the large reduction in the number of active fields operated by large operators, gas reserves for these operators declined by only 9 percent. These trends indicate that the reserves per large operator has increased by consolidating operations and shedding marginal fields. The movement allowed operators to focus efforts and capture available economies of scale. Consolidation contrasts to the earlier approach of diversifying operations across many fields to lower overall investment risk. This new strategy may have been motivated and enabled by technological developments, such as three-dimensional (3D) seismic technology, that enhance operator knowledge of the reservoir.

Another change in producer activity has occurred in the area of inventory management. More efficient production operations have allowed operators to reduce their inventory of proved gas reserves. Reduced inventory lowers the financial cost of "carrying" the investment costs until recovery of initial capital costs is complete. The accelerated field production profiles associated with the reduced inventory produce larger expected present-value revenues for the project, which increases expected profitability. The faster cost recovery also improves the economic attractiveness of many investments because it diminishes the perceived overall risk of the projects stemming from price, cost, and other uncertainties.

Evidence of the more efficient use of reserves is seen in the decline in the level of proved reserves relative to production volumes over the past decade. The ratio of proved reserves to production for the lower 48 States declined to 8.5:1 in 1994 from more than 10:1 in the mid-1980's. Related to the decline in the reserves-to-production ratio is a reduction in the surplus wellhead gas productive capacity. Unused productive capacity fell by half from 1984 to 1993 when the surplus was 11.2 billion cubic feet per day. The surplus is estimated to decline further in 1995 and 1996 to 8.8 and 7.1 billion cubic feet per day, respectively, while the corresponding capacity utilization rates hit 85.7 and 88.3 percent. $^{84}$ This reduction in the relative size of reserve inventories and surplus capacity has raised

\footnotetext{
${ }^{83}$ These data are not differentiated between gas and oil fields.

${ }^{84}$ Energy Information Administration, Natural Gas Productive Capacity for the Lower 48 States 1984 Through 1996, DOE/EIA-0524(96) (Washington, DC, February 1996).
}

concerns as a sign of increasing supply insecurity.$^{85}$ However, the general perception of abundant supplies and the lower unit costs have nonetheless yielded a steadily growing market for gas.

The substantial changes undertaken by producers to contain costs were predicated on regulatory reform of the transportation industry to move the larger volumes to market from new locations. Regulatory reform of the transmission industry, while not directly affecting producers, has been essential for the success of producers. Efficient use of the network and the capacity expansion response of the transmission companies allowed larger volumes to move to new markets. ${ }^{86}$

\section{Increased Productivity and Lower Costs}

Numerous measures show a definite increase in the productivity of various activities in the producing industry. One of the more striking examples is the average size of newly discovered gas fields. The traditional view of exploration is based on a discovery process model in which the largest volume prospects in each play are discovered more easily, hence earlier, so the trend in discovery size over a long period is expected to be downward. The historical performance of the industry tended to conform to this expectation until the 1980 's. The average size of new-field discoveries for the onshore Gulf Coast serves as an illustrative example of the divergence between industry performance and the implications of the theoretical model. The average size surged in the late 1980's (Figure 33). The average size of gas fields discovered between 1990 and 1994 was more than 50 percent greater than the average field size discovered during the 1980 's. Improvements in technology obviously have helped operators in the Gulf Coast to find better prospects or to provide a better initial estimate of proved reserves for the field. ${ }^{87}$

Newly completed wells also show better productive performance, as measured by produced volumes in the first producing year. Initial flow rate is a significant productivity

\footnotetext{
${ }^{85}$ For example, National Petroleum Council, The Potential for Natural Gas in the United States: Source and Supply (December 1992).

${ }^{80} \mathrm{~A}$ recent, major event in the transmission sector is the development of a resale market for surplus capacity on either a short-term or long-term basis. This important development is discussed in Chapter 2 of this report.

${ }^{87}$ In addition to improving finding rates by increasing the yield from any given region, technology can improve aggregate finding rates by providing the opportunity to explore new areas, some of which may have significatnly larger discovery sizes. Data for disovered fields in the deep water region of the Gulf of Mexico serve as a prime example of this benefit from technology. See Chapter 1, "Key Issues: Offshore Deep Water Development" for a comparison of finding rates for deep water in the Gulf and other regions of the lower 48 States.
} 
Figure 33. Average New Field Discovery Size in the Gulf Coast, 1977-1994

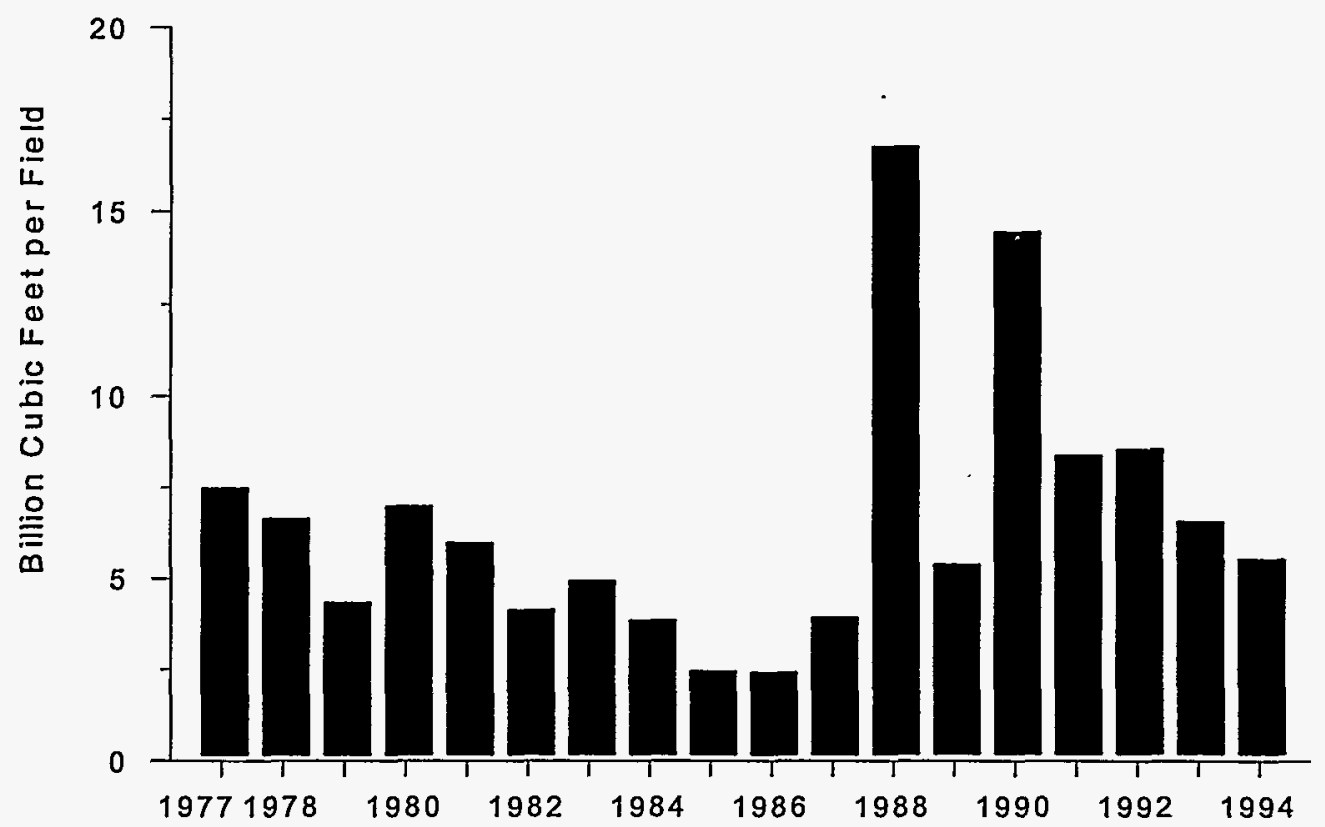

Note: The reported values are for nonassociated gas only. The reported values are based on the actual year the fields were discovered. Source: Energy Information Administration (EIA), Office of Oil and Gas. Derived from Form EIA-23, "Annual Survey of Domestic Oil and Gas Reserves."

measure for two reasons. The present-value revenue from a well is typically increased with larger produced volumes in the early years, which improves the expected value of returns from new drilling. Secondly, if the new wells decline at a rate comparable to that of earlier wells, ultimate recovery from new wells will exceed that of older ones. Larger recovery volumes also enhance the economic attractiveness of drilling prospects.

Technology has enhanced operator performance in field development and increased the productivity of supply activities. The effects of improved field development and increased productivity can be seen in the gains for estimated ultimate recovery from the largest five gas fields in the lower 48 States. The estimated ultimate recovery from gas fields in the lower 48 States grows during the producing life of the field to 770 percent of the initial proved reserves estimate, on average. A stylized representation of this phenomenon shows a growth period of 100 years (Figure 34), during which recovery increases but at a steadily diminishing rate. The largest five fields were all discovered by 1947 , so as mature fields they now should exhibit only modest growth in ultimate recovery. The estimated recovery from these five fields, however, rose rapidly after 1985 from a plateau in the 1981 to 1985 period (Figure 35).

Producers have had considerable success in containing costs, as indicated by recent trends in operating costs and lease equipment costs (all costs adjusted for inflation). Operating costs on average have dropped since the late 1980's. Average annual operating costs for all regions, depths, and wellproduction rates were $\$ 23,000$ per well in 1995 , after declining 3 percent between 1992 and 1995. The trend in operating costs is affected principally by recent changes in labor costs, which are a major influence on overall costs of gas well operations. Operating costs by region and depth show a consistent pattern of decline. Field equipment costs averaged over all regions, depths, and well-producing rates for the 1992 through 1995 period declined almost 10 percent, to $\$ 44,300$ per well. Within this average change, cost changes by well-producing rate ranged from a decrease of 14 percent for wells flowing 1 million cubic feet per day to a decrease of 3 percent for wells flowing 10 million cubic feet per day.

This evidence indicates the success of producers in meeting the need to improve basic operations and contain costs. As a result of the more competitive environment and lower prices, the industry has placed more reliance on innovation and technology, which has enhanced the industry's ability to find new reserves at higher productivity rates and lower unit costs. As new reserves "arrive" with ever-lower associated costs, these new gas supplies gain market share by bidding down prices. This is not a destabilizing factor within the industry, but it has maintained or increased downward pressure on wellhead prices throughout the lower 48 States. 
Figure 34. Growth in Ultimate Field Recovery: Recovery as Multiple of Initial Proved Reserves for a Stylized Field

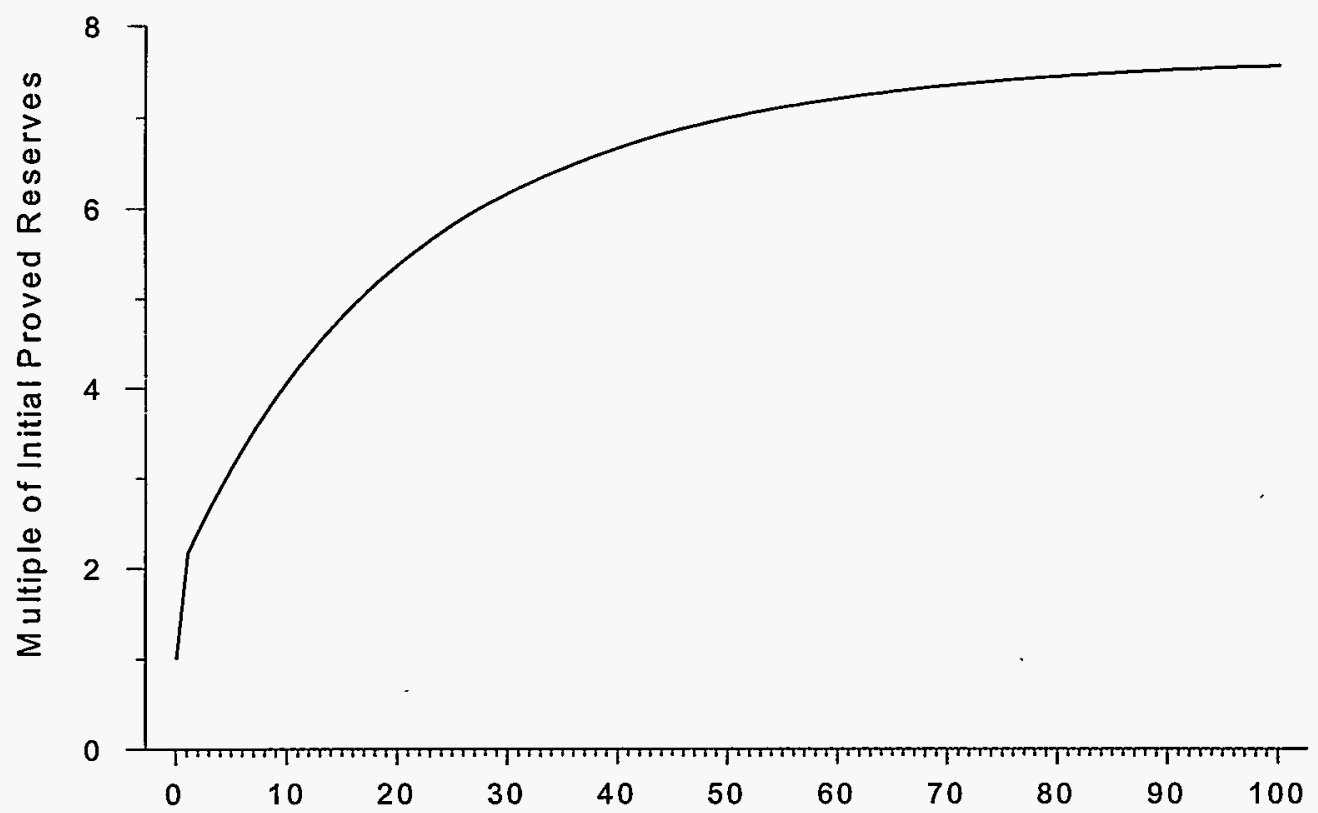

Source: Energy Information Administration, Office of Oil and Gas. Background information from The Domestic Oil and Gas Recoverable Resource Base: Supporting Analysis for the National Energy Strategy (December 1990).

Figure 35. Growth in Ultimate Recovery for the Top Five Gas Fields in the Lower 48 States, 1977-1992

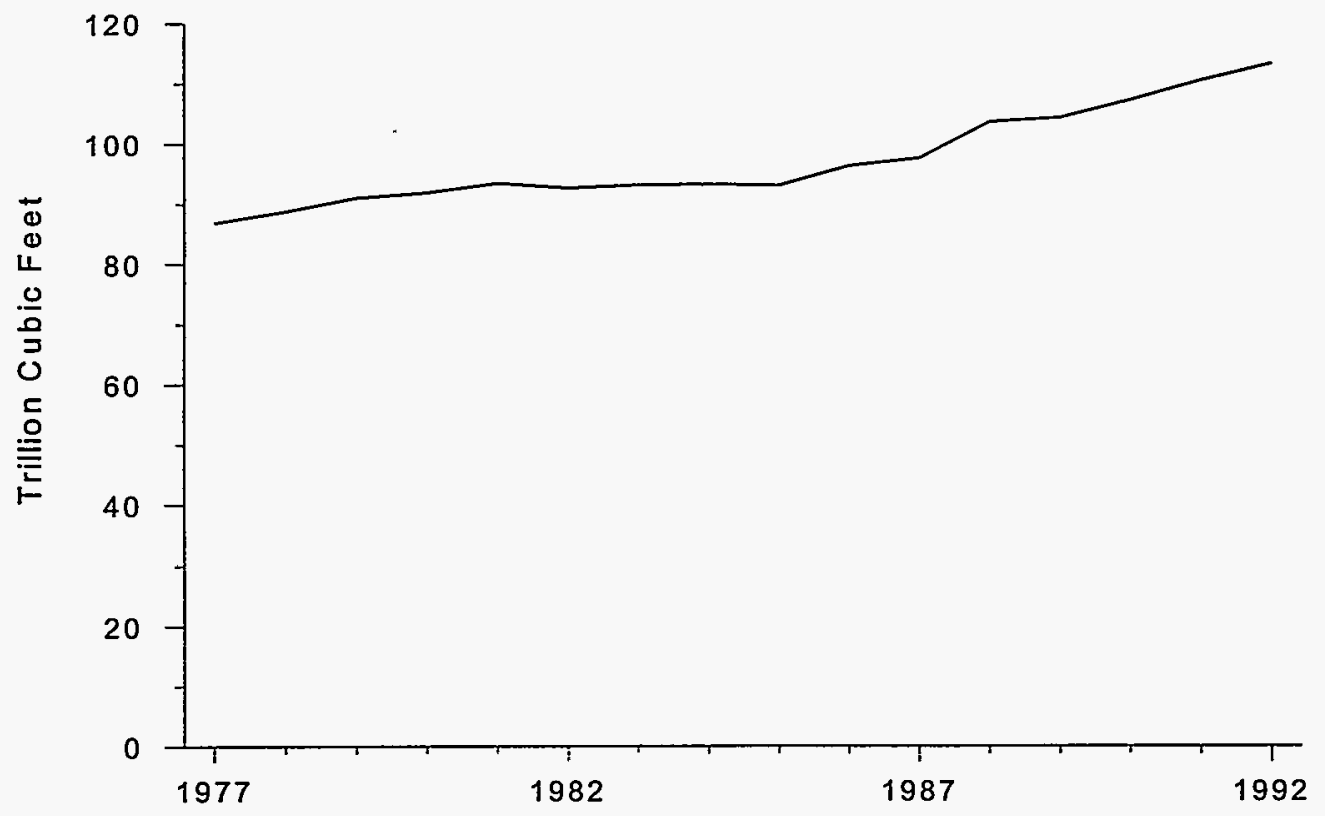

Source: Energy Information Administration, Office of Oil and Gas. Derived from data in Appendix B of U.S. Crude Oil, Natural Gas, and Natural Gas Reserves, various issues 


\section{Effects on Investment}

The average natural gas wellhead price from 1993 through 1995 was $\$ 1.86$ per thousand cubic feet (1995 dollars), which is 46 percent less than in 1985 . The relatively low price has had two likely implications for investment. The industry has invested in those projects that have very short expected payback periods, such as onshore development projects, and those that have very large expected recovery volumes, such as deepwater prospects. The preference for short payback periods is reflected in the falloff in new field discovery volumes as a share of total discoveries since $1990 .^{88}$ The relative falloff in new field discoveries is curious in light of the well-recognized success of new search technology such as 3D seismic. The enhanced reliability of 3D seismic lowers drilling costs in a number of ways, but especially by avoiding dry hole costs. Avoiding dry hole costs is especially important for new field wildcat projects because of the lower average success rate for this type of drilling. A key advantage of development for investors, however, is that such projects have shorter payback periods, which lessens the uncertainty for a project due to exposure to industry events that might thwart cost recovery.

The greater volumes associated with projects such as those in deep water have a number of advantages. Production performance of wells, measured in terms of annual flow rates and ultimate recovery, generally is highly correlated with expected recovery for the field. The deep water regions offer prospects with the highest volumetric return in the lower 48 States. Deep water projects also exhibit relatively rapid recovery because of the physical properties in the region that favor high well flow rates. Accelerated field production provides a more favorable present value return. Despite enormous project costs, the expected discovery size in the deep water area can yield low unit costs of discovery and development. The strong interest in these projects, despite continued large financial risks, may be explained at least in part as a response to the downward cost spiral in the industry.

\section{Corporate Strategies}

Producing companies increasingly have pursued opportunities for new lines of business or ways to expand their firms in terms of both scale of operation and in related new businesses of strategic importance. Major concerns of producers include the downward price pressure presented by competition among

\footnotetext{
${ }^{89} \mathrm{New}$ field discoveries for 1991 through 1993 were 10.2 percent of total discovery volumes, which is 34 percent below the 15.5 percent average for the 4 years ending in 1990 . The 15.2 percent figure for 1994 is due mainly to the unusually large deep water fields, which raised the Federal offshore rate to 33 percent.
}

domestic and foreign gas suppliers, and the low prices of competing fuels.

The composition of the industry is an important determinant of competition in the wellhead markets, which depends on both the number and relative size distribution of the firms in the industry. The presence of a few, relatively large firms in an industry frequently raises concerns about undue market power or unfair cost advantages accruing to the largest firms. A key feature of the gas-producing industry is that most of the producing firms are relatively small, privately held companies. The top 100 operators ${ }^{89}$ in 1993 had an average wet gas production rate of 151.8 billion cubic feet per year, with the top 10 averaging 721.6 billion cubic feet. The 10 largest operators supplied 38 percent of wet gas production in 1994. This contrasts greatly with the average of 0.028 billion cubic feet reported for the year by the almost 90 percent of operators at the low end of the production range. However, the relatively unconcentrated nature of the industry overall and the fluid, dynamic transmission system are consistent with a finding that regional markets are not likely to be controlled by any one firm. Regarding possible cost advantages because of firm size, a recent study by the Energy Information Administration finds that independent firms have reserve replacement costs that, at less than $\$ 1$ per thousand Btu, are almost equal to those of major producers. ${ }^{90}$

\section{Producer Marketing Cooperatives}

While producers continue as before to address the problems of discovery and extraction of natural gas from the ground, the growing competition in the wellhead market and the unbundling of services have caused producers to attend to gas marketing as never before. A number of producers have looked for opportunities to enhance their returns either by extending operations into other stages of the natural gas supply business such as storage or by forming strategic alliances that combine dissimilar activities in the vertically separated supply process to enhance their market position or capture economies of scale.

A number of firms have become concerned about what they perceive as their relatively limited market power (but not necessarily small size). A number of independent producers, dissatisfied with recent low prices and their impact on profitability, contend that they do not have the ability to compete with large marketers in the intensely competitive wholesale gas markets. Some argue that independents are at a disadvantage because they lack access to the breadth of

\footnotetext{
${ }^{89}$ Size is measured by production for the year 1994.

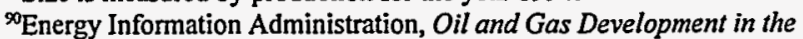
United States in the Early 1990s: An Expanded Role for Independent Producers, DOE/EIA-0600 (Washington, DC, October 1995).
} 
electronic information available to large marketers and that the large number of competing producers puts them at a competitive disadvantage in trying to sell their gas. In response to this situation, some independents have proposed the passage of legislation that would allow producers to form marketing cooperatives with limited exemption from Federal antitrust statutes (see box, p. 91).

Some expect that the formation of producer marketing cooperatives will provide considerable benefits to its members. Marketing cooperatives such as those in agriculture $^{91}$ provide various advantages, such as reducing transactions costs, providing joint sales promotions and advertising, and reducing costs to member firms through economies of large-scale purchasing and contracting for necessary goods and services. An additional advantage anticipated by proponents of gas producer cooperatives is sharing substantial amounts of timely information concerning market conditions. Further, such market combinations are expected to enhance the market position of independent producers given the expected large volume of produced gas managed by the cooperatives. Marketing cooperatives, according to this view, would provide market power, productivity and cost advantages, and overall efficiency gains.

The experience of other types of cooperatives indicates that it is not automatic that gas marketing cooperatives would be successful in influencing price to their members' advantage by reducing price volatility or avoiding low prices. Agricultural cooperatives do provide member farmers with certain costs savings and productivity enhancements. The record on the ability of cooperatives to support higher prices is much less clear. For example, agricultural commodities remain subject to cyclical variation in price despite the prevalence of "thousands of . . . cooperatives representing 2 million U.S. businesses with more than $\$ 82$ billion in combined revenues." ${ }^{.92}$ Additionally, marketing arrangements similar to the proposed producer cooperatives have been used in Canada for years without much success in avoiding low prices or price volatility, despite somewhat less restrictive antitrust laws in Canada (see box, p. 92). The average wellhead price in Alberta was roughly 66 percent of the average wellhead price in the lower 48 States for the 1990 to 1994 period. The ability of Canadian producers to influence wellhead prices seems to have been uncertain and highly

\footnotetext{
${ }^{9}$ Marketing cooperatives for agricultural products are allowed under the Capper-Volstead Act (CVA) of 1922. The CVA provides limited antitrust exemption to associations of agricultural producers, permitting farmers to join and act as one farmer. However, cooperative marketing associations under CVA remain liable for antitrust law violations.

${ }^{92}$ Obie O'Brien, Director of Governmental Affairs for Apache Corporation, "Rx for America's Natural Gas Market," presentation to the Califomia Independent Petroleum Association Annual Meeting (May 22, 1995).
}

subject to market forces, so reliance on producer marketing cooperatives in the United States may not prove useful to independent producers in the long term.

\section{Corporate Combinations}

Alternative strategies for marketing gas include the formation of new corporate ventures. Corporate combinations include mergers of gas-producing firms horizontally, vertically, or with firms that supply other forms of energy. Corporate combinations are becoming more frequent, so clearly these alliances are perceived to offer various advantages to the involved firms.

Horizontal combinations are mergers between firms at the same level of the supply process, so the merged firms have roughly the same operational capabilities, although at a larger scale. Horizontal combinations tend to be attractive if the involved firms can increase their potential market power to offset the perceived market position of competitors or downstream firms such as marketers. Mergers of gasproducing firms have not occurred to any great extent perhaps because the resulting combined firms are not expected to attain the possible advantages to a significant degree. Horizontal merger plans also are subject to risk because they tend to attract more intense antitrust scrutiny than vertical or conglomerate mergers.

Vertical combinations provide the advantage of additional capabilities at different levels of the supply process. Vertical combinations serve to extend operations into other stages of the industry for short- or long-term profit potential or for gaining a strategic advantage. Producing firms also are expanding by forming conglomerate-type mergers, in which the participating firms are involved in the production or marketing of different energy forms. This movement has been given considerable momentum by recent Federal initiatives to reduce regulation and restructure the electric generation industry. The transformation of the electric generation industry may have the strongest impact on gas producers in the next few years, as electric generation companies are both customers and competitors for natural gas producers-virtually at the same time. Additionally, the similarities in marketing natural gas and electric power offer potential synergies for large marketers handling more than one fuel.

The extension of the producer's role into marketing, storage, and other supply activities may be viewed as a reaction to the unbundling of services previously offered in combination by the pipeline companies. The transportation operations of interstate transmission companies were augmented by load 


\section{Proposed Legislation to Allow Producer Marketing Cooperatives}

A number of firms, most notably Apache Corp., have encouraged new legislation to rectify the reputed unfair market advantages enjoyed by gas marketers. The movement for new legislation resulted in the introduction by Reps. Lamar S. Smith (R-TX) and John Bryant (D-TX) of the "Natural Gas Competitiveness Act of 1995" (H.R. 2343) on September 14, 1995. This legislation, if passed and signed into law, would permit independent producers of natural gas to act together in associations "...in collectively producing, gathering, transporting, processing, storing, handling, and marketing in intrastate, interstate, and foreign commerce, natural gas (including natural gas liquids) produced in the United States." The association is prohibited from dealing in "natural gas (including natural gas liquids)" in an amount exceeding 20 percent of the volume of "natural gas (including natural gas liquids)" produced in the United States in the preceding calendar year.

The responsibility for policing associations' behavior for antitrust violations is delegated to the Attorney General of the United States. When the Attorney General believes that an association under the Act monopolizes or restrains trade to an extent that the price of natural gas is unduly enhanced, she may initiate administrative action. In addition, any person or State also may assert a claim against an association for violations of Federal antitrust law. At this point, the legislation is pending.

balancing, gas storage, local marketing (albeit limited), security of supply, and other services that enhanced the value of the delivered commodity to the consumer. The market power of interstate pipeline companies over transportation extended to these services, which precluded competition. The unbundling of nontransportation services provided potential competitors the opportunity to penetrate the separate markets for these services.

Over time, other firms saw the profit potential of separate, unbundled services. Many producers, however, were driven into marketing more by circumstances than by choice. The goals of conducting profit-making activities and developing needed capabilities to strengthen the overall market position of the firm led some producers initially to market their own gas. As competition in gas marketing increased, good economic performance in this area became more difficult.

Marketing difficulties have caused some producers to merge with marketing firms, thus resulting in a combination of activities. For example, Chevron Corporation and NGC Corporation, Houston, announced their intent to merge, thus forming the largest gas and natural gas liquids (NGL) marketer in North America, with sales exceeding 10 billion cubic feet per day. The merged company would be the largest NGL processor and marketer in North America, with volumes of 140,000 and 470,000 barrels per day, respectively. The expected advantages of the combination include lower unit costs for NGC and "new opportunities" because of its larger scale of operations. NGC will have the ability to offer a set of energy commodities including natural gas, gas liquids, electricity, and crude oil to customers. Other examples of corporate combinations involving producers include: Shell Oil Company, a unit of Royal Dutch Shell Group, which has joined forces with Tejas Gas Corporation; Mobil Corporation and PanEnergy who have agreed to market gas jointly; ${ }^{93}$ and Tenneco Energy and El Paso Energy. ${ }^{94}$

The marketer segment of the gas industry has experienced significant changes, which has important implications for the future of gas producers in light of the key position in the supply process that is occupied by marketers. Gas marketing has undergone dramatic consolidation. The top five marketers for 1995 moved 27.7 billion cubic feet per day, which is more than half the 46.2 billion cubic feet per day moved by the top 20 in 1993. Even new entrants can be sizeable competitors. CNG Energy Services and PennUnion, two companies that did not exist in 1994, were among the top 25 in 1995. Another significant feature of the top 25 marketers in 1995 is that no independent marketer is included. All of the top 25 are either producer or pipeline affiliates or gathering-processingmarketing companies. The trend of the past 3 years is expected to be continuing in 1996. Despite the shift to a core group of large marketers, smaller companies are expected to remain as specialized firms that operate in a certain geographic area or provide particular services.

The industry of the future does not require producer-marketer mergers across the industry, but it is one reaction to new industry realities. The evolution of the industry has created a complex environment in which the tradeoff between risk and reward is not readily grasped. In fact, no single strategy is likely to be appropriate for all, or even most, firms.

\footnotetext{
93"Front Burner: Tired of Phone Wars? Get Ready for a Fight to Sell Natural Gas,"Wall Street Journal (April 16, 1996), p. 1.

94*"El Paso to acquire Tenneco for \$4 billion" Gas Market Week (June 24, 1996), p. 1.
} 


\section{Canadian Natural Gas Marketing Arrangements}

The Canadian natural gas industry has relied for some time on a marketing system that has strong similarities to the proposed U.S. producer cooperatives. The Canadian system includes aggregators who purchase gas from several producers under netback-priced gas contracts. The price paid to the producer on a netback basis is determined by the resale price downstream. Under the Natural Gas Marketing Act (NGMA) enacted by Alberta in 1985,* producer interests in Alberta are protected by prohibiting an aggregator selling gas under a netback agreement from removing gas from Alberta or delivering it in Alberta for resale to another person, unless there has been a finding of producer support. Thus, producers retain an active role in the decision to execute a sale for resale on their behalf, which in practice is similar to the proposed role for U.S. producer cooperatives. This differs substantially from U.S. marketers, who simply purchase the gas outright from producers and then control its subsequent disposition. A second similarity to proposed U.S. cooperatives is that Canadian aggregators and producers have an opportunity to share information on the pending sale and current market conditions. This information-sharing reaches all parties and is facilitated by the information sessions.

Producer support is determined by the aggregators by a system of voting by ballots. Ballots consist of a question answerable by a "yes" or "no" response only. Prior to distribution of the ballots, aggregators often conduct information sessions to brief producers on their marketing efforts and to prompt them to accept the proposed contracts. The Bureau of Competition Policy (BCP) has evidenced concern that the information sessions are conducted circumspectly, and that anti-competitive activities or agreements are avoided. For example, producers should not agree to refrain from competition with the aggregators in certain markets; aggregators cannot encourage production curtailments to influence prices upward; and sensitive market information such as pricing strategies cannot be exchanged.

Canadian antitrust law, while similar to that of the United States, differs in the nature of prohibited actions. The major antitrust law in Canada is the Competition Act, which is intended to "remove impediments to free and open competition and is designed to promote efficiency at home and to expand opportunities for Canadian business abroad."** In pursuing anti-competitive behavior, the $\mathrm{BCP}$ gives top priority to behavior between competitors. Key provisions of the Act related to these offenses are:

- Section 45 - Conspiracy requires two elements: (1) existence of some degree of market power, and (2) existence of behavior likely to injure competition.

- Section 47 - Bid-rigging: one or more bidders refrain from submitting bids, or arranged bids are submitted. Bid-rigging is a per se offense.

- Section 61 - Price maintenance: an attempt to influence prices upward or discourage price reductions by agreement, threat, promise or like means.

An important activity promoting corporate compliance is the issuance of advisory opinions to firms concerning a proposed business plan or practice. In 1990, the BCP reviewed an instance in which an aggregator, six producers, and a local distribution company (LDC) were to negotiate a sales contract. The issues considered were whether the aggregator may hold meetings with the producers to discuss pricing strategy and whether two representatives of the producers may participate directly in the negotiations with the LDC. The BCP determined that these producers could not influence the price upward because they were a small portion of the industry-wide supply and a small portion of supply to the LDC, so the conspiracy and price maintenance provisions of the Act did not apply.

The 1990 opinion exhibits an interesting difference in Canadian antitrust law compared with that of the United States. Bid-rigging is illegal under Section 47 of the Competition Act, unless the "...situation is known to the person calling tenders..." Although "bidrigging is a per se offence in that no lessening of competition need be demonstrated," disclosure of the activity seems sufficient to remove culpability. The LDC was aware that the six producers were submitting a joint bid, so the bid-rigging provision did not apply. This is in contrast to U.S. antitrust case law, which generally holds that direct price-fixing agreements are per se violations of the law.

*British Columbia has similar legislation. British Columbia and Alberta together accounted for over 94 percent of 1994 Canadian natural gas production.

**Harry Chandler, Bureau of Competition Policy, Competition Law Issues in the Upstream Oil and Gas Industry, Notes for An Address to the Canadian Petroleum Law Foundation (Jasper, Alberta, June 11, 1992). 
Combinations such as those pursued by major producers with large marketing firms may reflect a changing outlook on longer-term strategic planning by the firm. Other corporate developments in the gas supply industry include firms that provide services that previously were internal to the transmission companies or are now internal to other large firms, such as the information activities of large gas marketers. The unbundling of transmission company services opened a myriad of commercial possibilities. Gas marketers arose to serve as gas aggregators and to focus on aggressive marketing. Storage operators provide a valued service to the markets. Market hubs evolved as an efficient combination of services offered in a particular locale. The combination of storage, load balancing, and physical interconnections for transportation and transfers of gas between firms provides important services and reduces the administrative burden for participating firms.

One already identified need, according to some firms, is for more reliable, timely information regarding regional market conditions. This has led to the creation of information services that provide data about sales at various locales on a daily basis. ${ }^{95}$ Other developments in this area include companies with refined information services that provide data on a realtime basis which are of comparable quality to the information collection and dissemination activities that are internal to the large marketing companies. This approach captures economies of scale and allows the cost of personnel, capital, and required expertise to be shared among the customers. This type of information service is provided to producing companies on a subscription basis.

\section{Foreign Trade: A Challenge to Domestic Producers}

Foreign trade is an important aspect of the U.S. natural gas industry and markets, especially with the stimulus from regulatory reform initiated in the mid-1980's. The U.S. Government has undertaken a number of policy actions directly related to foreign trade since the mid-1980's including the Canadian Free Trade Agreement (CFTA) and the North American Free Trade Agreement (NAFTA). The ratification of these treaties marked the endorsement of free trade principles. The practical significance of the treaties arguably has been modest because of already existing regulation that promoted free trade. The CFTA and NAFTA nonetheless are important actions that validate the free trade process. Further,

\footnotetext{
${ }^{95}$ Examples include selected spot prices as published by Pasha Publications, Inc. in the Gas Daily and by Dow Jones Telerate Energy Services.
}

these treaties may serve a key role in preventing any retreat or diversion from free trade principles in the future.

Foreign natural gas supplies are an attractive option for many U.S. consumers. Imports comprised almost 13 percent of U.S. consumption in 1995. Foreign gas producers, especially those in Canada, provide strong competition for U.S. producers, as evidenced by the large increase in natural gas import volumes since the mid-1980's (Figure 36). The vast share of U.S. natural gas imports is from Canada - over 97 percent from 1990 through 1995. Purchases of Canadian gas reached an alltime high of 2.82 trillion cubic feet in 1995. Other foreign supplies come from Mexico via pipeline and from Algeria as liquefied natural gas (LNG) in special tankers. Limitations on available supplies or transportation have kept other imports at a combined average of 40 billion cubic feet per year since the mid-1980's.

\section{Increased Supply from Canada}

Canadian exports to the United States since the mid-1980's were stimulated by regulatory reform in Canada (see box, p. 95). The Canadian government had moved to market-based prices for exports in 1985, and it virtually removed regulatory restrictions regarding approval of volumes for export in 1987. While regulatory reform provided the opportunity for export expansion, the realization of this potential required physical and economic characteristics that supported increased production and sales. Growing sales to the United States from Canada have benefited from a number of competitive advantages.

One contributing factor was the large stock of Canadian proved reserves relative to production that was present in the mid-1980's. Regulations pertaining to foreign sales in the 1980 's imposed large reserve requirements as a condition of approval. This resulted in a large reserves-to-production ratio, which was close to 30:1 for the Western Canada Sedimentary Basin during the first half of the $1980 \mathrm{\prime} s,{ }^{96}$ compared with the U.S. level of roughly 10:1 (Figure 37). When regulatory reform opened the way for increased exports, the relatively large gas inventory provided readily available supplies. It was also a relatively low-cost source of gas because the discovery costs of this gas already had been accounted for, and expanded sales depended only on the addition of development wells, which tend to cost less than exploratory wells.

\footnotetext{
${ }^{9}$ Data for the Western Canada Sedimentary Basin (WCSB) are used as representative of Canadian production potential because the region has been the source of roughly 99 percent of total production during the period of discussion. The WCSB is contained largely in British Columbia, Alberta, and Saskatchewan.
} 
Figure 36. U.S. Imports of Natural Gas: Total and from Canada, 1980-1995

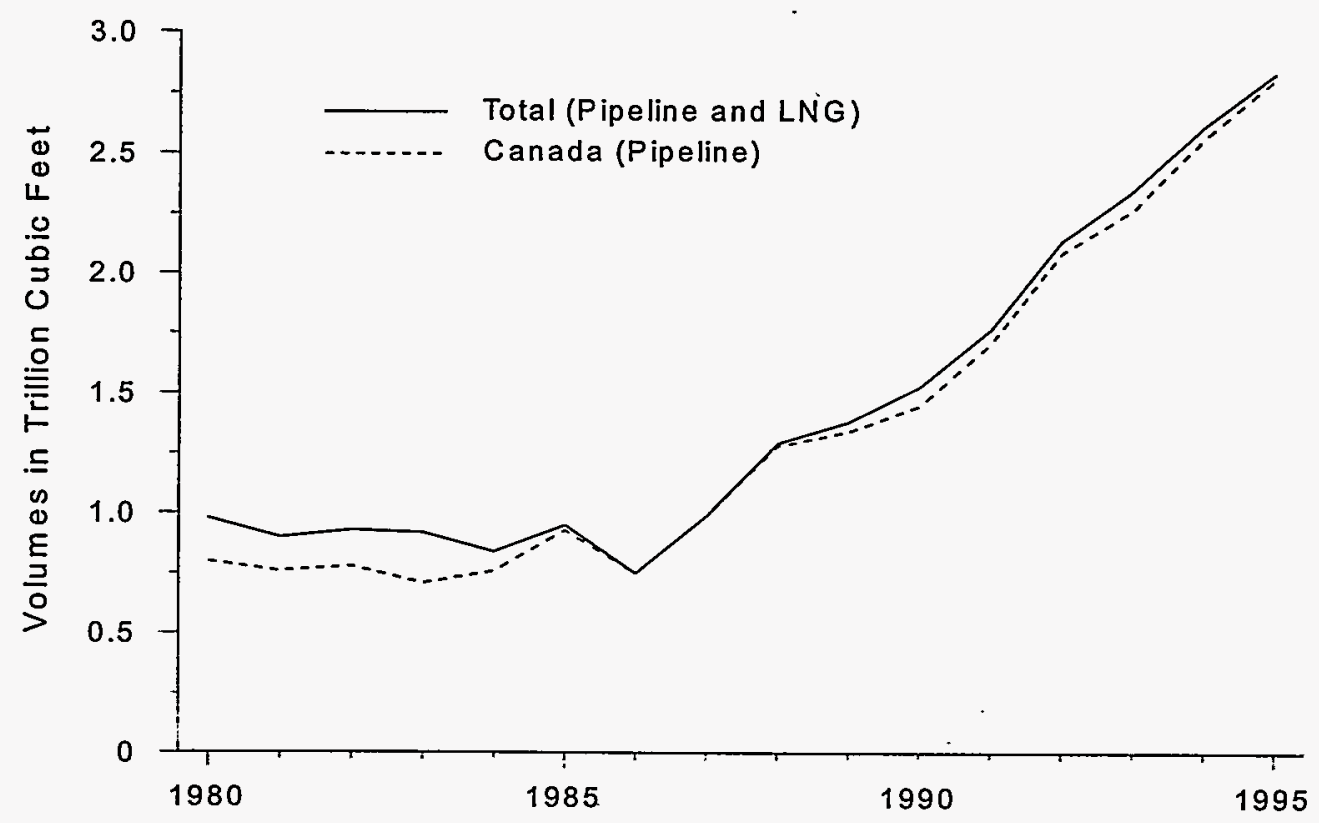

LNG $=$ Liquefied natural gas.

Source: Energy Information Administration, Office of Oil and Gas. 1980-1989: Natural Gas Monthly (August 1995). 1990-1995: Natural Gas Monthly (November 1996).

Certain characteristics of the Canadian industry provide further competitive advantages. The average gas flow rate per gas well in Canada has grown almost continuously since 1986 to a level of roughly 330 thousand cubic feet per day in 1994. This flow rate dwarfs the 1994 U.S. daily average of roughly 180 to 190 thousand cubic feet from 1990 to 1994 . Operating costs as a fraction of gross revenue in 1994 were at their lowest level since 1987. While expenditures on operating costs have grown gradually during the past decade, the relative decline in operating costs has been driven by the growth in Canadian production, which increased roughly 50 percent from 3.5 trillion cubic feet in 1990 to 5.2 trillion cubic feet in 1994.

Canadian gas exports also benefited from changes in the relative value of the currency. U.S. imports are generally priced in terms of U.S. dollars, so changing currency values are not reflected in the purchase prices to the U.S. consumer. However, the fall in the value of the Canadian dollar since 1990 has enhanced the monetary value to Canadian producers of gas sold to the United States. The change in the exchange rate alone increased the monetary value of gas sold to the United States by almost 20 percent between 1991 and 1995. The currency change in conjunction with market conditions resulted in a 1995 Western Canadian wellhead price of $\$ 1.38$
(Canadian dollars) per thousand cubic feet, comparable to the $\$ 1.36$ in 1991. In the United States, the 1995 price of $\$ 1.55$ per thousand cubic feet was more than 5 percent below the 1991 price of $\$ 1.61$ (nominal dollars).

Exchange rate fluctuations do not necessarily favor either country consistently, so they are not a reliable competitive advantage for Canadian producers. Further, it is the fluctuations rather than any relative value of the currencies that are problematic, because unanticipated shifts in the exchange rate thwart the intentions of parties to the crossborder trade contracts. Even relatively steady border prices measured in U.S. dollars may vary considerably when measured in Canadian dollars. If the currencies become unstable, the resulting uncertainty may hamper continued trade.

Additional price risk has arisen because of increased location risk between Alberta wellhead prices and prices in the established futures trading markets. Futures trading is used increasingly as a hedge to mitigate price risk and as a benchmark to determine sales prices under flexibly priced contracts. The location risk has increased, however, as the futures price series have failed to correlate well between eastern and western markets. This factor, if left unchecked, could impede export sales of Canadian gas, but this situation 


\section{Canadian Regulatory Changes}

The North American gas market is more interrelated today than it was just a few years ago. In 1984, 755 billion cubic feet of natural gas was exported by Canada to the United States, by 17 exporters. This volume has grown steadily to a level of 2,816 billion cubic feet in 1995, which was shipped by 205 exporters. The emergence of free markets across North America has stimulated strong industry performance that supports the growth of markets in the United States and Canada.

Major changes in regulation and legislation governing the Canadian gas market since 1983 have directly contributed to Canada's strong presence in the U.S. gas market. During the early 1980's, the Canadian gas market was characterized by oversupply. The combination of falling demand and increasing supply led to the emergence of excess productive capability. This problem of oversupply was exacerbated by the high reserves-to-production ratio requirement for export approval, which began in the late 1970's during widespread government intervention in Canadian gas markets. The Volume Related Incentive Pricing Program, introduced in 1983, allowed exporters to sell quantities of natural gas in excess of an established base level at an incentive price. The incentive prices, often tied to petroleum prices as well as the Weighted Average Cost of Gas (WACOG), proved an impediment to growth of gas sales to the United States. Subsequently, several policy changes made Canadian gas more competitive in export markets.

- The Agreement on Natural Gas Markets and Prices in 1985 changed the pricing policy from governmentadministered pricing to market-oriented pricing. This agreement made possible:

-- Direct sales negotiated between producers, distributors, and large industrial users

-- Competitive marketing programs allowing distributors to offer discounts

-- A review of the role of interprovincial and international pipeline companies

- Changes in export pricing policy allowing for negotiation to make Canadian gas more competitive in U.S. markets

-- Short-term export orders of up to 2 years without volume restrictions.

- The "market-based procedure" for determining the surplus natural gas available for export, adopted in 1987, replaced the previous reserves-to-production $(\mathrm{R} / \mathrm{P})$ ratio procedure. The $\mathrm{R} / \mathrm{P}$ ratio procedure required relatively high $\mathrm{R} / \mathrm{P}$ ratios in order to establish that gas for export was surplus to foreseeable Canadian requirements. This restriction limited production to a relatively low rate, which in turn constrained the amount available for export. Changes brought about by this procedure included a requirement that export sales contracts contain provisions permitting adjustments to reflect changing market conditions, and a provision to ensure that export arrangements provide a reasonable assurance that the gas contracted for would be taken.

- The U.S.-Canadian Free Trade Agreement of 1988 (CFTA) prohibited most import/export restrictions on energy products. The agreement eliminated import/export taxes, removed bilateral tariffs, and ended price discrimination. However, the agreement did allow either country to restrict exports in cases of supply shortage, to maintain a domestic price stabilization program, or to enact resource conservation measures. Subsidies and incentives for natural gas development were allowed to continue.

- In March 1993, the National Energy Board decided, after public hearing, that it would no longer include benefit-cost analysis in determining whether proposed natural gas exports were in the public interest. This facilitated sales of Canadian gas exported under short-term orders. There were 151 short-term import/export orders issued during 1990.

- The North American Free Trade Agreement (NAFTA), enacted at the end of 1993, created the largest trading block in the world. Since most trade barriers that existed between the United States and Canada were lifted by the U.S.Canadian Free Trade Agreement of 1988, NAFTA did not produce significant regulatory changes between the two countries.

- Effective November 1, 1993, the National Energy Board issued two orders ending restrictions of natural gas exports to northern California. The original orders, issued in 1992, restricted exports because of a dispute over short-term sales replacing long-term sales. The shift to short-term sales reflects a recognition that a free market framework is dominant in North American gas trade. 
Figure 37. Reserves-to-Production Ratios, United States and Canada, 1980-1994



Note: WCSB is the Western Canadian Sedimentary Basin, which is contained primarily in the Canadian provinces of British Columbia, Alberta, and Saskatchewan. It is the source of about 99 percent of Canadian production.

Source: Energy Information Administration, Office of Oil and Gas. Lower 48 States: derived from data published in U.S. Crude Oil, Natural Gas, and Natural Gas Liquids Reserves, various issues. WCSB: derived from data published in Statistical Handbook, Canadian Association of Petroleum Producers (July 1995).

has led to the creation of two futures contract markets for delivery in West Texas. ${ }^{97}$ Trading at the Waha Hub market center and the Permian Pool area is expected to lessen some of the location risk for Albertan traders because of the better correlation in price movements between these western markets. In addition, a new futures contract for delivery in Alberta, Canada, began trading in September 1996. This newest contract is expected to correlate more closely with Canadian prices and the U.S. markets served by Canadian natural gas. While location risk can be a significant factor affecting trade, it does not appear to have been a major barrier to trade between the two countries. Future Canadian imports are expected to show continued expansion, although it is unlikely to grow at levels comparable to that observed since 1990.

\footnotetext{
${ }^{97}$ The Kansas City Board of Trade futures contract was established in August 1995 for delivery at the Waha Hub in West Texas. The New York Mercantile Exchange (NYMEX) opened a new contract in July 1996 for delivery through the Permian Pool, also in West Texas. In late September 1996, NYMEX opened another new contract for delivery in Alberta, Canada.
}

\section{Potential U.S. Gas Market in Mexico}

The most far-reaching regulatory actions by the U.S. and Canadian governments regarding crossborder gas trade occurred by the end of 1987 , with no major changes in policy since then. Mexico, however, has initiated extensive regulatory changes in recent years to convert its energy industries and markets from highly regulated monopolies to a more open, competitive system. These changes are expected to provide opportunities for additional sales of U.S. gas over the next few years.

Mexico has a long tradition of national ownership of the means of discovery and production of energy resources. In 1994 and 1995, legislation was passed that effectively opened up the Mexican natural gas industry to more direct foreign participation. The legislation permits foreign ownership of natural gas transportation and electric power generation assets up to 49 percent, so that controlling interest remains with Mexican firms. Action also has been taken to allow foreign participation in production projects on a profit-sharing basis. The impact of these reforms has been limited thus far by concerns about their implementation and the macroeconomic conditions reflected in the devaluation of the peso. 
Petroleos Mexicanos (Pemex) remains a dominant force in any outlook for Mexican energy. Pemex controls most natural gas production, and most of the largest gas consumers are currently under long-term contracts. Pemex may have certain incentives to reposition itself away from particular markets, but such business shifts are unclear at present. For example, the far northwest regions of Mexico are not well located for obtaining supplies from Pemex production, most of which occurs in the Yucatan region in the southeast. Potential swaps of developing Mexican production in the northeast for gas delivered to the northwest are one promising option that allows Pemex involvement. Such cooperative arrangements, however, may require some time to develop.

The current trend in crossborder trade to the south is expected to persist for the near future, with Mexico remaining as a significant consumer of U.S. gas. Recent Mexican field development projects have increased indigenous production to about 1.4 trillion cubic feet per year from the 1.3 trillion cubic foot level that had persisted since the mid-1980's. The outlook for natural gas supplies suffered a significant setback recently with an explosion at a natural gas processing plant in southern Mexico in July 1996. This caused a 33-percent loss of natural gas processing capacity in the country, although smaller plants at the facility may resume operations soon. As a result, Mexico is expected to increase imports of U.S. gas by roughly 100 billion cubic feet per year. Greater development of Mexico's bountiful gas resources will take some time, during which the gas industries in both countries can evolve new ways of doing business together.

\section{Future Challenges}

The stages and operations of the natural gas industry have been integrated to an unprecedented degree across North America. The evidence seems clear that regional markets have become interrelated, although the degree of integration between any two markets is not uniform and can vary over time with changing market conditions. With increased integration, changes in any region will influence operations elsewhere. U.S. producers must anticipate the consequences of the successes and failures of supply activities in other regions of the country as well as in Canada and Mexico. Likewise, changes in demand, both short term (e.g., weather) and long term (structural change), may affect the success of supply projects in other regions.

Changes in response to the movement to less regulation have occurred rapidly. For the near term, it is likely that the producing industry will continue along the path it has taken in recent years. Thus, operations will become increasingly consolidated. Some firms will form alliances or mergers in a horizontal direction to establish a stronger market position. Other firms will develop in a vertical direction, combining production operations and marketing activities. These combinations will not necessarily extend to all firms. Undoubtedly, numerous producing firms may continue as entities focused solely on the efficient discovery and development of natural gas.

Two longer term problems for suppliers are likely. Cost containment is essential, but this is a continuation of a traditional requirement for suppliers in most industries. Secondly, the most significant future changes for the gas industry may be driven more by external events related to the regulatory reform of the electric power industry than by any likely (or expected) internal events. Such external forces probably comprise the next major challenge for the industry.

Electric generation is an important gas-consuming sector, and at the same time electricity is a major energy source that competes directly with gas in many markets. It is still highly uncertain how regulatory reform of the electric power industry will alter energy markets. Gas producers will need to position themselves to exploit opportunities and resolve difficulties. The options chosen by producing firms will be a major factor in determining the industry's future path.

Gas producers need to position themselves to take advantage of market and industry changes, whether transitory or longlasting. Gas producers have shown interest in diversification into other endeavors. The Chevron and NGC merger is intended to provide a commercial option for customers to enjoy one-stop energy shopping. The convenience of this approach should attract at least some additional customers, and it serves to mitigate the risk of supplying any particular energy form. Events or conditions that might negatively affect gas producers may pose opportunities for suppliers of other energy. For example, customers with the potential to shift to other fuels may be retained by a multiple-fuel firm as the customer selects among the low-cost options of that firm, without having to change to another supplier.

The natural gas industry has changed vastly with reduced regulation, which necessitated change, innovation, and adaptation in virtually every phase of operation. Difficulties will undoubtedly continue to confront firms in the industry. Successful firms are those that will adjust and avoid severe difficulties at least as quickly as their competitors. 


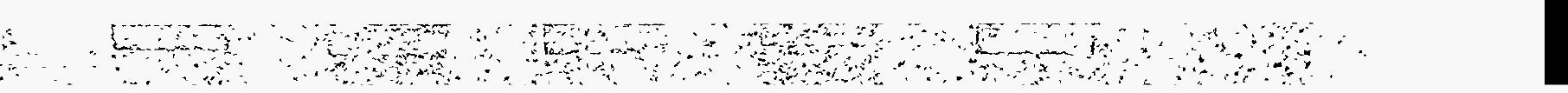




\section{Consumer Prices Reflect Benefits of Restructuring}

The restructuring of the natural gas industry has led to significant price changes in all phases of the industry, from the wellhead to the burnertip. Generally since restructuring began in the mid-1980's, national inflation-adjusted average gas prices to end-use consumers have been stable or falling while volumes of gas delivered have increased. This implies that gas is being produced and delivered more efficiently and that the benefits of this improved resource utilization are flowing directly to consumers.

Adjusted for inflation, average prices paid by electric utilities and customers purchasing gas from local distribution companies (LDCs) decreased by 13 percent between 1990 and $1995 . .^{98}$ But some types of customers have benefited substantially more than others. The electric utility and industrial gas consumers have benefited the most with price declines of 36 and 24 percent, respectively, since 1990 (Table 11). ${ }^{99}$ These customers have the option of multiple servers and may also have fuel-switching capability, which allows them to be more aggressive in negotiating contracts and services. In addition, many of them are large-volume, high-load-factor customers, ${ }^{100}$ which enables them to take advantage of economies of scale in purchases.

Residential and commercial gas users also have experienced lower gas prices since restructuring, but their gains have been substantially less than in the industrial and electric utility sectors. In 1995 constant dollars, prices in the residential sector declined from $\$ 6.67$ per thousand cubic feet in 1990 to $\$ 6.06$ in 1995 , while prices in the commercial sector declined from $\$ 5.55$ to $\$ 5.05$ per thousand cubic feet. Most of these customers have fewer options for service and require high quality service during periods of peak demand. These

\footnotetext{
${ }^{98}$ Prices are adjusted for inflation using the chain-weighted gross domestic product (GDP) price index from the U.S. Department of Commerce, Bureau of Economic Analysis. 1995=1.00.

9Percentage changes are calculated as the most recent year value less the initial year value divided by the most recent year value. For example, the percentage change in national average inflation-adjusted electric utility gas price is calculated as $[(\$ 2.02-\$ 2.74) / \$ 2.02]^{*} 100=-36$ percent. Each percentage change expresses the difference in price over the time interval relative to the most recent year's price for that category of transaction; therefore, a $\$ 0.72$ decline in inflation-adjusted electric utility prices equals a 36-percent price change. However, a price change of $\$ 0.72$ in another category, such as average residential price, would result in a different percentage measure. A $\$ 0.72$ change in the $\$ 6.06$ national average residential gas price would be only a 12-percent price change.

${ }^{100} \mathrm{High}$-load-factor customers use gas at relatively constant daily levels throughout the year. In contrast, low-load-factor customers use gas at variable rates. For example, gas-heating customers usually use large quantities of gas daily during cold weather seasons; however, during the summer season, the amount of gas consumed by these customers is greatly reduced.
}

customers may also be paying an increasing share of the fixed costs of long-distance transportation and local distribution as more industrial and electric utility customers choose to purchase gas from third parties rather than LDCs.

Major changes in the roles of gas pipeline and gas distribution companies have contributed to consumer price changes. However, not all the implications of these changes can be observed directly because data collection efforts have not been able to keep up with the pace of change in the industry. Information on purchases of gas services by residential, commercial, and industrial consumers from LDCs has been collected and reported for many years. However, information on transactions between consumers and many of the new, nontraditional natural gas suppliers is not available. The most significant missing information is the price paid by industrial customers who purchase gas from sources other than their traditional supplier.

New Federal regulations providing open pipeline transportation access for many parties allow third-party gas merchants to sell gas to LDCs as well as to many ultimate consumers. These regulations encouraged many new entrants to gas markets and caused LDCs to change their product lines to meet direct competition. ${ }^{101}$ By 1995, LDCs sold only about 63 percent of the gas they delivered (Table 12).$^{102}$ These sales are called the LDCs' onsystem sales, meaning that the LDC sells a bundle of all inclusive goods and services as a single package. The other 37 percent of the LDCs' deliveries involve gas sales by third parties. This development, often referred to as "offsystem" transactions, involves separate gas consumers, gas sellers, and gas transportation providers. The LDC sells gas distribution services; the final consumer buys gas from whomever it pleases; and the gas is delivered by pipeline and distribution companies as part of transportation services arranged through contracts and leases.

This chapter examines the differences in prices paid by final consumers for natural gas services in 1990 and 1995 (see box, p. 101). This period starts after the bulk of the changes in wellhead prices touched off by deregulation had already

\footnotetext{
${ }^{101}$ One mechanism LDCs have used to retain customers is to unbundle their services. The LDC offers customers the option of purchasing transportation service, sometimes accompanied by offers of ancillary service. This practice is called unbundling because traditionally gas services were offered only as a single bundled package that included the gas commodity, transportation to move that gas, and ancillary services.

${ }^{102}$ Derived by Energy Information Administration, Office of Oil and Gas, from Natural Gas Annual, DOE/EIA-0131(95) (Washington, DC, November 1996).
} 
Table 11. Constant Dollar Natural Gas Prices, 1990-1995

(1995 Dollars per Thousand Cubic Feet)

\begin{tabular}{|c|c|c|c|c|c|c|c|}
\hline Sector & 1990 & 1991 & 1992 & 1993 & 1994 & 1995 & $\begin{array}{c}\text { Percent } \\
\text { Change } \\
\text { 1990-1995 }\end{array}$ \\
\hline Wellhead & 1.97 & 1.81 & 1.87 & 2.14 & 1.90 & 1.55 & -27.1 \\
\hline Citygate & 3.48 & 3.21 & 3.24 & 3.36 & 3.14 & 2.78 & -25.2 \\
\hline Residential Consumers & 6.67 & 6.44 & 6.34 & 6.46 & 6.57 & 6.06 & -10.1 \\
\hline Commercial Onsystem Consumers & 5.55 & 5.32 & 5.25 & 5.47 & 5.57 & 5.05 & -9.9 \\
\hline Industrial Onsystem Consumers & 3.37 & 2.98 & 3.06 & 3.22 & 3.12 & 2.71 & -24.4 \\
\hline Electric Utilities & 2.74 & 2.41 & 2.54 & 2.74 & 2.34 & 2.02 & -35.6 \\
\hline
\end{tabular}

Note: Values expressed in 1995 dollars based on chain-weighted gross domestic product (GDP) deflator from the U.S. Department of Commerce, Bureau of Economic Analysis.

Source: Energy Information Administration, Natural Gas Annual 1995 (November 1996).

Table 12. Natural Gas Consumption and LDC Sales by Region, 1995 (Billion Cubic Feet and Percent of Lower 48 States)

\begin{tabular}{|c|c|c|c|c|c|c|c|c|}
\hline $\begin{array}{l}\text { Federal } \\
\text { Region }\end{array}$ & $\begin{array}{c}\text { Total } \\
\text { Consumption }\end{array}$ & $\begin{array}{c}\text { Residential } \\
\text {.Consumption }\end{array}$ & $\begin{array}{l}\text { Commercial } \\
\text { Consumption }\end{array}$ & $\begin{array}{l}\text { Commercial } \\
\text { Purchases } \\
\text { from LDCs }\end{array}$ & $\begin{array}{c}\text { Industrial } \\
\text { Consumption }\end{array}$ & $\begin{array}{l}\text { Industrial } \\
\text { Purchases } \\
\text { from LDCs }\end{array}$ & $\begin{array}{c}\text { Electric } \\
\text { Utility } \\
\text { Consumption }\end{array}$ & $\begin{array}{c}\text { Percent } \\
\text { Estimated } \\
\text { Offsystem }\end{array}$ \\
\hline New England & $\begin{array}{l}593.4 \\
(3.0 \%)\end{array}$ & $\begin{array}{l}173.6 \\
(3.6 \%)\end{array}$ & $\begin{array}{l}143.9 \\
(4.7 \%)\end{array}$ & $\begin{array}{l}124.6 \\
(5.4 \%)\end{array}$ & $\begin{array}{l}184.7 \\
(2.2 \%)\end{array}$ & $\begin{array}{l}73.9 \\
(3.6 \%)\end{array}$ & $\begin{array}{l}91.2 \\
(2.9 \%)\end{array}$ & 37.3 \\
\hline $\begin{array}{l}\text { New Jersey } \\
\text { \& New York }\end{array}$ & $\begin{array}{l}1,719.6 \\
\quad(8.7 \%)\end{array}$ & $\begin{array}{l}569.4 \\
(11.7 \%)\end{array}$ & $\begin{array}{l}370.4 \\
(12.2 \%)\end{array}$ & $\begin{array}{l}296.3 \\
(12.7 \%)\end{array}$ & $\begin{array}{l}487.6 \\
(5.7 \%)\end{array}$ & $\begin{array}{l}148.7 \\
(7.2 \%)\end{array}$ & $\begin{array}{l}292.2 \\
(9.1 \%)\end{array}$ & 41.0 \\
\hline Mid-Atlantic & $\begin{array}{c}1,318.4 \\
(6.7 \%)\end{array}$ & $\begin{array}{l}467.0 \\
(9.6 \%)\end{array}$ & $\begin{array}{l}296.1 \\
(9.8 \%)\end{array}$ & $\begin{array}{l}2,23.7 \\
\quad(9.6 \%)\end{array}$ & $\begin{array}{l}468.0 \\
(5.5 \%)\end{array}$ & $\begin{array}{l}82.1 \\
(4.0 \%)\end{array}$ & $\begin{array}{l}87.3 \\
(2.7 \%)\end{array}$ & 41.4 \\
\hline Southeast & $\begin{array}{l}2,181.0 \\
\quad(11.1 \%)\end{array}$ & $\begin{array}{l}406.5 \\
(8.4 \%)\end{array}$ & $\begin{array}{l}289.1 \\
(9.5 \%)\end{array}$ & $\begin{array}{l}267.8 \\
(11.5 \%)\end{array}$ & $\begin{array}{l}1,027.4 \\
(12.0 \%)\end{array}$ & $\begin{array}{l}385.4 \\
(18.7 \%)\end{array}$ & $\begin{array}{l}458.0 \\
(14.3 \%)\end{array}$ & 51.4 \\
\hline Midwest & $\begin{array}{l}4,116.6 \\
(20.9 \%)\end{array}$ & $\begin{array}{l}1,664.4 \\
(34.3 \%)\end{array}$ & $\begin{array}{l}831.4 \\
(27.4 \%)\end{array}$ & $\begin{array}{l}600.7 \\
(25.8 \%)\end{array}$ & $\begin{array}{l}1,512.5 \\
\quad(17.6 \%)\end{array}$ & $\begin{array}{l}233.6 \\
(11.3 \%)\end{array}$ & $\begin{array}{l}108.3 \\
(3.4 \%)\end{array}$ & 39.3 \\
\hline Central & $\begin{array}{l}942.4 \\
(4.8 \%)\end{array}$ & $\begin{array}{l}328.2 \\
(6.8 \%)\end{array}$ & $\begin{array}{l}208.5 \\
(6.9 \%)\end{array}$ & $\begin{array}{l}169.1 \\
(7.3 \%)\end{array}$ & $\begin{array}{l}358.3 \\
(4.2 \%)\end{array}$ & $\begin{array}{l}49.5 \\
(2.4 \%)\end{array}$ & $\begin{array}{l}47.4 \\
(1.5 \%)\end{array}$ & 42.0 \\
\hline Southwest & $\begin{array}{l}5,632.8 \\
(28.7 \%)\end{array}$ & $\begin{array}{l}397.6 \\
(8.2 \%)\end{array}$ & $\begin{array}{l}324.3 \\
(10.7 \%)\end{array}$ & $\begin{array}{l}241.5 \\
(10.4 \%)\end{array}$ & $\begin{array}{l}3,321.9 \\
(38.7 \%)\end{array}$ & $\begin{array}{l}882.6 \\
(42.8 \%)\end{array}$ & $\begin{array}{l}1,589.0 \\
(49.7 \%)\end{array}$ & 73.0 \\
\hline Mountain & $\begin{array}{l}557.0 \\
(2.8 \%)\end{array}$ & $\begin{array}{l}208.9 \\
(4.3 \%)\end{array}$ & $\begin{array}{l}139.0 \\
(4.6 \%)\end{array}$ & $\begin{array}{l}124.9 \\
(5.4 \%)\end{array}$ & $\begin{array}{l}195.2 \\
(2.3 \%)\end{array}$ & $\begin{array}{l}27.0 \\
(1.3 \%)\end{array}$ & $\begin{array}{l}13.9 \\
(0.4 \%)\end{array}$ & 35.2 \\
\hline Northwest & $\begin{array}{l}407.7 \\
(2.1 \%)\end{array}$ & $\begin{array}{l}93.9 \\
(1.9 \%)\end{array}$ & $\begin{array}{l}75.4 \\
(2.5 \%)\end{array}$ & $\begin{array}{l}70.0 \\
(3.0 \%)\end{array}$ & $\begin{array}{l}212.9 \\
\quad(2.5 \%)\end{array}$ & $\begin{array}{l}54.5 \\
(2.6 \%)\end{array}$ & $\begin{array}{l}25.5 \\
(0.8 \%)\end{array}$ & 46.4 \\
\hline West & $\begin{array}{l}2,050.6 \\
(10.4 \%)\end{array}$ & $\begin{array}{l}525.1 \\
(10.8 \%)\end{array}$ & $\begin{array}{l}325.7 \\
(10.7 \%)\end{array}$ & $\begin{array}{l}184.5 \\
(7.9 \%)\end{array}$ & $\begin{array}{l}746.2 \\
\quad(8.7 \%)\end{array}$ & $\begin{array}{l}91.3 \\
(4.4 \%)\end{array}$ & $\begin{array}{l}453.6 \\
(14.2 \%)\end{array}$ & 60.9 \\
\hline
\end{tabular}

LDC = Local distribution company.

Note: Percentages do not sum to 100 because natural gas consumption for vehicle fuel and consumption in the States of Alaska and Hawaii are excluded.

Source: Energy Information Administration, Natural Gas Annual 1995 (November 1996). 


\section{A Caution About the Reported Price Data}

Changes in prices over an interval, such as the period between 1990 and 1995 used in this chapter, may not be representative of all the incremental changes that took place during subperiods of that interval. In this study, the years 1990 and 1995 show a picture of various natural gas prices at two points in time. These years were chosen to highlight the impacts of recent trends at work in gas markets, but other results may appear more important if different pairs of years, past or future, are chosen for comparison.

Differences in prices by customer class should be viewed with some caution because,with the exception of the electric utilities, these prices apply only to the customers who continue to purchase bundled gas services from their local distribution company (LDC). Therefore, many large industrial and some of the larger commercial users are excluded from these price data. Offsystem gas consumers are likely to pay lower gas prices than the LDC onsystem customers. Most customers who use offsystem providers could buy onsystem supplies at retail tariff rates from an LDC.* Therefore, industry observers believe that offsystem gas consumers choose to buy gas from offsystem suppliers because these consumers expect to pay lower prices to these suppliers.

Retail tariffs are the rates approved by regulators for services sold by regulated firms and generally are set to recover the company's total cost for providing the regulated service. Some States have replaced cost-of-service rates with incentive regulation (see Chapter 6). The full cost of the LDCs' regulated activities may, for example, include charges the LDC incurred in settling old take-or-pay contact disputes. (The LDCs and interstate pipeline companies shared the cost of buying down high-cost gas contracts as part of the restructuring of the industry.) While the LDC recovers the cost of these obligations, LDC prices may be higher than they otherwise would have been. It may also result in LDC prices being higher than other marketers' prices, putting the LDC at a disadvantage in competing to retain customers who have market choices.

Other data sources are being developed to capture some data on purchases from third-party suppliers that are not used in this study. The Manufacturing Energy Consumption Survey (MECS), conducted every four years by the Energy Information Administration (EIA), collects data on natural gas and gas transportation purchases of manufacturing establishments. The most recent MECS collected data for calendar year 1994 and the results will be released in late 1996. On release, the data will be posted on the EIA home page addressed as http://www.eia.gov/ (see the Energy Consumption directory). They will also be published in ELA, Manufacturing Consumption of Energy, DOE/EIA-0512(94), June 1997 (planned). These forthcoming data are based on the purchases of natural gas by manufacturers and will provide a detailed picture of gas procurement in the manufacturing sector, accounting for about 75 percent of the industrial sector gas consumption discussed in this report. In addition, the Bureau of Labor Statistics Producer Price Indexes include series that cover the change in the price of transportation services provided by LDCs to ultimate consumers.

*In some jurisdictions such as Califomia, State regulators have divided consumers into core and non-core groups (see Chapter 6). Non-core customers must use market processes to obtain gas service and are not entitled to receive service from the LDC at tariff rates. Instead, these non-core customers buy gas services from competitive gas marketers. These gas marketers can include unregulated subsidiaries of some LDCs. The LDCs' jurisdictional to Califomia are required to provide transportation to non-core consumers but are not allowed to offer these customers bundled gas service at regulated rates.

occurred. Thus it permits focusing on changes in pipeline and distribution companies' organizations and objectives and the potential impact they can have on gas markets. During this time, wellhead prices declined 27.1 percent in real terms while citygate prices, the prices paid by LDCs, declined 25.2 percent, and prices paid by electric utilities for delivered natural gas generating fuel declined 35.6 percent (Table 11).
These citygate and electric utility price changes clearly show that something more than the increased competition at the wellhead is at work in downstream markets. In fact, both improvements in the efficiency of transporting and distributing natural gas and a reallocation of joint costs among different consumer groups may account for the relative size of price changes experienced by different types of consumers. 


\section{What Determines Gas Prices?}

Prices paid for natural gas vary. Gas prices are influenced by economic conditions, by weather, by regulations, and by taxes, particularly taxes on fuels and public utility franchises (see box, p. 103). However, setting these influences aside temporarily, price is generally a function of the quality of service, the location (both in time and space) at which a purchase is delivered, and the amount of competition among gas suppliers.

The quality of gas service is frequently measured by the firmness of the service, the so-called reliability of service. The stronger the assurance, the higher the price. Quality is described by the circumstances under which supply can be interrupted because interrupted service is considered less reliable. The most reliable service can be interrupted by only the worst events, such as natural disasters or acts of God, and commands a premium price. Service that can be interrupted under many circumstances, including the convenience of the supplier or shipper, is generally the least reliable and the least expensive.

The location of delivery also affects the price of gas service. Gas that is produced in places distant from the location where it will be purchased must be shipped, stored, and handled (compressed). All of these services add to the cost of serving any customer. The timing of the desired gas service also may add to the price because many gas-consuming activities are seasonal due to heavy consumption for space heating in winter months. Thus, firm gas service at great distances from reserves and in seasons of high demand commands premium prices. In contrast, interruptible gas service to locations close to producing reserves and at times of lesser demand is usually priced much lower. The mixture of the quality, location, and timing of gas purchases is reflected in national and regional prices. Moreover, changes in these three dimensions of gas service over time could appear to be changes in price but would actually reflect changes in the types of services used.

The amount of choice buyers have among providers of gas services also affects service prices. Buyers with several choices can fine tune their purchases to buy the service that best suits their needs. Buyers who have few choices buy the best available, but this can include paying for services that are of little value to them. Therefore, buyers with few choices pay higher prices per unit of service than would otherwise be necessary or forego services that they would otherwise enjoy. Moreover, sellers who must compete to capture customers are more careful in pricing their products because they are conscious that an unhappy or under-served buyer can easily turn to another seller. Therefore, choice enhances value both by allowing buyers to be selective in matching purchases to their needs and by shaping the sellers' concerns that the buyers perceive full value in the product.

Utilization patterns also affect prices. All other things being equal, the per unit cost of delivery for large volumes of gas is cheaper than for small volumes. Natural gas is costly to transport and distribute. Hence, large-volume consumers have a tendency to locate in areas with the lowest prices-the concentration of large industrial consumers in the Southwest, which is a major U.S. producing area, reflects the historic pattern of availability of low-cost gas in the region. Along those same lines, the Southwest and the West have a long history of using a much larger proportion of gas-fired electric generation than the other regions because gas was relatively cheaper than other fuels in those two regions. Concentrations of consumers encourage delivery systems for higher volumes of gas, put downward pressure on prices, and induce additional competitive suppliers to tailor supplies to customers' needs.

By regions, there are significant differences in the amount and purpose of gas use (Table 12). Residential consumption, primarily for heating, draws large quantities of gas into the Midwest, New York/New Jersey, West, and Mid-Atlantic regions. Gas consumption for electric generation is large in the Southwest, the Southeast, and the West, while industrial use is heavy in the Southwest, the Midwest, and the Southeast. These regional usage patterns influence and are in turn influenced by prices and price components in multiple ways.

\section{Prices to Final Consumers}

\section{Residential Consumers Pay the Highest Prices}

Among the factors that influence final consumers' willingness to purchase gas are its price and the prices and availability of competing fuels. Prices to final consumers vary greatly across the country (Figure 38). In all regions, however, residential consumers as a class pay the highest prices, ranging from $\$ 4.83$ per thousand cubic feet (Mcf) in the Mountain States to $\$ 9.06$ per Mcf in New England in 1995. ${ }^{103}$ Between 1990 and

${ }^{103}$ Data presented in this study concentrate on 10 Federal regions: New England (NE), New York/New Jersey (NY/NJ), Mid-Atlantic (MA), Southeast (SE), Midwest (MW), Central (CE), Southwest (SW), Mountain (MO), Northwest (NW), and West (WE). Alaska and Hawaii are excluded because they are isolated from the primary domestic natural gas markets. The price data are volume-weighted averages of data reported for cach State within each region. As such, they may not accurately portray individual transactions at each point within a region. However, these data do serve to indicate potential differences among individual activities in the national market. 


\section{Unintended Tax Effects of Restructuring}

State and local taxes on natural gas consumption are normally designed to fit the traditional single-server, monopoly franchise organization of most public utility companies. Sales, receipts, and franchise taxes on public utility services are important sources of income for many governmental entities. However, the restructuring of public utility industries is having unintended impacts on State and local taxes, receipts, and the competitive positions of some industry participants. Events in the natural gas industry demonstrate the extent of these unanticipated outcomes. When final consumers purchase gas and transportation services from parties other than the locally franchised provider, they may avoid paying some or all of State and local taxes that would have been collected on a sale had it been made by the traditional provider. Consequently, it is sometimes less expensive for final consumers to purchase services from third-party, out-of-State vendors even when the third-party vendor's prices before taxes are higher than the traditional provider's. The out-of-State vendor gains an immediate price advantage over an in-State seller, and the State or local government loses tax revenues.

As regulated service companies, many LDCs and other franchised public utilities are a source of tax revenues for State and local government bodies. The amount and incidence of these taxes differ significantly from one place to another, sometimes even within the same State because local franchise taxes rates can vary by local jurisdiction. These taxes are usually collected for the government by the utility as part of its billing process or passed along to consumers through special levees identified on utility bills. Taxes can be a source of significant variance in the prices paid by consumers.

Average regional prices may smooth over some of the impacts of differences in taxes, but the influence of taxes can be so large that they may have a significant impact on the measured differences in prices. One study estimates the total effective sales tax rate varies from as much as 22 percent in Prince Georges County, Maryland-the highest tax incidence found in the study-to almost zero in New Hampshire.* Differences in the amount of tax included in prices to final consumers can be $\$ 0.50$ per thousand cubic feet or more and could amount to nearly 10 percent of the average residential price.

As a result of the tax impact, an LDC can lose sales to out-of-jurisdiction competitors even when the LDC's prices are lower. One estimate shows that the average sales tax on a sample of LDCs amounts to 5.6 percent of the companies' revenues and ranges from 1.2 to 15.8 percent of revenues.** Many jurisdictions are now trying to remedy both the competitive and the revenue impacts of these taxes by replacing franchise and public utility sales taxes with energy importation or consumption taxes. At least one of these import tax mechanisms is currently being challenged before the U.S. Supreme Court (General Motors Corp. (GM) v. Tax Commissioner Roger W. Tracy. Roger Tracy is the tax commissioner for the State of Ohio). Furthermore, even if the replacement tax programs achieve their competitive and revenue objectives, they may still shift tax income to the State government and away from local government bodies. As the restructuring of the electric industry follows the pattern of the natural gas industry, these tax problems will likely have increasing financial ramifications for governments and service prices.

*Vincent J. Esposito, "Death by Taxes," Public Utilities Fortnightly (August 1995), pp. 23-25.

**American Gas Association, Gas Distribution Industry Pricing Strategies, 1995 Update (Arlington, VA, December 1995).

1995 , the average national price of gas delivered to residential customers declined modestly from $\$ 6.67$ per Mcf (measured in 1995 dollars) to $\$ 6.06$ per Mcf, a decline of 10 percent. ${ }^{104}$ Over this period, average prices to residential customers fell in nine regions and remained the same in New England. In the regions that experienced declining average residential gas prices, the price declines ranged from 18 to 2 percent with

10.N Natural gas prices cited in this chapter are based on data reported in the Energy Information Administration's Natural Gas Anmual 1995, DOE/EIA-0131(95) (Washington, DC, November 1996). the largest decline occurring in the Midwest Region. By contrast, wholesale gas prices and prices paid by many other types of consumers declined by much larger percentages during this same period. For example, national average wellhead prices fell about 27 percent and average citygate prices declined 25 percent.

There appear to be several factors that have restricted the decline in residential prices. Residential consumers remain captive to LDC service in all but a few States that are now 
Figure 38. Prices to Residential and Commercial Consumers, 1990 and 1995 (1995 Dollars per Thousand Cubic Feet)

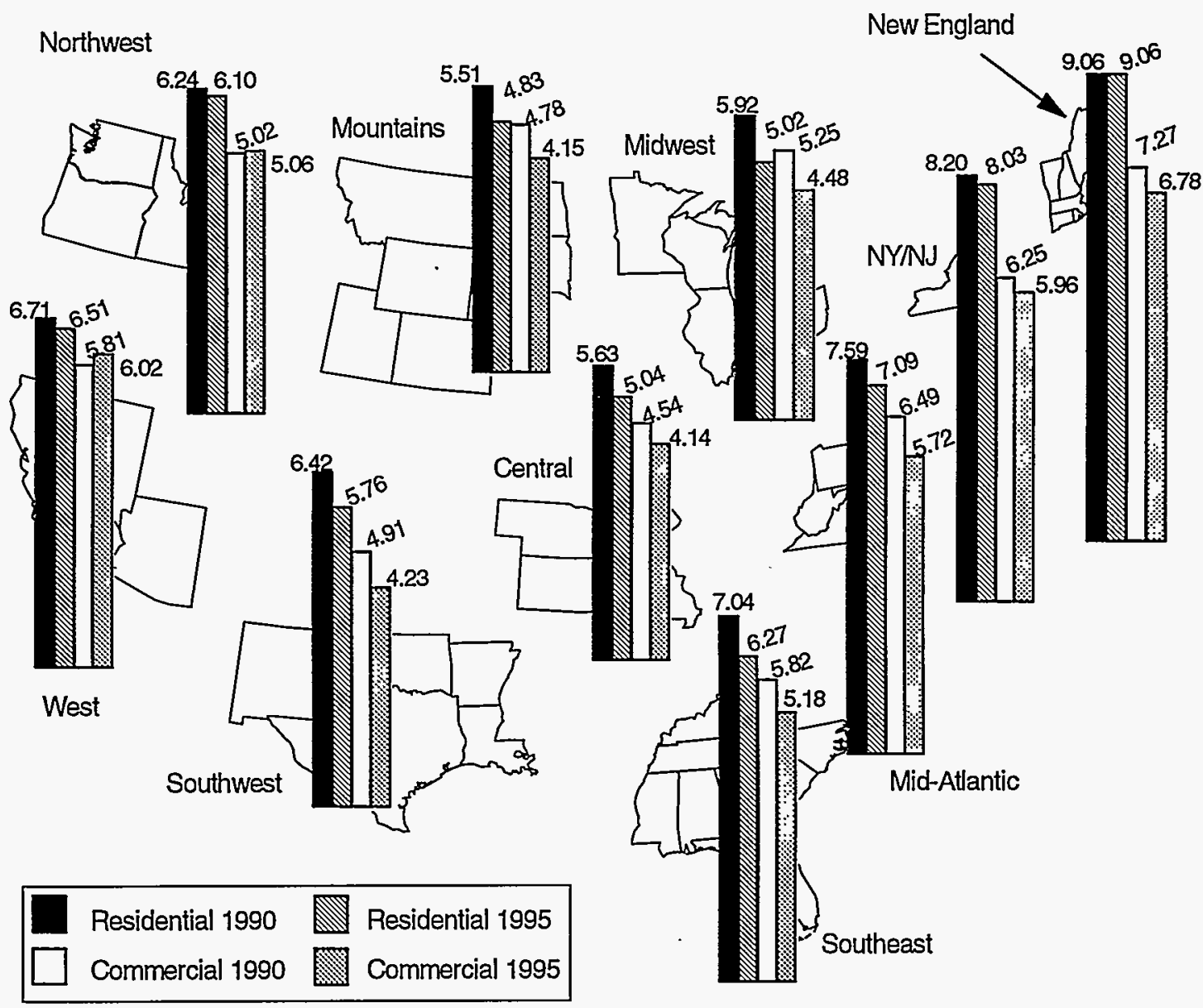

Note: Values expressed in 1995 dollars based on chain-weighted gross domestic product (GDP) deflator from the U.S. Department of Commerce, Bureau of Economic Analysis.

Source: Energy Information Administration, Natural Gas Annual 1995 (November 1996).

experimenting with programs to extend choice to smaller customers (see Chapter 6). Residential customers are the last class of customers to have options for service. Other LDC customers are now able to turn to alternative suppliers and negotiate better deals. As a resuit, despite price declines, the remaining $L D C$ customers, who are increasingly restricted to the residential sector, appear to have absorbed the brunt of the transition costs that LDCs have been required to pay for restructuring of the gas industry. Residential customers also may be paying an increasing share of the fixed costs of long- distance transportation and local distribution networks because they typically demand the highest quality of service at the time of peak demand.

Changes in pipeline company rate structures developed by the Federal Energy Regulatory Commission (FERC) as part of Order 636 shifted some transportation fees into reservation charges and out of usage charges. This rate change caused most pipeline companies to put all of their fixed costs in the reservation charge. The reservation charge is a fee paid by all firm transportation customers to assure that pipeline capacity will be available to that customer whenever it is needed. By placing all of a pipeline company's fixed costs in the reservation charge, FERC shifted the initial risk for cost recovery away from the pipeline companies and to their customers. The transportation customers most likely to purchase large amounts of firm service, and therefore to pay these higher reservation charges, are the LDCs. Thus, the FERC-initiated change in pipeline rate structure had the effect of increasing transportation costs of the LDCs' onsystem gas customers. FERC has estimated that the change in rate design to straight fixed variable reallocated approximately $\$ 1.7$ billion annually from the usage fee to the reservation fee component of transportation rates. 
Among the fixed costs of providing LDC services are not only normal business expenses, but also a variety of charges that have been assigned to LDCs as a result of the restructuring of the interstate pipeline companies-take-orpay gas contracts, transition costs, pipeline strandedinvestment costs, and pipeline charges based on older transportation obligations. These transition costs are passed through to LDCs by the pipeline companies. Moreover, the LDC may find that it too has incurred direct obligations that are stranded by unbundling local service. Costs from both sources are added to the LDC's rates if State utility regulators approve it. All of these cost adjustments contribute to the LDC's revenue requirements and have the effect of raising average prices for onsystem service.

The Energy Information Administration (EIA) does not have detailed information on how these structural costs (e.g., takeor-pay, stranded costs, etc.) are included in individual consumer prices. As of August 1995, $\$ 2.7$ billion in transition costs associated with Order 636 had been filed at the FERC for recovery through increased transportation rates. ${ }^{\text {i05 }}$ Contract reformation costs resulting from take-or-pay settlements totaled about $\$ 10.2$ billion as of May 1995, of which $\$ 6.6$ billion is being recovered from consumers.

\section{LDC Commercial Customers Pay the Next Highest Prices}

Commercial customers have increasingly been allowed to choose competitive gas suppliers, and the onsystem sales of LDCs now provide service to a declining share of commercial facilities. ${ }^{106}$ This is most noticeable in the West Region where onsystem sales in 1995 accounted for only 57 percent of commercial gas consumption. In the Southwest, Midwest, and Mid-Atlantic regions, onsystem sales to commercial facilities have declined to about 75 percent of commercial consumption (Table 12). In most regions, access to distribution, transportation, and the opportunity to purchase gas service from alternative suppliers is often controlled by the amount of gas a customer uses annually. The largest customers are generally the first to have this opportunity. Consequently, in regions where commercial onsystem sales have fallen significantly, it is generally the case that the smaller commercial customers are the ones that remain onsystem. Estimates show that the customers that remain onsystem consume on average only one-tenth the amount of gas in a year as those that buy gas from offsystem vendors. ${ }^{107}$ This seems to imply that most of the remaining LDC commercial gas customers are small establishments that may use gas largely for heating during the winter season.

Between 1990 and 1995, national average gas prices for onsystem commercial customers declined by nearly 10 percent, from $\$ 5.55$ to $\$ 5.05$ per thousand cubic feet (Mcf) in constant dollars. Across regions, average prices to commercial customers ranged from $\$ 4.14$ per Mcf in the Central Region to $\$ 6.78$ per Mcf in New England in 1995. Average prices to this customer class were lowest in the Mountain and Central regions and highest in New England and the West. Commercial customers in all but two regions experienced declines in average natural gas prices between 1990 and 1995. Average prices increased by 4 and 1 percent, respectively, in the West and Northwest. But average commercial prices declined in all other regions, with the largest decline of 17 percent occurring in the Midwest and the smallest decline, 5 percent, occurring in New York/New Jersey.

\section{All Onsystem Industrial Customers Have Had Large Price Decreases}

Nationally, industrial customers who remained onsystem during the 5-year interval paid gas prices that declined by 24 percent, falling from $\$ 3.37$ per Mcf to $\$ 2.71$ by 1995 . Regionally, industrial gas customers paid prices ranging from a low of $\$ 1.90$ per Mcf in the Southwest to a high of $\$ 4.34$ per Mcf in New England (Figure 39). Industrial onsystem customers in all regions experienced significant declines in average gas prices between 1990 and 1995 . These real price declines ranged from 11 percent in the Northwest to 42 percent in the New York/New Jersey Region.

Few industrial customers remain onsystem customers of LDCs. In fact, in 5 of the 10 Federal Regions (West, Mountain, Central, Midwest, and Mid-Atlantic), less than 20 percent of industrial consumption comes from LDC onsystem sales. By 1995, no region had more than 40 percent of industrial consumption in onsystem sales. The decline in industrial prices to those who remain onsystem may in part reflect discounting by the LDCs to retain some industrial load. Evien so, the industrial customers that continue to take onsystem service are likely to be small consumers with relatively low load factors.

\footnotetext{
${ }^{105}$ Sec Energy Information Administration, Energy Policy Act Transportation Study: Interim Report on Natural Gas Flows and Rates, DOE/EIA-0602 (Washington, DC, October 1995).

${ }^{100}$ Onsystem customers purchase bundled gas, transportation, and ancillary services as a single package from LDCs. Offsystem customers purchase gas from third-party gas suppliers rather than buying from regulated LDCs. However, many offsystem customers purchase transportation and other ancillary services from LDCs.
} 
Figure 39. Prices to Electric Utilities and Industrial Consumers, 1990 and 1995

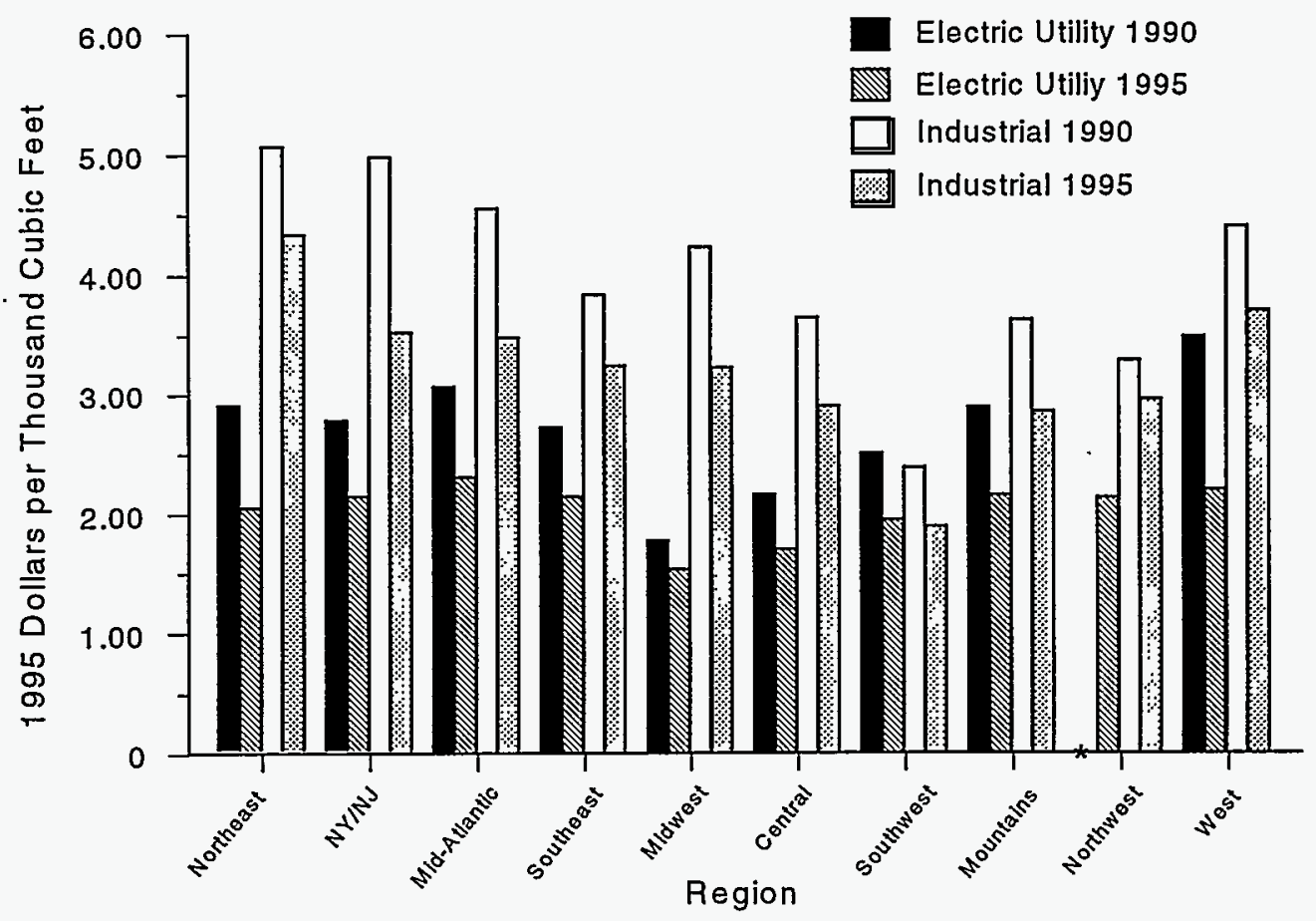

"Electric Utility for 1990 is set to zero.

Notes: Includes only onsystem industrials. Values expressed in 1995 dollars based on chain-weighted gross domestic product (GDP) deflator from the U.S. Department of Commerce, Bureau of Economic Analysis.

Source: Energy Information Administration, Natural Gas Annual 1995 (November 1996).

\section{Electric Utilities Have the Most Choice and Pay the Lowest Gas Prices}

Almost all electric utilities can take advantage of offsystem transportation and competitive gas supplies. The EIA data on electric utilities prices are derived from fuel costs reported for large generating units. ${ }^{108}$ Unlike industrial and commercial prices, these data represent most gas consumed in electric utility generation. ${ }^{109}$ In 1995 , the average price of natural gas consumed in utility generation was $\$ 2.02$ per Mcf, 36 percent lower than the constant dollar 1990 cost per Mcf. Regionally, utility gas costs in 1995 ranged from a high of $\$ 2.30$ per Mcf in the Mid-Atlantic States to a low of $\$ 1.54$ per Mcf in the

\footnotetext{
${ }^{105}$ Electric utility fuel costs are reported on FERC Form 423, "Monthly Report of Cost and Quality of Fuels for Electric Plants."

${ }^{109} \mathrm{Gas}$ used for electric generation at nonutility generators including cogenerators is treated as part of the industrial sector in this study.
}

Midwest. ${ }^{110}$ Electric utilities in many regions ${ }^{111}$ are able to concentrate their gas consumption in warmer summer months when gas prices are normally lower and transportation most readily available. The close proximity of Canadian gas supplies probably contributes to the ability of Midwestern electric utilities to purchase gas at prices below the average national wellhead price.

Electric utilities in most regions appear to have experienced a significant reduction in delivered gas costs over the past 5 years. In 1990, electric utility gas costs (in 1995 dollars) ranged from $\$ 3.50$ per Mcf in the West to $\$ 1.77$ per Mcf in the Midwest, 58 and 15 percent above the 1995 prices, respectively (Figure 39). The average price electric utilities paid for gas in

\footnotetext{
${ }^{110}$ Tn 1990, electric utility gas consumption in the Northwest was small and sporadic. Price data in 1990 for this region are unreliable and therefore excluded here.

inElectric utilities in the producing areas still use natural gas in some old gas-fired boilers to meet base load demands. As these gas-fired generators are replaced with other generating sources or newer technologies, gas consumption in these regions is expected to become more sensitive to market conditions. Until recently, the use of gas for electric generation in the gas-producing areas was motivated primarily by regional economic forces and differed significantly from gas consumption for generation in the rest of the country.
} 
1990 and 1995 was below the average citygate price in all regions except the West. These low electric utility prices probably reflect the special seasonal and volume choices that many electric utilities are able to make.

\section{Citygate Prices}

The average price paid by LDCs for natural gas, the citygate price, declined between 1990 and 1995 (Figure 40). Although the price decline is substantially larger in some areas than in others, the trend of declining wellhead prices and changing transportation rates has significantly affected the citygate prices paid by LDCs throughout the country. These citygate prices should include, in addition to gas commodity costs, the expense of transporting, storing, and managing gas supplies for delivery to the citygate. However, there is some evidence that not all gas acquisition costs are accounted for in the citygate prices, ${ }^{112}$ because of bookkeeping procedures that may not wholly reflect the restructuring of wholesale gas markets. Nevertheless, these average regional citygate prices are generally used to represent the wholesale cost of gas in scattered individual markets.

In 1995 , the national average citygate price was $\$ 2.78$ per thousand cubic feet (Mcf), down 25 percent from the constant dollar 1990 price of $\$ 3.48 .{ }^{113}$ Thus, compared with the average wellhead price, which dropped nearly 27 percent (from $\$ 1.97$ to $\$ 1.55$ per Mcf), citygate prices have declined a little less than wellhead prices.

Regional average citygate prices show significant variation in both 1995 and 1990. In 1995, citygate prices varied from a high of $\$ 3.82$ per Mcf in New England to a low of $\$ 2.07$ per Mcf in the West. By way of comparison in 1990, constant dollar citygate prices in New England were $\$ 3.97$ per Mcf, nearly 4 percent higher than the 1995 level, and $\$ 3.32$ per Mcf in the West where citygate prices declined more than 60 percent over the 5-year period. Although average citygate prices were lowest in the West in 1995, in 1990, the lowest average regional citygate price was found in the Northwest at $\$ 2.41$ per Mcf. By 1995 , average citygate prices in the Northwest had fallen to $\$ 2.25$ per Mcf, a decline of nearly 7 percent.

\footnotetext{
${ }^{112}$ For example, the use of financial instruments to stabilize the cost of gas supplies may not be included in reported citygate data. Moreover, more generic research suggests that some items associated with gas acquisition costs are not included in the purchased gas adjustment usually used to estimate citygate prices. For example, see Mary Barcella, "Saving a Bundle? The Cost Impacts of LDC Unbundling," Proceedings of the Fifth Annual DOE-NARUC Natural Gas Conference, St. Louis, MO. Forthcoming.

${ }^{113}$ Citygate price data are derived from the Energy Information Administration, Natural Gas Annual 1995, DOE/EIA-0131(95) (Washington, DC, November 1996).
}

Theoretically, the regional variation in average citygate prices should reflect two things: first, differences in transportation costs and second, differences in LDC load, procurement, and management policies. Certainly the influence of each of these forces can be observed in the data. For example, in the Northwest, the close proximity and abundant supplies of Canadian gas provide LDCs with ready access to low cost sources that need be transported only a short distance from the Canadian border to the citygate. ${ }^{114}$ Regional average citygate prices elsewhere in the country also show the influence of distance from sources of gas production. The New England citygate prices are about one-third higher than the national average, reflecting among other forces, the distance of these markets from gas fields.

The second set of determinants of citygate prices-load, procurement and management-is more difficult to summarize. Some aspects of LDC loads can be observed from commonly available statistics, such as the number and class of customers; however, the amount of gas demanded at specific times cannot be observed from aggregate data. In addition, LDC procurement and supply management policies are masked by averages and the complexities of accounting systems. Therefore, to the extent that load and policy differ by region, these differences are reflected in price differences by region.

For example, an LDC that wants to guarantee supply may sign long-term gas supply contracts that can increase its cost of gas supply vis-a-vis a company that relies on the spot market. Another company that is similarly concerned about deliverability may contract for a lot of firm transportation or storage close to its service territory. Expenditures on large amounts of high value transportation or large amounts of upstream storage would result in relatively high citygate prices when compared with other regions that chose to use a mixture of firm and interruptible transportation or to hold relatively little gas in outside storage. The available data on average citygate prices do not reveal LDC practices, and therefore cannot indicate how differences in practices contribute to the observed differences in prices.

\section{Price Components}

Differences in final prices to onsystem consumers are a reflection of differences in the cost of the elements that go into the final delivery of natural gas services. Some insight into the sources of price differences can be gained simply by observing the major components of average end-user prices.

\footnotetext{
${ }^{114}$ U.S. imports of gas from Canada are sold inclusive of transportation to the border crossing.
} 
Figure 40. Natural Gas Citygate Prices, 1990 and 1995

(1995 Dollars per Thousand Cubic Feet)

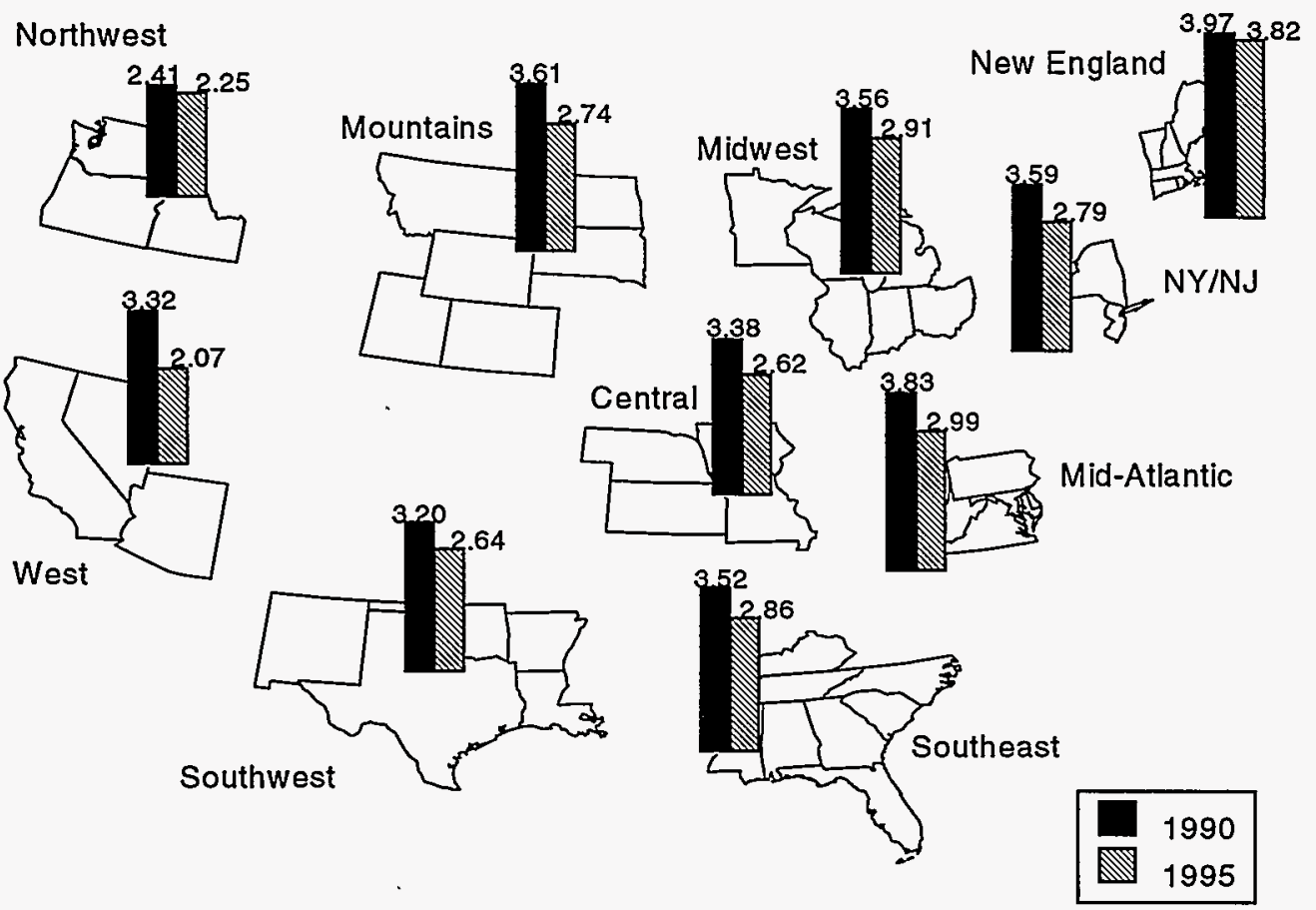

Note: Values expressed in 1995 dollars based on chain-weighted gross domestic product (GDP) deflator from the U.S. Department of Commerce, Bureau of Economic Analysis.

Source: Energy Information Administration, Natural Gas Annual 1995 (November 1996).

LDC prices for onsystem sales to final consumers can be disaggregated into two useful components: the cost of gas acquisition and the cost of distribution services. Arithmetically, these component estimates are calculated by subtracting the average citygate price from the average price to final consumers. ${ }^{115}$ The differences between average end-user prices and average citygate prices are sometimes referred to as the "margins" or the "mark ups" for distribution services. Since citygate prices are an approximation of the LDC's costs of acquiring gas and having it delivered to central locations in a timely fashion, the remainder of the final price produces an approximation of the LDC's cost to deliver gas to customers' burnertips. LDC margins must recover all of the distribution costs - both fixed and variable-a company incurs. These include the costs of building and maintaining miles of

\footnotetext{
${ }^{15}$ The calculations of the components of end-user prices depend on several simplifying assumptions. First, they assume that each consumer in a customer class is charged on the same rate schedule and receives essentially the same quality of service. Second, since these data are calculated as regional averages, they reflect volume weights among the markets aggregated into each of the regions. If any of the regions contain disparate patterns of pricing activity, the regional average may produce misleading indicators of the prices charged to consumers by individual companies.
}

distribution pipe, making safety inspections, reading meters, and billing customers. LDC margins are used as an indicator of the impact of distribution costs on final prices.

\section{Distribution Margins}

Gas distribution margins for residential and onsystem commercial consumers in 1995 ranged from \$5.24 in New England and NewYork/New Jersey to $\$ 1.41$ per thousand cubic feet in the Mountain Region (Figure 41). Residential consumers paid the higher margin in every region, but the price differences between the two types of customers range widely. Residential customers in the Southwest and New England regions on average paid nearly twice as much for distribution services than did onsystem commercial customers. By contrast, on average, residential customers in the West Region paid only 10 percent higher per-unit margins than onsystem commercial customers. In the other regions, residential margins ranged from 30 to 60 percent higher than onsystem commercial charges. 




Note: Includes onsystem commercial only. Values expressed in 1995 dollars based on chain-weighted gross domestic product (GDP) deflator from the U.S. Department of Commerce, Bureau of Economic Analysis.

Source: Energy Information Administration, Natural Gas Annual 1995 (November 1996).

In 1995, the average national distribution margin for residential consumers was $\$ 3.28$ per thousand cubic feet (Mcf), little changed from its 1990 value of $\$ 3.19$ per Mcf (adjusted to 1995 prices). Across regions, the 1995 margins ranged from a high of \$5.24 per Mcf in New England and New York/New Jersey to a low of $\$ 2.09$ per Mcf in the Mountain Region. The range of distribution margins appears not to have changed significantly over this 5-year interval. In 1990, the range in the margins expressed in 1995 dollars was similar, with New England having the largest at $\$ 5.10$ per Mcf and the Mountain States the lowest at $\$ 1.90$ per Mcf. Between 1990 and 1995, however, residential distribution margins declined in three regions: Southeast (by 4 percent), Midwest (by 12 percent), and Southwest (by 3 percent) but increased in New England (by 3 percent), New York/New Jersey (by 12 percent), Mid-Atlantic (by 8 percent), Central (by 7 percent), Mountain (by 9 percent), Northwest (by 1 percent), and West (by 24 percent). All the increases in residential distribution margins over the 5 years were less than $\$ 0.65$ per Mcf except in the West. The 24 percent increase in the West represents a $\$ 1.06$ increase during the 5-year period. Increases in the New York/New Jersey and Mid-Atlantic regions amounted to $\$ 0.63$ and $\$ 0.34$ per Mcf, respectively.
There is no single pattern in the changes in residential distribution margins over the 5-year interval. Regions in the western third of the country (including Mountain, Northwest, and West regions) all show increases in distribution margins. As discussed in Chapter 3, there is some indication that gas markets in these regions are not thoroughly integrated with the rest of the Nation, and by 1995 two of these three regions (Northwest and West) had the lowest citygate prices in the country. ${ }^{116}$ Consumption in the West Region is by far the largest of these three gas markets and is particularly affected by California. The rate of change in customer access, especially in the large California market, has been more rapid than in many other areas. The West Region ranked fifth in the level of distribution margins in 1990, but by 1995 the level was the third highest in the Nation.

Elsewhere in the country, residential distribution margins changed by smaller amounts. Margins increased by $\$ 0.63$, $\$ 0.34$, and $\$ 0.17$ per Mcf in the New York/New Jersey, MidAtlantic, and Central regions, respectively, but fell $\$ 0.25$ per Mcf in the Midwest and by smaller amounts in the Southwest and Southeast. The Midwest relies heavily on gas for

\footnotetext{
${ }^{116}$ Citygate prices in the Mountain Region nearly equal the national average citygate price.
} 
residential heating, accounting for 34 percent of total residential gas consumption nationwide. The Southwest and the Southeast each accounts for only about 8 percent of the residential market.

The average national distribution margin for commercial onsystem customers in 1995 was $\$ 2.27$ per Mcf, up slightly from the 1990 amount, adjusted to 1995 dollars, of $\$ 2.07$ per Mcf. The range of 1995 distribution margins is $\$ 1.41$ to $\$ 3.95$ per Mcf, which is generally lower than the spread in residential margins across regions. However, changes in distribution margins for both classes of customers move in the same direction except in New England. In the western third of the Nation (Mountain, Northwest, and West), margins increased for onsystem commercial customers. As with residential margins, the largest increase was in the West at $\$ 1.47$ per Mcf during the 5-year period. In most other regions, commercial margins also moved in the same direction as residential margins. And like the pattern in residential margins, the amount of change was generally small compared with the total price of gas service to this class of customers.

\section{Impact of Switch to More Offsystem Transactions}

The decline in industrial and commercial customer participation in onsystem sales means that those customers who do remain onsystem are likely to be paying more of the fixed cost of the distribution system. If reductions in fixed costs are smaller than the decline in gas sales, consumers that are still full service, bundled customers of an LDC will experience price increases. If the residential load does not expand rapidly enough or if the distribution costs cannot be reduced by efficiency improvements, the remaining onsystem customers end up paying higher prices.

The impact of competitive pressure to tailor special products to users' demands has been particularly influential as the restructuring of the natural gas supply industry has unfolded. One way to see this influence is to observe the aggregate percentage of customers who have gone offsystem. EIA collects and publishes data on the percentage of industrial and commercial onsystem gas deliveries. To round out the picture of the impact of changing industry structure, sales to the residential and electric utility sectors must be included. Since few residential customers had the opportunity to choose among competing suppliers in 1995, assume that all residential sales are currently made through LDCs. In contrast, almost all electric utilities have had the equivalent of access to competitive suppliers for several years; therefore, assume that all electric utility purchases are now effectively offsystem. This aggregate view of purchases shows that in the Southwest less than 30 percent of all gas deliveries to final consumers in 1995 were onsystem sales. Similarly California, the lead State in the West Region, started retail unbundling early, and by 1995 less than 40 percent of gas consumption was onsystem. However, in the Midwest where only 15 percent of industrial sales are onsystem, nearly 60 percent of all deliveries remain onsystem because offsystem industrial consumption is balanced by large amounts of residential consumption primarily in the winter heating season months (Table 12).

On the same note, some of the change in prices between 1990 and 1995 is due to reversing allocations of fixed costs that had been skewed to favor residential customers. When most enduse customers were dependent on the regulated LDCs to provide gas service, regulators could, and frequently did, deliberately allocate more of the fixed costs to industrial and large commercial consumers. As these customers acquire the opportunities to choose alternative suppliers who base their prices on the marginal cost of serving individual customers, they naturally choose the least cost supplier. If LDCs continue to impose extra premiums on industrial and commercial customers, these customers will choose alternative suppliers, and LDCs will raise prices to the remaining captive customers to cover the costs that had previously been assessed to their former industrial customers. As the gas industry is restructured, LDCs are losing the ability to force industrial customers to pay prices that exceed the cost of serving them.

When large-volume, high-load-factor customers switch to offsystem suppliers, the LDC's business becomes increasingly concentrated in the peak season, high reliability customer. This concentration has a tendency to cause LDCs to increase the quality of the supplies and delivery services they buy and thereby raise the citygate prices and increase the unit costs of distribution services provided to lower volume retail customers. This may cause prices to rise because the LDC is servicing a more specialized customer and losing some of the advantages of aggregating different types of loads.

LDCs may find themselves discounting sales to high-volume customers in order to retain their industrial load. That is, the public utility gas provider may find that to retain high-volume customers, it is necessary to reduce prices to these customers below the full cost of providing them service. In the short run, as long as revenue requirements cannot be decreased in proportion to falling volumes, all customers receiving service may be better off if high-volume customers remain onsystem and continue to contribute some portion of the fixed costs of the delivery system. As long as the price charged to highvolume customers exceeds the variable cost of serving these customers, their business continues to contribute payments that cover some part of the fixed cost of providing service. Therefore, so long as other adjustments cannot lower costs, 
reducing prices to high-volume customers may be in the best interest of all customers.

\section{Future Challenges}

In the future as additional customers have the choice of using alternative suppliers, the ability of an LDC to price services to some customers below the full cost of serving them will be diminished. If most consumers can choose among suppliers, all are likely to select suppliers that offer the best price for the desired services. Under these circumstances, LDCs will be unable to sustain discounting policies for selected customers. However, providing gas distribution services does involve some economies of scale that cannot be attributed to any individual or set of customers. These savings, to the extent they exist, permit an LDC to use some strategic discounts to attract customers that may be particularly price sensitive.

Finally, the role of competitive pressure in determining the price to final consumers cannot be overlooked. Even when LDCs had a monopoly on the delivery of gas services to final consumers, they were never free of competitive pressures from other fuels and alternative locations. However, it is fair to say that customizing products and minimizing cost have assumed much more pronounced roles in the restructured gas industry than ever before. Those segments of the industry that have had access to competitive suppliers have experienced significantly reduced prices. While it is true that part of the reduction in prices for the more open sectors of the market may be due to reduced cross-subsidies and changes in the quality of service, prices also have fallen for many who do not have access to multiple suppliers. These customers have benefited from upstream access even when they did not have individual choices themselves.

The extension of competitive pressures to the remaining customer classes is largely a matter of reducing regulatory barriers in retail markets. These markets are supervised by the
State public utility commissions. Just as the restructuring of the natural gas industry to date has grown from the deregulation of wellhead gas prices and the conversion of interstate gas pipeline companies from gas companies to transportation service companies, the next stage appears to be the transformation of the LDCs to distribution service companies rather than gas providers. This process is more diverse than the previous steps because each individual State will endorse changes that suit its circumstance. The next chapter provides a review of the status of this State regulatory transformation process.

The future of retail gas service can be very different from the past-these changes are not without costs and dangers but they also show promise to lower customers' prices. The reductions in citygate prices and in the prices paid by consumers that already have access to unbundled transportation over the past 5 years demonstrate the potential for change.

However, some additional costs have clearly been assigned to customers who have remained captive to LDCs. If these additional costs are transitory, prices to small commercial and residential customers could eventually decline even if there is no further restructuring of retail gas markets. These small customers might prefer not to be forced to find new gas suppliers or to choose among a variety of gas services, particularly if they are exposed to greater price fluctuation as a result of these new choices. The reduction in gas commodity prices and the efficiency improvements in long-distance transportation costs that have come from the restructuring so far have benefited all end-use consumers. Even though these benefits have not been distributed in equal proportion to all consumers, they are nevertheless real resource gains to households throughout the country. Whether or not the introduction of multiple marketers and individually tailored services can further reduce the cost of gas services to small consumers whose purchases are concentrated in peak demand periods will continue to challenge the industry, its regulators, and consumers. 



\section{State Regulators Promote Consumer Choice in Retail Gas Markets}

Restructuring of interstate pipeline companies has created new choices and challenges for local distribution companies (LDCs), their regulators, and their customers. The process of separating interstate pipeline gas sales from transportation service has been completed and has resulted in greater gas procurement options for LDCs. Now LDCs can buy gas directly from producers or third-party marketers in a competitive market, arrange for storage and other services, and contract with pipeline companies for transportation.

Large industrial customers and electric utilities have had access to competitively priced natural gas supplies for a number of years. Consequently, some high-volume users had physically bypassed LDC systems, buying transportation and gas supplies from pipeline companies and third-party marketers. State regulators wanted LDCs to be able to compete for large customers that have access to alternative sources of gas supply or alternative fuels. With the agreement of their regulators, LDCs began to develop transportation programs to compete for and retain the business of their large customers.

Unbundled sales and delivery services for large industrial and electric utility customers are now commonplace. Based on a sample of LDCs, bundled sales delivery to industrial customers has declined from over 47 percent in 1987 to barely 24 percent in 1995, while for commercial customers it declined from 93 percent to 77 percent (Figure 42). Meanwhile, residential customers continue to take almost 100 percent bundled service. The challenge for State regulators and other industry participants is to find ways to extend opportunities to choose gas service suppliers to smaller commercial and residential customers.

Some regulatory agencies have begun to reduce the threshold volume of gas consumption needed to qualify customers for LDC transportation-only services. They are initiating experiments to encourage smaller customers, even residential users, to aggregate into groups and exercise choice in gas markets. All of these changes are clearly driven by regulators and industry's desires to give consumers access to gas services that meet individual needs in the best way and at the least cost.

State regulators face an array of considerations in determining how to capture the benefits of unbundled wholesale and retail service for small commercial and residential customers. Some of these issues include:
- What is the smallest customer class that would benefit from taking unbundled sales and delivery service? Can the benefits of deregulation be extended to small customers through aggregation schemes? Can regulators avoid cost shifting from the competitive market to captive customers?

- What unbundled services can be offered competitively to all classes of customers? For example, should services such as billing, equipment repairs, and metering be offered competitively?

- How should unbundled service be priced? Regulators have traditionally based rates on the costs of providing the service. In a competitive market the price would reflect supply and demand. Some State regulators are attempting to bring the benefits of the competitive market to the noncompetitive market using performance-based rates.

- What obligation does the local distribution company have as a supplier of last resort to serve customers who have chosen to buy gas through a third party? Who is responsible for maintaining system reliability and how will its costs be allocated?

- How should costs associated with the transition to a competitive market be shared among LDC shareholders and the various customer classes?

- What is the appropriate corporate structure of an LDC in a more competitive environment?

Many of these issues relate to regulators' key responsibilities to ensure reliable service and to protect the interests of captive commercial and residential customers from excessive cost shifting by the industry. Many States are concluding that it is possible to capture the benefits of unbundled sales and delivery service for small customers, without degrading overall system performance.

\section{Extending Choice to Small Customers}

State regulators are experimenting with various methods to extend choice to small customers. Some regulators are 
Figure 42. LDCs Sell a Smaller Share to Industrial and Commercial Customers, 1989-1995



LDC $=$ Local distribution company.

Source: Energy Information Administration (EIA), Office of Oil and Gas, derived from Form EIA-176 data on sales and transportation deliveries by customer class, based on a large sample of LDCs.

making provisions to allow third-party marketers to aggregate gas needs of smaller residential and commercial customers to overcome minimum threshold requirements. ${ }^{117}$ Under these proposals, small customers would purchase gas from a gas broker who aggregates their loads and contracts for transportation and gas supplies with pipeline companies, producers, and/or other marketers. For example, the New York State Public Service Commission on May 1, 1996, permitted core customers who use more than 35,000 therms of gas annually to purchase gas from third-party marketers. This program allows marketers to aggregate smaller residential and commercial customer gas loads so that the minimum threshold requirement for obtaining unbundled delivery-only service from the LDC can be met.

One obstacle to retail competition is that most interstate pipeline capacity, storage, and other facilities for delivering gas to the citygate is held by LDCs. Some public utility commissions have required LDCs to assign a portion of their firm interstate pipeline commitments and storage capabilities to large industrial and commercial customers. This capacity can be used by these customers to transport gas purchased from a third-party marketer. As part of their unbundling programs, some regulators are requiring that $L D C s$ make available upstream facilities to their smaller customers, so that these customers do not have to contract with interstate pipeline companies directly. This "capacity" reassignment has the advantage of shifting some financial obligations from LDCs to the transportation customer, and any savings can be passed along to the LDCs' captive customers.

In extending choice to small consumers, regulators must ensure that remaining customers do not incur higher charges as a result of LDCs spreading their fixed costs over fewer customers. Customers leaving an LDC's system results in a shrinking customer base, and rates to remaining customers will likely increase, other things being equal. Most regulators are handling this problem by continuing to oversee rates charged to captive customers. However, others believe that a competitive retail gas market will not allow LDCs to pass along these higher costs.

\footnotetext{
${ }^{117}$ Minimum threshold requirements are often established to minimize the wholesale exodus of LDC customers to independent marketers, which could place the LDC in financial hardship and/or result in large price increases for remaining captive customers.
} 


\section{Unbundled Services}

States are challenged with identifying services that can be offered in a competitive market. They also must identify which customers would benefit from taking unbundled services. Unbundling need not stop with supply and transportation. LDCs provide many ancillary services, including storage, load balancing, billing, metering, and equipment repair that could be provided by third parties.

When deciding which services to unbundle, public utility commissions must first determine whether savings and gains in efficiency outweigh the cost of unbundling. They also want to ensure the quality of service for all customers, the dependability of third-party marketers, and avenues of recourse in the event that a marketer fails to perform on its contracts.

One rationale behind unbundling is that by picking and choosing, consumers can tailor gas service to meet their particular needs and in the process reduce their overall costs. For example, an industrial customer that has access to alternative fuels can afford greater risk in its supply and transportation arrangements, perhaps taking mostly interruptible service. Hospitals and schools require greater supply and transportation reliability to meet seasonal and daily requirements. They would probably also need expensive backup supply in case of an emergency. However, even they could benefit from unbundling which would enable them to contract for various qualities of supply and transportation that best fit their needs.

\section{Pricing of Unbundled Services}

The pricing of unbundled service will depend on the degree of competition for each of the services. On one hand, regulators need not oversee the pricing of gas services offered in a competitive market. On the other hand, regulators will want to continue to regulate the prices of monopoly services. Almost all,public utility commissions (PUCs) still consider gas delivery to be a monopoly service that should continue to be regulated. Consequently, PUCs are attempting to institute various incentive (or performance) based rate schemes to encourage LDCs to reduce distribution costs and then pass these savings through to consumers (see box, p. 116).

The correct determination of services that can be offered under competitive pricing is critical. If the PUC regulates rates for a competitive service, the LDC could lose customers and LDC rates to remaining customers would probably rise. If the PUC allowed excessive price flexibility for a service in a monopolistic market, higher prices and customer price discrimination could occur.
The industry is investigating the use of real-time pricing that allows variable pricing of services depending on system load. Pricing service this way could result in better load management as consumers become aware of peak prices and reduce their consumption during peak demand times. For these programs to succeed the extra expense of real-time metering must be less than the savings from better load management.

\section{Corporate Structure}

To ensure a fair and competitive retail market, State regulators will continue to oversee the corporate structure of LDCs. Many LDCs are establishing unregulated affiliates to compete with third-party marketers, pipeline companies, and producers. Regulators are requiring LDCs to restructure their operations so that they cannot show favor to their own marketing affiliates when setting transportation rates. Three types of unbundling provide increased assurance that corporate affiliates will not be given preferential treatment and that effective competition will be fostered.

- Functional Unbundling. Services are offered on an unbundled basis, but the corporate structure remains the same. This provides the least assurance that an LDC will be unable to provide preferential treatment to other arms of the company.

- Corporate Unbundling. Services are offered by separate corporations under an umbrella corporation or holding company. Various safeguards are erected to ensure that affiliate corporations do not provide preferential treatment to each other.

- Corporate Divestiture. The corporation is required to sell affiliates that could benefit from preferential treatment if it were to remain part of the corporation. This provides the most assurance that the company has no incentive to favor a particular marketer.

Brooklyn Union's corporate restructuring plan, recently filed with the New York Public Service -Commission, is one example of ongoing restructuring of LDCs. ${ }^{118}$ Under the plan, Brooklyn Union would become a holding company with three main business units concentrating on local distribution, energy marketing, and energy-related investments in international ventures.

As part of its plan, on May 2, 1996, Brooklyn Union announced the formation of a gas-marketing affiliate,

${ }^{118}$ Brooklyn Union Press Release (April 25, 1996). 


\section{Performance-Based Ratemaking}

Regulators have proposed and implemented a variety of rate structures that move away from traditional cost-of-service rates and provide incentives for firms to lower costs and operate more efficiently. Incentive rates provide opportunities for firms to earn and keep profits in excess of their allowed rate of return as long as prices to consumers do not increase too much or more than they would otherwise. The Federal Energy Regulatory Commission (FERC) has asked pipeline companies to file incentive rate proposals for transmission and other regulated tariffs, while several States have established incentives for local distribution companies (LDCs) to lower their gas purchase costs.

Traditional cost-of-service rates do not promote innovation and efficiency by regulated firms. Simply stated, cost-of-service rates are based on a "snapshot" of a firm's total cost of providing service plus a "fair" profit. Once rates are set by the regulator, there is no incentive for a company to try and reduce costs or operate more efficiently since in the long run they could not keep any additional profits in excess of the allowed return. In fact, cost-of-service rates can have the perverse effect of providing incentives for a firm to operate less efficiently. For example, since the rate of return is based on the cost of capital, firms could increase revenues by increasing their invested capital. Also, most day-to-day operating costs, such as the cost of gas for an LDC, can be passed straight through to customers, providing no incentive for firms to seek cheaper gas supplies. To address these issues, several types of incentive rate schemes have either been implemented or are under consideration, including: cost indexing, price caps, flexible rate of return, and profit sharing.

Cost indexing is similar to traditional cost-of-service based rates, but firms are allowed to keep additional profits resulting from cost reductions. A target rate for a service is established based on a firm's cost-of-service. The target rate is then indexed to a widely available price. For example, an LDC's gas purchase costs might be indexed to the price of gas on the spot market. Profits or losses resulting from deviations from the target are then shared between shareholders and customers. A major drawback to cost indexing is that a traditional rate review proceeding is required to establish costs in the base year. Regulators rely on data provided by the firm and there is an incentive for firms to overstate their costs in order to earn greater returns. Cost indexing is very similar to traditional cost-of-service rate regulation, and although it provides incentives for firms to operate more efficiently, it does not necessarily lead to an equitable solution or a more efficient market. However, a number of other incentive rate schemes have been proposed and implemented that provide incentives for firms to operate more efficiently and also lead to a more equitable solution for customers.

Price caps are one of the most widely used forms of incentive rate regulation and are used worldwide in the gas, electric, and telecommunications industries. Under a price cap, changes in the price of a service are constrained by indices that reflect overall industry cost trends adjusted for productivity improvements rather than costs for individual firms. This provides an incentive for the individual firm to try to reduce total costs and to exceed productivity growth of the industry average so that they can earn higher profits. Many price cap proposals share the higher profits between shareholders and customers, while other proposals allow the firm to retain all incremental profits. Allowing the firm to retain all incremental profits maximizes the incentive for a firm to cut costs, while the benefits accrue to consumers when the price cap is reduced at the next rate review.

Regulators must address a number of issues before price caps can be successfully implemented. For example, should price caps be placed on all services provided by a firm, or just on monopoly services? In competitive segments of an industry, firms already have a market incentive to reduce their costs. Placing price caps on monopolistic services would make it difficult for a firm to subsidize lower rates, in markets where it faces competition, by raising prices in the monopoly market. However, firms could potentially circumvent this aspect of price caps by reducing quality of service to their monopoly customers. A major disadvantage to price caps is that under favorable conditions a utility could potentially earn large windfall profits. Recent windfalls to electric utilities in Britain resulted in a public outcry and government review of utility price cap mechanisms. Several incentive rate proposals attempt to remedy these problems by placing a cap on profits rather than on prices.

Flexible rates of return place limits on the size of a firm's profits. "Dead bands" are developed around a predetermined rate of return in which the firm can operate and make a greater or lesser profit. For example, a regulator might establish a dead band between a rate of return of 11 and 14 percent, on either side of 12.5 percent, the firm's cost of capital determined in a conventional cost-of-service rate case. Between 12.5 percent and 14 percent, the LDC would retain all the profits. Profits exceeding 14 percent would be shared between the LDC and its customers. Likewise the LDC could add a charge to customers if the rate of return falls below 11 percent. Flexible rates of return are easier to implement than price caps, requiring less information about costs and indexes. However, the dead bands must be broad enough to provide sufficient incentives to the firm, while at the same time not resulting in unreasonable windfalls. Another variant of incentive rates, profit sharing, eliminates dead bands, with all profits shared between firm shareholders and customers.

Profit-sharing schemes are easier to implement than price caps or flexible rates of return, requiring less information by regulators. Under profit sharing, consumers and firm shareholders split profits over and above a specified level according to a predetermined share. 
KeySpan Energy Services Inc. ${ }^{119}$ KeySpan Energy Services will buy and sell gas and provide transportation and related services, initially to individual large commercial and industrial customers and then to aggregated residential and small commercial customers.

Another example is the plan by Pacific Gas and Electric (PG\&E), a leading distributor in California, to restructure its operations and form a holding company. Under the restructuring, PG\&E would transfer its ownership in Pacific Gas Transmission, an interstate pipeline company that transports gas from Canada to California, to the holding company. The restructuring is expected to be completed by the end of 1996.

\section{Obligation to Serve}

State regulators are responsible for ensuring safe and reliable service to core customers. If the LDC is responsible only for transporting gas for others, a question arises about who should provide gas in the event of a shortfall. Meeting peakday requirements is one of the most expensive services offered by LDCs. If customers buy relatively inexpensive supplies from third-party marketers, who then fail to perform during peak demand periods, should the LDC still be held to be the gas provider of last resort? If so, how should the LDC be compensated?

Many PUCs are settling this problem by simply providing customer choice and invoking "buyer beware" for those who choose to leave the LDC. Other PUCs are mandating that certain customers buy backup service from the LDC in addition to services they obtain from marketers. In general, PUCs will probably abandon traditional obligation to serve for sales service, but retain it for LDC delivery service to assure reliability of service.

\section{Transition Costs}

Regulators must address the incidence of costs resulting from the transition to a competitive retail market. In the wholesale market, the Federal Energy Regulatory Commission allowed interstate pipeline companies to pass transition costs to both core and non-core customers in the form of higher transportation tariffs. State commissions generally allowed LDCs to pass these costs along to their customers. However, under threat of bypass by industrial and large commercial customers, LDCs probably passed transition costs

\footnotetext{
${ }^{19}$ Brooklyñ Union Press Release (May 2, 1996).
}

disproportionally to captive residential and small commercial customers, while also absorbing some costs.

LDCs have incurred their own transition costs associated with contractual obligations for transmission capacity that is no longer required, supply contracts that are no longer needed, and overbuilding of distribution capacity to serve a market that has either disappeared or failed to materialize. As with the transition costs incurred from interstate pipeline companies, State regulators must decide how LDCs' transition costs should be allocated between LDC shareholders and customers. One solution to lessen the impact to these parties is for LDCs to turn back long-haul pipeline capacity rights not required to serve core customers to the pipeline companies (see Chapter 2).

The precise path taken by regulators towards a more competitive retail gas industry will vary by State and market conditions. The economics of building a retail distribution system to serve small commercial and residential customers probably precludes a competitive market developing for the local transportation of gas. Therefore, States would probably want to continue to regulate this segment of the industry to ensure service and rates to remaining customers. However, should LDCs abandon their merchant role as interstate pipeline companies have at the wholesale level, even the smallest consumers could potentially gain access to competitively priced natural gas supplies.

\section{Recent State Actions to Unbundle Retail Gas Markets}

Most States currently allow unbundled services only to large customers. Some States, for example Iowa, unbundled services to residential customers in the mid-1980's. Although in Iowa's case, a lack of marketer interest has hindered the development of effective competition. Many States are asking LDCs to propose plans to offer unbundled service to smaller customers, while others have begun implementing unbundling proposals. For illustrative purposes, highlights of programs are described for New York, Maryland, and California. New York was among the first States to restructure LDC operations down to the residential level; on May 1, 1996, Brooklyn Union became the first LDC to give all customers the option to purchase natural gas from third-party sources. Maryland approved small customer unbundling experiments by the largest LDCs, beginning in November 1996. California was chosen for its market size and the fact that as early as 1991, it offered small and medium-sized customers entry to competitive gas markets through its Core Aggregation Transportation (CAT) program. Table 13 summarizes recent actions taken in other States. 
Table 13. Unbundling Actions by Selected State Public Utility Commissions

\begin{tabular}{|c|c|c|c|}
\hline 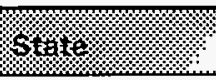 & 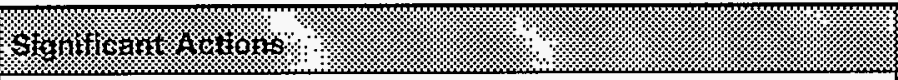 & $10 \mathrm{x}$ & 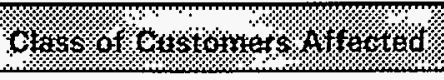 \\
\hline California & $\begin{array}{l}\text { Defined core and non-core market segments. Non-core segment } \\
\text { allowed to buy unbundled supply and transportation. } \\
\text { Statewide capacity brokering plan for allocation of interstate capacity } \\
\text { to non-core customers. } \\
\text { Adopted rules for a permanent core customer aggregation program } \\
\text { that allows small customers to pool together to receive } \\
\text { transportation-only service. Pacific Gas \& Electric should unbundle its } \\
\text { services by } 1 / 1 / 1998 \text { and Southern California gas and San Diego Gas } \\
\text { \& Electric should offer unbundled services by } 1 / 1 / 1999 \text {. }\end{array}$ & $\begin{array}{l}1986 \\
11 / 6 / 91 \\
7 / 19 / 95\end{array}$ & $\begin{array}{l}\text { Industrial and lárge commercial } \\
\text { Industrial and large commercial } \\
\text { Small commercial }\end{array}$ \\
\hline Connecticut & $\begin{array}{l}\text { Required firm transport service to commercial customers. } \\
\text { Order addressing cost-of-service methodologies and proposed tariffs } \\
\text { for unbundled services. Small customers will not need real-time } \\
\text { metering and will be able to choose the level of backup service. }\end{array}$ & $\begin{array}{l}1994 \\
11 / 2 / 95\end{array}$ & $\begin{array}{l}\text { Commercial } \\
\text { All }\end{array}$ \\
\hline Georgia & $\begin{array}{l}\text { Public Service Commission issued a policy statement including: } \\
\text { unbundling of interruptible service to non-core customers and the } \\
\text { establishment of a pilot program for unbundled service to core } \\
\text { customers; gradual movement to incentive rates; transition costs } \\
\text { should be charged to parties benefiting the most from competition; no } \\
\text { cross subsidies between utilities and their marketing affiliates. }\end{array}$ & $5 / 31 / 96$ & Industrial and commercial \\
\hline Illinois & $\begin{array}{l}\text { Northern Illinois Gas, Peoples Gas Light and Coke, MidAmerican } \\
\text { Energy Corporation, and North Shore Gas currently offer } \\
\text { transportation service. }\end{array}$ & -- & Industrial and commercial \\
\hline Indiana & $\begin{array}{l}\text { Indiana Gas Company proposal to provide unbundled services to some } \\
\text { customers. } \\
\text { Aggregation program for other customers under consideration. }\end{array}$ & -- & $\begin{array}{l}\text { Industrial and large and mid-sized } \\
\text { commercial } \\
\text { Small commercial }\end{array}$ \\
\hline lowa & $\begin{array}{l}\text { lowa's PUC adopted small customer unbundling in } 1986 \text {. However, } \\
\text { until recently the requirement for telemetering and standby service } \\
\text { and a lack of marketers willing to enter the market have prevented } \\
\text { effective choice. } \\
\text { MidAmerican Energy Corporation conducted a small residential pilot } \\
\text { program to unbundle service to all customers. }\end{array}$ & 1986 & Residential \\
\hline Maine & $\begin{array}{l}\text { Unbundling proposal by Northern Utilities under consideration by the } \\
\text { regulatory commission. }\end{array}$ & -- & Industrial and commercial \\
\hline Maryland & $\begin{array}{l}\text { Maryland Public Service Commission recommendation to unbundle } \\
\text { retail sale service into supply and delivery services for all customers. } \\
\text { Baltimore Gas and Electric's unbundling filings approved. }\end{array}$ & $\begin{array}{l}11 / 15 / 94 \\
8 / 2 / 95\end{array}$ & Residential and small commercial \\
\hline Massachusetts & $\begin{array}{l}\text { PUC approved proposal for a pilot residential unbundling program } \\
\text { before the } 1996 \text { heating season. }\end{array}$ & $12 / 31 / 95$ & Residential \\
\hline Michigan & $\begin{array}{l}\text { PUC requested comments from LDCs concerning the implementation } \\
\text { of small customer unbundling, specifically offering transportation-only } \\
\text { service. }\end{array}$ & 2/12/96 & To be determined \\
\hline Minnesota & $\begin{array}{l}\text { Minnegasco filed a proposal to unbundle services. Highlights: } \\
\text { - Unbundles long-haul pipeline transportation from local delivery } \\
\text { - Establishes a 3-year experiment for the aggregation of small } \\
\text { transportation customers } \\
\text { - In case of a shortage, Minnegasco will make efforts to supply } \\
\text { gas to transportation only customers at special rates. }\end{array}$ & $4 / 14 / 95$ & $\begin{array}{l}\text { Industrial and large and small } \\
\text { commercial }\end{array}$ \\
\hline
\end{tabular}


Table 13. Unbundling Actions by Selected State Public Utility Commissions (Continued)

\begin{tabular}{|c|c|c|c|}
\hline statk & - & otito & 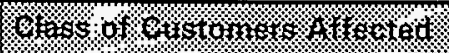 \\
\hline Montana & $\begin{array}{l}\text { PUC ordered Montana-Dakota utilities to file a gas-unbundling plan for } \\
\text { all customers by July } 1,1996 .\end{array}$ & - & To be determined \\
\hline Nebraska & LDCs not regulated by the State; all are local municipalities. & - & - \\
\hline Nevada & Unbundling activity has focused on workshops and issue statements. & -- & - \\
\hline New Hampshire & $\begin{array}{l}\text { Transportation offered to customers who consume more than } 10,000 \\
\text { therms a month. }\end{array}$ & & All \\
\hline New Jersey & $\begin{array}{l}\text { PUC issued guidelines. } \\
\text { LDCs required to file plans to unbundle rates to nonresidential } \\
\text { customers. }\end{array}$ & $\begin{array}{l}1 / 20 / 93 \\
3 / 29 / 95\end{array}$ & Nonresidential \\
\hline New Mexico & $\begin{array}{l}\text { Transmission, distribution, storage, standby service, and emergency } \\
\text { gas service are fully unbundled. }\end{array}$ & 1984 & All \\
\hline New York & $\begin{array}{l}\text { New York Public Service Commission (NYPSC) issued general } \\
\text { guidelines and asked the largest utilities to file unbundling plans. } \\
\text { NYPSC approved nine plans. } \\
\text { Brooklyn Union will offer transportation-only service to commercial } \\
\text { and residential customers. }\end{array}$ & $\begin{array}{l}12 / 20 / 94 \\
3 / 95 \\
5 / 1 / 96\end{array}$ & $\begin{array}{l}\text { Non-core customers } \\
\text { (industrial and large commercial) } \\
\text { Small commercial and residential }\end{array}$ \\
\hline Ohio & $\begin{array}{l}\text { Approved a transportation-only rate for schools served by East Ohio } \\
\text { Gas. } \\
\text { Issued a policy statement that expects large LDCs to formulate and } \\
\text { implement small commercial and residential programs. }\end{array}$ & $\begin{array}{l}11 / 3 / 94 \\
12 / 1 / 94\end{array}$ & Small commercial and residential \\
\hline Oklahoma & Always allowed transportation-only service. & $\rightarrow$ & Industrial and commercial \\
\hline Pennsylvania & $\begin{array}{l}\text { Equitable Gas filed plans with the Pennsylvania PUC to provide } \\
\text { customers in the Pleasant Hills area access to alternate gas suppliers. }\end{array}$ & Fall 1995 & $\begin{array}{l}\text { Small commercial and residential. } \\
\text { Minimum volume requirement of } \\
5,000 \text { Mcf per year. No more than } \\
10 \text { customers can aggregate to } \\
\text { overcome the minimum require- } \\
\text { ment threshold. }\end{array}$ \\
\hline Texas & Always allowed transportation-only service. & - & Industrial and commercial \\
\hline Washington & $\begin{array}{l}\text { Unbundled sales, transportation, storage, and standby service have } \\
\text { been in place since } 1989 .\end{array}$ & 1989 & - \\
\hline Wisconsin & $\begin{array}{l}\text { Commission endorsed unbundling basic distribution, competitive } \\
\text { supply, balancing, peak-day supply, and enhanced services (demand- } \\
\text { side management, social programs, etc.). } \\
\text { Wisconsin Gas Company began a pilot program of small customer } \\
\text { unbundling. }\end{array}$ & - & All \\
\hline \multirow[t]{2}{*}{ Wyoming } & Scheduled a conference on unbundling. & $6 / 6 / 95$ & $\begin{array}{l}\text { Proposes unbundled rates only } \\
\text { for non-core customers } \\
\text { (industrial and large commercial) }\end{array}$ \\
\hline & $\begin{array}{l}\text { Wyoming Public Service Commission approved KN Energy's } \\
\text { unbundled service program for its core customers. Under the proposal, } \\
\text { only gas sales would be opened to competition. All other services } \\
\text { would continue to be provided by KN Energy. }\end{array}$ & $2 / 96$ & All \\
\hline
\end{tabular}

-. = Not applicable. PUC $=$ Public utility commission. $L D C=$ Local distribution company. Mcf $=$ Thousand cubic feet.

Source: Energy Information Administration, Office of Oil and Gas, derived from various industry news sources. 
Each of the three States is a prime example of how some PUCs are promoting choices for residential customers. The three share many characteristics but also some differences. All PUCs must grapple with the fundamental question of how to offer consumers the greatest choice, and at the same time maintain reasonable rates and ensure service quality. To reach these objectives, PUCs may take different routes. Some may seek to maintain service quality, perhaps at the cost of higher rates. For example, New York requires small customers to take backup service from the LDC regardless of which marketer they obtain gas from. Maryland requires commercial customers who consume less than 2 million cubic feet per year to pay a flat fee for standby service. Other PUCs may seek to reduce rates as much as possible, in the belief that a competitive market will ensure service quality. California does not require small customers to take backup service, believing that the market will weed out marketers unable to perform during peak demand periods.

\section{California}

California was one of the first States to unbundle gas sales from transportation for certain customer classes. In 1986, the California Public Utilities Commission (CPUC) separated LDC customers into "core" and "non-core" categories. Core customers were defined as residential and commercial customers, while the non-core market was defined as large industrial and electric generating customers with alternative fuel burning capability. Subsequently these definitions were redefined based on customer demand levels, with core customers defined as consuming less than 250,000 therms per year. Initially, non-core customers were given the option to purchase unbundled LDC sales and transportation service, but by 1990 non-core customers were required to acquire their own gas from parties other than LDCs.

- Unbundled Service. On November 6, 1991, California adopted a Statewide "capacity brokering" plan for LDCs to broker their excess pipeline capacity not required to provide gas to core customers. ${ }^{120} \mathrm{LDCs}$ have proposed to unbundle services such as gas transmission, storage, and distribution, with separate rates charged for each service.

- Aggregation of Core Customers. In July 1995, an experimental core aggregation program, designed to allow smaller volume customers to benefit from unbundled sales and transportation, was made permanent. ${ }^{121}$ Core customers may elect to take traditional sales service from their LDC if they wish.

\footnotetext{
${ }^{120}$ California Public Utility Commission, Decision No. 91-11-025.

${ }^{121}$ California Public Utility Commission, Decision No. 95-07-058.
}

- Corporate Structure. LDCs that offer unbundled services have not been required, thus far, to separate out or spin off their sales divisions.

- Obligation to Serve. Although unbundling of core services has reduced the LDC's obligation to serve and could therefore reduce service quality, the California Public Utility Commission believes that the benefits of greater consumer choice will outweigh the cost of any diminished service.

- Transition Costs. Stranded costs associated with turning back unneeded interstate capacity will be allocated to all customers (core and non-core) on an equal basis (cents per therm consumed).

- Rates. California has unbundled interstate and intrastate transportation rates. Firm transportation service rates for non-core customers are calculated at the fully allocated cost of service, while rates for interruptible service can be discounted.

\section{New York}

The New York Public Service Commission adopted generic natural gas restructuring policies through orders issued on December 20, 1994, and August 11, $1995 .{ }^{122}$ The orders provide guidelines about:

- Unbundled Service. LDCs must provide firm customers access to pipeline capacity, storage, and receipt points. LDCs must market their surplus gas and capacity. They may retain 15 percent of the earnings, but must pay 85 percent to core customers.

- Aggregation of Core Customers. Core customers are defined as firm sales or transportation customers without access to alternative fuels. Third-party marketers can aggregate small customer loads to meet minimum volume requirements for receiving unbundled service.

- Corporate Structure. Marketing by an LDC subsidiary is allowed, however, the marketing subsidiary and the LDC must have separate operations, and there can be no direct transactions between an LDC and its affiliate. Brooklyn Union recently filed a petition with the New York Public Service Commission to organize its utility operations and those of its subsidiaries into a holding company. Brooklyn Union has announced plans to

\footnotetext{
${ }^{122}$ New York Public Service Commission, Opinion No. 94-26, "Opinion and Order Establishing Regulatory Policies and Guidelines for Natural Gas Distributors."
} 
expand gas marketing and energy management services to large-volume customers, potentially through new subsidiaries to be incorporated separately and owned by the holding company.

- Obligation to Serve. LDCs are not obligated to serve the non-core market. However, they must offer non-core customers standby or backup service at market-based rates. "Human needs" customers are required to take backup service from their LDC.

- Transition Costs. LDCs can fully recover transition costs from sales and transportation customers. Unrecovered pipeline purchased gas costs should be assigned solely to the sales customers of the LDCs and recovered through their gas cost adjustments. Transportation customers who pay directly for firm pipeline capacity were exempted from transition cost recovery. Stranded investment and gas supply realignment costs would be allocated to both sales and transportation customers. ${ }^{123}$

- Rates. Customers can be charged different rates depending on competitive conditions and the value attached to gas service by individual customer classes. LDCs can even sell gas to some customers at less than cost, as long as the average sales price will exceed the commodity cost over the course of the contract. Non-core customers can be charged market-based rates, although they are subject to a cap. Also, LDCs can earn profits up to a limit in excess of their allowed rate of return

In March 1995, the New York Public Service Commission approved unbundling plans for the nine largest gas and electric utilities. Over a year later (May 1, 1996), Brooklyn Union began the implementation of a program that allows customers using more than 35,000 therms annually to buy unbundled transportation-only service. Marketers will be able to combine small residential and commercial customers to meet this minimum requirement. Brooklyn Union will still retain responsibility for billing, meter reading, and other customer services. Most small customers also will be required to receive standby service from Brooklyn Union.

\section{Maryland}

On January 10, 1995, the Maryland Public Service Commission (MPSC) issued Order 71703, which called for

\footnotetext{
${ }^{123}$ Stranded investments represent assets previously used to provide bundled sales service. Gas supply realignment costs result from the LDC reforming or buying out existing supply contracts or continuing to perform under certain contracts.
}

phased unbundling. Phase I required three major utilities in Maryland to make plans by November 1995 to offer unbundled transportation and sales to large volume customers. ${ }^{124}$ Phase II required utilities to have plans in place by November 1996 to offer unbundled services to small volume customers. The three utilities already offered unbundled service options to their largest customers. The MPSC's ultimate aim is to replace retail sales service with unbundled sales and delivery service and to eliminate barriers such as minimum-take requirements, metering, and obligation to serve.

MPSC has accepted a pilot plan from Baltimore Gas and Electric's (BG\&E) to offer services on an unbundled basis. Under BG\&E's plan:

- BG\&E's interstate pipeline capacity rights will be assigned to its customers under 1-year terms.

- Nonstandby transportation service will be offered to customers such as small apartment complexes that contain three or more units served by a single meter.

- Comprehensive balancing service will be offered to transportation customers. This was initially priced at $\$ 0.35$ a therm. Customers who do not take the balancing service, and either under or overtake gas, will be charged penalties.

- A third-party billing system will be made available to third-party marketers.

To prevent preferential treatment of its affiliates, BG\&E will restructure its operations to establish clear delineations between its transportation, sales, and marketing affiliates. BG\&E will also contract out services such as balancing, storage, and risk management services.

On November 1, 1995, Columbia Gas of Maryland began offering transportation-only service to any industrial or commercial customer that burned less than 2 million cubic feet per year. To meet its obligation to serve, Columbia requires the smaller customers to purchase standby gas service at a flat fee of $\$ 21$ per month for commercial customers and $\$ 223$ per month for industrial customers. To reflect the new services offered, Columbia established new procedures for curtailing customers in the event of a gas or capacity shortage. Customers with access to alternative fuels would be curtailed first, followed by manufacturers, and finally commercial customers. Columbia also established new charges to customers who take more than their annual

\footnotetext{
${ }^{124}$ Baltimore Gas and Electric, Columbia Gas, and Washington Gas Companies.
} 
contracted volumes, which allows Columbia gas to recover any penalties assessed by its affiliate Columbia Gas Transmission.

On September 1, 1995, Washington Gas began offering interruptible customers transportation-only service with minimum annual requirements of 40,000 therms. Previously the minimum requirement was 80,000 therms. On November 1,1995 , the company expanded firm transportation to firm industrial, commercial, and group-metered apartment customers with minimum annual requirements of 40,000 therms.

Washington Gas also implemented a 2-year pilot program that assigned capacity on the utility's existing interstate transportation capacity. Under the program any industrial, commercial, and group metered apartment customer would be assigned a portion of Washington Gas' firm interstate pipeline capacity to transport gas purchased from a third-party supplier. Small customers would be able to secure their own gas supplies without having to obtain pipeline capacity.

Washington Gas is also undertaking efforts to educate small customers about unbundling, the choices it offers them, and new billing procedures. This is in anticipation of November 1996, when residential customers will be allowed to purchase gas from a choice of nine third-party marketers, including Washington Gas' marketing arm.

\section{The Impact on Consumers}

As retail unbundling reaches smaller commercial and residential consumers, their customary way of purchasing gas will be radically changed. They will no longer be limited to taking gas services from their local distribution company, but will be able to choose service from the supplier that best meets their needs at the lowest price.

It is very unlikely that smaller customers would take fully unbundled service and contract for separate supply, long-haul transportation, citygate transmission, storage, standby service, and balancing, because the transaction costs of contracting for individual services would probably be higher than any savings. Instead, intermediate marketers will rebundle these services and offer them to consumers as a competitively priced package. The new retail gas market will have many similarities to current phone service. Consumers will use local distributors to deliver gas much the same as their local telephone company delivers long-distance service from longdistance phone carriers, such as AT\&T, MCI, or Sprint.

Some small commercial consumers are already benefiting from retail unbundling and deregulation. The Archdiocese of
Chicago estimates that it has saved $\$ 8$ million over the past 5 years by buying gas from the marketing arm of Enron Corporation. ${ }^{125}$ However, some consumers may be exposed to more risk than they are comfortable with. LDCs provide gas at fairly predictable prices, evening out seasonal and daily price fluctuations. Some marketers are offering gas indexed to the price of gas in the commodity markets. Others are offering a variety of programs to insulate consumers from some types of market risks. But all these hedging services are available only to customers who are willing to pay additional fees. When daily prices spike, as they did on February 2 to $\$ 15.50$ per thousand cubic feet, the full cost of using gas that day could be passed along to the consumer ${ }^{126}$ Consumers will need to evaluate their own risk tolerance before buying a particular service.

Unbundled service to residential customers is generally now available only on a limited basis as part of experimental programs instituted by State regulators or LDCs. For example, on November 1, 1995, the town of Rock Valley, Iowa became one of the first communities in the United States to be offered a choice of gas suppliers. Under a pilot project, MidAmerican Energy (the LDC serving Rock Valley) offered approximately 875 residential and 80 commercial and industrial customers a choice of three marketers. The marketers were chosen by MidAmerican Energy from a pool of more than 50 applicants based on criteria such as experience, corporate resources, and a willingness to meet MidAmerican's obligation to serve. Each marketer was required to sign up at least 50 customers or drop out of the program. Only two marketers remained after initial customer balloting. Both companies employed marketing techniques customary to other deregulated utility services, such as guaranteed monthly savings offered by longdistance telephone companies.

Rock Valley was considered ideal for the experiment since the town received real-time meters in 1990 as part of an energy efficiency test. A lack of expensive real-time metering systems to track consumption is perceived as a major roadblock to providing choice to residential customers elsewhere. Conventional meters track consumption, but realtime meters track consumption, the time it occurred, and associated prices. As part of the trial, MidAmerican Energy switched the marketers' nominations process from reliance on real-time metering to forecasted load levels. MidAmerican wanted to see whether suppliers could maintain service continuity through their own supplies or whether they fell back on MidAmerican's supplies during demand peaks. Also, if forecasting proved a reliable alternative to expensive realtime metering, a major hurdle to residential unbundling would

\footnotetext{
125“'Tired of Phone Wars? Get Ready for a Fight to Sell Natural Gas,"Wall Street Journal (April 16, 1996).

${ }^{126}$ Pasha Publications, Inc., Gas Daily (February 2, 1996).
} 
have been overcome. The test was a success and MidAmerican now relies on load forecasts rather than real time metering.

The Rock Valley experiment has shown that marketers will employ innovative methods to differentiate themselves to consumers. Recently announced mergers between large oil and gas producers and gas marketers (Chapter 1) suggests that in the near future gas could be marketed under such brand names as Chevron, Mobil, and Exxon.

To see how much consumers might save under retail unbundling, it is instructive to look to Canada, specifically the province of Ontario, where limited residential retail unbundling was implemented in 1987.

\section{The Canadian Experience with Retail Unbundling}

Canada first began to experiment with consumer choice and market pricing for retail natural gas with the adoption of the Halloween Agreements in 1985. ${ }^{127}$ The Canadian provinces of Ontario, Manitoba, and Quebec were among the first to develop plans that strongly promote retail unbundling for small customers. Other provinces, such as British Columbia, were more cautious and initially only unbundled services to larger industrial and commercial customers.

Canadian unbundling of services is very different from that currently proposed in the United States. Retail unbundling plans in the United States focus on the separation of LDC sales from distribution. In contrast, LDCs in Ontario were not required to exit from the sales side of their business. Rather, consumers contract with third-party marketers who arrange for gas supplies and interstate pipeline capacity and then sell the gas to the LDC for delivery to consumers. Consumers pay the LDC the usual price for gas service, however, savings are passed along to those who contract with marketers in the form of rebates that show up on their retail service bill. Under this market structure, the marketer receives a brokering fee for providing cheaper gas, the LDC maintains its overall sales levels, and those consumers taking part benefit from cheaper gas. ${ }^{128}$

In 1987, the Ontario Energy Board implemented open access and unbundled services to all customers, regardless of size. Using price as a criterion, the program in Ontario can be judged a success. In 1985, residential consumers in Ontario

\footnotetext{
${ }^{127}$ The Agreement on Natural Gas Markets and Prices was signed by the governments of Canada and its provinces on October 31, 1985.

${ }^{128} \mathrm{LDCs}$ traditionally pass the cost of procuring gas through to end users.
}

paid almost 20 percent more than the national average for natural gas. The premium fell steadily through the decade, and by 1994 residential consumers paid only 9 percent more for natural gas. ${ }^{129}$

In terms of reliability and the obligation to serve, the results of retail unbundling have been somewhat mixed. The method adopted by Ontario worked as long as marketers could procure gas and transmission capacity at prices lower than those paid by LDCs under their customary long-term fixed price contracts. For most of the latter half of the 1980's, Canadian wellhead prices were below the contract price paid by LDCs. However, this market arrangement ran into some problems in 1993 when the wellhead price of gas rose above the long-term contract price, causing some marketers to renege on contracts and to shift customers back to the LDC.

To address some of these issues, the Ontario Energy Board is considering a complete separation of LDC distribution and sales roles. If this were to happen, LDC unbundling in Canada would become more like the proposals currently under consideration in the United States. Some Canadian marketers and end users believe that the adoption of a fully unbundled open access market in Canada would result in even further savings to consumers.

\section{Future Challenges}

State efforts to provide smaller residential and commercial customers service choice by providing access to unbundled gas services are gaining momentum. Many States are actively examining or implementing some form of retail unbundling which will give smaller LDC customers the same access to competitive gas markets already enjoyed by their larger customers.

LDCs originally began offering unbundled service to retain large industrial and electric utility customers in the face of stiff competition from interstate pipeline companies. End-use prices to different customer classes provide evidence that small customers received significantly fewer benefits from the transition of the wholesale market to competition. Between 1990 and 1995, prices to residential customers appear to have fallen 10 percent from $\$ 6.67$ per thousand cubic feet $(1995$ dollars) to $\$ 6.06$ per thousand cubic feet. In contrast, over the same period, prices to industrial customers appeared to fall in excess of 24 percent, from $\$ 3.37$ per thousand cubic feet to $\$ 2.71$ per thousand cubic feet (Table 11, Chapter 5).

\footnotetext{
${ }^{129} \mathrm{~K}$. W. Costello, and J.R. Lemon, The National Regulatory Research Institute, Unbundling the Retail Gas Market: Current Activities and Guidance for Serving Residential and Small Commercial Customers (May 1996), p. 21
} 
State regulators and consumer groups want to extend the benefits of retail competition to smaller LDC customers. However, they face many challenges along the way, including appropriate pricing of services, what services should be unbundled, service reliability, corporate structure, and the allocation of costs associated with the transition to the competitive market. Also, although aggregate savings from unbundling and greater competition could be considerable, in terms of the price paid for gas by small consumers, questions abound about the magnitude of the saving. For example, to satisfy the obligation to provide secure supplies on demand, many PUCs are requiring small customers to continue to take backup service from their LDC. The requirement to take this expensive service could offset any savings from unbundling and prevent the formation of a competitive market.

As unbundling proceeds, transition costs will continue to accumulate. Some LDCs may find themselves paying for long-term firm interstate pipeline capacity that they no longer need. How these costs are apportioned among interstate pipelines companies, LDC shareholders, and the different classes of LDC customers will significantly affect the savings to individual stakeholders. However, many in the industry believe that the long-term benefits of retail competition will far outweigh any short-term costs incurred along the way. 
Appendix A

Chapter 1

Supplement 



\section{Appendix A}

\section{Chapter 1 Supplement}

Figure A1. Supply Regions

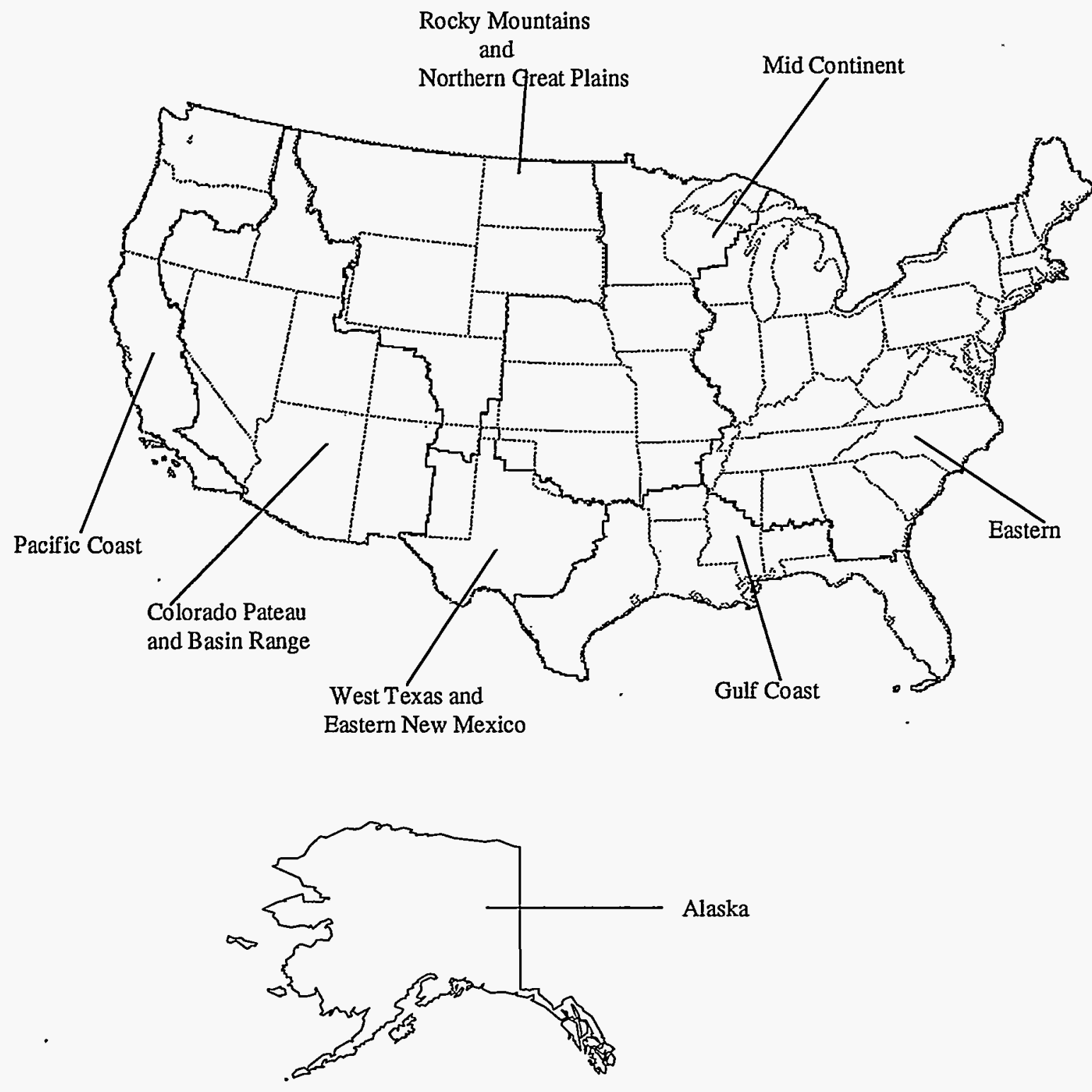

Source; U,S. Department of Interior, U.S. Geological Survey, 1995 National Assessment of United States Oil and Gas Resources (1995). 
Table A1. Key Mergers and Acquisitions in the Gas Industry During 1995 and 1996

\begin{tabular}{|c|c|c|}
\hline $\begin{array}{l}\text { Larger Company / Smaller } \\
\text { Company }\end{array}$ & $\begin{array}{l}\text { Merger } \\
\text { Status }\end{array}$ & Company Structure \\
\hline \multicolumn{3}{|l|}{  } \\
\hline $\begin{array}{l}\text { Chevron / Natural Gas Clearing } \\
\text { House (NGC) } \\
\text { New Company: NGC }\end{array}$ & $\begin{array}{l}\text { Announced: } \\
1 / 22 / 96 \\
\text { Completed } \\
8 / 31 / 96\end{array}$ & $\begin{array}{l}\text { NGC will market virtually all of Chevron's North American production of natural gas, natural gas } \\
\text { liquids, and electricity. The new company will make arrangements to supply energy and } \\
\text { feedstocks to Chevron's refineries, chemical plants, and other corporate facilities in North } \\
\text { America. } \\
\text { The new company would include all of NGC and most of two Chevron operations: Houston-based } \\
\text { Natural Gas Business Unit and Tulsa-based Warren Petroleum, with the exception of Warren's } \\
\text { Venice, Louisiana, processing complex. }\end{array}$ \\
\hline $\begin{array}{l}\text { Mobil Natural Gas Inc. I } \\
\text { PanEnergy } \\
\text { New Company: PanEnergy }\end{array}$ & $\begin{array}{l}\text { Announced: } \\
\text { 1/30/96 } \\
\text { Completed } \\
8 / 1 / 96\end{array}$ & $\begin{array}{l}\text { PanEnergy will operate the joint venture and hold a } 60 \text {-percent stake, with Mobil Natural Gas Inc. } \\
\text { retaining a } 40 \text {-percent stake in the new entity. PanEnergy Field Services acquired about } 2,600 \\
\text { miles of gathering, processing, and interstate pipelines as well as Mobil's interests in } 24 \text { gas- } \\
\text { processing plants located in Texas, Oklahoma, Louisiana, and Utah. }\end{array}$ \\
\hline $\begin{array}{l}\text { Tenneco / El Paso } \\
\text { New Company: El Paso } \\
\text { Energy Corp. }\end{array}$ & $\begin{array}{l}\text { Announced: } \\
6 / 19 / 96 \\
\text { Pending }\end{array}$ & $\begin{array}{l}\text { The combination of El Paso and Tenneco Energy's operations will create one of the Nation's } \\
\text { leading natural gas pipeline and marketing companies, accounting for approximately } 20 \text { percent } \\
\text { of gas transported in the United States. In the first quarter of 1996, El Paso sold about } 3.9 \text { billion } \\
\text { cubic feet of gas, while Tenneco Energy sold about } 2.6 \text { billion cubic feet. }\end{array}$ \\
\hline $\begin{array}{l}\text { Shell Oil / Tejas Gas } \\
\text { New Company: Coral Energy } \\
\text { Resources }\end{array}$ & $\begin{array}{l}\text { Completed } \\
\text { July } 1995\end{array}$ & $\begin{array}{l}\text { Tejas Alliance Holding Company, a subsidiary of Tejas Gas, was organized in July } 1995 \text { to hold } \\
\text { an interest in Coral Energy Resources, an energy marketing joint venture with Shell Oil Company. } \\
\text { Coral Energy Resources has access to Tejas' pipelines and storage facilities and Shell dedicates } \\
\text { over } 2 \text { billion cubic feet per day of natural gas production to the new company. In addition, Tejas } \\
\text { provides intrastate marketing expertise and Shell provides interstate marketing expertise. }\end{array}$ \\
\hline \multicolumn{3}{|l|}{ 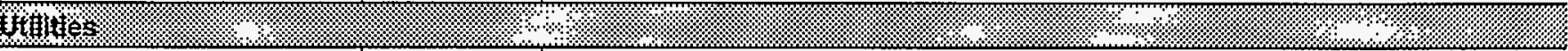 } \\
\hline $\begin{array}{l}\text { Puget Sound Power / } \\
\text { Washington Energy }\end{array}$ & $\begin{array}{l}\text { Announced: } \\
\text { 5/18/95 } \\
\text { Pending }\end{array}$ & $\begin{array}{l}\text { The merger would create the largest combined electric and gas utility in the State of Washington. } \\
\text { Puget Sound Power (an electric company) would merge with Washington Energy Company (a } \\
\text { combined electric and gas company). }\end{array}$ \\
\hline $\begin{array}{l}\text { Northern States Power I } \\
\text { Wisconsin Energy } \\
\text { New Company: Primenergy }\end{array}$ & $\begin{array}{l}\text { Announced: } \\
\text { 5/1/95 } \\
\text { Pending }\end{array}$ & $\begin{array}{l}\text { The merger was approved by The Michigan Public Service Commission on April 10, } 1996 \text { and by } \\
\text { The North Dakota Public Service Commission on June 26, 1996. State commissions in Minnesota } \\
\text { and Wisconsin will consider the merger. } \\
\text { A holding company, Primenergy Corporation, will be formed with two subsidiaries: Northern } \\
\text { States Power Company and Wisconsin Energy (which consists of Wisconsin Electric Power } \\
\text { Company and Wisconsin Natural Gas Company). }\end{array}$ \\
\hline $\begin{array}{l}\text { Baltimore Gas and Electric / } \\
\text { Potomac Electric Power } \\
\text { Company } \\
\text { New Company: Constellation } \\
\text { Energy }\end{array}$ & $\begin{array}{l}\text { Announced: } \\
9 / 25 / 95 \\
\text { Pending }\end{array}$ & $\begin{array}{l}\text { Constellation Energy Corporation, will be structured as a single utility with subsidiaries conducling } \\
\text { the non-utility operations. The service territory of Constellation Energy Corporation will } \\
\text { encompass } 10 \text { Maryland counties, Baltimore City, and Washington, DC. }\end{array}$ \\
\hline $\begin{array}{l}\text { Public Service Co. of Colorado } \\
\text { (PSCO) / Southwestern Public } \\
\text { Service (SPS) } \\
\text { New Company: New Century } \\
\text { Energies }\end{array}$ & $\begin{array}{l}\text { Announced: } \\
8 / 23 / 95 \\
\text { Pending }\end{array}$ & $\begin{array}{l}\text { PSCO and SPS and their subsidiaries will be placed under the New Century Energies holding } \\
\text { company. Current SPS subsidiaries are Utility Engineering Corporation (engineering, design, and } \\
\text { construction management services) and Quixx Corp. (nonutility power generation projects). } \\
\text { PSCO subsidiaries include Cheyenne Light Fuel and Power Co., e prime (provides energy-related } \\
\text { products and services), and Natural Fuels Corp. (sells compressed natural gas as a } \\
\text { transportation fuel). }\end{array}$ \\
\hline $\begin{array}{l}\text { Kansas City Power and } \\
\text { Light (KCPL) / Utilicorp }\end{array}$ & $\begin{array}{l}\text { Announced: } \\
1 / 22 / 96 \\
\text { Rejected by } \\
\text { KCPL } \\
\text { shareholders } \\
10 / 27 / 96\end{array}$ & $\begin{array}{l}\text { A new KCPL subsidiary would have been created that would have been merged into Utilicorp. } \\
\text { Utilicorp then would have merged with KCPL to form the combined company. In filings with the } \\
\text { Federal Energy Regulatory Commission, the two utilities stated that they expected to save } \\
\text { approximately } \$ 600 \text { million from reduced fuel consumption, avoided capital expenditures and } \\
\text { duplications, consolidated internal computer and communications systems, combined workforces, } \\
\text { and improved use of facilities and inventories. KCPL is now subject to a hostile takeover by } \\
\text { Western Resources Inc., a Kansas-based combination electric/gas utility. }\end{array}$ \\
\hline
\end{tabular}

Source: Energy Information Administration, Office of Oil and Gas, derived from various industry news sources as of November 1996. 
Appendix B

Analysis of Firm Transportation Contracts: Results and Methodology 



\section{Appendix B}

\section{Analysis of Firm Transportation Contracts: Results and Methodology}

The analysis of firm transportation contracts in Chapter 2 uses data from the Index of Customers filed with the Federal Energy Regulatory Commission (FERC). The file was posted August 28, 1996, on the FERC Bulletin Board Network and contains data for the April 1, 1996, reporting period. According to the Index of Customers Manual page 2, "Each interstate pipeline regulated by the Commission that provides firm transportation or storage service under Subparts B or G of Part 284 of the Commission's regulations must file this information and post it on its EBB."

The pipeline companies must provide firm transportation contract information on customer names, rate schedules, begin dates, end dates, "rollover" or evergreen days (if any), maximum daily transportation and storage capacity, and units of measurements. The measurements can be reported in thousand cubic feet (Mcf), decatherms (Dth), or million Btu (MMBtu). For this analysis, all values are in MMBtu.

The units of measurement and contract begin and end dates were adjusted for several of the original Index of Customers (IOC) data. Units of measurement that were reported in Mcf were multiplied by 1.03 to convert to units in MMBtu. In this way, all IOC data were converted to equivalent units for the analysis ( $1 \mathrm{MMBtu}$ equals $1 \mathrm{Dth})$. In several cases, the contract begin and end dates were adjusted to show the actual expiration of rollover contracts. In some cases, rollover contracts had end dates that preceded April 1, 1996, indicating that the contract was operating on its rollover provision. In order to show the actual contract expiration date, multiples of the rollover days were added to the filed end date until the revised end date occurred after April 1, 1996. Once a revised end date was established, a revised begin date was derived by subtracting the stated rollover days from the revised end date. Thus, this analysis assumes that rollover contracts, which represented 8 percent of the total firm capacity under contract as of April 1, 1996, will not continue indefinitely into the future.

Once the IOC data were adjusted, the contract level data were used to analyze contract lengths. Then, the contract level data were sorted by pipeline company and grouped into six geographic regions of the United States for other analysis.

The regional divisions of the United States are from the Energy Information Administration report, Capacity and Service on the Interstate Natural Gas Pipeline System 1990. Each interstate pipeline company was assigned to a region based on its end-use deliveries. End-use deliveries were derived by adding State-level sales and transportation volumes of residential, commercial, industrial, nonutility power producers, and electric utility gas consumers as reported on Form EIA-176, "Annual Report of Natural and Supplemental Gas Supply and Disposition." The State values for individual pipeline companies were added together to get the regional total for a pipeline company. The pipeline company was then assigned to the region in which it had the largest volume of deliveries to end users

In addition to pipeline company and regional divisions, data for 1996 were broken down into three types of contracts (rollover, short term, and long term) based upon the newly calculated begin and end dates. If a contract had an end date of 1996 and a rollover amount, it was considered a rollover contract. Short-term contracts were any contracts that had an end date of 1996, no rollover amount, and a term of less than 1 year. Long-term contracts were contracts with end dates of 1996 , no rollover amount, and a contract length of 1 year or more. 
Table B1. Summary of FERC Index of Customers Data - Firm Transportation Capacity Under Contract as of April 1, 1996

\begin{tabular}{|c|c|c|c|c|c|c|}
\hline Pipeline Company Name & $\begin{array}{c}\text { FERC } \\
\text { Pipollino } \\
\text { Code }\end{array}$ & $\begin{array}{c}\text { Geographic } \\
\text { Reglon }\end{array}$ & $\begin{array}{l}\text { Total Capacity } \\
\text { Undor Contract } \\
\text { as of April 1, } 1996\end{array}$ & $\begin{array}{c}\text { Rollover and } \\
\text { Short-Term } \\
\text { Capactty Explring } \\
1996 \\
\end{array}$ & $\begin{array}{c}\text { Long-Term } \\
\text { Capacity Expiring } \\
1996 \\
\end{array}$ & $\begin{array}{c}\text { Total } \\
\text { Capaclty Expling } \\
1996 \\
\end{array}$ \\
\hline $\begin{array}{l}\text { Canyon Creok Compression Company } \\
\text { Colorado Intorstate Gas Company } \\
\text { KN Interstato Gas Transmission Co. } \\
\text { Miga, Inc. } \\
\text { Nonthern Border Pipeline Company } \\
\text { Northem Natural Gas Company } \\
\text { Questar Pipeline Company } \\
\text { Trailblazer Pipeline Company } \\
\text { Williams Natural Gas Company } \\
\text { Whliston Basin Intorstate Pipeline Company } \\
\text { Wyoming Interstate Company, Ltd. } \\
\text { Total Central }\end{array}$ & $\begin{array}{l}067 \\
032 \\
053 \\
047 \\
089 \\
059 \\
055 \\
068 \\
043 \\
049 \\
076\end{array}$ & $\begin{array}{l}\text { CE } \\
C E \\
C E \\
C E \\
C E \\
C E \\
C E \\
C E \\
C E \\
C E \\
C E\end{array}$ & $\begin{array}{r}225,764 \\
2,096,216 \\
612,454 \\
12,000 \\
1,684,194 \\
4,813,245 \\
1,093,946 \\
284,271 \\
2,697,941 \\
427,394 \\
500,000 \\
14,447,425\end{array}$ & $\begin{array}{r}2,000 \\
96,940 \\
381,586 \\
0 \\
0 \\
180,225 \\
134,847 \\
110,111 \\
716,097 \\
450 \\
0 \\
1,622,256\end{array}$ & $\begin{array}{r}0 \\
1,343,335 \\
107,731 \\
0 \\
0 \\
0 \\
264,159 \\
8,349 \\
50,280 \\
71,278 \\
6,764 \\
58,000 \\
1,909,896\end{array}$ & $\begin{array}{r}2,000 \\
1,440,275 \\
489,317 \\
0 \\
0 \\
444,384 \\
143,196 \\
160,391 \\
787,375 \\
7,214 \\
58,000 \\
3,532,152\end{array}$ \\
\hline $\begin{array}{l}\text { ANR Pipeline Company } \\
\text { Crossroads Pipeline Company } \\
\text { Great Lakos Gas Transmission Limitod Partnorshif } \\
\text { Michigan Gas Storago Company } \\
\text { Mid Louisiana Gas Company } \\
\text { Midwestam Gas Transmission Company } \\
\text { Mississippi River Transmission Corporation } \\
\text { Natural Gas Pipeline Co. Of America } \\
\text { Panhandb Eastem Pipe Line Company } \\
\text { Toxas Gas Transmission Corporation } \\
\text { Trunkline Gas Company } \\
\text { Viking Gas Transmission Company } \\
\text { Total Mitwest }\end{array}$ & $\begin{array}{l}048 \\
123 \\
051 \\
124 \\
015 \\
005 \\
025 \\
026 \\
028 \\
018 \\
030 \\
082\end{array}$ & $\begin{array}{l}M W \\
M W \\
M W \\
M W \\
M W \\
M W \\
M W \\
M W \\
M W \\
M W \\
M W\end{array}$ & $\begin{array}{r}4,367,844 \\
91,769 \\
3,895,797 \\
2,700,000 \\
130,383 \\
762,090 \\
1,600,841 \\
7,113,877 \\
2,540,173 \\
1,641,239 \\
2,059,353 \\
472,401 \\
27,375,767\end{array}$ & $\begin{array}{r}28,110 \\
91,769 \\
1,229,526 \\
2,490,000 \\
0 \\
700 \\
252,349 \\
518,506 \\
88,090 \\
0 \\
223,632 \\
63,529 \\
4,986,211\end{array}$ & $\begin{array}{r}159,924 \\
0 \\
0 \\
0 \\
67,899 \\
37,800 \\
192,314 \\
258,757 \\
343,525 \\
69,267 \\
343,269 \\
4,680 \\
1,477,435\end{array}$ & $\begin{array}{r}188,034 \\
91,769 \\
1,229,526 \\
2,490,000 \\
67,899 \\
38,500 \\
444,663 \\
777,263 \\
431,615 \\
68,267 \\
566,001 \\
68,209 \\
6,463,646\end{array}$ \\
\hline $\begin{array}{l}\text { Algonquin Gas Transmission Company } \\
\text { Camegio Interstate Pipeline Company } \\
\text { CNG Transmission Conp. } \\
\text { Columbia Gas Transmission Corporation } \\
\text { Columbia Gulf Transmission Company } \\
\text { Cove Point Lng Limited Partmership } \\
\text { Equitrans Inc } \\
\text { Granite State Gas Transmission,lnc. } \\
\text { Iroquois Pipeline Operating Company } \\
\text { Kontuck West Virginis Gas Co } \\
\text { National Fuel Gas Supply Corporation } \\
\text { Nora Transmission Co } \\
\text { Tennesseo Gas Pipeline Company } \\
\text { Toxes Eastom Transmission Corporation } \\
\text { Transcontinontal Gas Pipe Line Corp. } \\
\text { Total Northeast }\end{array}$ & $\begin{array}{l}020 \\
120 \\
022 \\
021 \\
070 \\
127 \\
024 \\
004 \\
110 \\
046 \\
016 \\
100 \\
009 \\
017 \\
029\end{array}$ & $\begin{array}{l}\text { NE } \\
N E \\
N E \\
N E \\
N E \\
N E \\
N E \\
N E \\
N E \\
N E \\
N E \\
N E \\
N E \\
N E \\
N E\end{array}$ & $\begin{array}{r}1,812,309 \\
85,000 \\
4,750,112 \\
8,911,651 \\
3,345,481 \\
24,000 \\
358,798 \\
177,367 \\
876846 \\
138,442 \\
1,853,613 \\
35,000 \\
5,655,492 \\
4,098,907 \\
5,518,592 \\
37,641,610\end{array}$ & $\begin{array}{r}62,912 \\
0 \\
120,000 \\
225,408 \\
324,799 \\
0 \\
20,117 \\
0 \\
62624 \\
31,172 \\
9,813 \\
35,000 \\
282,052 \\
1,678 \\
400,297 \\
1,575,872\end{array}$ & $\begin{array}{r}182,620 \\
0 \\
16,600 \\
16,243 \\
686,404 \\
0 \\
0 \\
0 \\
0 \\
0 \\
3,743 \\
0 \\
74,792 \\
9,500 \\
10,000 \\
999,902\end{array}$ & $\begin{array}{r}245,532 \\
0 \\
136,600 \\
241,651 \\
1,011,203 \\
0 \\
20,117 \\
0 \\
62624 \\
31,172 \\
13,556 \\
35,000 \\
356,844 \\
11,178 \\
410,297 \\
2,575,774\end{array}$ \\
\hline $\begin{array}{l}\text { Alabama-Tennesseo Natural Gas Company } \\
\text { East Tennessee Natural Gas Company } \\
\text { Florida Gas Transmission Company } \\
\text { Mobile Bay Pipolino Company } \\
\text { South Georgia Natural Gas Company } \\
\text { Southem Natural Gas Company } \\
\text { Total Southeast }\end{array}$ & $\begin{array}{l}001 \\
002 \\
034 \\
114 \\
008 \\
007\end{array}$ & $\begin{array}{l}\text { SE } \\
\text { SE } \\
\text { SE } \\
\text { SE } \\
\text { SE } \\
\text { SE }\end{array}$ & $\begin{array}{r}132,502 \\
598,108 \\
1,532,921 \\
27,885 \\
114,341 \\
2,557,874 \\
4,963,629\end{array}$ & $\begin{array}{r}205 \\
25,083 \\
50,215 \\
0 \\
8,941 \\
178,848 \\
263,292\end{array}$ & $\begin{array}{r}23,316 \\
150 \\
15,765 \\
0 \\
6,452 \\
41,289 \\
86,972\end{array}$ & $\begin{array}{r}23,521 \\
25,233 \\
65,980 \\
0 \\
15,393 \\
220,137 \\
350,264\end{array}$ \\
\hline $\begin{array}{l}\text { Black Marlin Pipeline Company } \\
\text { High Island Offshore System } \\
\text { Koch Gatoway Pipolino Company } \\
\text { Noram Gas Transmission Company } \\
\text { Oktox Pipeline Company } \\
\text { Ozark Gas Transmission System } \\
\text { Sabine Pipe Line Company } \\
\text { Soa Robin Pipeline Company } \\
\text { Stingray Pipeline Company } \\
\text { Total Southwest }\end{array}$ & $\begin{array}{l}088 \\
077 \\
011 \\
031 \\
116 \\
073 \\
079 \\
006 \\
069\end{array}$ & $\begin{array}{l}\text { SW } \\
\text { SW } \\
\text { SW } \\
\text { SW } \\
\text { SW } \\
\text { SW } \\
\text { SW } \\
\text { SW } \\
\text { SW }\end{array}$ & $\begin{array}{r}250,383 \\
215,460 \\
2,370,751 \\
2,729,150 \\
33,600 \\
124,333 \\
185,000 \\
159,275 \\
167,181 \\
6,235,133\end{array}$ & $\begin{array}{r}26,383 \\
0 \\
0 \\
586,091 \\
0 \\
109,333 \\
100,000 \\
10,948 \\
58,450 \\
891,205\end{array}$ & $\begin{array}{r}0 \\
194,180 \\
0 \\
0 \\
200,617 \\
0 \\
0 \\
0 \\
25,000 \\
0 \\
0 \\
419,797\end{array}$ & $\begin{array}{r}26,383 \\
194,180 \\
0 \\
788,708 \\
0 \\
109,333 \\
125,000 \\
10,948 \\
58,450 \\
1,311,002\end{array}$ \\
\hline $\begin{array}{l}\text { El Paso Natural Gas Company } \\
\text { Kom River Gas Transmission Company } \\
\text { Mojavo Pipeline Company } \\
\text { Northwest Pipeline Corporation } \\
\text { Pacific Gas Transmission Company } \\
\text { Pacific Interstate Offshore Company } \\
\text { Paiure Pipeline Company } \\
\text { Riverside Pipeline Company L.P. } \\
\text { Transwostern Pipolino Company } \\
\text { Tuscarora Gas Transmission Company } \\
\text { Total West }\end{array}$ & $\begin{array}{l}033 \\
099 \\
092 \\
037 \\
086 \\
064 \\
041 \\
128 \\
042 \\
126\end{array}$ & $\begin{array}{l}\text { WE } \\
\text { WE } \\
\text { WE } \\
\text { WE } \\
\text { WE } \\
\text { WE } \\
\text { WE } \\
\text { WE } \\
\text { WE } \\
\text { WE }\end{array}$ & $\begin{array}{r}3,978,504 \\
730,000 \\
2,681,600 \\
3,533,131 \\
2,847,102 \\
35,000 \\
138,780 \\
130,000 \\
2,536,948 \\
106,250 \\
16,717,315\end{array}$ & $\begin{array}{r}334,221 \\
25,000 \\
1,396,500 \\
151,033 \\
0 \\
0 \\
0 \\
0 \\
614,612 \\
0 \\
2,521,366\end{array}$ & $\begin{array}{r}24,830 \\
0 \\
0 \\
232,191 \\
0 \\
0 \\
0 \\
0 \\
20,000 \\
0 \\
277,021\end{array}$ & $\begin{array}{r}359,051 \\
25,000 \\
1,396,500 \\
383,224 \\
0 \\
0 \\
0 \\
0 \\
634,612 \\
0 \\
2,798,387\end{array}$ \\
\hline Total & & & $107,380,879$ & $11,860,202$ & $5,171,023$ & $17,031,225$ \\
\hline
\end{tabular}


Table B1. Summary of FERC Index of Customers Data - Firm Transportation Capacity Under Contract as of April 1, 1996 (Continued)

\begin{tabular}{|c|c|c|c|c|c|}
\hline Plpollne Company Name & $\begin{array}{c}\text { Total } \\
\text { Capaclty Expiring } \\
1997\end{array}$ & $\begin{array}{c}\text { Total } \\
\text { Capaclty Expiring } \\
1998\end{array}$ & $\begin{array}{c}\text { Total } \\
\text { Capaclty Expiring } \\
1999\end{array}$ & $\begin{array}{c}\text { Total } \\
\text { Capaclty Expiring } \\
2000 \\
\end{array}$ & $\begin{array}{c}\text { Total } \\
\text { Capacity Explring } \\
2001\end{array}$ \\
\hline $\begin{array}{l}\text { Canyon Crook Compression Company } \\
\text { Colorado Intorstato Gas Company } \\
\text { KN Intorstato Gas Transmission Co. } \\
\text { Migc, Inc. } \\
\text { Northom Bordor Pipolino Company } \\
\text { Northem Natural Gas Company } \\
\text { Questar Pipelino Company } \\
\text { Trailblazor Pipoline Company } \\
\text { Williams Natural Gas Company } \\
\text { Williston Basin Intorstato Pipolino Company } \\
\text { Wyoming Interstate Company, Ltd. } \\
\text { Total Central }\end{array}$ & $\begin{array}{r}0 \\
44,907 \\
16,670 \\
0 \\
0 \\
1,914,625 \\
54,284 \\
62,400 \\
70,002 \\
470,913 \\
5,680 \\
2,579,481\end{array}$ & $\begin{array}{r}0 \\
34,171 \\
9,950 \\
0 \\
0 \\
61,687 \\
50,924 \\
0 \\
538,694 \\
86 \\
19,320 \\
714,832\end{array}$ & $\begin{array}{r}47,746 \\
16,932 \\
0 \\
0 \\
0 \\
10,400 \\
798,902 \\
51,940 \\
339,282 \\
0 \\
0 \\
1,265,202\end{array}$ & $\begin{array}{r}0 \\
61,365 \\
2,850 \\
12,000 \\
0 \\
8,248 \\
0 \\
0 \\
0 \\
277 \\
0 \\
84,740\end{array}$ & $\begin{array}{r}0 \\
60,000 \\
16,200 \\
0 \\
850,541 \\
45,824 \\
15,700 \\
0 \\
14,925 \\
0 \\
0 \\
1,003,190\end{array}$ \\
\hline $\begin{array}{l}\text { ANR Pipoline Company } \\
\text { Crossroads Pipeline Company } \\
\text { Great Lokes Gas Transmission Limited Partnershij } \\
\text { Michigan Gas Storago Company } \\
\text { Mid Louisiana Gas Company } \\
\text { Midwestorn Gas Transmission Company } \\
\text { Mississippi River Transmission Corporation } \\
\text { Natural Gas Pipeline Co. Of America } \\
\text { Panhandle Eastom Pipe Lino Company } \\
\text { Texas Gas Transmission Corporation } \\
\text { Trunklino Gas Company } \\
\text { Viking Gas Transmission Company } \\
\text { Total MIdwest }\end{array}$ & $\begin{array}{r}268,814 \\
0 \\
176,000 \\
0 \\
0 \\
1,500 \\
20,624 \\
664,079 \\
529,346 \\
221,104 \\
275,953 \\
19,912 \\
2,177,332\end{array}$ & $\begin{array}{r}123,876 \\
0 \\
12,000 \\
0 \\
62,484 \\
14,355 \\
20,400 \\
2,343,801 \\
342,868 \\
375,379 \\
161,095 \\
55,350 \\
3,517,608\end{array}$ & $\begin{array}{r}280,416 \\
0 \\
15,250 \\
0 \\
0 \\
0 \\
825,160 \\
323,741 \\
408,055 \\
157,210 \\
24,816 \\
0 \\
2,034,648\end{array}$ & $\begin{array}{r}564,662 \\
0 \\
252,325 \\
0 \\
0 \\
317,742 \\
0 \\
2,378,036 \\
235,670 \\
136,663 \\
403,115 \\
256,798 \\
4,545,011\end{array}$ & $\begin{array}{r}24,391 \\
0 \\
6,716 \\
0 \\
0 \\
0 \\
0 \\
194,291 \\
4,508 \\
135,000 \\
35,000 \\
0 \\
399,906\end{array}$ \\
\hline $\begin{array}{l}\text { Algonquin Gas Transmission Company } \\
\text { Camegio Intorstato Pipeline Company } \\
\text { CNG Transmission Corp. } \\
\text { Columbia Gas Transmission Corporation } \\
\text { Columbia Gulf Transmission Company } \\
\text { Cove Point Lng Limited Partnership } \\
\text { Equitrans Inc } \\
\text { Granite State Gas Transmission, Inc. } \\
\text { Iroquois Pipoline Operating Company } \\
\text { Kontucky West Virginie Gas Co } \\
\text { Nationol Fuol Gas Supply Corporation } \\
\text { Nora Transmission Co } \\
\text { Tennesseo Gas Pipoline Company } \\
\text { Texas Eastem Transmission Corporation } \\
\text { Transcontinental Gas Pipe Line Corp. } \\
\text { Total Northeast }\end{array}$ & $\begin{array}{r}13,391 \\
62,000 \\
8,320 \\
50,574 \\
188,000 \\
0 \\
1,400 \\
0 \\
20703 \\
107,270 \\
6,263 \\
0 \\
176,633 \\
0 \\
37,900 \\
672,454\end{array}$ & $\begin{array}{r}0 \\
10,000 \\
3,070 \\
114,177 \\
160,288 \\
0 \\
0 \\
0 \\
21 \\
0 \\
0 \\
0 \\
73,461 \\
4,234 \\
151,039 \\
516,290\end{array}$ & $\begin{array}{r}75,448 \\
13,000 \\
5,875 \\
8,000 \\
31,198 \\
0 \\
500 \\
0 \\
0 \\
0 \\
9,964 \\
0 \\
23,812 \\
690,016 \\
93,400 \\
951,213\end{array}$ & $\begin{array}{r}91,794 \\
0 \\
0 \\
3,880 \\
1,302 \\
0 \\
18,288 \\
170,247 \\
3387 \\
0 \\
12,580 \\
0 \\
3,892,032 \\
454,457 \\
343,925 \\
4,991,892\end{array}$ & $\begin{array}{r}0 \\
0 \\
1,958,340 \\
0 \\
0 \\
0 \\
0 \\
276,000 \\
0 \\
0 \\
0 \\
0 \\
0 \\
14,000 \\
104,313 \\
63,279 \\
2,415,932\end{array}$ \\
\hline $\begin{array}{l}\text { Alabama-Tonnesseo Natural Gas Company } \\
\text { East Tennesseo Natural Gas Company } \\
\text { Florida Gas Transmission Company } \\
\text { Mobilo Bay Pipoline Company } \\
\text { South Georgia Natural Gas Company } \\
\text { Southorn Natural Gas Company } \\
\text { Total Southeast }\end{array}$ & $\begin{array}{r}18,006 \\
300 \\
7.726 \\
0 \\
10,153 \\
78,924 \\
115,109\end{array}$ & $\begin{array}{r}35,815 \\
0 \\
1,000 \\
0 \\
0 \\
676,292 \\
713,107\end{array}$ & $\begin{array}{r}0 \\
0 \\
8,301 \\
27,885 \\
300 \\
117,209 \\
153,695\end{array}$ & $\begin{array}{r}42,165 \\
474,638 \\
422,097 \\
0 \\
373 \\
221,483 \\
1,160,756\end{array}$ & $\begin{array}{r}12,995 \\
0 \\
0 \\
0 \\
0 \\
13,694 \\
26,689\end{array}$ \\
\hline $\begin{array}{l}\text { Black Marlin Pipoline Company } \\
\text { High Island Offshore System } \\
\text { Koch Gatoway Pipeline Company } \\
\text { Noram Gas Transmission Company } \\
\text { Oktox Pipolino Company } \\
\text { Ozark Gas Transmission Systom } \\
\text { Sabine Pipe Line Company } \\
\text { Soa Robin Pipeline Company } \\
\text { Stingray Pipeline Company } \\
\text { Total Southwest }\end{array}$ & $\begin{array}{r}135,000 \\
0 \\
683,325 \\
210,602 \\
0 \\
15,000 \\
60,000 \\
108,327 \\
0 \\
1,212,254\end{array}$ & $\begin{array}{r}0 \\
0 \\
57,979 \\
205,368 \\
0 \\
0 \\
0 \\
0 \\
0 \\
263,347\end{array}$ & $\begin{array}{r}75,000 \\
0 \\
1,629,447 \\
35,225 \\
17600 \\
0 \\
0 \\
0 \\
0 \\
1,757,272\end{array}$ & $\begin{array}{r}14,000 \\
21,280 \\
0 \\
1,126,582 \\
0 \\
0 \\
0 \\
0 \\
40,000 \\
0 \\
1,201,862\end{array}$ & $\begin{array}{r}0 \\
0 \\
0 \\
62,600 \\
16000 \\
0 \\
0 \\
0 \\
3,893 \\
82,493\end{array}$ \\
\hline $\begin{array}{l}\text { El Paso Natural Gas Company } \\
\text { Korn River Gas Transmission Company } \\
\text { Mojavo Pipolino Company } \\
\text { Northwost Pipoline Corporation } \\
\text { Pacific Gas Transmission Company } \\
\text { Pacific Intorstato Offshore Company } \\
\text { Paiute Pipoline Company } \\
\text { Rivorside Pipolino Company L.P. } \\
\text { Transwesstern Pipeline Company } \\
\text { Tuscarora Gas Transmission Company } \\
\text { Total West }\end{array}$ & $\begin{array}{r}1,196,220 \\
0 \\
380,100 \\
11,934 \\
0 \\
0 \\
0 \\
0 \\
55,400 \\
0 \\
1,643,654\end{array}$ & $\begin{array}{r}0 \\
0 \\
200,000 \\
7,250 \\
0 \\
35,000 \\
0 \\
0 \\
20,000 \\
0 \\
262,250\end{array}$ & $\begin{array}{r}100,000 \\
0 \\
0 \\
91,200 \\
0 \\
0 \\
0 \\
0 \\
0 \\
0 \\
191,200\end{array}$ & $\begin{array}{r}148,335 \\
0 \\
0 \\
0 \\
0 \\
0 \\
0 \\
0 \\
290,249 \\
0 \\
438,584\end{array}$ & $\begin{array}{r}1,023 \\
0 \\
0 \\
61,500 \\
0 \\
0 \\
0 \\
0 \\
60.714 \\
0 \\
123.237\end{array}$ \\
\hline Total & $8,400,284$ & $5,981,434$ & $6,353,230$ & $12,422,845$ & $4,051,447$ \\
\hline
\end{tabular}


Table B1. Summary of FERC Index of Customers Data - Firm Transportation Capacity Under Contract as of April 1, 1996 (Continued)




Table B1. Summary of FERC Index of Customers Data - Firm Transportation Capacity Under Contract as of April 1, 1996 (Continued)

\begin{tabular}{|c|c|c|c|c|c|}
\hline Plpelline Company Name & $\begin{array}{c}\text { Total } \\
\text { Capacity Expiring } \\
2007 \\
\end{array}$ & $\begin{array}{c}\text { Total } \\
\text { Capacity Expiring } \\
2008 \\
\end{array}$ & $\begin{array}{c}\text { Total } \\
\text { Capacity Expiring } \\
2009 \\
\end{array}$ & $\begin{array}{c}\text { Total } \\
\text { Capacity Expiring } \\
2010 \\
\end{array}$ & $\begin{array}{c}\text { Total } \\
\text { Capacity Expiring } \\
2011 \\
\end{array}$ \\
\hline $\begin{array}{l}\text { Canyon Creok Compression Company } \\
\text { Colorado Interstate Gas Company } \\
\text { KN Interstate Gas Transmission Co. } \\
\text { Migc, Inc. } \\
\text { Northem Border Pipeline Company } \\
\text { Northem Natural Gas Company } \\
\text { Questar Pipolino Company } \\
\text { Trailblazer Pipoline Company } \\
\text { Williams Natural Gas Company } \\
\text { Williston Basin Interstate Pipoline Company } \\
\text { Wyoming Interstate Company, Ltd. } \\
\text { Tolal Contral }\end{array}$ & $\begin{array}{r}0 \\
13,051 \\
0 \\
0 \\
59,085 \\
589,912 \\
10,177 \\
0 \\
0 \\
0 \\
0 \\
672,225\end{array}$ & $\begin{array}{r}0 \\
38,952 \\
0 \\
0 \\
112,590 \\
1,300 \\
0 \\
0 \\
7,852 \\
0 \\
0 \\
160,694\end{array}$ & $\begin{array}{r}0 \\
24,100 \\
0 \\
0 \\
47,347 \\
9,220 \\
0 \\
0 \\
0 \\
0 \\
0 \\
80,667\end{array}$ & $\begin{array}{r}0 \\
6,000 \\
64,867 \\
0 \\
135,565 \\
30,000 \\
0 \\
0 \\
198 \\
0 \\
0 \\
236,630\end{array}$ & $\begin{array}{r}0 \\
8,600 \\
0 \\
0 \\
0 \\
35,000 \\
763 \\
0 \\
0 \\
0 \\
0 \\
44,363\end{array}$ \\
\hline $\begin{array}{l}\text { ANR Pipeline Company } \\
\text { Crossroads Pipeline Company } \\
\text { Groat Lakes Gas Transmission Limited Partnershif } \\
\text { Michigan Gas Storago Company } \\
\text { Mid Louisiana Ges Company } \\
\text { Midwestem Gas Transmission Company } \\
\text { Mississippi River Transmission Corporation } \\
\text { Natural Gas Pipoline Co. Of America } \\
\text { Panhandle Eastom Pipe Line Company } \\
\text { Toxas Gas Transmission Corporation } \\
\text { Trunklino Gas Company } \\
\text { Viking Gas Transmission Company } \\
\text { Total Mldwest }\end{array}$ & $\begin{array}{r}12,822 \\
0 \\
0 \\
0 \\
0 \\
0 \\
0 \\
200,000 \\
0 \\
34,272 \\
31,050 \\
0 \\
278,144\end{array}$ & $\begin{array}{r}526,993 \\
0 \\
213,500 \\
0 \\
0 \\
0 \\
0 \\
106,000 \\
0 \\
0 \\
0 \\
47,400 \\
893,893\end{array}$ & $\begin{array}{r}35,958 \\
0 \\
0 \\
0 \\
0 \\
0 \\
0 \\
31,258 \\
0 \\
0 \\
0 \\
0 \\
67,216\end{array}$ & $\begin{array}{r}33,115 \\
0 \\
15,000 \\
0 \\
0 \\
0 \\
0 \\
0 \\
0 \\
0 \\
0 \\
507 \\
48,622\end{array}$ & $\begin{array}{r}470,760 \\
0 \\
85,000 \\
0 \\
0 \\
0 \\
0 \\
0 \\
0 \\
14 \\
0 \\
0 \\
555,774\end{array}$ \\
\hline $\begin{array}{l}\text { Algonquin Gas Transmission Company } \\
\text { Camegie Interstate Pipeline Company } \\
\text { CNG Transmission Corp. } \\
\text { Columbia Gas Transmission Corporation } \\
\text { Columbia Gulf Transmission Company } \\
\text { Cove Point Lng Limited Pertnorship } \\
\text { Equitrans Ine } \\
\text { Granite State Gas Transmission, Inc. } \\
\text { lroquois Pipolino Operating Company } \\
\text { Kentucky West Virginia Gas Co } \\
\text { National Fuol Gas Supply Corporation } \\
\text { Nora Transmission Co } \\
\text { Tennessee Gas Pipeline Company } \\
\text { Texas Eastern Transmission Corporation } \\
\text { Transcontinental Gas Pipo Line Corp. } \\
\text { Total Northeast }\end{array}$ & $\begin{array}{r}0 \\
0 \\
118,687 \\
0 \\
0 \\
0 \\
0 \\
0 \\
0 \\
0 \\
112,558 \\
0 \\
28,300 \\
18,000 \\
107,427 \\
384,972\end{array}$ & $\begin{array}{r}40,000 \\
0 \\
294,213 \\
61,699 \\
12,027 \\
0 \\
0 \\
0 \\
0 \\
0 \\
5,816 \\
0 \\
0 \\
140,000 \\
53,648 \\
607,403\end{array}$ & $\begin{array}{r}132,929 \\
0 \\
11,100 \\
106,189 \\
62,089 \\
0 \\
0 \\
0 \\
16995 \\
0 \\
0 \\
0 \\
0 \\
79,120 \\
224,000 \\
632,422\end{array}$ & $\begin{array}{r}37,192 \\
0 \\
45,850 \\
102,097 \\
4,601 \\
0 \\
0 \\
0 \\
0 \\
0 \\
0 \\
0 \\
65,096 \\
92,306 \\
595,546 \\
942,688\end{array}$ & $\begin{array}{r}221,400 \\
0 \\
187,438 \\
84,500 \\
21,583 \\
0 \\
0 \\
0 \\
143273 \\
0 \\
0 \\
0 \\
134,150 \\
29,000 \\
30,050 \\
851,394\end{array}$ \\
\hline $\begin{array}{l}\text { Alobama-Tonnesseo Natural Gas Company } \\
\text { East Tonnessoe Natural Gas Company } \\
\text { Florida Gas Transmission Company } \\
\text { Mobilo Bay Pipoline Company } \\
\text { South Georgia Natural Gas Company } \\
\text { Southorn Natural Gas Company } \\
\text { Total Southeast }\end{array}$ & $\begin{array}{r}0 \\
0 \\
50,651 \\
0 \\
11,877 \\
270,699 \\
333,227\end{array}$ & $\begin{array}{r}0 \\
0 \\
0 \\
0 \\
0 \\
392,870 \\
392,870\end{array}$ & $\begin{array}{r}0 \\
0 \\
0 \\
0 \\
0 \\
13,000 \\
13,000\end{array}$ & $\begin{array}{r}0 \\
19,973 \\
0 \\
0 \\
0 \\
0 \\
19,973\end{array}$ & $\begin{array}{l}0 \\
0 \\
0 \\
0 \\
0 \\
0 \\
0\end{array}$ \\
\hline $\begin{array}{l}\text { Black Marlin Pipeline Company } \\
\text { High Island Offshore System } \\
\text { Koch Gatoway Pipelins Company } \\
\text { Noram Gas Transmission Company } \\
\text { Oktox Pipolino Company } \\
\text { Ozark Gas Transmission System } \\
\text { Sabine Pipe Lino Company } \\
\text { Soa Robin Pipolino Company } \\
\text { Stingray Pipelino Company } \\
\text { Total Southwost }\end{array}$ & $\begin{array}{l}0 \\
0 \\
0 \\
0 \\
0 \\
0 \\
0 \\
0 \\
0 \\
0\end{array}$ & $\begin{array}{l}\mathbf{0} \\
0 \\
0 \\
0 \\
0 \\
0 \\
0 \\
0 \\
0 \\
0 \\
0\end{array}$ & $\begin{array}{l}0 \\
0 \\
0 \\
0 \\
0 \\
0 \\
0 \\
0 \\
0 \\
0\end{array}$ & $\begin{array}{l}0 \\
0 \\
0 \\
0 \\
0 \\
0 \\
0 \\
0 \\
0 \\
0\end{array}$ & $\begin{array}{l}\mathbf{0} \\
0 \\
0 \\
0 \\
0 \\
0 \\
0 \\
0 \\
0 \\
0\end{array}$ \\
\hline $\begin{array}{l}\text { El Paso Natural Gas Company } \\
\text { Kern River Gas Transmission Company } \\
\text { Mojave Pipeline Company } \\
\text { Northwest Pipeline Corporation } \\
\text { Pacific Gas Transmission Company } \\
\text { Pacifie Interstate Offehore Company } \\
\text { Paiute Pipeline Company } \\
\text { Rivorside Pipolino Company L.P. } \\
\text { Transwestem Pipolino Company } \\
\text { Tuscarora Ges Transmission Company } \\
\text { Total West }\end{array}$ & $\begin{array}{r}690,525 \\
705,000 \\
140,000 \\
102,037 \\
0 \\
0 \\
0 \\
0 \\
470,000 \\
0 \\
2,107,562\end{array}$ & $\begin{array}{r}0 \\
0 \\
0 \\
525,045 \\
0 \\
0 \\
0 \\
0 \\
0 \\
0 \\
525,045\end{array}$ & $\begin{array}{r}0 \\
0 \\
0 \\
269,761 \\
15,708 \\
0 \\
0 \\
130,000 \\
0 \\
0 \\
415,469\end{array}$ & $\begin{array}{r}0 \\
0 \\
0 \\
153,175 \\
0 \\
0 \\
0 \\
0 \\
0 \\
0 \\
153,175\end{array}$ & $\begin{array}{r}0 \\
0 \\
0 \\
0 \\
20,000 \\
0 \\
0 \\
0 \\
0 \\
0 \\
20,000\end{array}$ \\
\hline Total & $3,776,130$ & $2,579,905$ & $7,208,774$ & $1,401,088$ & $1,471,531$ \\
\hline
\end{tabular}


Table B1. Summary of FERC Index of Customers Data - Firm Transportation Capacity Under Contract as of April 1, 1996 (Continued)

\begin{tabular}{|c|c|c|c|c|c|}
\hline Plpellne Company Name & $\begin{array}{c}\text { Total } \\
\text { Capacity Expiring } \\
2012 \\
\end{array}$ & $\begin{array}{c}\text { Total } \\
\text { Capacity Expiring } \\
2013 \\
\end{array}$ & $\begin{array}{c}\text { Total } \\
\text { Capacity Expiring } \\
2014 \\
\end{array}$ & $\begin{array}{c}\text { Total } \\
\text { Capacity Expiring } \\
2016 \\
\end{array}$ & $\begin{array}{c}\text { Total } \\
\text { Capacity Expiring } \\
2016 \\
\end{array}$ \\
\hline $\begin{array}{l}\text { Canyon Creok Compression Company } \\
\text { Colorado Interstate Gas Company } \\
\text { KN Interstate Gas Transmission Co. } \\
\text { Migc, Inc. } \\
\text { Northom Border Pipelino Company } \\
\text { Northom Natural Gas Company } \\
\text { Questar Pipeline Company } \\
\text { Trailblazer Pipolino Company } \\
\text { Williams Natural Gas Company } \\
\text { Williston Basin Intorstato Pipoline Company } \\
\text { Wyoming Interstate Company, Ltd. } \\
\text { Total Central }\end{array}$ & $\begin{array}{r}0 \\
0 \\
0 \\
0 \\
39,409 \\
0 \\
0 \\
0 \\
0 \\
8,000 \\
0 \\
47,409\end{array}$ & $\begin{array}{r}0 \\
0 \\
0 \\
0 \\
0 \\
0 \\
0 \\
0 \\
908,214 \\
461 \\
0 \\
908,675\end{array}$ & $\begin{array}{l}0 \\
0 \\
0 \\
0 \\
0 \\
0 \\
0 \\
0 \\
0 \\
0 \\
0 \\
0\end{array}$ & $\begin{array}{r}0 \\
0 \\
0 \\
0 \\
0 \\
0 \\
0 \\
0 \\
3,412 \\
0 \\
0 \\
3,412\end{array}$ & $\begin{array}{l}0 \\
0 \\
0 \\
0 \\
0 \\
0 \\
0 \\
0 \\
0 \\
0 \\
0 \\
0\end{array}$ \\
\hline $\begin{array}{l}\text { ANR Pipeline Company } \\
\text { Crossroads Pipeline Company } \\
\text { Great Lakes Gas Transmission Limited Partnershif } \\
\text { Michigan Gas Storago Company } \\
\text { Mid Louisiana Gas Company } \\
\text { Midwestem Gas Transmission Company } \\
\text { Mississippi River Transmission Corporation } \\
\text { Natural Gas Pipeline Co. Of America } \\
\text { Panhandle Eastem Pipe Line Company } \\
\text { Texas Gas Transmission Corporation } \\
\text { Trunkline Gas Company } \\
\text { Viking Gas Transmission Company } \\
\text { Total Mldwest }\end{array}$ & $\begin{array}{l}0 \\
0 \\
0 \\
0 \\
0 \\
0 \\
0 \\
0 \\
0 \\
0 \\
0 \\
0 \\
0\end{array}$ & $\begin{array}{r}106,276 \\
0 \\
57,398 \\
0 \\
0 \\
0 \\
0 \\
0 \\
0 \\
10,450 \\
0 \\
99,672 \\
0 \\
273,796\end{array}$ & $\begin{array}{r}207,900 \\
0 \\
0 \\
0 \\
0 \\
0 \\
0 \\
0 \\
38,315 \\
0 \\
27,303 \\
0 \\
273,518\end{array}$ & $\begin{array}{r}0 \\
0 \\
168,203 \\
0 \\
0 \\
0 \\
0 \\
0 \\
50,093 \\
0 \\
0 \\
0 \\
218,296\end{array}$ & $\begin{array}{r}0 \\
0 \\
0 \\
0 \\
0 \\
0 \\
0 \\
0 \\
0 \\
138,998 \\
0 \\
0 \\
0 \\
138,998\end{array}$ \\
\hline $\begin{array}{l}\text { Algonquin Gas Transmission Company } \\
\text { Carnegie Interstate Pipeline Company } \\
\text { CNG Transmission Corp. } \\
\text { Columbia Gas Transmission Corporation } \\
\text { Columbia Gulf Transmission Company } \\
\text { Cove Point Lng Linited Partnership } \\
\text { Equitrans Inc } \\
\text { Granite State Gas Transmission, Inc. } \\
\text { Iroquois Pipoline Operating Company } \\
\text { Kentucky West Virginia Gas Co } \\
\text { National Fuol Gas Supply Corporation } \\
\text { Nora Transmission Co } \\
\text { Tennessee Gas Pipoline Company } \\
\text { Toxas Eastem Transmission Corporation } \\
\text { Transcontinental Gas Pipe Line Corp. } \\
\text { Tota! Northeast }\end{array}$ & $\begin{array}{r}584,857 \\
0 \\
112,500 \\
55,000 \\
0 \\
0 \\
0 \\
7,120 \\
490229 \\
0 \\
0 \\
0 \\
284,263 \\
1,044,194 \\
414,648 \\
2,992,811\end{array}$ & $\begin{array}{r}37,455 \\
0 \\
98,233 \\
0 \\
0 \\
0 \\
0 \\
0 \\
61800 \\
0 \\
16,837 \\
0 \\
104,080 \\
123,866 \\
161,326 \\
603,597\end{array}$ & $\begin{array}{r}29,758 \\
0 \\
17,200 \\
113,790 \\
0 \\
0 \\
0 \\
0 \\
56650 \\
0 \\
18,100 \\
0 \\
61,500 \\
98,181 \\
46,691 \\
441,870\end{array}$ & $\begin{array}{r}95,455 \\
0 \\
26,200 \\
0 \\
0 \\
0 \\
0 \\
0 \\
0 \\
0 \\
0 \\
0 \\
11,947 \\
132,905 \\
127,287 \\
393,794\end{array}$ & $\begin{array}{r}62,000 \\
0 \\
0 \\
0 \\
0 \\
0 \\
24,000 \\
0 \\
0 \\
0 \\
0 \\
0 \\
0 \\
0 \\
183,321 \\
800 \\
270,121\end{array}$ \\
\hline $\begin{array}{l}\text { Alabama-Tennessee Natural Gas Company } \\
\text { East Tennessee Natural Gas Company } \\
\text { Florida Gas Transmission Company } \\
\text { Mobile Bay Pipeline Company } \\
\text { South Georgia Natural Gas Company } \\
\text { Southorn Natural Gas Company } \\
\text { Total Southeast }\end{array}$ & $\begin{array}{r}0 \\
44,193 \\
10,603 \\
0 \\
0 \\
20,000 \\
74,796\end{array}$ & $\begin{array}{r}0 \\
15,079 \\
0 \\
0 \\
0 \\
0 \\
15,079\end{array}$ & $\begin{array}{l}0 \\
0 \\
0 \\
0 \\
0 \\
0 \\
0\end{array}$ & $\begin{array}{r}0 \\
16,115 \\
445,512 \\
0 \\
0 \\
100,000 \\
561,627\end{array}$ & $\begin{array}{r}0 \\
0 \\
70,916 \\
0 \\
0 \\
0 \\
70,916\end{array}$ \\
\hline $\begin{array}{l}\text { Black Marlin Pipeline Company } \\
\text { High Island Offshore System } \\
\text { Koch Gatoway Pipeline Company } \\
\text { Noram Gas Transmission Company } \\
\text { Oktox Pipolino Company } \\
\text { Ozark Gas Transmission System } \\
\text { Sabine Pipe Line Company } \\
\text { Soa Robin Pipeline Company } \\
\text { Stingray Pipeline Company } \\
\text { Total Southwost }\end{array}$ & $\begin{array}{r}0 \\
0 \\
0 \\
14,500 \\
0 \\
0 \\
0 \\
0 \\
0 \\
14,500\end{array}$ & $\begin{array}{l}0 \\
0 \\
0 \\
0 \\
0 \\
0 \\
0 \\
0 \\
0 \\
0\end{array}$ & $\begin{array}{l}0 \\
0 \\
0 \\
0 \\
0 \\
0 \\
0 \\
0 \\
0 \\
0\end{array}$ & $\begin{array}{l}0 \\
0 \\
0 \\
0 \\
0 \\
0 \\
0 \\
0 \\
0 \\
0\end{array}$ & $\begin{array}{l}0 \\
0 \\
0 \\
0 \\
0 \\
0 \\
0 \\
0 \\
0 \\
0\end{array}$ \\
\hline $\begin{array}{l}\text { El Paso Natura! Gas Company } \\
\text { Kern River Gas Transmission Company } \\
\text { Mojave Pipeline Company } \\
\text { Northwest Pipeline Corporation } \\
\text { Pacific Gas Transmission Company } \\
\text { Pacific Intorstate Offshore Company } \\
\text { Paiute Pipeline Company } \\
\text { Riverside Pipeline Company L.P. } \\
\text { Transwostern Pipeline Company } \\
\text { Tuscarora Gas Transmission Company } \\
\text { Total West }\end{array}$ & $\begin{array}{r}0 \\
0 \\
0 \\
243,467 \\
0 \\
0 \\
0 \\
0 \\
0 \\
0 \\
243,467\end{array}$ & $\begin{array}{r}0 \\
0 \\
0 \\
259,044 \\
7,158 \\
0 \\
0 \\
0 \\
0 \\
0 \\
266,202\end{array}$ & $\begin{array}{r}0 \\
0 \\
0 \\
77,595 \\
0 \\
0 \\
0 \\
0 \\
0 \\
0 \\
77.595\end{array}$ & $\begin{array}{r}0 \\
0 \\
0 \\
206,123 \\
290,795 \\
0 \\
0 \\
0 \\
0 \\
106,250 \\
603,168\end{array}$ & $\begin{array}{r}0 \\
0 \\
0 \\
38,056 \\
44,700 \\
0 \\
0 \\
0 \\
0 \\
0 \\
82,756\end{array}$ \\
\hline Total & $3,372,983$ & $2,067,349$ & 792,983 & $1,780,297$ & 562,701 \\
\hline
\end{tabular}


Table B1. Summary of FERC Index of Customers Data - Firm Transportation Capacity Under Contract as of April 1, 1996 (Continued)




Table B1. Summary of FERC Index of Customers Data - Firm Transportation Capacity Under Contract as of April 1, 1996 (Continued)

\begin{tabular}{|c|c|c|c|c|}
\hline Pipeline Company Name & $\begin{array}{c}\text { Total } \\
\text { Capacity Explring } \\
2022\end{array}$ & $\begin{array}{c}\text { Total } \\
\text { Capacity Explring } \\
2023\end{array}$ & $\begin{array}{c}\text { Total } \\
\text { Capacity ExpIring } \\
2024 \\
\end{array}$ & $\begin{array}{c}\text { Total } \\
\text { Capaclty Explring } \\
2025\end{array}$ \\
\hline $\begin{array}{l}\text { Canyon Creek Compression Company } \\
\text { Colorado Interstate Gas Company } \\
\text { KN Interstate Gas Transmission Co. } \\
\text { Migc, Inc. } \\
\text { Northem Border Pipeline Company } \\
\text { Northern Natural Gas Company } \\
\text { Questar Pipeline Company } \\
\text { Trailblazer Pipeline Company } \\
\text { Williams Natural Gas Company } \\
\text { Williston Basin Intorstato Pipoline Company } \\
\text { Wyoming Interstate Company. Ltd. } \\
\text { Total Contral }\end{array}$ & $\begin{array}{l}0 \\
0 \\
0 \\
0 \\
0 \\
0 \\
0 \\
0 \\
0 \\
0 \\
0 \\
0\end{array}$ & $\begin{array}{l}0 \\
0 \\
0 \\
0 \\
0 \\
0 \\
0 \\
0 \\
0 \\
0 \\
0 \\
0\end{array}$ & $\begin{array}{l}0 \\
0 \\
0 \\
0 \\
0 \\
0 \\
0 \\
0 \\
0 \\
0 \\
0 \\
0\end{array}$ & $\begin{array}{l}0 \\
0 \\
0 \\
0 \\
0 \\
0 \\
0 \\
0 \\
0 \\
0 \\
0 \\
0\end{array}$ \\
\hline $\begin{array}{l}\text { ANR Pipeline Company } \\
\text { Crossroads Pipeline Company } \\
\text { Great Lakes Gas Transmission Limited Partnershif } \\
\text { Michigan Gas Storage Company } \\
\text { Mid Louisiana Gas Company } \\
\text { Midwestem Gas Transmission Company } \\
\text { Mississippi River Transmission Corporation } \\
\text { Natural Gas Pipeline Co. Of America } \\
\text { Panhandle Eastem Pipe Line Company } \\
\text { Texas Gas Transmission Corporation } \\
\text { Trunkline Gas Company } \\
\text { Viking Gas Transmission Company } \\
\text { Total Midwest }\end{array}$ & $\begin{array}{l}0 \\
0 \\
0 \\
0 \\
0 \\
0 \\
0 \\
0 \\
0 \\
0 \\
0 \\
0 \\
0\end{array}$ & $\begin{array}{r}0 \\
0 \\
0 \\
210,000 \\
0 \\
0 \\
0 \\
0 \\
0 \\
0 \\
0 \\
0 \\
210,000\end{array}$ & $\begin{array}{l}0 \\
0 \\
0 \\
0 \\
0 \\
0 \\
0 \\
0 \\
0 \\
0 \\
0 \\
0 \\
0 \\
0\end{array}$ & $\begin{array}{r}21,000 \\
0 \\
0 \\
0 \\
0 \\
0 \\
0 \\
0 \\
0 \\
0 \\
0 \\
0 \\
0 \\
21,000\end{array}$ \\
\hline $\begin{array}{l}\text { Algonquin Gas Transmission Company } \\
\text { Camegie Interstate Pipeline Company } \\
\text { CNG Transmission Corp. } \\
\text { Columbia Gas Transmission Corporation } \\
\text { Columbia Gulf Transmission Company } \\
\text { Cove Point Lng Limited Partnership } \\
\text { Equitrans Inc } \\
\text { Granite State Gas Transmission, lnc. } \\
\text { Iroquois Pipoline Operating Company } \\
\text { Kentucky West Virginia Gas Co } \\
\text { National Fuel Ges Supply Corporation } \\
\text { Nora Transmission Co } \\
\text { Tennessee Gas Pipeline Company } \\
\text { Toxas Eastern Transmission Corporation } \\
\text { Transcontinental Gas Pipe Line Corp. } \\
\text { Total Northeast }\end{array}$ & $\begin{array}{l}0 \\
0 \\
0 \\
0 \\
0 \\
0 \\
0 \\
0 \\
0 \\
0 \\
0 \\
0 \\
0 \\
0 \\
0 \\
0\end{array}$ & $\begin{array}{l}0 \\
0 \\
0 \\
0 \\
0 \\
0 \\
0 \\
0 \\
0 \\
0 \\
0 \\
0 \\
0 \\
0 \\
0 \\
0\end{array}$ & $\begin{array}{l}0 \\
0 \\
0 \\
0 \\
0 \\
0 \\
0 \\
0 \\
0 \\
0 \\
0 \\
0 \\
0 \\
0 \\
0 \\
0\end{array}$ & $\begin{array}{l}0 \\
0 \\
0 \\
0 \\
0 \\
0 \\
0 \\
0 \\
0 \\
0 \\
0 \\
0 \\
0 \\
0 \\
0 \\
0\end{array}$ \\
\hline $\begin{array}{l}\text { Alabama-Tennesseo Natural Gas Company } \\
\text { East Tennessee Natural Gas Company } \\
\text { Florida Gas Transmission Company } \\
\text { Mobile Bay Pipeline Company } \\
\text { South Georgia Natural Gas Company } \\
\text { Southem Natural Gas Company } \\
\text { Total Southeast }\end{array}$ & $\begin{array}{l}0 \\
0 \\
0 \\
0 \\
0 \\
0 \\
0\end{array}$ & $\begin{array}{r}0 \\
0 \\
0 \\
0 \\
0 \\
2,740 \\
2,140\end{array}$ & $\begin{array}{l}0 \\
0 \\
0 \\
0 \\
0 \\
0 \\
0\end{array}$ & $\begin{array}{l}0 \\
0 \\
0 \\
0 \\
0 \\
0 \\
0\end{array}$ \\
\hline $\begin{array}{l}\text { Black Marlin Pipoline Company } \\
\text { High Island Offshore System } \\
\text { Koch Gatoway Pipolino Company } \\
\text { Noram Gas Transmission Company } \\
\text { Oktex Pipeline Company } \\
\text { Ozark Gas Transmission System } \\
\text { Sabine Pipe Line Company } \\
\text { Sea Robin Pipoline Company } \\
\text { Stingray Pipeline Company } \\
\text { Total Southwest }\end{array}$ & $\begin{array}{l}0 \\
0 \\
0 \\
0 \\
0 \\
0 \\
0 \\
0 \\
0 \\
0\end{array}$ & $\begin{array}{l}0 \\
0 \\
0 \\
0 \\
0 \\
0 \\
0 \\
0 \\
0 \\
0\end{array}$ & $\begin{array}{l}0 \\
0 \\
0 \\
0 \\
0 \\
0 \\
0 \\
0 \\
0 \\
0 \\
0\end{array}$ & $\begin{array}{l}0 \\
0 \\
0 \\
0 \\
0 \\
0 \\
0 \\
0 \\
0 \\
0\end{array}$ \\
\hline $\begin{array}{l}\text { El Paso Natural Gas Compeny } \\
\text { Korn River Gas Transmission Company } \\
\text { Mojave Pipoline Company } \\
\text { Northwest Pipolino Corporation } \\
\text { Pacific Gas Transmission Company } \\
\text { Pacific Interstate Offehore Company } \\
\text { Paiute Pipeline Company } \\
\text { Riverside Pipeline Company L.P. } \\
\text { Transwestern Pipeline Company } \\
\text { Tuscarora Gas Transmission Company } \\
\text { Total Wost }\end{array}$ & $\begin{array}{l}0 \\
0 \\
0 \\
0 \\
0 \\
0 \\
0 \\
0 \\
0 \\
0 \\
0\end{array}$ & $\begin{array}{r}0 \\
0 \\
0 \\
0 \\
1,724,421 \\
0 \\
0 \\
0 \\
0 \\
0 \\
1,124,421\end{array}$ & $\begin{array}{l}0 \\
0 \\
0 \\
0 \\
0 \\
0 \\
0 \\
0 \\
0 \\
0 \\
0\end{array}$ & $\begin{array}{r}0 \\
0 \\
0 \\
20,000 \\
84,900 \\
0 \\
0 \\
0 \\
0 \\
0 \\
104,900\end{array}$ \\
\hline Total & $\mathbf{0}$ & $1,336,561$ & 0 & 125,900 \\
\hline
\end{tabular}


Appendix C

Summary of

Industry Surveys on

Future Capacity

Commitments 


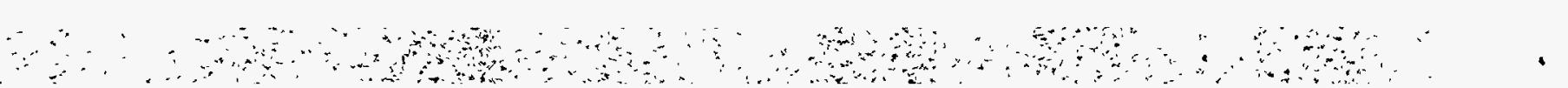


Appendix C

\section{Summary of Industry Surveys on Future Capacity Commitments}

Table C1. Summary of Industry Surveys on Future Capacity Commitments

\begin{tabular}{|c|c|c|c|c|c|}
\hline \multicolumn{2}{|c|}{ INGAA } & \multicolumn{4}{|c|}{ LDC Caucus } \\
\hline Reglon & $\begin{array}{c}\text { Estimated } \\
\text { Unsubscrlbed } \\
\text { Firm Capaclty } \\
\text { by } 2002 \\
\text { (MMBtu/d) }\end{array}$ & Reglon & $\begin{array}{l}\text { Probabllity of } \\
\text { Experlencing } \\
\text { Unsubscribed } \\
\text { Capacity } \\
\text { (7 = very likely) }\end{array}$ & $\begin{array}{c}\text { Excess } \\
\text { Capacity } \\
\text { Average Day } \\
\text { (MMBtu/d) }\end{array}$ & $\begin{array}{l}\text { Excess } \\
\text { Capaclty } \\
\text { PeakDay } \\
\text { (MMBtu/d) }\end{array}$ \\
\hline West & $2,832,500$ & California & 7 & $2,060,000$ & $4,944,000$ \\
\hline East & $2,636,800$ & East South Central & 5 & $1,236,000$ & $3,399,000$ \\
\hline Midwest & $4,171,500$ & Middle Atlantic & 2 & $1,339,000$ & $12,978,000$ \\
\hline \multirow[t]{5}{*}{ Rockies } & 247,200 & New England & 4 & $1,133,000$ & 721,000 \\
\hline & & North Central East & 7 & $7,004,000$ & $2,266,000$ \\
\hline & & Pacific Northwest & 1 & $1,030,000$ & $1,751,000$ \\
\hline & & South Atlantic & 1 & $1,442,000$ & 309,000 \\
\hline & & West North Central & 5 & $5,047,000$ & 824,000 \\
\hline
\end{tabular}

MMBtu/d = Million Btu per day.

Sources: Interstate Natural Gas Association of America (INGAA): The Effect of Restructuring on Long-term Contracts for Interstate Pipeline Capacity (September 1995); and LDC Caucus, American Gas Association, Future Unsubscribed Pipeline Capacity (December 1995). 
a 
Appendix D

Comparison of Firm

Commitments by Pipeline Company 



\section{Comparison of Firm Commitments by Pipeline Company}

Table D1. Comparison of Firm Commitments for a Sample of Pipeline Companies, 1990 and 1996

\begin{tabular}{|c|c|c|c|c|}
\hline \multirow[b]{2}{*}{ Pipellne Company } & \multirow{2}{*}{$\begin{array}{c}\text { FERC } \\
\text { Pipellne } \\
\text { Code }\end{array}$} & \multirow{2}{*}{$\begin{array}{c}\text { Geographlc } \\
\text { Reglon }\end{array}$} & \multicolumn{2}{|c|}{ Firm Contract Demand (million Btu) } \\
\hline & & & 1990 & 1996 \\
\hline Colorado Interstate Gas Company & 32 & CE & $2,691,390$ & $2,096,216$ \\
\hline KN Interstate Gas Transmission Company & 53 & $\mathrm{CE}$ & 278,100 & 612,454 \\
\hline Northern Border Pipeline Company & 89 & CE & $2,223,770$ & $1,684,194$ \\
\hline Northern Natural Gas Company & 59 & CE & $3,248,620$ & $4,813,245$ \\
\hline Questar Pipeline Company & 55 & CE & 693,190 & $1,093,946$ \\
\hline Trailblazer Pipeline Company & 68 & $\mathrm{CE}$ & 311,060 & 284,271 \\
\hline Williams Natural Gas Company & 43 & CE & $1,961,120$ & $2,697,941$ \\
\hline Williston Basin Interstate Pipeline Company & 49 & CE & 289,430 & 427,394 \\
\hline Wyoming Interstate Company, Ltd. & 76 & $\mathrm{CE}$ & 515,000 & 500,000 \\
\hline Total Central & & & $12,211,680$ & $14,209,661$ \\
\hline ANR Pipeline Company & 48 & MW & $6,014,170$ & $4,367,844$ \\
\hline Great Lakes Gas Transmission Limited Partnership & 51 & MW & $1,842,670$ & $3,895,797$ \\
\hline Midwestem Gas Transmission Company & 5 & MW & 842,540 & 762,090 \\
\hline Mississippi Aiver Transmission Corporation & 25 & MW & 878,590 & $1,600,841$ \\
\hline Natural Gas Pipeline Company of America & 26 & MW & $4,148,840$ & $7,113,877$ \\
\hline Panhandle Eastem Pipe Line Company & 28 & MW & $2,164,030$ & $2,540,173$ \\
\hline Texas Gas Transmission Corporation & 18 & MW & $2,576,030$ & $1,641,239$ \\
\hline Trunkdine Gas Company & 30 & MW & $2,566,760$ & $2,059,353$ \\
\hline Viking Gas Transmission Company & 82 & MW & 280,160 & 472,401 \\
\hline Total Mldwest & & & $21,313,790$ & $24,453,615$ \\
\hline Algonquin Gas Transmission Company & 20 & NE & 872,410 & $1,812,309$ \\
\hline CNG Transmission Corp. & 22 & NE & $3,736,840$ & $4,750,112$ \\
\hline Columbla Gas Transmission Corporation & 21 & NE & $5,183,990$ & $8,911,651$ \\
\hline Columbia Gull Transmission Company & 70 & NE & $1,277,200$ & $3,345,481$ \\
\hline Equilrans Inc. & 24 & NE & 557,230 & 358,798 \\
\hline Granite State Gas Transmission,Inc. & 4 & NE & 138,020 & 177,367 \\
\hline National Fuel Gas Supply Corporation & 16 & NE & $1,365,780$ & $1,853,613$ \\
\hline Tennessee Gas Pipeline Company & 9 & NE & $5,004,770$ & $5,655,492$ \\
\hline Texas Eastern Transmission Corporation & 17 & NE & $6,023,440$ & $4,098,907$ \\
\hline Transcontinental Gas Pipe Line Corp. & 29 & NE & $3,751,260$ & $5,518,592$ \\
\hline Total Northeast & & & $27,910,940$ & $36,482,322$ \\
\hline Alabama-Tennessee Natural Gas Company & 1 & SE & 109,180 & 132,502 \\
\hline East Tennessee Natural Gas Company & 2 & SE & 544,870 & 598,106 \\
\hline Florida Gas Transmission Company & 34 & SE & 950,690 & $1,532,921$ \\
\hline South Georgia Natural Gas Company & 8 & $S E$ & 42,230 & 114,341 \\
\hline Southern Natural Gas Company & 7 & SE & $2,119,740$ & $2,557,874$ \\
\hline Total Southeast & & & $3,766,710$ & $4,935,744$ \\
\hline Koch Gateway Pipeline Company & 11 & sw & $2,632,680$ & $2,370,751$ \\
\hline Noram Gas Transmission Company & 31 & SW & 838,420 & $2,729,150$ \\
\hline Ozark Gas Transmission System & 73 & sw & 175,100 & 124,333 \\
\hline Total Southwest & & & $3,646,200$ & $5,224,234$ \\
\hline El Paso Natural Gas Company & 33 & WE & $4,682,380$ & $3,978,504$ \\
\hline Northwest Pipeline Corporation & 37 & WE & $1,809,710$ & $3,533,131$ \\
\hline Pacific Gas Transmission Company & 86 & WE & $1,561,480$ & $2,847,102$ \\
\hline Transwestem Pipeline Company & 42 & WE & 797,220 & $2,536,948$ \\
\hline Total West & & & $8,850,790$ & $12,895,685$ \\
\hline
\end{tabular}

Sources: 1990: Energy Information Administration, Capacity on the Interstate Natural Gas Pipeline System 1990 (Washington, DC, June 1992). 1996: Federal Energy Regullatory Commission (FERC), Index of Customer Data in effect as of April 1, 1996, FERC Bulletin Board (August 28, 1996). 





Appendix E

Analysis of Capacity Release Trading:

Results and Methodology 


\section{Appendix $E$}

\section{Analysis of Capacity Release Trading: Results and Methodology}

The data used in the capacity release analysis in Chapter 2 were obtained from: (1) Electronic Data Interchange (EDI) data downloaded by the Federal Energy Regulatory Commission (FERC) from pipeline company electronic bulletin boards (EBBs), and (2) keypunched data assembled by Pasha Publications, Inc. (Pasha) from the pipeline company EBBs. The EDI data were the primary source of information for current periods, while the Pasha data were used to provide information on all data during the period before July 1994 and to fill gaps in the EDI data. For example, EDI data were missing for several pipeline companies because FERC has not completed editing and verifying the data. Thus, data for several pipeline companies were included in Pasha but not in the EDI data. Also, although storage capacity transactions are included in the EDI and Pasha data, these transactions were removed for purposes of the analysis of transportation activity.

Prior analyses of the capacity release market by the Energy Information Administration (EIA) were based exclusively on the Pasha data, which are less detailed than the EDI data. A comparison of EDI and Pasha data for comparable periods identified some inconsistencies in the Pasha data. As a result, the present analysis corrects the few cases where capacity release revenues and average prices were overstated in previous EIA analyses. The EDI data allow for reservation and/or usage prices, which are applied either monthly or daily. The price is stated either as a percentage of or discount from the maximum price. The price might also change depending on whether the capacity is released during a heating or nonheating season. The capacity amount can be expressed either in million Btu or in thousand cubic feet (Mcf).

In order to calculate the regional and U.S. average price and revenue for the capacity release transactions, the data were processed and merged to develop a single set. First, price gaps in the EDI data were filled with the appropriate Pasha data. If an EDI record did not have an amount in the price field and there was an exact match of Pasha transaction information (pipeline company name, offer number, and begin date), the price was obtained from Pasha data. There were 4,254 instances (13.percent of the 31,170 EDI records) where Pasha data price information was appended to EDI data. When there were no Pasha data that matched the EDI transaction or the Pasha price data were missing, the average price of all other transactions on the same day for that pipeline company was used. Average prices for the day were used for 1,569 transactions. These adjustments established complete price information for 30,933 of the 31,170 EDI records. The companies with the greatest number of imputed prices were: El Paso, 884 Pasha prices of 1,643 records; Northwestern, 856 Pasha prices of 1,799 records; Pacific Gas, 243 Pasha prices of 684 records; Tenneco, 379 Pasha prices and 657 average prices of 2,680 records; Transco, 384 Pasha prices and 137 average prices of 2,144 records; Panhandle, 366 Pasha prices of 1,051 records; and Northern Natural, 126 average prices of 1,283 records.

Once the EDI data had been processed to remedy the price data gaps, a single data set was constructed by merging the adjusted EDI and Pasha data. Pasha data were included for all transactions with start dates occurring before July 20, 1994. EDI data were included for all transactions with begin dates after July 19, 1994, except when data were unavailable. Pasha data with start dates after July 19, 1994, were used for the following companies: $\mathrm{KN}$ Energy (877 records), Trunkline (431 records), Canyon Creek (28 records), Equitrans (57 records), Great Lakes (120 records), Iroquois (1 record), Kern River (5 records), Koch (3 records), National Fuel (615 records), and Viking ( 7 records). The combined file has a total of 38,040 transportation records.

Finally, the records of the merged file were "exploded" to analyze the amounts of capacity held by replacement shippers at different periods. The merged file was exploded by extending the records for the number of days the transaction was effective. For example, if an award was for $\mathbf{2 0}$ days, then 20 records with identical daily price and volume were created, one record for each day of award. The full 38,040 record file exploded to 1,451,196 records. This file was then summarized by region and heating season to produce the tables and figures used in the Chapter 2 analysis. 
Table E1. Summary of Capacity Release Data by Pipeline Company, November 1993 - March 1996

\begin{tabular}{|c|c|c|c|c|c|c|c|c|}
\hline Season / Region / Plpeline Company Name & $\begin{array}{l}\text { Data } \\
\text { Source }\end{array}$ & $\begin{array}{c}\text { Number } \\
\text { of } \\
\text { Awards }\end{array}$ & $\begin{array}{l}\text { Average } \\
\text { Award } \\
\text { Length } \\
\text { (days) }\end{array}$ & $\begin{array}{c}\text { Capacity Held } \\
\text { by Replacement } \\
\text { Shippers } \\
\text { (million cubic feet) }\end{array}$ & $\begin{array}{c}\text { Revenue } \\
(\$ 000)\end{array}$ & $\begin{array}{c}\text { Average } \\
\text { Rate } \\
\text { (\$/Mcf-mo) }\end{array}$ & $\begin{array}{l}\text { Percent } \\
\text { Discounted } \\
\text { from } \\
\text { Max Rate } \\
\end{array}$ & $\begin{array}{c}\text { Percent } \\
\text { of Capaclty } \\
\text { Subject } \\
\text { to Recall } \\
\end{array}$ \\
\hline \multicolumn{9}{|l|}{$\begin{array}{l}\text { 1993-94 Heating Season } \\
\text { Central Region }\end{array}$} \\
\hline Colorado Interstate Gas Co & Pasha & 40 & 24 & 6,426 & 1,506 & 7.13 & . & - \\
\hline KN interstate Gas Co & Pasha & 95 & 19 & 8,273 & 942 & 3.46 & . & - \\
\hline Mississippi River Transmission Co & Pasha & 81 & 36 & 10,249 & 1,146 & 3.40 & . & - \\
\hline Natural Gas Pipeline Co of America & Pasha & 222 & 21 & 38,137 & 6,474 & 5.16 & - & . \\
\hline Northem Border Pipeline Co & Pasha & 20 & 22 & 7.145 & 165 & 0.70 & - & - \\
\hline Northern Natural Gas Co & Pasha & 92 & 31 & 24,854 & 2,253 & 2.76 & - & - \\
\hline Trailblazer Pipeline Co & Pasha & 25 & 40 & 10,688 & 1,219 & 3.47 & . & - \\
\hline Williams Natural Gas Co & Pasha & 51 & 29 & 7,001 & 476 & 2.07 & . & - \\
\hline Regional Total & & 626 & 26 & 112,773 & 14,181 & 3.82 & - & - \\
\hline \multicolumn{9}{|l|}{ Midwest Region } \\
\hline ANR Pipeline Co & Pasha & 78 & 21 & 9.417 & 2,181 & 7.04 & . & - \\
\hline Midwestern Gas Transmission Co & Pasha & 5 & 19 & 763 & 36 & 1.42 & . & - \\
\hline Panhandle Eastern Pipeline Co & Pasha & 178 & 25 & 23,513 & 2,600 & 3.36 & - & - \\
\hline Texas Gas Transmission Co & Pasha & 177 & 54 & 30,649 & 3,153 & 3.13 & . & - \\
\hline Regional Total & & 438 & 36 & 64,342 & 7,969 & 3.77 & - & . \\
\hline \multicolumn{9}{|l|}{ Northeast Region } \\
\hline Algonquin Gas Transmission Co & Pasha & 17 & 1,399 & 6,533 & 1,326 & 6.17 & . & . \\
\hline Columbia Gas Transmission Co & Pasha & - 464 & 81 & 76,681 & 8,473 & 3.36 & . & - \\
\hline CNG Transmission Co & Pasha & 204 & 82 & 46,327 & 5.455 & 3.58 & . & - \\
\hline East Tennessee Gas Co & Pasha & 25 & 662 & 11,014 & 2,596 & 7.17 & . & - \\
\hline Equitrans inc & Pasha & 2 & 26 & 1,515 & 151 & 3.04 & . & . \\
\hline Iroquis Gas & Pasha & 1 & 29 & 290 & 1 & 0.06 & . & - \\
\hline Tennessee Gas Pipeline Co & Pasha & 149 & 215 & 26,411 & 7,201 & 8.29 & . & - \\
\hline Texas Eastem Transmission Co & Pasha & 137 & 112 & 26,872 & 2,948 & 3.34 & - & - \\
\hline Transcontinental Gas Pipeline Co & Pasha & 42 & 577 & 6,080 & 1,418 & 7.09 &.. & . \\
\hline Trunkline Gas Co & Pasha & 53 & 23 & 8,190 & 1,040 & 3.86 & . & - \\
\hline Regional Total & & 1,094 & 153 & 209,913 & 30,609 & 4.44 & . & - \\
\hline \multicolumn{9}{|l|}{ Southeast Region } \\
\hline Florida Gas Transmission Co & Pasha & 15. & 58 & 1,319 & 37 & 0.86 & . & - \\
\hline Southern Natural Gas Co & Pasha & 54 & 29 & 9,039 & 365 & 1.23 & . & - \\
\hline Regional Total & & 69 & 35 & 10,358 & . 403 & 1.18 & - & - \\
\hline \multicolumn{9}{|l|}{ Southwest Region } \\
\hline NORAM Gas Transmission & Pasha & 20 & 231 & 4,819 & 342 & 2.16 & - & - \\
\hline Regional Total & & 20 & 231 & 4,819 & 342 & 2.16 & - & • \\
\hline \multicolumn{9}{|l|}{ West Region } \\
\hline El Paso Natural Gas Co & Pasha & 197 & 25 & 54,974 & 9,040 & 5.00 & . & . \\
\hline Northwest Pipeline Co & Pasha & 80 & 68 & 19,041 & 5,288 & 8.45 & - & . \\
\hline Pacific Gas Transmission Co & Pasha & 189 & 82 & 83,147 & 10,102 & 3.70 & - & . \\
\hline Paiute Pipeline Co & Pasha & 5 & 14 & 13 & 4 & 9.76 & . & . \\
\hline Transwestern Gas Pipeline Co & Pasha & 11 & 38 & 7,308 & 520 & 2.17 & - & - \\
\hline Regional Total & & 482 & 55 & 164,483 & 24,955 & 4.61 & · & - \\
\hline 1993-94 Heating Season Total & & 2,729 & 85 & 566,688 & 78,459 & 4.21 & . & . \\
\hline
\end{tabular}

$\$ /$ Mcf-mo = Dollars per thousand cubic feet-per month. Merged file = Data file created by combining Pasha and EDI data. EDI = Federal Energy Regulatory Commission, Electronic Data Interchange capacity release data set. Pasha = Pasha Publications, Inc. capacity release data set.

Source: Energy Information Administration, Office of Oil and Gas, derived from: November 1993 - July 1994: Pasha Publications, Inc. July 1994 - March 1996: Federal Energy Regulatory Commission, Electronic Data Interchange (EDI) data. 
Table E1. Summary of Capacity Release Data by Pipeline Company, November 1993 - March 1996 (Continued)

\begin{tabular}{|c|c|c|c|c|c|c|c|c|}
\hline Season / Reglon / PIpelline Company Name & $\begin{array}{c}\text { Data } \\
\text { Source }\end{array}$ & $\begin{array}{c}\begin{array}{c}\text { Number } \\
\text { of } \\
\text { Awards }\end{array} \\
\end{array}$ & \begin{tabular}{|c|} 
Average \\
Award \\
Length \\
(days)
\end{tabular} & $\begin{array}{c}\text { Capacity Held } \\
\text { by Replacement } \\
\text { Shippers } \\
\text { (million cubic feet) }\end{array}$ & $\begin{array}{c}\text { Revenue } \\
(\$ 000)\end{array}$ & $\begin{array}{c}\begin{array}{c}\text { Average } \\
\text { Rate } \\
\text { (\$/Mcf-Mo) }\end{array} \\
\end{array}$ & $\begin{array}{c}\text { Percent } \\
\text { Discounted } \\
\text { from } \\
\text { Max Rate } \\
\end{array}$ & $\begin{array}{c}\text { Percent } \\
\text { of Capaclty } \\
\text { Subject } \\
\text { to Recall }\end{array}$ \\
\hline \multicolumn{9}{|l|}{$\begin{array}{l}1994 \text { Nonheating Season } \\
\text { Central Reglon }\end{array}$} \\
\hline Colorado Interstate Gas Co & Merged File & 205 & 59 & 23,262 & 4,430 & 5.79 & 98 & 24 \\
\hline KN Interstate Gas Co & Pasha & 255 & 23 & 29,425 & 2,039 & 2.11 & . & . \\
\hline Mississippi River Transmission Co & Merged File & 103 & 40 & 13,536 & 1,572 & 3.53 & . & 20 \\
\hline Natural Gas Pipeline Co of America & Merged File & 621 & 30 & 215,165 & 56,986 & 8.06 & . & 81 \\
\hline Northern Border Pipeline Co & Merged File & 25 & 27 & 11,641 & 700 & 1.83 & - & . \\
\hline Northern Natural Gas Co & Merged File & 214 & 39 & 73,839 & 4,832 & 1.99 & . & . \\
\hline Trailblazer Pipeline Co & Merged File & 69 & 94 & 60,010 & 5,645 & 2.86 & - & 59 \\
\hline Williams Natura! Gas Co & Merged File & 303 & 36 & 62,182 & 3,251 & 1.59 & 98 & 99 \\
\hline Reglonal Total & & 1,795 & 38 & 489,060 & 79,455 & 4.94 & 98 & 82 \\
\hline \multicolumn{9}{|l|}{ Midwest Reglon } \\
\hline ANR Plpeline Co & Merged File & 238 & 33 & 69,123 & 5,425 & 2.39 & 85 & 63 \\
\hline Midwestern Gas Transmission Co & Merged File & 47 & 20 & 8,094 & 253 & 0.95 & . & 86 \\
\hline Panhandle Eastern Pipeline Co & Merged File & 375 & 20 & 32,179 & 3,508 & 3.32 & . & 50 \\
\hline Texas Gas Transmission Co & Merged File & 609 & 23 & 77,068 & 6,247 & 2.47 & . & 87 \\
\hline Viking Gas Transmission Co & Pasha & 7 & 57 & 6.607 & 490 & 2.26 & . & - \\
\hline Regional Total & & 1,276 & 24 & 193,070 & 15,924 & 2.51 & 85 & 72 \\
\hline \multicolumn{9}{|l|}{ Northeast Region } \\
\hline Algonquin Gas Transmission Co & Merged File & 80 & 72 & 20,832 & 2,522 & 3.68 & . & 32 \\
\hline Columbia Gas Transmission Co & Merged File & 920 & 43 & 144,032 & 14,762 & 3.12 & 96 & 33 \\
\hline Columbia Gulf Transmission Co & Merged File & 485 & 22 & 61,682 & 539 & 0.27 & 94 & 25 \\
\hline CNG Transmission Co & Merged File & 574 & 30 & 94,676 & 4,388 & 1.41 & 91 & 64 \\
\hline East Tennessee Gas Co & Merged File & 108 & 38 & 23,940 & 4,436 & 5.64 & • & 98 \\
\hline Equitrans lne & Pasha & 2 & 31 & 1.551 & 155 & 3.04 & . & • \\
\hline National Fuel Gas Supply Co & Pasha & 73 & 27 & 3,536 & 207 & 1.78 & . & 97 \\
\hline - Tennessee Gas Pipeline Co & Merged File & 1,009 & 35 & 171,016 & 15,835 & 2.82 . & - & 73 \\
\hline Texas Eastern Transmission Co & Merged File & 339 & 103 & 138,385 & 8,948 & 1.97 & 59 & 84 \\
\hline Transcontinental Gas Pipeline Co & Merged File & 450 & 63 & 55,411 & 6,604 & 3.63 & . & 64 \\
\hline Trunkline Gas Co & Pasha & 91 & 28 & 8,560 & 566 & 2.01 & - & 34 \\
\hline Regional Total & & 4,131 & 44 & 723,621 & 58,962 & 2.48 & 84 & 57 \\
\hline \multicolumn{9}{|l|}{ Southeast Reglon } \\
\hline Florida Gas Transmission Co & Merged File & 18 & 21 & 2,373 & 408 & 5.23 & . & 43 \\
\hline Southern Natural Gas Co & Merged File & 390 & $47^{\circ}$ & 81,543 & 10,035 & 3.74 & . & 99 \\
\hline Regional Total & & 408 & 46 & 83,916 & 10,443 & 3.79 & - & 93 \\
\hline \multicolumn{9}{|l|}{ Southwest Region } \\
\hline NORAM Gas Transmission & Merged File & 73 & 150 & 9,814 & 1,072 & 3.32 & - & 67 \\
\hline Regional Total & & 73 & 150 & 9,814 & 1.072 & 3.32 & - & 67 \\
\hline \multicolumn{9}{|l|}{ West Region } \\
\hline El Paso Natural Gas Co & Merged File & 465 & 27 & 225,479 & 15,563 & 2.10 & . & 61 \\
\hline Kern River Transmission Co & Pasha & 5 & 30 & 995 & 146 & 4.46 & . & - \\
\hline Northwest Pipeline Co & Merged File & 144 & 133 & 57,043 & 8,825 & 4.71 & . & . \\
\hline Paciflc Gas Transmission Co & Merged File & 328 & 118 & 191,133 & 22,307 & 3.55 & . & 74 \\
\hline Palute Pipeline Co & Merged File & 11 & 21 & 363 & 42 & 3.54 & . & . \\
\hline Transwestern Gas Pipeline Co & Merged File & 82 & 34 & 63,940 & 2,138 & 1.02 & . & 76 \\
\hline Reglonal Total' & & 1,035 & 71 & 538,953 & 49,021 & 2.77 & . & 65 \\
\hline 1994 Nonheating Season Total & & 8,718 & 44 & $2,038,435$ & 214,877 & 3.21 & 92 & 67 \\
\hline
\end{tabular}

$\$ /$ Mcf-mo $=$ Dollars per thousand cubic feet per month. Merged file $=$ Data file created by combining Pasha and EDI data. EDI $=$ Federal Energy Regulatory Commission, Electronic Data Interchange capacity release data set. Pasha = Pasha Publications, Inc. capacity release data set.

Source: Energy Information Administration, Office of Oil and Gas, derived from: November 1993 - July 1994: Pasha Publications, Inc. July 1994 - March 1996: Federal Energy Regulatory Commission, Electronic Data Interchange (EDI) data. 
Table E1. Summary of Capacity Release Data by Pipeline Company, November 1993 - March 1996 (Continued)

\begin{tabular}{|c|c|c|c|c|c|c|c|c|}
\hline Season I Reglon / Plpellne Company Name & $\begin{array}{c}\text { Data } \\
\text { Source } \\
\end{array}$ & $\begin{array}{c}\text { Number } \\
\text { of } \\
\text { Awards }\end{array}$ & \begin{tabular}{|c|} 
Average \\
Award \\
Length \\
(days) \\
\end{tabular} & $\begin{array}{c}\text { Capacity Held } \\
\text { by Replacement } \\
\text { Shippers } \\
\text { (million'cubic feet) }\end{array}$ & $\begin{array}{c}\text { Revenue } \\
(\$ 000)\end{array}$ & $\begin{array}{c}\text { Average } \\
\text { Rate } \\
\text { (\$/Mct-Mo) }\end{array}$ & $\begin{array}{c}\text { Percent } \\
\text { Discounted } \\
\text { from } \\
\text { Max Rate } \\
\end{array}$ & $\begin{array}{c}\text { Percent } \\
\text { of Capacity } \\
\text { Subject } \\
\text { to Recall } \\
\end{array}$ \\
\hline \multicolumn{9}{|l|}{$\begin{array}{l}\text { 1994-95 Heating Season } \\
\text { Central Region }\end{array}$} \\
\hline Canyon Creek Gas Co & Merged File & 7 & 33 & 2,917 & 29 & 0.30 & 85 & . \\
\hline Colorado interstate Gas Co & Merged File & 186 & 26 & 19,551 & 3,597 & 5.60 & 98 & 66 \\
\hline KN Interstate Gas Co & Pasha & 172 & 20 & 16,404 & 1,129 & 2.09 & 68 & 93 \\
\hline Mississippi River Transmission Co & Merged File & 49 & 38 & 5,995 & 709 & 3.59 & 42 & 99 \\
\hline Natural Gas Pipeline Co of America & Merged File & 376 & 36 & 111,961 & 32,434 & 8.81 & 53 & 89 \\
\hline Northem Border Pipeline Co & Merged File & 6 & 181 & 2,855 & 3 & 0.04 & 99 & . \\
\hline Northern Natural Gas Co & Merged File & 293 & 35 & 75,301 & 3,911 & 1.58 & 81 & . \\
\hline Trailblazer Pipeline Co & Merged File & 84 & 40 & 42,099 & 3,079 & 2.22 & & 35 \\
\hline Williams Natural Gas Co & Merged File & 267 & 82 & 71,360 & 6,271 & 2.67 & 98 & 94 \\
\hline Regional Total . & & 1,440 & 42 & 348,443 & 51.163 & 4.47 & 93 & 79 \\
\hline \multicolumn{9}{|l|}{ Midwest Region } \\
\hline ANR Pipeline Co & Merged File & 258 & 21 & 30,637 & 2,493 & 2.48 & 78 & 71 \\
\hline Midwestern Gas Transmission Co & Merged File & 31 & 9 & 3,616 & 85 & 0.72 & . & 40 \\
\hline Panhandle Eastem Pipeline Co & Merged File & 254 & 28 & 26,150 & 3,071 & 3.57 & 77 & 70 \\
\hline $\begin{array}{l}\text { Texas Gas Transmission Co } \\
\text { Regional Total }\end{array}$ & Merged File & $\begin{array}{r}608 \\
1.151\end{array}$ & $\begin{array}{l}26 \\
25\end{array}$ & $\begin{array}{r}63,883 \\
124,286\end{array}$ & $\begin{array}{r}7,056 \\
12,705\end{array}$ & $\begin{array}{l}3.36 \\
3.11\end{array}$ & $78^{\circ}$ & $\begin{array}{l}91 \\
80\end{array}$ \\
\hline \multicolumn{9}{|l|}{ Northeast Region } \\
\hline Algonquin Gas Transmission Co & Merged File & 58 & 439 & 15,162 & 1,689 & 3.39 & 96 & 60 \\
\hline Columbia Gas Transmission Co & Merged File & 1,021 & 53 & 137,147 & 9,644 & 2.14 & 76 & 68 \\
\hline Columbia Gulf Transmission Co & Merged File & 644 & 96 & 127,339 & 6,744 & 1.61 & 72 & 65 \\
\hline CNG Transmission Co & Merged File & 512 & 32 & 90,696 & 10,754 & 3.61 & 46 & 81 \\
\hline East Tennessee Gas Co & Merged File & 42 & 44 & 12,418 & 2,875 & 7.04 & 46 & 91 \\
\hline Equitrans lnc & Pasha & 15 & 24 & 3,035 & 281 & 2.82 & $\cdot$ & 94 \\
\hline National Fuel Gas Supply Co & Pasha & 108 & 28 & 7.714 & 806 & 3.18 & 16 & 74 \\
\hline Tennessee Gas Pipeline Co & Merged File & 429 & 26 & 52,322 & 7,843 & 4.56 & 77 & * 82 \\
\hline Texas Eastem Transmission Co & Merged File & 204 & 240 & 151,981 & 14,209 & 2.84 & 45 & 83 \\
\hline Transcontinental Gas Pipeline Co & Merged File & 321 & 100 & 52,735 & 11,118 & 6.41 & & 66 \\
\hline Trunkline Gas Co & Pasha & 145 & 33 & 24,561 & 1,840 & 2.28 & 84 & 77 \\
\hline Regional Total & & 3,499 & 74 & 675,111 & 67,802 & 3.05 & 62 & 74 \\
\hline \multicolumn{9}{|l|}{ Southeast Region } \\
\hline Florida Gas Transmission Co & Merged File & 36 & 25 & 4,903 & 1,004 & 6.23 & 78 & 80 \\
\hline Southern Natural Gas Co & Merged File & 301 & 18 & 74,403 & 3,697 & 1.51 & . & 99 \\
\hline Regional Total & & 337 & 19 & 79,305 & 4,702 & 1.80 & - & 98 \\
\hline \multicolumn{9}{|l|}{ Southwest Region } \\
\hline Koch Gateway Pipeline Co & Merged File & 3 & 605 & 4,450 & 1,990 & 13.60 & . & . \\
\hline NORAM Gas Transmission & Merged File & 51 & 130 & 5,726 & 1,081 & 5.74 & 33 & 89 \\
\hline Regional Total & & 54 & 156 & 10,177 & 3,071 & 9.18 & 33 & 43 \\
\hline \multicolumn{9}{|l|}{ West Region } \\
\hline $\begin{array}{l}\text { Northwest Pipeline Co } \\
\text { Pacific Gas Transmission Co }\end{array}$ & Merged File & $\begin{array}{r}0 \\
153\end{array}$ & 309 & 11,141 & 2,894 & 7.90 & - & - \\
\hline $\begin{array}{l}\text { Pacific Gas Transmission Co } \\
\text { Paiute Pipeline Co }\end{array}$ & Merged File & 153 & 309 & 163,652 & 19,678 & 3.66 & 69 & 42 \\
\hline $\begin{array}{l}\text { Paiute Pipeline Co } \\
\text { Transwestern Gas Pipeline Co }\end{array}$ & Merged File & 24 & 20 & 161 & 55 & 10.34 & - & 93 \\
\hline Transwestern Gas Pipeline Co & Merged File & 63 & 62 & 49,512 & 1,477 & 0.91 & - & 58 \\
\hline Regional Total & & 501 & 116 & 349,532 & 33,302 & 2.90 & 81 & 36 \\
\hline 1994-95 Heating Season Total & & 6,982 & 60 & $1,586,854$ & 172,744 & 3.31 & 82 & 69 \\
\hline
\end{tabular}

$\$ /$ Mcf-mo $=$ Dollars per thousand cubic feet per month. Merged file $=$ Data file created by combining Pasha and EDI data. EDI $=$ Federal Energy Regulatory Commission, Electronic Data Interchange capacity release data set. Pasha = Pasha Publications, Inc. capacity release data set.

Source: Energy Information Administration, Office of Oil and Gas, derived from: November 1993 - July 1994: Pasha Publications, Inc. July 1994 - March 1996: Federal Energy Regulatory Commission, Electronic Data Interchange (EDI) data. 
Table E1. Summary of Capacity Release Data by Pipeline Company, November 1993 - March 1996 (Continued)

\begin{tabular}{|c|c|c|c|c|c|c|c|c|}
\hline Season I Reglon / Plpellne Company Name & $\begin{array}{c}\text { Data } \\
\text { Source }\end{array}$ & $\begin{array}{c}\begin{array}{c}\text { Number } \\
\text { of } \\
\text { Awards }\end{array} \\
\end{array}$ & \begin{tabular}{|c|}
$\begin{array}{c}\text { Average } \\
\text { Award } \\
\text { Length } \\
\text { (days) }\end{array}$ \\
\end{tabular} & $\begin{array}{c}\text { Capacity Held } \\
\text { by Replacement } \\
\text { Shlppers } \\
\text { (million cubic feet) }\end{array}$ & $\begin{array}{c}\text { Revenue } \\
(\$ 000)\end{array}$ & $\begin{array}{c}\begin{array}{c}\text { Average } \\
\text { Rate } \\
\text { (\$/Mcf-Mo) }\end{array} \\
\end{array}$ & $\begin{array}{c}\text { Percent } \\
\text { Discounted } \\
\text { from } \\
\text { Max Rate } \\
\end{array}$ & $\begin{array}{c}\text { Percent } \\
\text { of Capacity } \\
\text { Subject } \\
\text { to Recall } \\
\end{array}$ \\
\hline \multicolumn{9}{|l|}{$\begin{array}{l}1995 \text { Nonheating Season } \\
\text { Central Region }\end{array}$} \\
\hline Canyon Creek Gas Co & Pasha & 12 & 72 & 13,354 & 273 & 0.62 & 69 & 42 \\
\hline Colorado Interstate Gas Co & Merged File & 293 & 30 & 43,884 & 7,940 & 5.50 & 58 & 59 \\
\hline KN Interstate Gas Co & Pasha & 194 & 27 & 22,713 & 2,047 & 2.74 & 75 & 96 \\
\hline Mississippi River Transmission Co & Merged File & 179 & 130 & 46,881 & 1.160 & 0.75 & 77 & 14 \\
\hline Natural Gas Pipeline Co of America & Merged File & 653 & 33 & 314,472 & 77,615 & 7.51 & 31 & 92 \\
\hline Northern Border Pipeline Co & Merged File & 20 & 752 & 8,646 & 19 & 0.07 & 99 & 4 \\
\hline Northern Natural Gas Co & Merged File & 528 & 41 & 204,048 & 7.010 & 1.05 & 86 & . \\
\hline Trailblazer Pipeline Co & Merged File & 111 & 51 & 100,272 & 11,527 & 3.50 & & $61^{\circ}$ \\
\hline Williams Natural Gas Co & Merged File & 468 & 40 & 123,046 & 8,695 & 2.15 & $99^{\circ}$ & 97 \\
\hline Regional Total & & 2,458 & 49 & 877,316 & 116,285 & 4.03 & 92 & 79 \\
\hline Midwest Region & & & $m$ & & & & & \\
\hline ANR Pipeline Co & Merged File & 474 & 29 & 113,241 & 6,480 & 1.74 & 84 & 66 \\
\hline Midwestern Gas Transmission Co & Merged File & 10 & 20 & 2,264 & 24 & 0.32 & 86 & \\
\hline Panhandle Eastern Pipeline Co & Merged File & 322 & 28 & 42,392 & 4.161 & 2.99 & 75 & $71^{\circ}$ \\
\hline Texas Gas Transmission Co & Merged File & 834 & 32 & 119,422 & 8,049 & 2.05 & & 84 \\
\hline Reglonal Total & & 1,640 & 30 & 277.319 & 18,715 & 2.05 & 81 & 75 \\
\hline \multicolumn{9}{|l|}{ Northeast Region } \\
\hline Algonquin Gas Transmission Co & Merged File & 157 & 34 & 33,055 & 2,666 & 2.45 & 89 & 32 \\
\hline Columbia Gas Transmission Co & Merged File & 1,243 & 39 & 189,581 & 9,881 & 1.59 & 82 & 32 \\
\hline Columbia Gulf Transmission Co & Merged File & 1,029 & 36 & 188,196 & 5,812 & 0.94 & 80 & 36 \\
\hline CNG Transmission Co & Merged File & 700 & 33 & 146,627 & 5,656 & 1.17 & 84 & 69 \\
\hline East Tennessee Gas Co & Merged File & 74 & 59 & 24,453 & 3,960 & 4.93 & 79 & 99 \\
\hline Equitrans Inc & Pasha & 31 & 29 & 7,514 & 502 & 2.03 & 96 & 90 \\
\hline National Fuel Gas Supply Co & Pasha & 199 & 30 & 11,666 & 769 & 2.00 & 64 & 59 \\
\hline Tennessee Gas Pipeline Co & Merged File & 899 & 40 & 184,513 & 15,931 & 2.63 & 84 & 81 \\
\hline Texas Eastern Transmission Co & Merged File & 732 & 49 & 339,568 & 24.807 & 2.22 & 55 & 72 \\
\hline Transcontinental Gas Pipeline Co & Merged File & 950 & 47 & 166,255 & 19,898 & 3.64 & $\mathbf{5 7}$ & 62 \\
\hline Trunkline Gas Co & Pasha & 77 & 42 & 25,758 & 1,118 & 1.32 & 88 & 68 \\
\hline Regional Total & & 6,091 & 40 & $1,317,185$ & 90,999 & 2.10 & 75 & 60 \\
\hline \multicolumn{9}{|l|}{ Southeast Region } \\
\hline Florida Gas Transmission Co & Merged File & 110 & 33 & 11,387 & 2,887 & 7.71 & 66 & 26 \\
\hline Southern Natural Gas Co & Merged File & 555 & 31 & 125,401 & 3,762 & 0.91 & 92 & 98 \\
\hline Stingray Pipeline Co & Merged File & 85 & 28 & 6,974 & 746 & 3.25 & . & 78 \\
\hline Reglonal Total & & 750 & 31 & 143,762 & 7,395 & 1.56 & 87 & 91 \\
\hline \multicolumn{9}{|l|}{ Southwest Region } \\
\hline Koch Gateway Pipeline Co & Pasha & 0 & & 6,899 & 3,118 & 13.75 & & . \\
\hline NORAM Gas Transmission & Merged File & 36 & 214 & 20,947 & 2.161 & 3.14 & 75 & 18 \\
\hline Regional Total & & 36 & 198 & 27,846 & 5,279 & 5.77 & 75 & 14 \\
\hline \multicolumn{9}{|l|}{ West Region } \\
\hline EI Paso Natural Gas Co & Merged File & 671 & 29 & 306,668 & 29,813 & 2.96 & 68 & 14 \\
\hline Northwest Pipeline Co & Merged File & 571 & 48 & 119,585 & 10,870 & 2.76 & 70 & 82 \\
\hline Pacific Gas Transmission Co & Merged File & 209 & 191 & 207,141 & 27,342 & 4.01 & 63 & 31 \\
\hline Palute Pipeline Co & Merged File & 130 & 27 & 2,345 & 400 & 5.19 & 97 & 95 \\
\hline Transwestern Gas Pipeline Co & Merged File & 34 & 46 & 45,276 & 2,209 & 1.48 & & 39 \\
\hline Regional Total & & 1,615 & 57 & 681,014 & 70,634 & 3.15 & 72 & 33 \\
\hline 1995 Nonheating Season Total & & 12,590 & 43 & $3,324,442$ & 309,307 & 2.83 & 83 & 61 \\
\hline
\end{tabular}

$\$ / M c f-m o=$ Dollars per thousand cubic feet per month. Merged file = Data file created by combining Pasha and EDI data. EDI $=$ Federal Energy Regulatory Commission, Electronic Data Interchange capacity release data set. Pasha = Pasha Publications, Inc. capacity release data set.

Source: Energy Information Administration, Office of Oil and Gas, derived from: November 1993 - July 1994: Pasha Publications, Inc. July 1994 - March 1996: Federal Energy Regulatory Commission, Electronic Data Interchange (EDI) data. 
Table E1. Summary of Capacity Release Data by Pipeline Company, November 1993 - March 1996 (Continued)

\begin{tabular}{|c|c|c|c|c|c|c|c|c|}
\hline Season / Region / PIpeline Company Name & $\begin{array}{c}\text { Data } \\
\text { Source }\end{array}$ & $\begin{array}{c}\text { Number } \\
\text { of } \\
\text { Awards }\end{array}$ & \begin{tabular}{|c|} 
Average \\
Award \\
Length \\
(days)
\end{tabular} & $\begin{array}{c}\text { Capacity Held } \\
\text { by Replacement } \\
\text { Shippers } \\
\text { (million cubic feet) } \\
\end{array}$ & $\begin{array}{c}\text { Revenue } \\
(\$ 000)\end{array}$ & $\begin{array}{c}\text { Average } \\
\text { Rate } \\
\text { (\$/Mcf-Mo) }\end{array}$ & $\begin{array}{c}\text { Percent } \\
\text { Discounted } \\
\text { from } \\
\text { Max Rate } \\
\end{array}$ & $\begin{array}{c}\text { Percent } \\
\text { of Capacity } \\
\text { Subject } \\
\text { to Recall } \\
\end{array}$ \\
\hline \multicolumn{9}{|l|}{$\begin{array}{l}\text { 1995-96 Heating Season } \\
\text { Central Region }\end{array}$} \\
\hline Canyon Creek Gas Co & Pasha & 7 & 209 & 11,614 & 320 & 0.84 & 59 & 65 \\
\hline Colorado Interstate Gas Co & Merged File & 117 & 22 & 15,158 & 3,005 & 6.03 & 32 & 67 \\
\hline KN Interstate Gas Co & Pasha & 131 & 34 & 11,354 & 1,978 & 5.30 & 38 & 100 \\
\hline Mississippi River Transmission Co & Merged File & 61 & 26 & 41,161 & 1,430 & 1.06 & 60 & 19 \\
\hline Natural Gas Pipeline Co of America & Merged File & 259 & 112 & 221,363 & 66,171 & 9.09 & 51 & 95 \\
\hline Northem Border Pipeline Co & Merged File & 16 & 891 & 15,891 & 6 & 0.01 & . & - \\
\hline Northem Natural Gas Co & Merged File & 332 & 51 & 123,707 & 7,065 & 1.74 & 84 & 90 \\
\hline Trailblazer Pipeline Co & Merged File & 83 & 84 & 53,779 & 5,135 & 2.90 & . & 71 \\
\hline Williams Natural Gas Co & Merged File & 214 & 41 & 76,549 & 7,215 & 2.87 & 99 & 98 \\
\hline Regional Total & & 1,220 & 71 & 570,575 & 92,324 & 4.92 & 85 & 82 \\
\hline \multicolumn{9}{|l|}{ Midwest Region } \\
\hline ANR Pipeline Co & Merged File & 223 & 32 & 53,711 & 10,959 & 6.21 & 40 & 82 \\
\hline Great Lakes Transmission Co & Pasha & 110 & 175 & 48,203 & 9,760 & 6.16 & 18 & 42 \\
\hline Midwestem Gas Transmission Co & Merged File & 32 & 31 & 17,401 & 613 & 1.07 & 49 & 99 \\
\hline Panhandle Eastem Pipeline Co & Merged File & 235 & 39 & 48,463 & 16,270 & 10.21 & 18 & 44 \\
\hline Texas Gas Transmission Co & Merged File & 812 & 43 & 180,970 & 24,910 & 4.19 & - & 83 \\
\hline Regiona! Total & & 1,412 & 51 & 348,747 & 62,513 & 5.45 & 27 & 72 \\
\hline \multicolumn{9}{|l|}{ Northeast Region } \\
\hline Algonquin Gas Transmission Co & Merged File & 22 & 80 & 17,437 & 3,054 & 5.33 & 28 & 38 \\
\hline Columbia Gas Transmission Co & Merged File & 1,006 & 50 & 135,297 & 16,463 & 3.70 & 53 & 58 \\
\hline Columbia Gulf Transmission Co & Merged File & 364 & 80 & 68,930 & 4,148 & 1.83 & 64 & 35 \\
\hline CNG Transmission Co & Merged File & 509 & 61 & 108,369 & 15,561 & 4.37 & 31 & 39 \\
\hline East Tennessee Gas Co & Merged File & 59 & 377 & 12,150 & 2,746 & 6.87 & 9 & 97 \\
\hline Equitrans Inc & Pasha & 6 & 23 & 2,095 & 108 & 1.57 & & 96 \\
\hline National Fuel Gas Supply Co & Pasha & 221 & 26 & 11,981 & 1,391 & 3.53 & 88 & 34 \\
\hline Tennessee Gas Pipeline Co & Merged File & 614 & 47 & $\cdot 133,143$ & 31,336 & 7.16 & 43 & 85 \\
\hline Texas Eastern Transmission Co & Merged File & 403 & 182 & 245,599 & 54,699 & 6.77 & 25 & 85 \\
\hline Transcontinental Gas Pipeline Co & Merged File & 232 & 172 & 81,136 & 15,064 & 5.65 & 20 & 49 \\
\hline Trunkline Gas Co & Pasha & 49 & 39 & 30,462 & 6,045 & 6.04 & 54 & 91 \\
\hline Regional Total & & 3,485 & 82 & 846,599 & 150,617 & 5.41 & 40 & 67 \\
\hline \multicolumn{9}{|l|}{ Southeast Region } \\
\hline Alabama-Tennessee Gas Co & Merged File & 6 & 363 & 1,176 & 160 & 4.13 & 32 & 99 \\
\hline Florida Gas Transmission Co & Merged File & 33 & 91 & 3,935 & 749 & 5.79 & 75 & 34 \\
\hline Southern Natural Gas Co & Merged File & 314 & 33 & 77,290 & 3,499 & 1.38 & 88 & 97 \\
\hline Stingray Pipeline Co & Merged File & 82 & 84 & 1,984 & 247 & 3.79 & & 87 \\
\hline Regional Tolal & & 435 & 52 & 84,385 & 4,655 & 1.68 & 87 & 94 \\
\hline \multicolumn{9}{|l|}{ Southwest Region } \\
\hline Koch Gateway Pipeline Co & Pasha & 0 & & 4,868 & 2,200 & 13.75 & . & - \\
\hline NORAM Gas Transmission & Merged File & 0 & & 15,673 & 1,392 & 2.70 & 76 & 3 \\
\hline Regional Total & & 0 & & 20,541 & 3,592 & 5.32 & 76 & 2 \\
\hline \multicolumn{9}{|l|}{ West Region } \\
\hline El Paso Natural Gas Co & Merged File & 489 & 43 & 173,252 & 22,377 & 3.93 & 50 & 33 \\
\hline Northwest Pipeline Co & Merged File & 591 & 180 & 194,552 & 30,172 & 4.72 & 46 & 64 \\
\hline Pacific Gas Transmission Co & Merged File & 187 & 637 & 190,487 & 24,390 & 3.89 & $\cdot$ & 19 \\
\hline Paiute Pipeline Co & Merged File & 67 & 27 & 1,334 & 295 & 6.73 & 97 & $\therefore$ \\
\hline Transwestern Gas Pipeline Co & Merged File & 33 & 61 & 20,161 & 1.497 & 2.26 & . & 22 \\
\hline Regional Total & & 1,367 & 183 & 579.786 & 78,731 & 4.13 & 48 & 39 \\
\hline 1995-96 Heating Season Total & & 7,919 & 90 & $2,450,634$ & 392,432 & 4.87 & 65 & 65 \\
\hline
\end{tabular}

$\$ /$ Mcf-mo = Dollars per thousand cubic feet per month. Merged file $=$ Data file created by combining Pasha and EDI data. EDI $=$ Federal Energy Regulatory Commission, Electronic Data Interchange capacity release data set. Pasha = Pasha Publications, Inc. capacity release data set.

Source: Energy Information Administration, Office of Oil and Gas, derived from: November 1993 - July 1994: Pasha Publications, Inc. July 1994 - March 1996: Federal Energy Regulatory Commission, Electronic Data Interchange (EDI) data. 


\section{Appendix F \\ Existing and \\ Proposed \\ Underground Storage \\ Facilities}




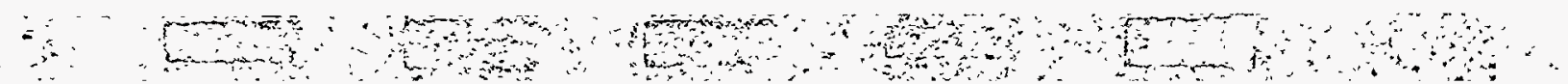




\section{Appendix F}

\section{Existing and Proposed Underground Storage Facilities}

This appendix provides additional information on the underground storage. segment of the natural gas industry. Storage is extremely important to the efficient and reliable delivery of natural gas supply to end users during peakdemand periods and as backup during system emergencies. It is also becoming increasingly important as a tool for pipeline companies, market centers, and shippers to maintain flow balances and inventory control in a restructured and more complex national transmission and distribution network.

\section{Overall Changes}

At the end of 1995, 403 underground storage sites were in operation in the United States (Table F1) and 11 in Canada. Pennsylvania (60), Michigan (47), and Texas (38) had the largest number of sites; the latter two States together represent 30 percent of overall working gas capacity (Figure F1). Five new sites were placed in operation during 1995, and expansions at seven sites were completed (Chapter 1 , Figure 7). The new sites are located in Texas, Louisiana, Kansas, Michigan, and Kentucky. The seven completed projects represented an increase of 47 billion cubic feet in working gas capacity and 1,395 million cubic feet of daily deliverability over 1994 levels.

During 1995, 10 underground sites were also abandoned (taken out of service). Five of the abandoned sites were in the Central Region (one in Colorado and three in Kansas) and three were in the Northeast (one in New York and two in Pennsylvania). The amount of capacity represented by the abandoned sites was 16 billion cubic feet of working gas and 85 million cubic feet per day of deliverability.

Based upon current information, perhaps $2 i$ more sites will be placed in operation by the early part of the next decade (Table F2) and 37 existing sites could be expanded. These 58 sites would represent an increase of 14 percent in both working gas capacity (268 billion cubic feet) and in daily deliverability ( 9.9 million cubic feet per day).

Three principal types of underground storage sites are in operation in the United States today: depleted reservoirs in oil and/or gas fields (337), aquifers (40), and salt cavern formations (26). Some supplemental gas supplies stored at liquefied natural gas and propane-air facilities and used primarily for peaking services are not covered in this appendix. The capability of an underground storage facility is primarily measured by its working gas capacity, that is, the amount of gas in inventory that can be readily withdrawn for delivery to customers, and the amount of gas that can be withdrawn from that inventory on a peak-day basis, also referred to as daily deliverability. Those sites that can rapidly deplete their inventory, primarily salt cavern facilities, are known as high-deliverability sites.

\section{Growth in High-Deliverability Storage}

Although salt cavern storage still represents a small percentage of total U.S. working gas capacity, its share of total daily deliverability has grown to 14 percent, from 6 percent in $1992 .{ }^{130}$ Today the industry, especially market centers, finds that high-deliverability storage is an integral part of their successful operation. Of the 19 salt cavern facilities located in the production area of the Southwest, 13 are used by market centers (see Chapter 3). Highdeliverability storage is also an ideal supply source for electric utilities and large industrial users, because their usage patterns match well with the salt cavern's peaking and shortnotice withdrawal capabilities.

Over the next several years additional storage facilities, 7 of which are high-deliverability sites, are planned to be developed and placed in service (Table F3). An additional 14 facilities are to be expanded. By the end of the decade, salt cavern working gas capacity could increase by 7 percent, or 73 billion cubic feet, and daily deliverability by 60 percent, or 5.9 billion cubic feet per day. The most likely projects to be completed will be those that support market center operations or supplement local seasonal needs.

Additional daily deliverability will also be developed at a number of conventional (depleted field) storage facilities. While expansions will add only 461 million cubic feet per day of deliverability to these sites, new sites could add as much as 3,250 million cubic feet per day to this type of storage. This

\footnotetext{
${ }^{130}$ Energy Information Administration, "The Expanding Role of Underground Storage," Natural Gas Monthly, DOE/EIA-0130(93-10) (Washington, DC, October 1993).
} 
Table F1. Summary of Existing Underground Natural Gas Storage, by Region and Type of Reservoir and Operator, 1995

\begin{tabular}{|c|c|c|c|c|c|c|c|c|c|c|c|c|}
\hline \multirow[b]{2}{*}{$\begin{array}{l}\text { Region/ } \\
\text { Operator }\end{array}$} & \multicolumn{3}{|c|}{ Depleted Gas/OII } & \multicolumn{3}{|c|}{ Aquifer Storage } & \multicolumn{3}{|c|}{ Salt Cavern Storage } & \multicolumn{3}{|c|}{ Total } \\
\hline & $\begin{array}{c}\text { Number } \\
\text { of } \\
\text { Sites }\end{array}$ & $\begin{array}{c}\text { Working } \\
\text { Gas } \\
\text { Capacity } \\
\text { (BcI) }\end{array}$ & $\begin{array}{l}\text { Daily } \\
\text { Deliver- } \\
\text { ability } \\
\text { (MMcf/d) }\end{array}$ & $\begin{array}{c}\text { Number } \\
\text { of } \\
\text { Sites }\end{array}$ & $\begin{array}{c}\text { Working } \\
\text { Gas } \\
\text { Capacity } \\
\text { (Bcf) }\end{array}$ & $\begin{array}{l}\text { Daily } \\
\text { Deliver- } \\
\text { ability } \\
\text { (MMcf/d) }\end{array}$ & $\begin{array}{c}\text { Number } \\
\text { of } \\
\text { Sites }\end{array}$ & $\mid \begin{array}{c}\text { Working } \\
\text { Gas } \\
\text { Capacity } \\
\text { (Bcf) }\end{array}$ & $\begin{array}{c}\text { Daily } \\
\text { Deliver- } \\
\text { ability } \\
\text { (MMcf/d) }\end{array}$ & $\begin{array}{c}\text { Number } \\
\text { of } \\
\text { Sites }\end{array}$ & $\begin{array}{c}\text { Working } \\
\text { Gas } \\
\text { Capacity } \\
\text { (BCf) }\end{array}$ & $\begin{array}{c}\text { Daily } \\
\text { Dellver- } \\
\text { ability } \\
\text { (MMcf/d) }\end{array}$ \\
\hline \multicolumn{13}{|l|}{ Northeast } \\
\hline Interstate & 93 & 602 & 10,956 & 0 & 0 & 0 & 0 & 0 & 0 & 93 & 602 & 10,956 \\
\hline Intrastate & 0 & 0 & 0 & 0 & 0 & 0 & 0 & 0 & 0 & 0 & 0 & 0 \\
\hline LDC & 23 & 29 & 506 & 0 & 0 & 0 & 0 & 0 & 0 & 23 & 29 & 506 \\
\hline Independent & 2 & 11 & 99 & 0 & 0 & 0 & 0 & 0 & 0 & 2 & 11 & 99 \\
\hline Total & 118 & 643 & 11,562 & 0 & 0 & 0 & 0 & 0 & 0 & 118 & 643 & 11,562 \\
\hline \multicolumn{13}{|l|}{ Southeast } \\
\hline Interstate & 7 & 114 & 2,164 & 0 & 0 & 0 & 1 & 5 & 1,500 & 8 & 119 & 3,664 \\
\hline Intrastale & 0 & 0 & 0 & 0 & 0 & 0 & 0 & 0 & 0 & 0 & 0 & 0 \\
\hline LDC & 16 & 23 & 523 & 2 & 5 & 65 & 1 & 2 & 120 & 19 & 30 & 709 \\
\hline Independent & 1 & 1 & 3 & 0 & 0 & 0 & 2 & 5 & 670 & 3 & 6 & 673 \\
\hline Total & 24 & 137 & 2,691 & 2 & 5 & 65 & 4 & 12 & 2,290 & 30 & 154 & 5,046 \\
\hline \multicolumn{13}{|l|}{ Midwest } \\
\hline Interstale & 35 & 455 & 6,489 & 6 & 52 & 1,383 & 0 & 0 & 0 & 41 & 508 & 7,872 \\
\hline Intrastate & 0 & 0 & 0 & 0 & 0 & 0 & 0 & 0 & 0 & 0 & 0 & 0 \\
\hline LDC & 54 & 401 & 8,997 & 22 & 196 & 3,486 & 2 & 2 & 85 & 78 & 599 & 12,568 \\
\hline Independent & 8 & 115 & 1,517 & 0 & 0 & 0 & 0 & 0 & 0 & 8 & 115 & 1,517 \\
\hline Total & 97 & 971 & 17,004 & 28 & 249 & 4,869 & 2 & 2 & 85 & 127 & 1,222 & 21,959 \\
\hline \multicolumn{13}{|l|}{ Central } \\
\hline Interstate & 21 & 380 & 3,710 & 7 & 88 & 1,215 & 0 & 0 & 0 & 28 & 469 & 4,925 \\
\hline Intrastate & 0 & 0 & 0 & 0 & 0 & 0 & 0 & 0 & 0 & 0 & 0 & 0 \\
\hline LDC & 16 & 90 & 358 & 1 & 9 & 350 & 0 & 0 & 0 & 17 & 99 & 708 \\
\hline Independent & 2 & 5 & 56 & 0 & 0 & 0 & 1 & 2 & 100 & 3 & 7 & 156 \\
\hline Total & 39 & 475 & 4,124 & 8 & 97 & 1,565 & 1 & 2 & 100 & 48 & 574 & 5,789 \\
\hline \multicolumn{13}{|l|}{ Southwest } \\
\hline Interstate & 15 & $478^{\circ}$ & 5,594 & 0 & 0 & 0 & 3 & 15 & 1,000 & 18 & 493 & 6,594 \\
\hline Intrastate & 12 & 167 & 2,766 & 0 & 0 & 0 & 2 & 8 & 1,200 & 14 & 175 & 3,966 \\
\hline LDC & 14 & 117 & 1,350 & 1 & 6 & 15 & 4 & 20 & 1,414 & 19 & 143 & 2,780 \\
\hline Independent & 7 & 147 & 1,015 & 0 & 0 & 0 & 10 & 31 & 3,915 & 17 & 178 & 4,930 \\
\hline Total & 48 & 910 & 10,726 & 1 & 6 & 15 & 19 & 74 & 7,529 & 68 & 990 & 18,271 \\
\hline \multicolumn{13}{|l|}{ Westem } \\
\hline Interstate & 0 & 0 & 0 & 0 & 0 & 0 & 0 & 0 & 0 & 0 & 0 & 0 \\
\hline Intrastate & 0 & 0 & 0 & 0 & 0 & 0 & 0 & 0 & 0 & 0 & 0 & 0 \\
\hline LDC & 10 & 226 & 6,480 & 1 & 12 & 525 & 0 & 0 & 0 & 11 & 238 & 7,005 \\
\hline Independent & 1 & 7 & 5 & 0 & 0 & 0 & 0 & 0 & 0 & 1 & 7 & 5 \\
\hline Total & 11 & 232 & 6,485 & 1 & 11 & 525 & 0 & 0 & 0 & 12 & 244 & 7,010 \\
\hline \multicolumn{13}{|l|}{ United States } \\
\hline Interstate & 171 & 2,030 & 28,915 & 13 & 141 & 2,598 & 4 & 20 & 2,500 & 188 & 2,191 & 34,013 \\
\hline Intrastate & 12 & 167 & 2,766 & 0 & 0 & 0 & 2 & 8 & 1,200 & 14 & 175 & 3,966 \\
\hline LDC & 133 & 886 & 18,215 & 27 & 228 & 4,441 & 7 & 24 & 1,619 & 167 & 1,139 & 24,277 \\
\hline Independent & 21 & 285 & 2,696 & 0 & 0 & 0 & 13 & 38 & 4,685 & 34 & 323 & 7,381 \\
\hline Total & 337 & 3,368 & 52,592 & 40 & 369 & 7,039 & 26 & 90 & 10,004 & 403 & 3,828 & 69,637 \\
\hline
\end{tabular}

Bcf = Billion cubic feet. MMcf/d = Million cubic feet per day.

Source: Energy Information Administration (EIA), EIAGIS-SD Geographic Information System, Underground Natural Gas Storage Database, as of December 1995, based on data from Form ElA-191, "Underground Gas Storage Report." 




Source: Energy Information Administration (EIA), EIAGIS-NG Geographic Information System, Natural Gas Underground Storage Database, compiled from Form ElA-191, "Underground Gas Storage Report."

is more than $1 \frac{1 / 2}{2}$ times as much as planned new salt cavern sites and almost as much as the planned expansions to salt cavern storage. In the area of expansions alone, Columbia Gas Transmission Company will be upgrading its facilities at 13 of its 43 sites and increasing daily deliverability by more than 326 million cubic feet per day during the heating season.

\section{- Ownership of Storage}

There has been a substantial shift in the percentage of working gas capacity and daily deliverability owned by the various types of storage operators. Because the new salt cavern sites have been developed primarily by independent operators, the growth in this category of storage has increased the amount of capacity and deliverability owned by this group to more than 8 percent, compared with only 4 percent in 1992.
The majority of the existing storage working gas capacity is located in the Midwest Region, which is also the largest market for natural gas in the United States. The second largest working gas capacity is in the Southwest Region, which is the source of much of the Nation's gas production. The Southwest is also the same region where the greatest amount of new storage capability is planned. Through 1999, more than 91 additional billion cubic feet of new working gas capacity and 4.3 billion cubic feet per day deliverability is planned, the largest of any region.

\section{Regional Developments}

The production area of the Southwest Region accounted for three of the five new sites that became operational during 1995. These new sites are located in the production areas of Texas and Louisiana. Alone, they represent about 87 percent 
Table F2. Proposed Underground Natural Gas Storage, by Planned In-Service Year and Type of Project, 1996-2000

\begin{tabular}{|c|c|c|c|c|c|c|c|c|c|c|c|c|}
\hline \multirow[b]{2}{*}{$\begin{array}{c}\text { Year / } \\
\text { Type }\end{array}$} & \multicolumn{3}{|c|}{ Depleted Gas/Oil } & \multicolumn{3}{|c|}{ Aquifer Storage } & \multicolumn{3}{|c|}{ Salt Cavern Storage } & \multicolumn{3}{|c|}{ Total } \\
\hline & $\begin{array}{c}\text { Number } \\
\text { of } \\
\text { Sites }\end{array}$ & $\begin{array}{c}\text { Working } \\
\text { Gas } \\
\text { Capacity } \\
\text { (Bcf) }\end{array}$ & $\begin{array}{l}\text { Daily } \\
\text { Deliver- } \\
\text { ability } \\
\text { (MMcf/d) }\end{array}$ & $\begin{array}{c}\text { Number } \\
\text { of } \\
\text { Sites }\end{array}$ & $\begin{array}{c}\text { Working } \\
\text { Gas } \\
\text { Capacity } \\
\text { (BcI) }\end{array}$ & $\begin{array}{l}\text { Daily } \\
\text { Deliver- } \\
\text { ability } \\
\text { (MMcf/d) }\end{array}$ & $\begin{array}{c}\text { Number } \\
\text { of } \\
\text { Sites }\end{array}$ & $\begin{array}{c}\text { Working } \\
\text { Gas } \\
\text { Capacity } \\
\text { (Bcf) }\end{array}$ & $\begin{array}{c}\text { Daily } \\
\text { Deliver- } \\
\text { ability } \\
\text { (MMcf/d) }\end{array}$ & $\begin{array}{c}\text { Number } \\
\text { of } \\
\text { Sites }\end{array}$ & $\begin{array}{c}\text { Working } \\
\text { Gas } \\
\text { Capacity } \\
\text { (Bcf) }\end{array}$ & $\begin{array}{c}\text { Daily } \\
\text { Deliver- } \\
\text { ability } \\
\text { (MMcf/d) }\end{array}$ \\
\hline Existing End of 1995 & 337 & 3,368 & 52,592 & 40 & 369 & 7,039 & 26 & 90 & 10,004 & 403 & 3,828 & 69,637 \\
\hline \multicolumn{13}{|l|}{1996} \\
\hline New & 5 & 103 & 2,070 & 0 & 0 & 0 & 2 & 1 & 105 & 7 & 104 & 2,175 \\
\hline Expansion & 2 & 2 & 65 & 1 & 1 & 0 & 5 & 8 & 575 & 8 & 12 & 640 \\
\hline Total & $\overline{7}$ & 105 & 2,135 & 1 & 1 & 0 & 7 & 9 & 680 & 15 & 116 & 2,815 \\
\hline \multicolumn{13}{|l|}{1997} \\
\hline New & 2 & 15 & 500 & 1 & 4 & 100 & 2 & 3 & 445 & 5 & 22 & 1,045 \\
\hline Expansion & 6 & 5 & 252 & 1 & 2 & 50 & 4 & 20 & 2,370 & 11 & 27 & 2,672 \\
\hline Total & 8 & 20 & 752 & 2 & 6 & 150 & 6 & 23 & 2,815 & 16 & 50 & 3,717 \\
\hline \multicolumn{13}{|l|}{1998} \\
\hline New & 2 & 31 & 400 & 0 & 0 & 0 & 2 & 17 & 900 & 4 & 48 & 1,300 \\
\hline Expansion & 3 & 0 & 33 & 1 & 2 & 50 & 2 & 3 & 300 & 6 & 5 & 383 \\
\hline Total & 5 & 31 & 433 & 1 & 2 & 50 & 4 & 20 & 1,200 & 10 & 53 & 1,683 \\
\hline \multicolumn{13}{|l|}{1999} \\
\hline New & 4 & 24 & 280 & 0 & 0 & 0 & 0 & 0 & 0 & 4 & 24 & 280 \\
\hline Expansion & 6 & 1 & 111 & 1 & 2 & 50 & 3 & 10 & 680 & 10 & 13 & 841 \\
\hline Total & 10 & 25 & 391 & 1 & 2 & 50 & 3 & 10 & 680 & 14 & 37 & 1,121 \\
\hline \multicolumn{13}{|l|}{2000} \\
\hline New & 0 & 0 & 0 & 0 & 0 & 0 & 1 & 5 & 500 & 1 & 5 & 500 \\
\hline Expansion & 0 & 0 & 0 & 2 & 4 & 100 & 0 & 0 & 0 & 2 & 4 & 100 \\
\hline Total & 0 & 0 & 0 & 2 & 4 & 100 & 1 & 5 & 500 & 3 & 9 & 600 \\
\hline \multicolumn{13}{|l|}{ Grand Total } \\
\hline New & 13 & 173 & 3,250 & 1 & 4 & 100 & 7 & 27 & 1,950 & 21 & 205 & 5,300 \\
\hline Expansion & 17 & 8 & 461 & 6 & 11 & 250 & 14 & 42 & 3,925 & 37 & 62 & 4,636 \\
\hline Total & 30 & 181 & 3,711 & 7 & 15 & 350 & 21 & 69 & 5,875 & 58 & 268 & 9,936 \\
\hline
\end{tabular}

Bcf = Billion cubic feet. MMcf/d = Million cubic feet per day.

Source: Energy Information Administration (EIA), EIAGIS-NG Geographic Information System, Proposed Underground Storage Database, as of September 1996, based on Federal Energy Regulatory Commission filings and information compiled from various industry new sources.

of national new-site working gas capacity ( 28 billion cubic feet) and 89 percent of new-site daily deliverability $(850$ million cubic feet per day). Completed expansion projects in the region accounted for an additional 6.3 billion cubic feet in working gas capacity and 300 million cubic feet per day in deliverability, almost all of it at high-deliverability sites. Most of these sites were operational during the past heating season and, with their high-deliverability features and increased tie-in with market center operations, provided additional support to the needs of customers in the Northeast and Midwest markets during the cold snaps in early 1996. 
Table F3. Summary of Proposed Underground Natural Gas Storage, by Region and Type of Reservoir and Operator, 1996-2000

\begin{tabular}{|c|c|c|c|c|c|c|c|c|c|c|c|c|}
\hline \multirow[b]{2}{*}{$\begin{array}{l}\text { Reglon/ } \\
\text { Operator }\end{array}$} & \multicolumn{3}{|c|}{ Depleted Gas/Oll } & \multicolumn{3}{|c|}{ Aquifer Storage } & \multicolumn{3}{|c|}{ Salt Cavern Storage } & \multicolumn{3}{|c|}{ Total } \\
\hline & $\begin{array}{l}\text { Number } \\
\text { of } \\
\text { sltes }\end{array}$ & $\begin{array}{c}\text { Worklng } \\
\text { Gas } \\
\text { Capaclty } \\
\text { (Bcl) }\end{array}$ & $\begin{array}{l}\text { Dally } \\
\text { Dellver- } \\
\text { abllity } \\
\text { (MMct/d) }\end{array}$ & $\begin{array}{c}\text { Number } \\
\text { of } \\
\text { sites }\end{array}$ & $\begin{array}{c}\text { Working } \\
\text { Gas } \\
\text { Capacity } \\
\text { (Bct) }\end{array}$ & $\begin{array}{l}\text { Dally } \\
\text { Dellver- } \\
\text { abllity } \\
\text { (MMcl/d) }\end{array}$ & $\begin{array}{c}\text { Number } \\
\text { of } \\
\text { sltes }\end{array}$ & $\begin{array}{c}\text { Working } \\
\text { Gas } \\
\text { Capacity } \\
\text { (Bci) }\end{array}$ & $\begin{array}{l}\text { Dally } \\
\text { Dellver- } \\
\text { abllity } \\
\text { (MMcf/d) }\end{array}$ & $\begin{array}{c}\text { Number } \\
\text { of } \\
\text { Sites }\end{array}$ & $\begin{array}{c}\text { Working } \\
\text { Gas } \\
\text { Capacity } \\
(\mathrm{Bcf})\end{array}$ & $\begin{array}{l}\text { Dally } \\
\text { Dellver- } \\
\text { abllity } \\
\text { (MMcf/d) }\end{array}$ \\
\hline \multicolumn{13}{|l|}{ Northeast } \\
\hline Interstate & 9 & 1 & 225 & 0 & $\mathbf{0}$ & 0 & 4 & 5 & 525 & 13 & 7 & 780 \\
\hline Intrastate & 1 & 1 & 60 & 0 & 0 & 0 & 1 & 0 & 80 & 2 & 2 & 140 \\
\hline LDC & 0 & 0 & 0 & 0 & 0 & 0 & 0 & 0 & 0 & 0 & 0 & 0 \\
\hline Independent & 2 & 6 & 70 & 0 & 0 & 0 & 2 & 5 & 550 & 4 & 11 & 620 \\
\hline Tolal & 12 & 9 & 385 & 0 & 0 & 0 & 7 & 11 & 1,155 & 19 & 21 & 1,540 \\
\hline \multicolumn{13}{|l|}{ Southeast } \\
\hline Interstate & 0 & 0 & 0 & 0 & 0 & 0 & 0 & 0 & 0 & 0 & 0 & 0 \\
\hline Intrastate & 0 & 0 & 0 & 0 & 0 & 0 & 0 & 0 & 0 & 0 & 0 & 0 \\
\hline LDC & 0 & 0 & 0 & 0 & 0 & 0 & 0 & 0 & 0 & 0 & 0 & 0 \\
\hline Independent & 5 & 24 & 280 & 0 & 0 & 0 & 1 & 2 & 220 & 6 & 26 & 500 \\
\hline Total & 5 & 24 & 280 & 0 & 0 & 0 & 1 & 2 & 220 & 6 & 26 & 500 \\
\hline \multicolumn{13}{|l|}{ Midwest } \\
\hline Interslate & 7 & 42 & 876 & 0 & 0 & 0 & 0 & 0 & 0 & 7 & 42 & 876 \\
\hline Intraslale & 0 & 0 & 0 & 0 & 0 & 0 & 0 & 0 & 0 & 0 & 0 & 0 \\
\hline LDC & 1 & 17 & 200 & 1 & 1 & 0 & 0 & 0 & 0 & 2 & 18 & 200 \\
\hline Independent & 0 & 0 & 0 & 1 & 4 & 100 & 1 & 15 & 350 & 2 & 19 & 450 \\
\hline Total & 8 & 59 & 1,076 & 2 & 5 & 100 & 1 & 15 & 350 & 5 & 79 & 1,526 \\
\hline \multicolumn{13}{|l|}{ Central } \\
\hline Interstate & 0 & 0 & 0 & 0 & 0 & 0 & 1 & 5 & 500 & 1 & 5 & 500 \\
\hline Intrastale & 0 & 0 & 0 & 0 & 0 & 0 & 0 & 0 & 0 & 0 & 0 & 0 \\
\hline LDC & 0 & 0 & 0 & 0 & 0 & 0 & 0 & 0 & 0 & 0 & 0 & 0 \\
\hline Independent & 1 & 3 & 120 & 0 & 0 & 0 & 4 & 5 & 500 & 5 & 9 & 620 \\
\hline Total & 1 & 3 & 120 & 0 & 0 & 0 & 5 & 10 & 1,000 & 6 & 14 & 1,120 \\
\hline \multicolumn{13}{|l|}{ Soulhwest } \\
\hline Interstate & 0 & 0 & 0 & 0 & 0 & 0 & 1 & 7 & 600 & 1 & 7 & 600 \\
\hline Intrastate & 0 & 0 & 0 & 0 & 0 & 0 & 2 & 13 & 1,000 & 3 & 16 & 1,000 \\
\hline LDC & 0 & 0 & 0 & .0 & 0 & 0 & 0 & 0 & 0 & 0 & 0 & 0 \\
\hline Independent & 2 & 57 & 1,150 & 0 & 0 & 0 & 4 & 10 & 1,550 & 7 & 67 & 2,700 \\
\hline Total & 2 & 57 & 1,150 & 0 & 0 & 0 & 7 & 30 & 3,150 & 11 & 91 & 4,300 \\
\hline \multicolumn{13}{|l|}{ Western } \\
\hline Interstate & 0 & 0 & 0 & 0 & 0 & 0 & 0 & 0 & 0 & 0 & 0 & 0 \\
\hline Intrastate & 0 & 0 & 0 & 0 & 0 & 0 & 0 & 0 & 0 & 0 & 0 & 0 \\
\hline LDC & 0 & 0 & 0 & 5 & 10 & 250 & 0 & 0 & 0 & 5 & 10 & 250 \\
\hline Independent & 2 & 29 & 700 & 0 & 0 & 0 & 0 & 0 & 0 & 2 & 29 & 700 \\
\hline Total & 2 & 29 & 700 & 5 & 10 & 250 & 0 & 0 & 0 & 7 & 39 & 950 \\
\hline \multicolumn{13}{|l|}{ United States } \\
\hline Interstate & 16 & 43 & 1,131 & 0 & 0 & 0 & 6 & 17 & 1,625 & 22 & 61 & 2,756 \\
\hline Intrastate & 1 & 1 & 60 & 0 & 0 & 0 & 3 & 14 & 1,080 & 4 & 16 & 1,140 \\
\hline LDC & 1 & 17 & 200 & 6 & 11 & 250 & 0 & 0 & 0 & 7 & 28 & 450 \\
\hline Independent & 12 & 120 & 2,320 & 1 & 4 & 100 & 12 & 37 & 3,170 & 25 & 162 & 5,590 \\
\hline Total & 30 & 181 & 3,711 & 7 & 15 & 350 & 21 & 69 & 5,875 & 58 & 268 & 9,936 \\
\hline
\end{tabular}

Bcf = Billion cubic feet. MMcf/d = Million cubic feet per day. LDC = Local distribution company.

Source: Energy Information Administration, EIAGIS.NG Geographic Information System, Proposed Underground Storage Database, as of September 1996, based on Federal Energy Regulatory Commission filings and information compiled from various industry new sources. 

Appendix G

\section{Pipeline Expansions}





\section{Appendix G}

\section{Pipeline Expansions}

Expansion of the interstate pipeline grid has slowed somewhat in recent years. However, several new projects are planned to remove some system bottlenecks and move low-cost supplies located in the Central United States and Western Canada to markets in the U.S. Midwest and Northeast. Currently, the capability to do so is limited. The price differentials between supplies sold at the centers in West Texas and those in East Texas and the Henry Hub were often quite significant during the 1995-96 heating season, far exceeding the cost of transportation alone-if transport was available. Several proposed new pipelines and expansions to a number of existing systems could potentially increase the volume of business transacted at several market centers located in the Central United States and Canada.

As of September 30, 1996, the Energy Information Administration was tracking approximately 88 planned pipeline expansions and new pipeline projects at various stages of development in the United States, Canada, and Mexico (Table G1). If all U.S. projects were completed, the amount of new capacity would add 17,043 million cubic feet of daily deliverability on the national network (one project is entirely in Mexico and four entirely in Canada). ${ }^{131}$ Of the total projects, 19 are planned for completion in 1996, 40 in 1997, 21 in 1998, 7 in 1999, and 1 in the year 2000. Thirty of the projects call for development of new pipeline systems or new facilities at international border points.

The least amount of new construction is planned in the Western Region, 95 million cubic feet (MMcf) per day. This is not surprising since the region now is experiencing an excess of interstate capacity. Between 1990 and 1995, interstate capacity within and into the region increased by 58 percent, from 16,545 to $26,088 \mathrm{MMcf}$ per day, more than any other region. The Northeast has the next lowest amount of planned pipeline expansions, 2,310.MMcf per day, but it has the largest number of proposed new projects (26). Proposed capacity additions in the Southeast Region for the most part are geared toward improving specific services to customers in North and South Carolina, although two major projects are designed to increase regional access to deep water production in the Gulf of Mexico by as much as 2 billion cubic feet per day by 1999 .

\footnotetext{
${ }^{13}$ However, 118 nillion cubic feet of the Transcanada Pipeline Expansion Project's 286 million cubic feet of daily deliverability represents planned increases to export capability.
}

This appendix examines the nature and type of proposed pipeline projects announced or approved for construction during the next several years in the United States. It also includes those projects in Canada and Mexico that tie-in with U.S. markets or projects.

\section{Regional Developments}

\section{Gulf of Mexico}

\section{Deep Water Access}

One of the more significant developments of the past year has been the increased attention to development of gas resources in deeper waters in the Gulf of Mexico, off Louisiana and Mississippi. Since the beginning of 1996, six new pipelines, representing more than 4,400 MMcf per day (not including gathering lines), have been proposed to reach into the deep water area of the Gulf to tap the several new production sources being developed there, notably the Ship Shoal, Green Canyon, Destin Corridor, and Misşissippi Canyon areas of the Gulf. Companies such as Marathon Oil, Shell Oil, and Texaco are represented (Figure G1). Several additional projects, representing about $375 \mathrm{MMcf}$ per day, also are being developed in the Gulf by Stingray Pipeline Company and Centana Energy Corporation to increase access to production closer to shore in the Main Pass and Vermillion Block areas.

\section{Southwest}

Development of offshore and deep water pipeline-related projects represent 70 percent of the 3,954 MMcf per day planned additions in the Southwest Region. Several of the remaining projects are also significant, because they will increase access to supplies from the San Juan Basin of New Mexico and direct them eastward toward West Texas market centers.

\section{Southern Colorado and the San Juan Basin Area of Northern New Mexico}

The amount of pipeline capacity available to move gas from the San Juan Basin area eastward is quite limited. Further 
Table G1. Major Pipeline Construction Projects Planned or Announced for Development, by Terminating Region and Planned In-Service Year, 1996-2000

\begin{tabular}{|c|c|c|c|c|c|c|c|c|c|c|c|}
\hline Year & Pipeline/Project Name & $\begin{array}{l}\text { Map } \\
\text { Key }\end{array}$ & $\begin{array}{l}\text { FERC } \\
\text { Docket } \\
\text { Number }\end{array}$ & $\begin{array}{c}\text { Status } \\
\text { As of } \\
9-30-96^{t}\end{array}$ & $\begin{array}{c}\text { New } \\
\text { or } \\
\text { Expansion }\end{array}$ & $\begin{array}{l}\text { Began in } \\
\text { Region }\end{array}$ & $\begin{array}{l}\text { Stat } \\
\text { Begin }\end{array}$ & End & Miles & $\begin{array}{c}\text { Cost } \\
\text { Estimate } \\
\text { (million \$) }\end{array}$ & $\begin{array}{c}\text { Added } \\
\text { Capacity } \\
\text { (MMcf/d) }\end{array}$ \\
\hline \multicolumn{12}{|c|}{ Canada } \\
\hline 1996 & ANR Link & A1 & СР93-564 & Approved & New & Midwest & MI & ON & 12 & 15 & 150 \\
\hline 1996 & Great Lakes St Clair Loop & $\mathrm{A} 2$ & CP96-26 & Approved & Expn & Midwest & MI & ON & NA & 4 & 50 \\
\hline 1998 & TransCanada System & A3 & N/A & Approved & Expn & Canada & SK & QU & 128 & 900 & 286 \\
\hline 1998 & Palliser Pipeline & A4 & NA & Announced & New & Canada & $A B$ & $A B$ & 590 & 219 & 1,000 \\
\hline 1998 & Foothills Eastem Expn & A5 & NA & Announced & Expn & Canada & SK & SK & 0 & 0 & 700 \\
\hline \multirow[t]{2}{*}{1999} & Sable Transcanadian & A6 & NA & Pending & New & Canada & NS & QU & 128 & 899 & 400 \\
\hline & & & & & & & & & \multicolumn{2}{|c|}{ Total New Capacity } & 2,586 \\
\hline \multicolumn{12}{|c|}{ Central } \\
\hline 1996 & NGPL Amarillo Upgrade & B1 & CP94-577 & Approved & Expn & Southwest & OK & NE & 14 & 33 & -25 \\
\hline 1996 & ClG Pisceance Lateral & $\mathrm{B} 2$ & CP95-106 & Pending & New & Central & $\mathrm{co}$ & $\mathrm{CO}$ & NA & 9 & 37 \\
\hline 1996 & KN Interstate Casper Loop & B3 & CP95-113 & Approved & Expn & Central & $W Y$ & WY & 52 & 15 & 48 \\
\hline 1996 & Mid-Continent Hub Link & B4 & NA & Announced & New & Central & KS & KS & 9 & 10 & 100 \\
\hline 1996 & Viking Northern Looping & B5 & CP96-32 & Pending & Expn & Canada & $\mathrm{CN}$ & WI & 14 & 8 & 194 \\
\hline 1996 & Williams Springfield Expn & B6 & CP95-700 & Approved & Expn & Central & MO & MO & 28 & 14 & 23 \\
\hline 1996 & CIG Wind River Lateral Expn & B7 & CP96-289 & Approved & Expn & Central & WY & WY & NA & 11 & 72 \\
\hline 1997 & Trailblazer Eastward Expn & B8 & NA & Approved & Expn & Central & $\mathrm{CO}$ & NE & 445 & NA & 105 \\
\hline 1997 & Wyoming Interstate Eastward & B9 & CP96-288 & Approved & Expn & Central & WY & $\mathrm{CO}$ & NA & 40 & 192 \\
\hline 1997 & Williams Gas WY-KS Expn & B10 & NA & Planning & Expn & Central & WY & KS & NA & NA & 30 \\
\hline 1997 & Williams Gas KS-MO Expn & B11 & NA & Planning & Expn & Central & KS & MO & NA & NA & 15 \\
\hline 1997 & KN Interstate Pony Express & $\mathrm{B} 12$ & CP96-477 & Pending & New & Central & Wr & MO & 850 & 154 & 255 \\
\hline 1998 & Altamont Pipeline & B13 & CP90-1372 & Approved & New & Canada & CN & Wr & 620 & 139 & 737 \\
\hline 1998 & Northem Border Monchy Expn & B14 & CP95-194 & Approved & Expn & Canada & MT & IA & 243 & 797 & 700 \\
\hline \multirow[t]{2}{*}{1998} & Northem Border Haper Expn & B15 & CP95-194 & Approved & Expn & $\overrightarrow{\text { Central }}$ & IA & IA & 142 & NA & 962 \\
\hline & & & & & & & & & \multicolumn{2}{|c|}{ Total New Capacity } & 3,444 \\
\hline \multicolumn{12}{|c|}{ MIdwest } \\
\hline 1996 & Great Lakes PLLooping I & $\mathrm{C} 2$ & CP95-375 & Approved & Expn & Midwest & MI & MI & 14 & 17 & 5 \\
\hline 1996 & Great Lakes PI Looping II & C3 & CP96-297 & Pending & Expn & Midwest & MI & MI & 25 & 44 & 0 \\
\hline 1996 & Northem Natural Zone EF & $\mathrm{C} 4$ & CP96-57 & Approved & Expn & Midwest & MN & WI & 30 & 19 & 46 \\
\hline 1997 & ANR Joliet Project & C5 & NA & Announced & Expn & Central & IA & IL & NA & NA & 660 \\
\hline 1997 & ANR Michigan Leg Expn & $\mathrm{cg}$ & CP96-641 & Pending & Expn & Central & IL & MI & 120 & 19 & 135 \\
\hline 1997 & TransCanada Import Expn & $\mathrm{C} 10$ & N/A & Approved & Expn & Canada & $\mathrm{CN}$ & $\mathrm{MN}$ & NA & NA & 56 \\
\hline 1998 & NGPL Amatillo Expn & C6 & CP96-27 & Approved & Expn & $\overline{\text { Central }}$ & IA & IL & 85 & 85 & 345 \\
\hline 1998 & Northem Border Manhattan & $\mathrm{C7}$ & CP95-194 & Approved & New & Central & IA & IL & 200 & NA & 684 \\
\hline 1998 & Great Lakes System Wide Expn & $\mathrm{C} 2$ & CP95-647 & Pending & Expn & Central & $\mathrm{CN}$ & MI & 200 & 149 & 126 \\
\hline \multirow[t]{2}{*}{1999} & Alliance Project & $\mathrm{C8}$ & NA & Planning & New & Canada & $\mathrm{CN}$ & IL & 1864 & NA & 1,200 \\
\hline & & & & & & & & & \multicolumn{2}{|c|}{ Total New Capaclty } & 3,257 \\
\hline \multicolumn{12}{|c|}{ Northeast } \\
\hline 1996 & Texas Eastem Flex-X Oxford & D1 & CP95-74 & Pending & Expn & Northeast & PA & PA & 2 & 8 & 31 \\
\hline 1996 & Texas Eastem Flex-X Philly Lat & D2 & CP95-76 & Approved & Expn & Northeast & PA & PA & 24 & 8 & 12 \\
\hline 1996 & Texas Eastem ITP Phase 1 & D3 & CP92-184 & Approved & Expn & Midwest & $\mathrm{OH}$ & NJ & NA & 233 & 25 \\
\hline 1997 & Columbia Gas Market Expn & D4 & CP96-213 & Pending & Expn & Northeast & PA & VA & 379 & 64 & 232 \\
\hline 1997 & CNG Seasonal Service Expn & D5 & CP96-492 & Pending & Expn & Northeast & WV & PA & 16 & 0 & 100 \\
\hline 1997 & CNG PL-1 Phase I & D6 & CP96-492 & Pending & Expn & Northeast & PA & VA & NA & NA & 15 \\
\hline 1997 & CNG Woodhull/Avoca Line & D7 & CP96-493 & Pending & New & Northeast & NY & NY & 16 & 0 & 100 \\
\hline 1997 & Iroquois Import Expn & D15 & CP96-687 & Pending & Expn & Northeast & NY & NY & 200 & NA & 35 \\
\hline 1997 & Maritimes \& Northeast Phase I & D8 & CP96-178 & Approved & New & Northeast & MA & ME & 64 & 82 & 60 \\
\hline 1997 & National Fuel Niagara Expn & $\mathrm{D} 12$ & CP96-671 & Pending & Expn & Northeast & NY & PA & 138 & 11 & 48 \\
\hline 1997 & Transco Seaboard Expn & D9 & CP96-545 & Pending & Expn & Northeast & PA & NY & 36 & 118 & 115 \\
\hline 1997 & TransCanada Import (Iroquois) & D15 & N/A & Pending & Expn & Canada & $\mathrm{CN}$ & NY & NA & NA & 24 \\
\hline 1997 & TransCanada Import (Chippawa) & D12 & N/A & Pending & Expn & Canada & $\mathrm{CN}$ & NY & NA & NA & 48 \\
\hline 1997 & TransCanada Import (Niagara) & $\mathrm{C} 12$ & N/A & Pending & Expn & $\overline{\text { Canada }}$ & $\mathrm{CN}$ & NY & NA & NA & 39 \\
\hline 1997 & Texas Eastem Winternet I & D10 & CP96-606 & Pending & Expn & Northeast & PA & PA & NA & NA & 20 \\
\hline 1997 & Columbia Gas WV Expn & D11 & CP95-217 & Approved & Expn & Northeast & WV & WV & 18 & 17 & 28 \\
\hline 1998 & Columbia Gas Market Expn II & D4 & CP96-213 & Pending & Expn & Northeast & $P A$ & VA & 379 & 64 & 275 \\
\hline 1998 & Tenneco Mid-Atlantic & D6 & NA & Announced & New & Northeast & WV & PA & NA & NA & 335 \\
\hline 1998 & CNG PL-1 Phase II & D12 & CP96.492 & Pending & Expn & Northeast & PA & VA & NA & NA & 25 \\
\hline 1998 & Portland Pipeline & D13 & CP95-52 & Approved & New & Canada & CN & ME & 200 & 260 & 250 \\
\hline 1998 & Tenneco/DOMAC & D14 & CP96-164 & Pending & New & Northeast & MA & MA & 8 & 26 & 55 \\
\hline 1998 & Texas Eastem Winternet II & D10 & NA & Pending & Expn & Northeast & PA & PA & NA & NA & 20 \\
\hline 1999 & CNG PL-1 Phase III & D6 & CP96-492 & Pending & Expn & Northeast & PA & VA & NA & NA & 25 \\
\hline 1999 & Maritimes \& Northeast Phase II & D15 & CP96-178 & Pending & New & Canada & CN & MA & 386 & 404 & 440 \\
\hline 1999 & Texas Eastem Winternet III & D10 & CP96-606 & Pending & Expn & Northeast & PA & PA & NA & NA & 12 \\
\hline 2000 & Texas Eastem Winternet IV & D10 & CP96-606 & Pending & Expn & Northeast & PA & PA & NA & NA & 12 \\
\hline & & & & & & & & & Total I & apacity & 2,310 \\
\hline
\end{tabular}

Energy Information Administration Natural Gas 1996: Issues and Trends 
Table G1. Major Pipeline Construction Projects Planned or Announced for Development, by Terminating Region and Planned In-Service Year, 1996-2000 (Continued)

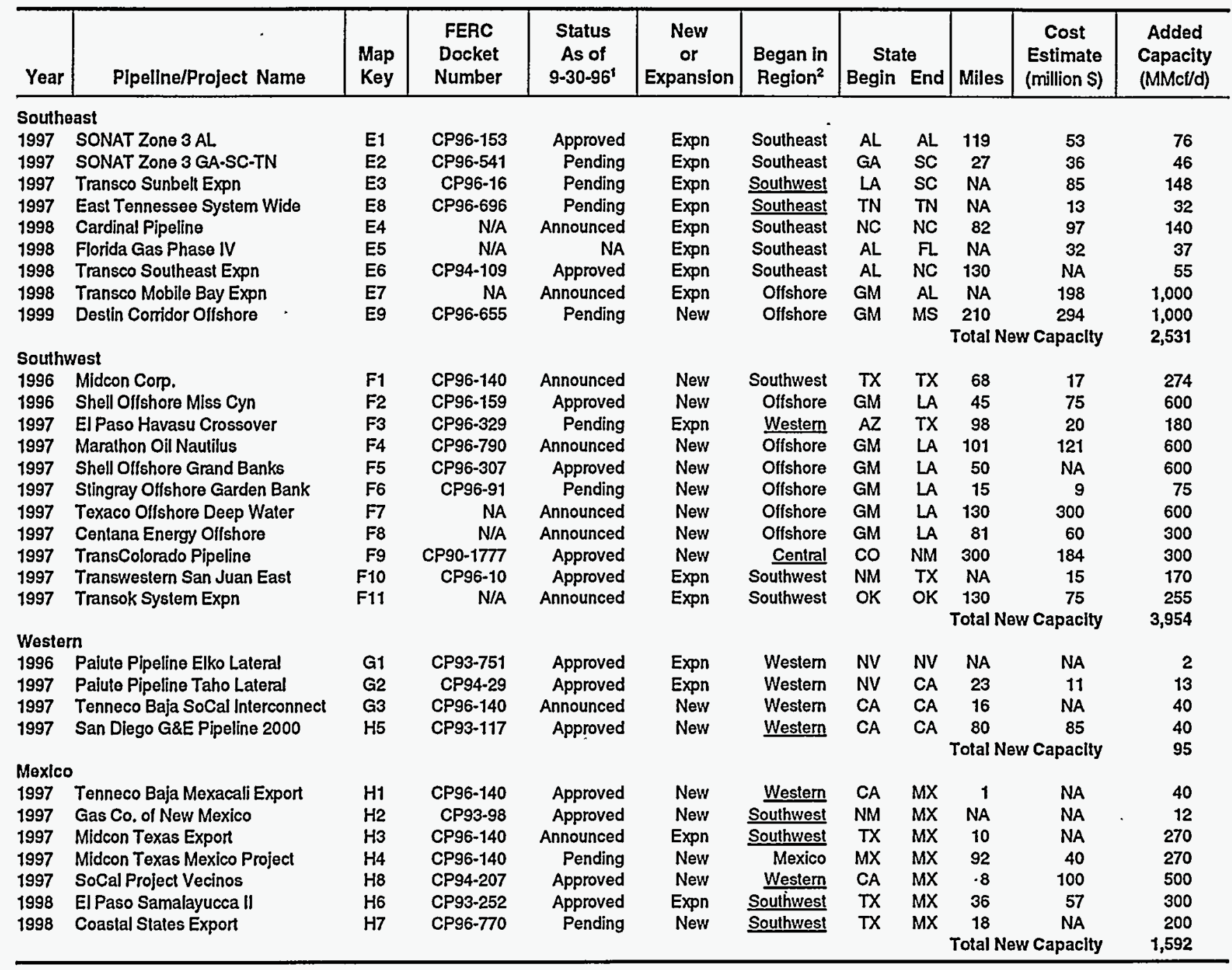

'Announced $=$ Prior to filing with regulatory authorities. Pending $=$ Before regulatory authority for review and acceptance. Approved $=$ Fully or conditionally approved by regulating authority; may or may not be under construction.

'Underlined items indicate project crosses regional boundary.

MMct/d = Million cubic feet per day. Expn = Expansion. $N A=$ Not available. $N / A=$ Not applicable.

NGPL = Natural Gas Pipeline Co. of America; $\mathrm{ClG}=$ Colorado Interstate Gas Co.; CNG = CNG Transmission Co; SONAT = Southern Natural Gas Co.

Source: Energy Information Administration, EIAGIS-NG Geographic Information System, Natural Gas Proposed Pipeline Construction Database, as of September 1996, compiled from Federal Energy Regulatory Commission filings and various industry news sources. 
Figure G1. General Location of Major Pipeline Construction Projects, Approved or Announced, 1996-2000

(Keyed to Table G1)

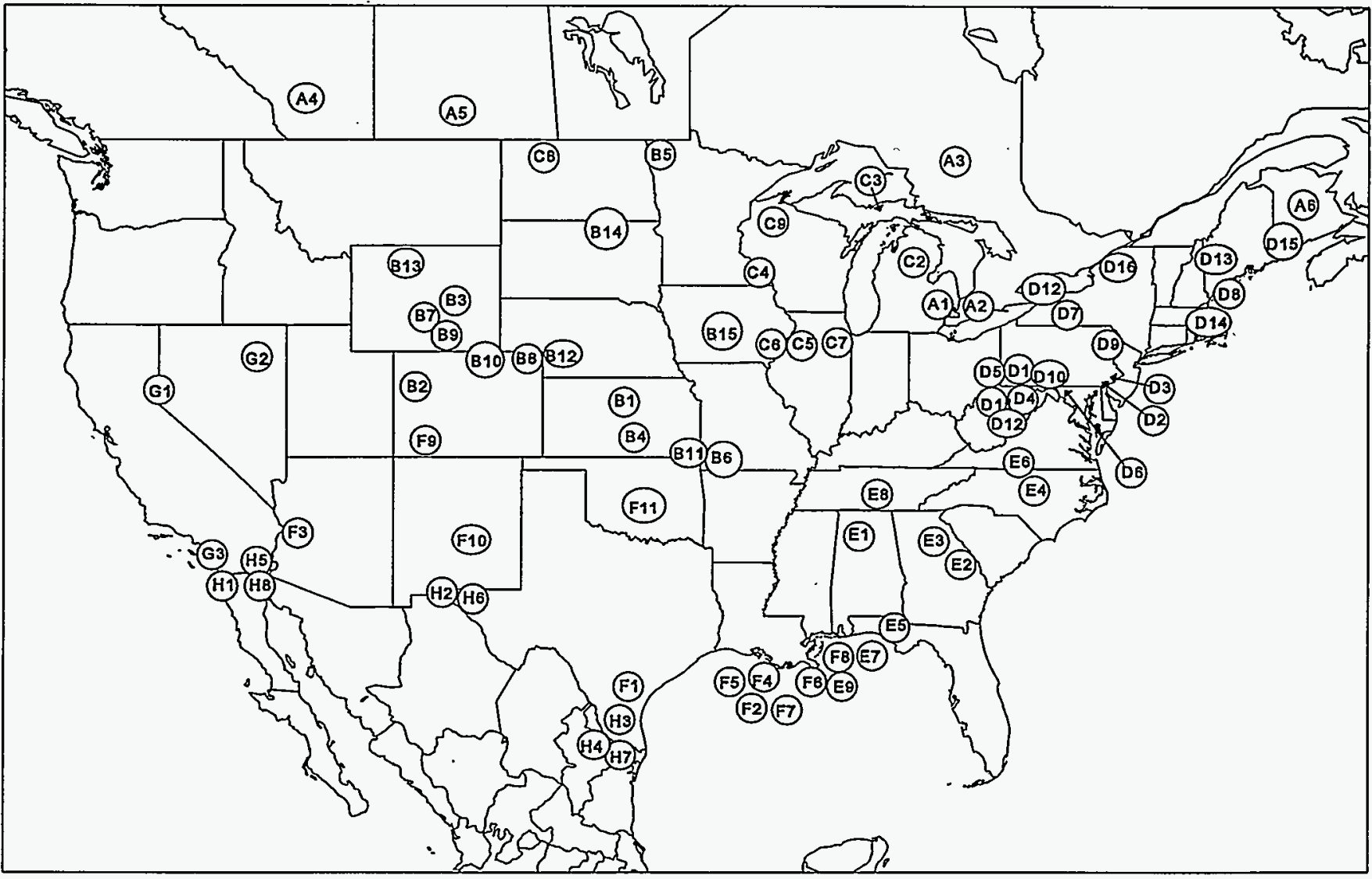

Source: Energy Information Administration (EIA), EIAGIS-NG Geographic Information System, Natural Gas Proposed Pipeline Construction Database, as of September 1996, based on information filed with the Federal Energy Regulatory Commission and compiled from various industry sources.

development of the area's coalbed methane and other supplies in the area has led to excess supply. Originally this production was expected to be consumed in the California market, and pipeline capacity was developed with that in mind. Today, however, the emphasis is on finding ways to move some of this supply eastward to link with market centers in the Waha area of Texas and from there to redirect the gas through northern and eastern Texas to Midwest and Northeast markets. The pipeline companies in the area, Transwestern Pipeline and El Paso Natural Gas, are planning to expand the capacity on that portion of their systems (Figure G2, items A and $\underline{B}$, respectively) to direct more production eastward to the Waha/Permian Basin centers.

In particular, these expansions will increase the operations of the Blanco center, which is strategically located at the terminus of the Transwestern and El Paso pipeline systems exiting the San Juan Basin in northern New Mexico. This center has been operating at full capacity and could grow significantly as additional capacity becomes available and the option to move greater volumes eastward increases. The effect on those market centers to the west, for instance the California Energy (SoCal) and Mojave center, is problematic since those centers are geared more toward parking and loaning services with limited emphasis on transportation services. The most significant impact can be expected at the Waha area and Buffalo Wallow centers as they compete with each other to direct the additional flows to the eastern Texas area and beyond.

\section{Access to Oklahoma's Anadarko Basin}

The Oklahoma Anadarko Basin is another production area that has the potential for development of greater access to regional market centers, although currently only one major project, the Transok Pipeline Company's system-wide expansion project, is slated for the area. Market centers located in eastern Texas and northern and southern Louisiana 
Figure G2. Planned Expansions to Improve Service From San Juan (Blanco) Area to West and North Texas Market Centers, 1997



Note: Not all area pipelines are represented.

Source: Energy Information Administration (EIA), EIAGIS-NG Geographic Information System, Natural Gas Market Center/Hub and Natural Gas Proposed Pipeline Construction Databases, as of September 1996, based on information filed with the Federal Energy Regulatory Commission and from various industry news sources.

could benefit from interest and increased access to the relatively lower priced production in the area. Current regional pipeline systems, with some improvements in interconnections, could direct some of their flows eastward-for instance, via the Transok Pipeline system onto the Ozark and NORAM Pipeline systems for routing to the Perryville centers in northern Louisiana (Figure G3). Another option would be to route their flows through the Carthage center in southeast Texas via the intrastate Texoma Pipeline system which runs southward from northeast Texas. Tejas Gas Company, which is a major marketer (shipper) as well as an administrator of several market center operations, recently acquired the Transok system, perhaps in part with the intention of rerouting some of the Anadarko production to higher priced markets via current and future market center interconnections. ${ }^{132}$

${ }^{132}$ See "Tejas Gas Buys Transok," Gas Processors Report (Houston, TX, June 3, 1996).

\section{Northeast}

Planned expansions in the Northeast Region are somewhat unique in that a number of the projects represent cooperative efforts between several of the regional pipeline systems. For instance, the CNG Transmission and Texas Eastern Transmission Companies have several projects planned to improve service to their own customers that are tied to the completion of the others. The Texas Eastern expansion of service to some of its Virginia and eastern Pennsylvania service areas is dependent, in part, upon the completion of the CNG Transmission PL-1 line and Seasonal Service expansion projects (including improvements to storage deliverability).

Columbia Gas Transmission, with its "Market Expansion" project, is also providing improvements (especially to storage services) on its system that increase deliverability to several major interconnections with these same pipelines. National 




Note: Not all area pipelines are represented.

Source: Energy Information Administration (EIA), EIAGIS-NG Geographic Information System, Natural Gas Market Center/Hub and Natural Gas Proposed Pipeline Construction Databases, as of September 1996, based on information filed with the Federal Energy Regulatory Commission and from various industry news sources.

Fuel Gas Supply Company, another major regional system, has proposed upgrades to its system based upon the eventual completion of projects by Columbia, CNG, and Texas Eastern. In particular, National Fuel's project will complement CNG's planned improvement of its system that flows gas between Leidy, Pennsylvania, a major storage area and hub interconnection point, and Steuben County, New York and northward, where CNG and National Fuel have major interconnections.

Of the 26 projects planned within the region representing 2,310 MMcf per day of new capacity, 17 projects are either directly or indirectly linked by mutual service needs or partnerships. ${ }^{133}$ These 17 constitute about 50 percent, or 1,115 MMcf per day, of the new capacity additions in the region.

\footnotetext{
${ }^{133}$ Transcontinental Gas Pipeline Company and Tennessee Gas Pipeline Company also have several projects in the region that will benefit from and support the expansions in the region.
}

Import capacity from Canada also would increase in the region with the completion of several border interconnection enhancements between U.S. pipelines and Transcanada Pipeline $\mathrm{Ltd} .^{134}$ Pipeline capacity increases are planned at several points in New York State that are tied in with expansion projects announced by Iroquois Pipeline Company and National Fuel Gas Supply Company.

\section{Central}

Proposed capacity additions in the Central Region are second only to those of the other major producing area, the Southwest. The major reasons for this are (1) the expansion of the Northern Border Pipeline and Viking systems and proposed completion of the long-delayed Altamont system connecting with supplies from Canada, and (2) the expansion

\footnotetext{
${ }^{134}$ These projects are part of the Transcanada system-wide expansion projects slated to improve exports to the United States by 169 MMcf per day.
} 
of capacity out of the Rocky Mountain area toward the East (see below). In all, additions amounting to 3,444 MMcf per day of new capacity are planned.

The "Alliance Project" (Table G1 under Midwest), planned for completion by 1999 , could also potentially add to the available deliverability in the Central Region. Its route from British Columbia to Illinois will take it through the Central Region but no interconnections within the region have been announced.

\section{Rocky Mountain Supplies Redirected Toward Eastern Markets}

In the past, Wyoming and Utah supplies generally moved to a strong southern California gas market, but that market has developed an excess of pipeline capacity during the past several years and is currently considered a soft market for natural gas. With an emphasis on the western market, pipeline capacity eastward was limited over the years.

On the other hand, customers in the Midwest and East are very interested in having greater access to these lower priced supplies. ${ }^{135}$ The situation has generated planning on the part of several pipeline companies in the area to expand capacity and fill the need. For instance, $\mathrm{KN}$ Interstate has announced plans for the "Pony Express" line (255 MMcf per day), and Trailblazer/Overthrust/Wyoming Interstate system (100 to 200 MMcf per day) have filed expansion plans with the Federal Energy Regulatory Commission. The latter expansion would dovetail with Natural Gas Pipeline Company of America's plans to expand capacity on its Amarillo line moving supplies to the Midwest Region (Figure G4). The several market centers at either end of this expansion could be expected to benefit, although some centers located in the Waha and Texas Panhandle may experience greater competition for their Midwestern business.

\section{Midwest}

During the next several years, service to the Midwest Region will grow with 3,257 MMcf per day of new interstate capacity added, ranking it third among the six regions. What distinguishes the growth in the Midwest is that the vast majority of this new capacity would be on newly built trunklines or extensions to existing pipelines bringing

\footnotetext{
${ }^{13}$ Producers in the Rocky Mountain area have had to endure low prices for their gas for the past several years because of this limited access. They hope that expanded access to these markets will bring them the prices currently experienced at the East Texas and Louisiana interconnections. Most likely, however, most analysts agree, price levels will equalize somewhere between the two.
}

supplies from Canada. The Midwest will be the terminus for the planned Alliance project, which alone would increase area service by $1,200 \mathrm{MMcf}$ per day. Coupled with the extension of the Northern Border Pipeline to Manhattan, Illinois, near Chicago, completion of these projects would increase the Midwest Region's access to Canadian supplies by more than 116 percent from levels in 1990.

Within the region, the Great Lakes Transmission Company will complete its system expansion that began during the early 1990 's. Besides adding to overall system capacity, the multiyear projects emphasize development and enhancement of system security and backup. Two of the three projects will add $131 \mathrm{MMcf}$ per day of new system capacity. The third, the enhancement of the St. Clair, Michigan border crossing site, will add $50 \mathrm{MMcf}$ per day of new capacity at that point (Table G1, under Canada). However, in the latter case, the primary purpose of the project was to provide additional backup capability at the crossing.

\section{Canadian Expansions}

Ten projects are planned that will add $3,576 \mathrm{MMcf}$ per day to U.S. import capacity from Canada over the next 4 years, an increase of 36 percent from 1995 levels. The volume increase is almost as much as the import capacity added between 1991 and 1994, 3,717 MMcf per day. ${ }^{136}$ This anticipated growth reflects the continuing U.S. demand for Canadian natural gas, especially in the Midwest and Northeast regions.

Several projects are also planned that will direct $200 \mathrm{MMcf}$ per day of new capacity from the United States into Canada. These projects will increase bidirectional service capability at the border and also direct some supplies for transhipment to Niagara, New York, via Canadian pipelines.

Within Canada itself, several projects are planned that will improve operational flows somewhat, add to export capability, and enhance the business operations of several of the regional market centers. For instance, several Canadian market centers are currently limited by available capacity on the TransCanada Pipeline system. Production capabilities in Western Canada, especially in Alberta, exceed the amount of pipeline capacity now existing on the system in that area. As a result, Canadian shippers are unable to reach their full potential market to the east and market centers in the area. The Intra-Alberta, Empress, and AECO-C hubs in particular,

\footnotetext{
${ }^{136}$ Energy Information Administration, Energy Policy Act Transportation Study: Interim Report on Natural Gas Flows and Rates, DOE/EIA-0602 (Washington, DC, October 1995), p. 22.
} 


\section{Figure G4. Planned Central Region Pipeline Expansions to Improve Service to the Midwest}

Region, 1996-1999

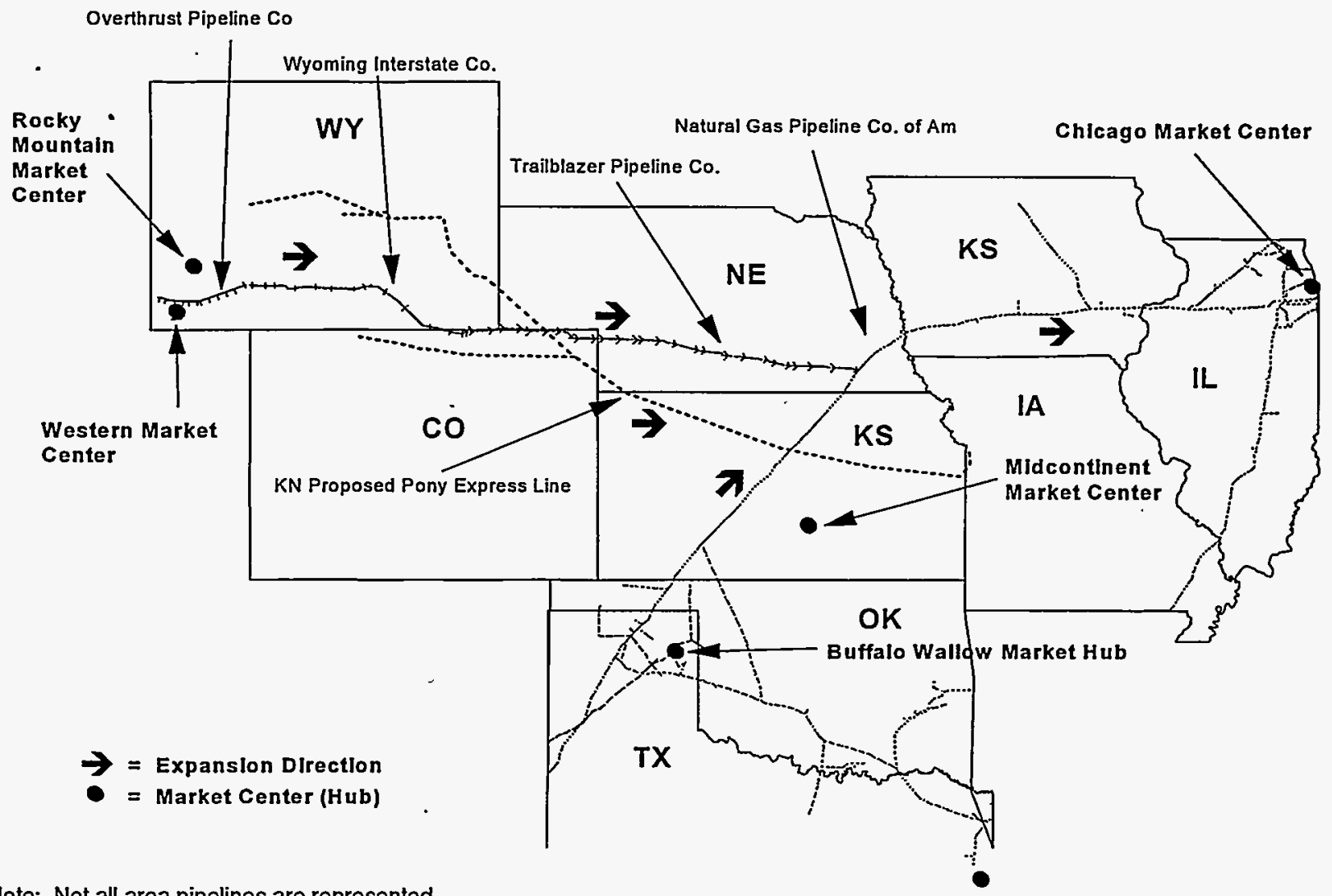

Note: Not all area pipelines are represented.

Source: Energy Information Administration (EIA), EIAGIS-NG Geographic Information System, Natural Gas Market Center/Hub and Natural Gas Proposed Pipeline Construction Databases, as of.September 1996, based on information filed with the Federal Energy Regulatory Commission and from various industry news sources.

are well positioned but unable to grow further. To help alleviate the situation, several expansions and two new pipeline projects have been proposed. In the latter case, a new natural gas pipeline (the Alliance project) would bring natural gas from British Columbia to the Chicago, Illinois area along the right-of-way of an existing oil pipeline (Figure G5). Another new system, the Palliser Pipeline, will be constructed within the province of Alberta and linked to the TransCanada pipeline system. It is being planned as an alternative route to the existing NOVA system. On the Canadian east coast, the Sable TransCanadian project will be constructed to bring supply to the eastern region from the soon-to-be-developed Sable Island Offshore project.

TransCanada Pipeline Ltd. has also applied to the Canadian National Energy Board for permission to expand its facilities from Saskatchewan to Quebec (286 million cubic feet in 1996 with additional expansions in 1997 and 1998). These expansion plans, when completed, should not only provide room for growth at the Alberta hubs but should also affect the operations at the several market centers located along the proposed expansion corridors. The Iroquois center (NY), and perhaps the Grand Lac (MI) and Union Gas (ON) centers, could benefit from TransCanada's expansion, while the Chicago center may benefit if the Alliance project is completed and the appropriate interconnection(s) can be developed.

In August 1996, the Federal Energy Regulatory Commission approved construction of the Northern Border Pipeline Company expansion project, which would add $700 \mathrm{MMcf}$ per day to import capacity at the Montana border. Correspondingly, Foothill Pipe Line Ltd. of Canada, which interconnects with Northern Border Pipeline at Monchy, Montana, will expand its eastern leg by the same amount. 
Figure G5. Planned Canadian Import Expansion Areas, 1995-1999

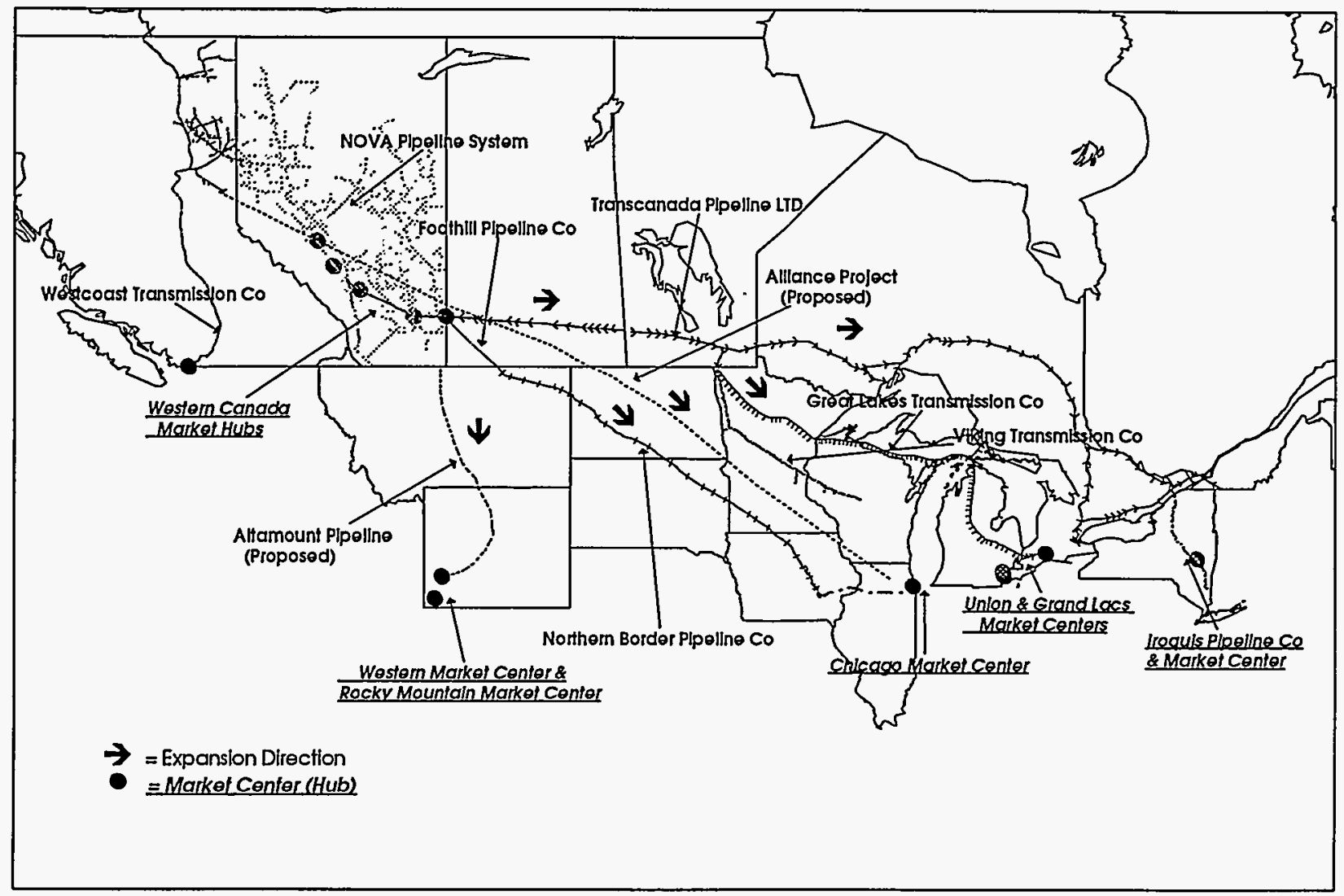

Note: Not all area pipelines are represented.

Source: Energy Information Administration (EIA), ElAGIS-NG Geographic Information System, Natural Gas Market Center/Hub and Natural Gas Proposed Pipeline Construction Databases, as of September 1996, based on information filed with the Federal Energy Regulatory Commission and from various industry news sources.

\section{Mexican Connections}

Several projects have been proposed to add capacity to the export capability of U.S. natural gas companies located near the border with Mexico. None of the projects represent enhancements to import capabilities, which currently is at $350 \mathrm{MMcf}$ per day, a figure that has not changed since the 1980 's. All of the proposed projects are to support mostly industrial and power generator customers located in the border area.

None of the projects proposed since 1991 have actually been implemented, when export capacity to Mexico stood at 889 MMcf per day. Several of the projects are competing within and for the same market. For example, the Southern California Gas Company's Project Vecinos (jointly with Pacific Interstate Offshore Corporation) and the El Paso
Natural Gas Company's Samalayucca project are both seeking to negotiate with Mexican buyers for firm shipping agreements at essentially the same location. Nevertheless, both companies view their projects as proceeding regardless of the outcome of negotiations.

Most of the proposed projects have been proceeding slowly for environmental, economic, and regulatory reasons. One obstacle has been overcome with the installation of Mexico's newly formed regulatory authority, the Comision de Energia (CRE). The CRE has issued less restrictive regulations on foreign investment in Mexico affecting the ownership and operation of pipeline facilities owned by others. It is expected that in the fall of 1996 the CRE will announce the successful domestic bidder for natural gas services and power generation in the Baha area of northern Mexico, leading to final implementation of several of the proposed projects, assuming financing and other arrangements are completed. 
Current projects represent approximately 1,592 MMcf per day of additional capacity. Midcon Texas, Inc. and Coastal States Gas Transmission Company also have plans to construct pipelines within Mexico that will link with their border crossing project and Texas intrastate pipeline construction projects. If completed, these pipelines will be the first ones constructed in Mexico by U.S. companies in recent memory. 